\title{
AN INVESTIGATION OF POSSIBILITIES AND LIMITATIONS OF 'EDUCATION BORROWING' IN BARBADOS AND TRINIDAD AND TOBAGO
}

\author{
ELAINE KAYUET LAM
}

A thesis submitted in partial fulfilment of the requirements of Bath Spa University for the degree of Doctor of Philosophy

School of Education, Bath Spa University

June 2009 


\section{Abstract}

This doctoral research investigates possibilities and limitations of 'education borrowing' in Barbados and Trinidad and Tobago in the midst of competing objectives of improving quality in secondary education, encouragement of 'sharing' by the international community and the impulses towards the 'centre'. Two types of 'borrowing' are identified. The first involves 'horizontal borrowing', in which countries borrow from each other in the manner suggested by UNESCO and Commonwealth Secretariat policy documents. The second involves 'vertical borrowing' in which states are influenced by policies from the 'centre', usually countries of powerful significance due to relationships with the metropole or in the bid to raise achievement. The thesis analyzes literature on both types of 'education borrowing' and identifies policies encouraging 'horizontal borrowing' by the international community. Fieldwork was undertaken to identify pulses of foreign influence and innovation for policies in Barbados and Trinidad and Tobago. 50 interviews and 87 hours of observation for the purpose of triangulation took place between January - November 2007. Respondents include teachers, heads of departments, senior school managers, policymakers, local academics and members of regional and international institutions. Mathematics curricula and teaching were selected as the focus for examining policy. Drawing on the policy review and fieldwork data, patterns of policy 'borrowing' in the Caribbean are uncovered and considerations for policymakers are noted.

There are two main findings: 1) Despite encouragement by UNESCO and Commonwealth Secretariat policy documents, there was no evidence of 'horizontal borrowing' between Barbados and Trinidad and Tobago and 2) Possibilities for cross-national attraction were limited due to the overriding attention paid to the global 'centre' for 'vertical borrowing' rather than concern for regional growth and cohesion. There appear to be three tenets of limitations to 'horizontal borrowing': 1) Island policymakers look internationally for innovation, thereby rejecting policies advocating 'borrowing' from each other; 2) Sharing is not part of the island histories and cultures; and 3) Forces of tradition bind existing teaching and education values. Although some of the implications of this thesis may be valuable in other contexts, the findings cannot be extrapolated to the whole of the Caribbean, to other small states or to developing countries in general. As states are often treated similarly in 
policies advocating 'horizontal borrowing', more analysis is needed to unpack patterns of influence, dynamics of change and the needs of under-researched countries. 


\section{Research aim and objectives}

Aim:

The aim of this study is to contribute to the literature on 'education borrowing' by adding a Commonwealth Caribbean perspective through an investigation of the possibilities and limitations for 'borrowing' in the small states of Barbados and Trinidad and Tobago. Attention will be paid to competing objectives of improving quality in secondary education, encouragement of 'sharing' by the international community and the impulses towards the 'centre'.

\section{Objectives:}

1. Analyze literature on 'education borrowing'.

2. Investigate policies that encourage 'education borrowing'.

3. Identify and discuss pulses of foreign influence and innovation for policies in Barbados and Trinidad and Tobago through fieldwork focusing on Mathematics education.

4. Draw conclusions on the patterns of policy 'borrowing' in the Caribbean and note some considerations for policymakers. 


\section{Acknowledgements}

I am grateful to my Director of Studies, Professor David Coulby for his guidance and support, and my second supervisor, Dr. Colin Brock for his invaluable input and tutelage. I would also like to thank my 'third' supervisor, my husband Paul, for his encouragement and love. I deeply appreciate the continued support of our wonderful parents and families in Toronto and Barbados. 1 am very grateful for the contributions of the respondents for participating in this study and my contacts in the Caribbean for helping me make connections. I would also like to acknowledge the School of Education, Bath Spa University for funding my doctoral studies. Thank you for believing in me as a young researcher.

This thesis is dedicated to my grandparents for teaching me about the intricacies of culture. Your imprint on my life is enormous. 


\section{Table of contents}

1. Introduction and Rationale: Setting the scene

Page 11

1.1. Why Barbados and Trinidad and Tobago?

$\underline{\text { Page } 11}$

1.2 Progression of research question

Page 14

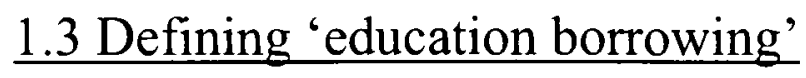

Page 16

1.4 Charting the course

Page 19

2. The Context of the Caribbean: Geopolitical and sociocultural considerations for literature, policy and fieldwork

Page 20

2.1. Geopolitical Context

Page 21

2.1.1 Significance of Scale

Page 23

2.1.2 Nationhood and regionalism

Page 26

2.1.3 Impact of multilateralism

Page 28

2.1.4 American influence

Page 30

2.2 Sociocultural Context

Page 33

2.2.1 Race

Page 33

2.2.2 Gender roles

Page 35

2.2.3 Family structures

Page 36

2.2.4 Child rearing

Page 38

3. Literature Review of 'Education Borrowing' and Research in the Caribbean: The state of an under researched field

Page 40

3.1 Theoretical considerations

Page 41

3.1.1 Reasons and Motives

Page 41

3.1.2 Views on the Process

Page 43

3.2. Towards a Model for 'Education borrowing'

Page 45

3.2.1 Phillips and Ochs' Model

Page 46 
4. The Research Journey: Methodological considerations for investigating pulses for 'horizontal' and 'vertical borrowing'

Page 75

4.1 Rationale and considerations

Page 75

4.1.1 Rationale for qualitative methods

Page 75

4.1.2 Ethical Considerations

Page 80

4.2 Detailed methodology

Page 84

4.2.1 Sampling

Page 84

4.2.2 Methods used

Page 86

4.3. Lessons from the pilot

Page 90

4.3.1 Findings from the pilot

Page 91

4.3.2 Discussion

Page 99

4.4. Analysis of methodology

Page 102

4.4.1 Effectiveness of methods

Page 103

4.4.2 Reliability and validity

Page 108

4.4.3 Generalizability

Page 111

4.4.4 Consideration of ethics

Page 113 


\section{Policy Review of International and National Documents: Investigating}

encouragement and responses towards notions of 'borrowing', regionalism and improving quality

Page 116

5.1. International documents

$\underline{\text { Page } 116}$

5.1.1 Education for All: An international initiative on quality

Page 117

5.1.2 Possibilities for cooperation and 'sharing best practices'

Page 121

5.1.3 Local context, global agenda, outward view

Page 128

5.2. National Documents: Barbados

Page 131

5.2.1 Self-modeling

Page 131

5.2.2 Curriculum Change: guiding principles

Page 133

5.2.3 New certification, same problems?

Page 134

5.3 National Documents: Trinidad and Tobago

Page 137

5.3.1 Viewing itself: a critical but ambitious approach

Page 138

5.3.2 Education for development

Page 140

5.3.3: A holistic approach: Aims of the NCSE

Page 141

5.3.4 Building a workforce of teachers

Page 143

5.4 Analysis of Mathematics Curriculum Documents

$\underline{\text { Page } 144}$

5.4.1. Barbados

Page 144

5.4.2 Trinidad and Tobago

Page 148

5.5 Discussion

Page 152

5.5.1 Similarities in policies

Page 152

5.5.2 Differences in policies

Page 155

6. Fieldwork Findings: Voices of respondents on the school system, pedagogy and 'borrowing'

Page 157

6.1 The respondents

$\underline{\text { Page } 157}$ 
$\underline{6.2 \text { Perceived similarities and differences }}$

Page 158

6.2.1 Barbados: Identified areas of strengths and weaknesses

Page 159

6.2.2 Trinidad and Tobago: Identified areas of strengths and weaknesses

Page 161

6.2.3 Teachers

Page 163

6.2.4 Hierarchy of secondary schools

Page 166

6.3 Syllabuses and Examinations

Page 167

6.3.1 National syllabuses

Page 167

6.3.2 Perspectives on CXC exams

Page 169

6.4. Aspects of teaching and learning

Page 170

6.4.1 Rote methods

Page 171

6.4.2 'Real life' Mathematics

Page 174

6.4.3 Mathematics and Caribbean culture

Page 175

6.4.4 Accommodations for lower achieving pupils

Page 176

6.5 Perspectives on 'horizontal' and 'vertical borrowing'

$\underline{\text { Page } 179}$

7. Analysis of Research Data: Examining the gaps between theory and practice

Page 185

7.1 Analysis of Data

Page 185

7.1.1 Discussion of Data

Page 185

7.1.2 Consistencies and gaps between fieldwork and policy review

Page 190

7.2 Conceptions of Data

Page 196

7.2.1 Current realities and ideal dynamics

Page 196

7.2.2 Assessing Phillips and Ochs' (2004) model

Page 198

7.2.3 Other conceptions of 'borrowing'

Page 199

7.3 Explanations of some aspects of data

Page 203

7.3.1 Cultural resistance to 'borrowing'

Page 203

7.3.2 Forces of tradition

Page 204

7.3.3 The impact of colonialism: desire and resistance

Page 205 
7.3.4 Globalization and convergence

Page 208

7.3.5 Divide between policy and practice

Page 215

8. Conclusion: Moving forward and considerations for policymakers

Page 218

8.1 Summary of main findings

Page 218

8.2 Limitations of findings

Page 221

$\underline{8.3 \text { Contribution to existing research }}$

Page 222

8.4 Areas for further research

Page 224

$\underline{8.5 \text { Final comments }}$

Page 226

Bibliography

Page 229

Table of Appendices

Page 238 


\section{Introduction and Rationale: Setting the scene}

This chapter sets the scene by explaining the choice of the topic and the writer's background. The decision to focus on Barbados and Trinidad and Tobago will be explained in 1.1 , followed by a discussion of the research question in 1.2. Definitions of "education borrowing' will feature in 1.3. The course of the thesis will be charted in 1.4 to indicate how the chapters fit together to investigate the possibilities and limitations of "education borrowing' in Barbados and Trinidad and Tobago.

\subsection{Why Barbados and Trinidad and Tobago?}

The journey of embarking on Ph.D research began with an initial interest in the notion of 'education borrowing'. It is remarkable that one of the most quoted warnings regarding 'education borrowing' still appears to be unheeded by uncritical policy transfer:

We cannot wander at pleasure among the educational systems of the world, like a child strolling through a garden, and pick of a flower from one bush and some leaves from another, and then expect that if we stick what we have gathered into the soil at home, we shall have a living plant. A national system of Education is a living thing, the outcome of forgotten struggles and difficulties and 'of battles long ago'. It has in it some of the secret workings of national life (Sadler, 1900 cited in Ochs and Phillips, 2004: 7)

Interest in 'education borrowing' led to the finding that 'borrowing' from each other is encouraged in UNESCO and Commonwealth Secretariat documents. Perhaps this is due to the dilemma faced by Rodwell (1998: 52): “...in the absence of indigenized models and with the general trend towards the internationalization of educational management, any vacuum may be filled by the uncritical transfer of 'Western' models and materials." The degree of implementation of 'education borrowing' policies appeared to be intriguing in a climate of globalization. As the Four Tigers of Hong Kong, Singapore, South Korea and Taiwan are high achieving countries, the first six months of Ph.D research was spent reading on 'borrowing' within the South East Asia and building networks in the region. However, there was a problem of access due to language fluency. Attention was then paid to other Commonwealth countries, where access could be realized due to my marital ties to a Barbadian who previously taught at a local secondary school. Interest in the impact of 
globalization and colonialism on policy formation in small states contributed to the research topic. Further, through informal conversations with teachers, it became apparent they were interested in the education systems of United Kingdom and Canada. There appeared to be two types of 'borrowing'; 'horizontal borrowing', the process of islands borrowing from each other as suggested by UNESCO and Commonwealth Secretariat policy documents, and 'vertical borrowing', in which states are influenced by policies from the 'centre', usually countries of powerful significance due to relationships with the metropole or in the bid to raise achievement. After a few months of networking, developing research tools and reading literature on the Caribbean context, a pilot trip was made to Barbados in January 2007 to examine the presence of 'horizontal' and 'vertical borrowing'. Prior to leaving for this first trip, the search for another Caribbean island also began. The similarities of geopolitical context lead to interest in other Anglophone Commonwealth Caribbean islands. Education for All (EFA) Global Monitoring Report (UNESCO, 2007) indicators revealed the notable financial efforts of Trinidad and Tobago, and its achievement of some of the EFA goals. One respondent in Barbados provided a contact name for a teacher in Trinidad. Although this contact was never reached due to lack of specific details, the hope of gaining access motivated the search for participants. In May 2007, a trip to Trinidad and Tobago was taken and pilot interviews were completed.

The geopolitical and sociocultural similarities identified in literature justified the choice for Barbados and Trinidad and Tobago. They are seen as regional leaders along with Guyana and Jamaica, in part due to their historical status as the four countries grouped together as the failed Federation of the West Indies. In CARICOM, the four above named countries are described as more developed countries. More developed nations have more rights and vetoing power in the 2001 CARICOM treaty. Although Barbados, Trinidad and Tobago, Guyana and Jamaica have some voting power, special provisions are made for less developed nations (see CARICOM, 2001, Part 11I). Barbados, through the Prime Minister, is responsible for the implementation of the Caribbean Single Market Economy (Government of Barbados, 2007). There are commonalities in sociocultural aspects as they are both matrifocal societies with similarities in family structures, child rearing practices and contain a Creole continuum (see 2.2.1). 
Barbados and Trinidad and Tobago were also selected as they can be perceived as highachieving Caribbean countries. Although other countries in the Caribbean have been noted for their achievements, both Barbados and Trinidad and Tobago have received praise from international policy documents. Barbados in particular is praised for success in education, governance and financial aspects. Jules and Panneflek (2000) cite the establishment of the early childhood education board in Barbados as a best practice that comprises members from the health, social services and education sector. Barbados is also praised for satisfying the demand for places for school-aged children in high percentages of the total population (UNESCO Santiago, 2007). Almost all primary school children reached the last grade in Barbados, Aruba and Cuba (UNESCO, 2008). Brock (1984) provides historical and geographical reasons for Barbados' success in schooling. Although this was atypical, slaves received education provision through paternalistic plantocracy (Brock, 1984). Due to the small scale of Barbados, settlement spaces for post-emancipation slaves were scarce, leading to the sharing of institutions such as education as they developed nationally on the island (Brock, 1984). While it is not possible to replicate historical and geographical circumstances, Howe (2003: 16) writes that other countries should follow Barbados' example in ensuring "more serious efforts are made to adopt a more student-centred approach to the teaching-learning process, thereby necessitating alternative and more innovative ways of student assessment". Good governance resulted in positive development in Barbados (Briguglio, Persaud and Stern, 2006). In terms of economic success, Briguglio, Persaud and Stern (2006: 17, 24, 22) note that Barbados is a "good examples of the successful implementation of VAT", has developed "vibrant financial sectors", and is highly successful in attracting foreign investment.

Trinidad and Tobago were praised to a much lesser degree in policy documents. Although Briguglio, Persaud and Stern (2006: 4) write "(v)irtually all small economies have been impacted by terms of trade shocks, including those stemming from oil-price fluctuations such as... Trinidad and Tobago", the twin isle state also received praise for attracting large amounts of Foreign Direct Investment (FDI) (Briguglio, Persaud and Stern 2006). Trinidad and Tobago were noted for their doubled participation rates in tertiary education (UNESCO, 2008) as well as the recognition within policy documents of the multiracial nature of society, where "conditions are sought to respond to different contexts and cultures" (UNESCO Santiago, 2007: 62). The same document points out that Trinidad and 
Tobago provided specific programmes on living together and peaceful conflict resolution for the purpose of building a culture of peace (UNESCO Santiago, 2007: 38). However, both countries acknowledge the presence of a spectrum of achievement across schools and a hierarchy in status.

\subsection{Progression of research question}

The focus on 'education borrowing' persisted throughout the research project as the policies promoting 'horizontal borrowing' were clear. Curiosity about whether islands were responding to global initiatives or pursuing 'vertical borrowing' motivated the study. After pilot interviews, there appeared to be no evidence of 'horizontal borrowing' between Barbados and Trinidad and Tobago, although this needed to be verified by further interviews. However, some respondents noted the influence of foreign ideas from other places, such as the United Kingdom and New Zealand. While many lessons were learned from the pilot interviews, more consideration of the research question was required. Interview questions were revised to understand the resistance to 'horizontal borrowing'. Further questions developed such as the following: Is there resistance to national initiatives? How do teachers respond to the actual goals of Education for All and other UNESCO and Commonwealth Secretariat goals to improve the quality of education? The aim of the work was clarified to help investigate the research question. The aim of this study is to contribute to the literature on 'education borrowing' by adding a Commonwealth Caribbean perspective through an investigation of the possibilities and limitations for 'borrowing' in the small states of Barbados and Trinidad and Tobago. Attention will be paid to competing objectives of improving quality in secondary education, encouragement of 'sharing' by the international community and the impulses towards the 'centre'. This aim is realized by the four objectives:

1. Analyze literature on 'education borrowing'.

2. Investigate policies that encourage 'education borrowing'.

3. Identify and discuss pulses of foreign influence and innovation for policies in Barbados and Trinidad and Tobago through fieldwork on Mathematics education. 
4. Draw conclusions on the patterns of policy 'borrowing' in the Caribbean and note some considerations for policymakers.

This study intends to shed light on the complicated nature of 'education borrowing' in two island states to uncover patterns of influence and the forces behind them. By turning attention to an under-researched and vulnerable region, the impact of globalization will be magnified as the small states of the Caribbean continue to exist on the periphery of world order. While the study cannot be generalized to the larger developing country context, one of the aims is to draw attention to intricacies of 'borrowing' and dissemination of global policies, particularly those created by the international community to 'benefit' small states and developing countries. As research in education reform may implicitly aim to benefit systems in need, the potential of 'borrowing' is uncovered in this thesis with specific reference to Barbados and Trinidad and Tobago. Although the work cannot prophesy the benefits or disadvantages of 'education borrowing' to improve education systems, it gives insight into the possibilities and limitations with particular emphasis on the Caribbean.

The work of international agencies has impacted the Caribbean region. Of central concern is the quality of education at the primary and secondary level. While UNESCO advocates dissemination and indigenization of global initiatives such as Education for All, the Commonwealth Secretariat uses the phrase 'replication' and publishes documents on 'best practices'. Similarities between education reforms in Barbados and Trinidad and Tobago are thus notable, as they may be a result of dissemination of central policies or may have evolved from convergence. Through drawing conclusions from the theories of borrowing, policy documents and fieldwork findings, these other explanations for similarities between islands, resistance to 'horizontal borrowing' and the gaze towards the 'centre' is probed. Mathematics education formed the focus of the fieldwork as it is often regarded as 'culture free' (see Bishop, 1994) and thus would be an interesting subject to investigate in light of Howe's (2003) recommendations to the International Bureau of Education to ensure a Caribbean context in education (see 5.1.2.1). Mathematics is also a key subject of importance in the Caribbean (see Bell-Hutchinson, 2004). Further, as a former secondary Mathematics teacher, the writer has strong subject knowledge in this area. The focus on Mathematics educators in fieldwork interviews and observations also helps reduce confounding factors as secondary school subjects differ in pedagogy and assessment. 
Mathematics curricula will be examined in 5.4, providing a context for interview responses in $6.2,6.3$ and 6.4 .

\subsection{Defining 'education borrowing'}

This section explores the definitions and features of 'education borrowing' in the current literature. Although the nonsensical nature of 'borrowing' and 'lending' policies has been pointed out, the term is recognized in the literature of comparative and international education despite other expressions to describe the practice of looking for policies elsewhere such as replication, importation, transfer, appropriation, copying, and finally the term cross-national attraction which is advocated by Phillips and Ochs (Phillips 1989, 1993; Ochs and Phillips, 2002a, b, cited in Phillips and Ochs, 2004). One particular definition of 'education borrowing' provided by Phillips and Ochs (2004: 775) posits 'borrowing' as the "conscious adoption in one context of policy observed in another". The idea of 'borrowing' is not new as historical roots of this notion can be traced back to MarcAntoine Julien in 1816-17 (Fraser, 1964, cited in Philips and Ochs, 2004). While the first stage of Noah and Eckstein's (1969: 15) account of comparative education consists of 'travellers' tales, the second stage was 'education borrowing' in which educationalists were "motivated by a desire to gain useful lessons from abroad". Within 'education borrowing' discourse, there is recognition of the "fallacious assumptions behind the notion that policy can simply be transplanted from one national context to another" (Phillips and Ochs, 2004: 773).

Phillips (2000: 299) argues that 'education borrowing' is "the most obvious consequence of learning from and understanding what is happening "elsewhere' in education"'. However, Ochs (2006) and Ochs and Phillips (2004: 601) argue that 'education borrowing' is just one type of educational transfer which can be viewed within a continuum ranging from transfer under totalitarian or authoritarian rule to policy 'borrowed purposefully' at the other end of the range. Ochs (2006: 601) posits policy 'negotiated under constraint' as required by aid agreements in the middle. Dolowitz and Marsh (2000, cited in Ochs, 2006: 13) distinguish also between 'lesson drawing' out of interest and 'coercive transfer' in the political driven realm of imposition. Thus, in the eyes of Phillips and Ochs (2004: 775), the signifier of 'education borrowing' is deliberation evidenced in the ability to "pinpoint an innovation in 
education and trace it to a model already in evidence elsewhere". The two writers are clear in their particular definition of 'education borrowing' as it should not include the "less well-defined susceptibility to influence through the general recognition of importance shown to particular practices elsewhere and a less conscious reflection of those practices in policy 'at home'" (Phillips and Ochs, 2004: 776).

Although the definition of Phillips and Ochs (2004) is quite specific, they also pay attention to different views of the ways in which educational ideas are shaped in similar ways. They pay tribute to the work undertaken by Schriewer (1998, cited in Phillips and Ochs, 2004: 775) who tests his theory that 'educational knowledge' can be transferred across country contexts and establish an "internationalization" of educational thinking", such as the work of Marx in the education systems of East Europe, Soviet Union and China (Phillips and Ochs, 2004). Other writers in this field have also noted that the use of external ideas is not as simplistic as 'borrowing' an idea. Silvona (2004: 76) notes the cultural approach which "challenges the assumption that globalization leads to homogenization and results in the international convergence of educational systems". Further, this approach emphasizes local agency at the centre of 'borrowing' and thus it is viewed as a regulated reflection of reform (Silvona, 2004). The complicated and interlocking aspects of globalization, homogenization, local agency and self-regulated reform will be examined closely in the literature review in Chapter 3. Within the articles and books reviewed in this thesis, there is recognition of the range of definitions and stages of education policy transfer as they may have strong - if not parallel - links to the more particular practice of 'borrowing' as defined by Phillips and Ochs. It is important to note that two key texts, one edited by Phillips and Ochs (2004) and the other by Steiner-Khamsi (2004) include articles that refer to aspects of policy transfer. Thus, it could be postulated that this field of study largely recognized as 'education borrowing' not only contains research into specific incidents that fall into Phillips and Ochs' definition of 'borrowing', but also cases of policy transfer or the use of foreign examples in shaping home policies. If the process of 'borrowing' is seen in a circular fashion (as proposed by Phillips and Ochs, 2004), the cases of policy transfer or use of foreign examples may be conceived as the first part of the full process of "education borrowing' according to the model discussed in section 3.2.1 provided by Phillips and Ochs (2004). Steiner-Khamsi (2004: 217) calls for a wider appreciation of 'education borrowing' among theorists by "enlarg(ing) their repertory by looking into 'globalization' or 'lessons 
from elsewhere' as effective policy strategies that increasingly are used as arguments for justifying the need for fundamental educational reform at home."

This thesis recognizes that there may be impulses towards other types of transfer as well as strict 'education borrowing' by Phillips and Ochs' (2004) definition and circular model. In the literature reviewed in Chapter 3 , the use of foreign examples ranged from direct importation to the more implicit shaping of home policies as well as the problematic nature of 'policy negotiated under constraint' (Ochs, 2006: 601). While Phillips and Ochs draw largely on the historical example of Germany, the potential for 'education borrowing' in developing countries such as Barbados and Trinidad and Tobago may require a broader view of how policy is shaped by examples from elsewhere. It is impossible to find two identical nation states and thus experiences of 'borrowing' and the contexts in which they operate may not fit proposed models. Thus other terms such as policy transfer and the use of foreign examples will be used to denote processes that may be part of Phillips and Ochs' model or linked to notions of 'education borrowing' discussed in current literature.

While most of the discussion above refers to the strength or purposefulness of 'borrowing', attention needs to be paid to the direction of borrowing. For the purpose of discussing findings in the thesis, two types of 'borrowing' are identified, namely 'horizontal' and 'vertical borrowing'. In the case of Barbados and Trinidad and Tobago, the direction of 'borrowed' ideas is significant as policy documents recommend 'borrowing' ideas from each other, or 'horizontal borrowing'. Conversely, findings reveal the presence of foreign ideas from the 'centre', otherwise known as 'vertical borrowing'. Distinguishing between 'horizontal' and 'vertical borrowing' will aid communication of findings. However, the theoretical discussion on 'borrowing' in the literature review maps out perspectives of writers on the entire concept of 'borrowing' regardless of direction, and thus this term will be mostly used in the latter half of the thesis, notably Chapters 5, 6,7 and 8. It is important to note the later development of the term 'horizontal' and 'vertical borrowing' as a way of conceptualizing findings. Interview respondents were asked questions using the general term 'education borrowing'.

By investigating the gap between the ideal and the reality more discussion will be generated in this field regarding the significance of scale, the complexities of development and 
implications to consider for future policies. Patterns of 'borrowing' in Barbados and Trinidad and Tobago were found to be complex, with aspects of dissemination from global policies stemming from Education for All, the use of foreign rather than regional examples in policy formation, and the preference towards the 'centre' over support for national initiatives. This leads to further discussions regarding globalization, convergence, postcolonialism and forces of tradition, which will be discussed alongside other conceptions of data and possible explanations in 7.2 and 7.3.

\subsection{Charting the course}

This chapter sets the scene by discussing the choice of islands, the progression of the research question and discusses the notion of 'education borrowing', with particular emphasis on the process of influence of foreign ideas as well as distinguishing between 'horizontal' and 'vertical borrowing'. The next chapter focuses on context, following Sir Michael Sadler's assertion that context is central in comparative education as education systems are shaped by societal values and relationships with forces outside the school community (1900, cited in Phillips and Ochs, 2004). In particular, geopolitical and sociocultural context will be examined as they are closely linked with the review of academic literature on 'education borrowing' and research in the Caribbean in Chapter 3. This literature review informs choices made in the methodology as it shapes ethical considerations and provides insight into the schooling environment. Methodological approaches are discussed in Chapter 4, enabling a clear picture of how the research aims and objectives were approached in data collection tools. Chapter 5 provides a close examination into the first method used as it analyzes the policies of the international community which encourage borrowing and the subsequent response of the governments of Barbados and Trinidad and Tobago, as noted in their national documents. Chapter 6 highlights narratives from the fieldwork interviews and triangulates some of these responses with classroom observations. Chapter 7 provides a full analysis of the gaps between theory, policy and practice by bringing together the research of this thesis study. Conceptions of data are identified and discussed, and other explanations of data are proposed. Lastly, the conclusions in Chapter 8 provide ways forward and indicate considerations for policymakers. The value of this research is in its emphasis on the importance of understanding and appreciating context - particularly two under researched 
small states in the Caribbean - to privilege the voices of educationalists in response to global policies of 'horizontal borrowing'. As context is central to this thesis, a chapter dedicated to geopolitical and sociocultural aspects follows to provide a basis for understanding this research. 


\section{The Context of the Caribbean: Geopolitical and sociocultural considerations for literature, policy and fieldwork}

This chapter will cover two particular contexts of the Caribbean: geopolitical and sociocultural aspects. While historical, political, economic and telecommunications contexts would help illustrate the uniqueness of the Caribbean, geopolitical and sociocultural contexts are particularly relevant to the literature reviewed and the policies under discussion in this thesis. The focus on geopolitical and sociocultural issues follows the tradition of small states research. Louisy (1999) notes interest in small states began with political, economic, geographic and social issues. As this thesis does not focus on economic and financial factors, the other aspects listed will be discussed. The geopolitical context of small states situates the research into a larger realm for consideration, as existence on the periphery of world order impacts the patterns of 'horizontal' and 'vertical borrowing', as discussed in the findings of this thesis (see 6.5). Aspects of geopolitical context, such as the significance of scale, nationhood and regionalism, the impact of multilateralism and American influence play a role in the forces that impact Barbados and Trinidad and Tobago. Similarly, discussion of the sociocultural context situates information presented in this thesis. Section 2.3 begins with a discussion of race, which is relevant for policies promoting cultural heritage and identity (see 5.1.2.1 and 5.2.2), as Trinidad and Tobago have been regarded as a model in this respect (UNESCO Santiago, 2007). This is followed by a section on gender, which reflects a focal point of academic literature on the Caribbean (see 3.4.2.3). Insight into family structures and the matrifocal society of the Caribbean provides a context for gender issues as well as pedagogy (see 3.4.2.1). Finally, the discussion on child rearing will provide some insight on preferences for teacher centred classrooms and rote teaching (see 6.4.1), as children tend to have low interaction with parents.

The context of this research is vital in providing a framework for understanding education in the Caribbean, as Sadler's historic comment on comparative education holds true: "the things outside the schools matter even more than the things inside the schools and govern and interpret the things inside" (1900, cited in Phillips and Ochs, 2004: 7). By dedicating a short chapter on context, other aspects of the Ph.D study such as regional studies and policies discussed in Chapters 3 and 5 will be richer in meanings and juxtapositions. 
Context was also heavily used to inform fieldwork decisions and build relationships with contacts. This section will explore the diversity of the region by focusing on aspects of geopolitical and sociocultural and context, both of which are closely linked to research in small states and studies on teaching and learning in the Caribbean respectively. While there are other aspects of context such as the media and the arts, geopolitical and sociocultural aspects are directly related to many aspects of this thesis study. The impact of relationships inside and outside the Caribbean is central to the thesis work, rendering significance to geopolitical aspects. Teaching practices and relationships between teachers and pupils have a complicated dynamic with societal ideals and gender roles - both of which will be discussed in this section. While this study does not focus specifically on teaching and learning and the correlation with sociocultural values, providing a context will help the reader understand the background of the literature and policy review, as well as fieldwork data.

\section{$\underline{2.1 \text { Geopolitical context }}$}

Donnell and Welsh (1996: 9) aptly conclude that the Caribbean experience is characterized by both hybridity and plurality. The Caribbean region comprises of several groups or chains of islands typically categorized as two groups: the Greater and Lesser Antilles. The Greater Antilles comprise of the four larger islands: Cuba, Jamaica, Hispaniola (present day Haiti and Dominican Republic) and Puerto Rico. The Virgin Islands, as well as the Leeward and Windward Islands make up the Lesser Antilles. The Leeward Islands consist of those that are away from the wind ("lee") such as the Virgin Islands; Antigua and Barbuda; St. Kitts and Nevis; Guadeloupe; Montserrat; Dominica and Anguilla. In contrast, the Windward Islands face the wind and form a southeastern chain of St. Vincent and the Grenadines, St. Lucia, Grenada and Martinique. Island states such as Barbados and Trinidad and Tobago are sometimes included in these categories, or listed separately for their historical and political significance. Both Belize and Guyana are associated with the Caribbean but are situated in Central and South America respectively. The term 'Caribbean' is sometimes preferred to 'West Indian' as it geographically places the region in the context of the Caribbean Sea rather than in a political nature. The term 'West Indian' seems to refer to former and current British colonies (Donnell and Welsh, 1996) and does not appear to be inclusive of the wider geopolitical and historical nature of the region of former Spanish, 
Dutch and French colonies. Where possible, the term 'Caribbean' will be used to describe the geographical entities in the Caribbean Sea whereas 'West Indian' will be used in reference to specific former and current British colonies.

\subsubsection{Significance of scale}

The island states of the Caribbean range in population numbers. Barbados is home to approximately 281,000 people and Trinidad and Tobago contains a population over 1 million people (CIA Factbook, 2008). As such, both countries qualify as small states. Despite a lack of a common definition of small states, Brock's (1988) criteria are widely accepted. He sets out three criteria of territorial, demographical and economic features of less than 100,000 square kilometers, less than 2 million citizens and a GDP per capita of less than $\$ 500$ USD (Brock, 1988). Barbados, however, has a GNP per capita of $\$ 18,900$ and Trinidad has a GNP of $\$ 25,400$ (CIA, 2008). Most small states can be found in the island zones of the Caribbean, Indian Ocean and South Pacific. Brock (1988) also provides some key features of small states such as insularity, political and strategic significance, and dependency on outside maritime services and airlines. Bacchus and Brock (1987) also point to the infrastructural problems that small states may experience such as high public expenditure on water, electricity, gas and transport and hence the dominance of the public sector; lack of a private sector; high distance costs both internally and externally; aid dependency and the pressure for a dual economy of local and international needs. Bacchus (2008: 131) notes that small states tend to focus their production on a single or limited range of commodities, "which made their economies even more susceptible to fluctuations on the world market prices". Thus, they do not reap the outcomes of competition, which is able to improve efficiency, lower prices and move towards innovation (Bacchus, 2008). With regards to education, Crossley and Holmes (1999: 48) list critical issues for education development in small states: "globalization, growth and influence of transnational corporations, economic liberalization, rapid technological change, instantaneous communications, mobility of capital, goods and services, new international division of labour, changing disparities between wealth and poverty, increased global competition, economic instability, volatile markets". Global trends in education policy have a large impact on small states as they must seek ways to reduce their isolation by participation in the global community without increasing dependency and losing identity (Crossley and 
Holmes, 1999). At the same time, the degree to which international trends meet the needs and objectives of small states is questionable and thus there is a serious risk of inappropriately adopting external strategies (Crossley and Holmes, 1999). Many of these aspects are mentioned in Phillips and Schweisfurth's (2008: 139-140) list of education ramifications for small states in three categories of scale, isolation and dependency, some of which are noted:

- Difficulties in mapping education provision to manpower needs

- A tendency to work through interpersonal networks, which may affect educational management styles and career prospects...

- The need for versatility among education personnel

- ...(T)he potential for more efficient education reform as the scale of the system allows a quicker response

- A 'brain drain' to larger metropolitan centres

Phillips and Schweisfurth (2008) are quick to point out differences between small states, an assertion that is certainly true for the Caribbean despite some similarities in sociocultural context (see 2.2). The Caribbean as a region is not a unified geographical entity as the distance between islands is vast. While some islands are grouped together such as St. Vincent and the Grenadines, others are island nation entities such as Barbados. The growth of particular islands may be attributed to the past significance and popularity of entrepots during the era of sugar imperialism. The Windward Islands, for example, continue to depend on Barbados as an entrepot for the area. Historical shipping routes also dictated the significance of islands and their ports as "the Caribbean is easy to enter from the east, but hard to leave" (Parry and Sherlock, 1956: vi) and the earliest settlements naturally grew along well defined routes: "Until the steamship and the aircraft brought them some measure of freedom, the West Indians were at the mercy of the winds and currents which governed the movement of sailing ships" (Parry and Sherlock, 1956: vi). While the emergence of air travel in the region has decreased reliance on older shipping routes, international airlines and regional travel patterns may contribute to present day insularity of islands. The vulnerability of small states to larger powers is both a problem and an advantage. On the one hand, the smallness of scale has also contributed to a colonial identity. Naipaul (1969, cited in Brock, 1988) refers to the small West Indian islands as 'manufactured societies' and 'creations of empire' while Beckford (1972: 235, cited in Brock, 1988) states that " $(t)$ he most intractable problem of dependent societies is the colonized condition of the minds of the people". On the other hand, Parry and Sherlock (1956) argue that the 
introduction of slavery and its subsequent abolition were revolutions which were introduced outside of the West Indies. They further argue that present day events are largely a result of outside circumstances. With respect to politics, Parry and Sherlock (1956: vii) argue that nationalism and self-governance originate from Europe and "those West Indians who profess them most vehemently seem uncertain about the scale on which they are to be applied". However, this may be a result of a colonial mindset rather than the scope of scale. Further discussion of the impact of colonization is provided in 3.4 .1 and 7.3.3 as Brock (1984: 169) notes, "(t)o the West Indian, the slave saga, and its sequel of economic dependence are the root cause of his alienation" (Brock, 1984: 169). To this end, a history of the Caribbean focusing on colonization is provided in Appendix A as Phillips and Schweisfurth (2008) note the importance of analyzing historical events to appreciate their explanatory power in comparative studies.

Globalization indeed creates both pathways for participation in a global community and at the same time further isolates groups by deepening inequalities of wealth and opportunity. Louisy (2004: 286), the governor-general of St. Lucia, notes the inequalities of globalization: "Instead of a global culture born of the uniqueness and originality of the world's diverse cultures, we are witnessing the erosion of cultures which do not have access to the technology and capital at the disposal of G8 countries..." The inevitable dominance of larger countries does not preclude contributions by the Caribbean, as Louisy writes: "there must be some way in which small states can contribute to bigger developed countries, and it is in this way that we become interdependent (Louisy, 1993 cited in Louisy, 2004: 288). Yet small states remain on the periphery of global order, which Louisy (2001: 426) refers to as a “...a particularly difficult position in this increasingly alien landscape". Louisy (2001: 429) further articulates the characteristics facing this group of countries:

Among these are remoteness and isolation, their greater degree of openness and greater exposure to global events over which they have little influence; their susceptibility to natural disasters and environmental damage; their limited scope for diversification; their limited manpower and institutional capacity; their income volatility and their limited access to external capital. In this changed global community, these countries face very stiff challenges of economic and social development and significant threats to greater marginalization of global economic activity. 
While the notion of 'international cooperation' commonly refers to relationships in the developed world or points to aid relationships, small states are forgotten due to their isolation. Although the special circumstances and challenges facing small states have been recognized by the Commonwealth Secretariat, and more recently the World Bank, the United Nations does not place small states in a special category (Louisy, 2001). A vulnerability index has recently been developed to help agencies understand why small states need to be treated with special attention (Crossley and Holmes, 1999). The index comprises three components of vulnerability, namely the degree of diversification, proportion of people affected by natural disasters and dependence on external trade (Crossley and Holmes, 1999). This should help donors understand the particular situation of small states who face "the threat of graduation from Least Developing Country status" as a result of the favourable income levels they enjoy as well as the rapid globalization trade (Crossley and Holmes, 1999: 56). Thus, they face a "...loss of differential treatment in terms of their special access to financial resources, markets, and technical assistance from multilateral development agencies and donors" (Commonwealth Secretariat 1998 cited in Crossley and Holmes, 1999: 56). One of the more recent examples of the lack of special treatment accorded to small states is the initiative by the World Trade Organization to equalize opportunities to the market in Europe for all banana-producing nations. Globalization will be discussed further in 7.3.4 and aspects of aid will be discussed in 7.3.3.

\subsubsection{Nationhood and regionalism}

Patrick Anthony stated that the question for the millennium for individuals involved in Caribbean civilization development was simply "how can Caribbean people save their souls in a globalizing environment that is oblivious to national boundaries and hostile to cultural identity?" (Louisy, 2001: 431). Jules (1998) ponders "whether the region is to be the scavenger of civilization or the inheritor of rainbow possibilities and the creator of new sensibilities" (cited in Louisy, 2001: 432). The proximity to the United States exacerbates cultural globalization as well as the Caribbean's “...historical predisposition to adapt to external influences, be they benign or hostile" (Louisy, 2001: 432). Thus, Louisy (2001) asserts that the role for education should be to ground nationals firmly in their cultural context in order for them to function well in the new globalized environment. Certainly Creole realities should be treated as an asset to maintain diversity and delay assimilation 
(Louisy 2001); further Jules (1998, cited in Louisy, 2001) suggests the only strategy for small states is the tool of differentiation to explore global opportunities. The extent to which this is currently happening in the Caribbean is not evidenced by the fieldwork data as teachers did not feel strongly about the intersection of pedagogy and cultural identity of the pupils' own cultures and 'other' cultures. The small states of the Caribbean are also caught between contributing towards regional spaces for a larger collective voice and ceding some of their national identity. Formal and informal hemispheric alliances or 'functional cooperation' is a coping mechanism to deal with the challenges of scale, isolation and dependence (Louisy, 2001: 430). Some examples of regional organizations include the Caribbean Free Trade Zone Agreement (CARIFTA), the Single Market Caribbean Community through CARICOM and the Caribbean Development Bank. Smaller regional organizations such as those for the Eastern Caribbean are notable, such as the Eastern Caribbean Central Bank and the Organization of Eastern Caribbean States. The views of multilateral agencies on regionalism are discussed in 5.1.2.1. Louisy (2004: 291) optimistically describes regional alliances as "being embraced as a strategy for strengthening local and regional capacity". The collective voice is certainly advocated by Louisy (2004) who conceptualizes the potential for the region to become a global partner in policy making, which may engage the Caribbean to search for innovative insights. Lavia (2007: 190) also feels regionalization has created a platform for dialogue and collaboration "in research, policy development and practice around global education agendas". While global education agendas may dictate some of the conversations, Lavia (2007) notes that regional sharing has the potential to transform national and local levels. In the area of education, island states have built their own capacity while harmonizing policies and practices in the region, as well as pooling their weight into collective institutions (Louisy, 1993 cited in Louisy, 2001)

While the Caribbean Examinations Council is an obvious example, Louisy (2001) also raises the work of the Organization for Eastern Caribbean States (OECS) Education Reform Unit, which monitors member implementation of the 1991 reform strategies such as harmonizing grade level names, curriculum standards, accreditation practices and establishing a college council as agreed by its members. Callender (2000) has described the Education Reform Unit as "the most sustained and effective networking mechanisms for regional development in education in the Caribbean" (cited in Louisy, 2001: 434). Yet 
regionalism has certainly faced its challenges. Louisy (2001) notes the 1960s collapse of the West Indies Federation as well as the 1980 aborted attempt of the OECS Political Union. While Louisy (2001) does not delve into aspects contributing to the failures and challenges of regionalism, this is not unusual in education literature of the Caribbean. Perhaps this is due to the need to build collective capacity in research in the face of globalization and multilateralism. A critique of regionalism may create further divide in the small states of the Caribbean. Although small states are not specially recognized by the UN, UNESCO has set up studies and activities in the area of small states development such as its attempt at enabling consultative dialogue through UNESCO's 'Focus on the Caribbean' initiative where Caribbean states presented their development priorities (Crossley and Holmes, 1999). Crossley and Holmes (1999: 50) declare this a success: "Out of the consultative process came the most comprehensive analysis of development needs coming from the region to date..." More research needs to be completed on the impact of UN and Commonwealth consultation in the Caribbean states. For a review of the policies of the Commonwealth Secretariat and UNESCO, see 5.1.

\subsubsection{Impact of multilateralism}

Meeting the needs of small states in an overwhelming global agenda is a particularly difficult issue for the Caribbean as Louisy (2004: 288) describes how the two forms of the Education for All (EFA) initiative were ill received:

[The Dakar World Education Forum] does not provide a common frame of reference for local policy makers or practitioners, let alone for those at the global level. The Caribbean delegation to the 1990 Jomtien World Conference, Education for All, found the new vision not readily discernible.

As UN member states were required to make plans to achieve EFA goals at the regional and national level, a Caribbean Education for All Plan of Action was developed, aimed at the "...mastery of language, mathematics, science and 'the digital world', with attention being paid to vernacular education" (Hickling-Hudson, 2004: 296) as well as the value of culture and arts. While Hickling-Hudson (2004: 296) does not disagree with these criteria of quality, she cautions slogans such as 'education for all' if they are not supported by "...critical analysis of what kind of education is being offered to 'all". There is an assumption that 'literacy' and 'education for all' are keys to development but this "...fails 
to challenge the model of literacy and education being promoted" (Hickling-Hudson, 2004: 296). Although this 'global' aid agenda was apparently built on by consensus, participation of researchers, governments and NGO personnel from developing countries in creating initiatives such as the Jomtien EFA Declaration was "minor, if not minimal" (King, 2007: 381 ). According to Jones (2007a: 334), “Commitments to universal primary schooling are half-hearted; commitments to other dimensions of Education for All (EFA) are a mockery of any decent sense of human dignity, entitlement or productivity".

While the EFA agenda has been scrutinized by both academics working outside the Caribbean as well as local writers, the Commonwealth Secretariat has faced less criticism in the Caribbean education community. With 32 of the 54 Commonwealth member countries categorized as small states according to the population limit of 1.5 million people, small states research only began in 1965. Yet Crossley and Holmes (1999: 3) assert that the Commonwealth Secretariat "is widely regarded as the leading international organization for small states". It acts as "advocate, broker and catalyst for timely, relevant and practical initiatives" (Crossley and Holmes, 1999: 64). In the review of their work, Crossley and Holmes (1999: 64) conclude it has "an enviable international reputation as a responsive and continuously evolving organization". Further, Phillips and Ochs (2003: 134) support their work on 'horizontal borrowing':

The Commonwealth Secretariat has served as an important agent in all four stages of policy borrowing - in facilitating cross-national attraction, decision-making, and the implementation and internalization of important educational reform suitable to the local milieux of small states.

Crossley and Holmes' (1999) publication on history of the Commonwealth Secretariat's work on small states offers a summary of activities as well as a limited critique as their book was published by the organization. They provide a review of the materials produced, pointing out the strengths and limitations, some of which are noted below:

(a) ... (I)t is recommended that a full assessment of the impact of such networks deserves a detailed study of their activities and sustainability in future years

(b) With regard to the Mauritius meetings call for the improved 'flow of information' to small Commonwealth countries about comparative experience' much has been achieved - especially given the climate of increasingly constrained resources... The core publications have also been distributed widely within small states making much more useful and comparative material available for isolated personnel... Little 
systematic and empirical data exists on how these materials have impacted upon practice, though anecdotal evidence derived from multiple sources is consistently positive

(c) ...(P)rogress has been incremental and organic in nature suggesting the need for greater formalization, co-ordination and visibility if the Mauritius vision is to be fully realized in this respect (Crossley and Holmes, 1999: 45-46)

While their singular view of the Commonwealth Secretariat limits discussions and critiques of the organization, it must be noted that little is written on this topic. Rodwell (1998) briefly mentions the Commonwealth Secretariat's 'Better Schools Project, a cooperative initiative in several African countries to create material writing teams coordinated by consultants in the UK in the area of education management. While this is meant to be a regional model "which aims towards polycentrism with each country developing its own indigenized version of the 'original'...the extent to which they have been truly indigenized at present remains unclear" (Rodwell, 1998: 50). Jules (2008), however, notes that agendas are not set singularly as institutions such as UNESCO, the World Bank and western universities work together, weakening the establishment of developmental initiatives created by small states.

\subsubsection{American influence}

The Anglophone West Indies region is highly influenced by both the USA and the UK. The influence from the UK arises from membership in the Commonwealth and colonial history, which will be discussed further in 3.4.1 and 7.3.3. This section will thus focus largely on the relationship between the islands and the United States - one which is steeped in the need to ensure status with the 'centre'. The need for international relations is particularly acute in the age of globalization and the knowledge economy. Despite the movement of a small elite from island states to internationally reputable universities, which Brock (1988) attributes to arcane notions of achievement, migration barriers prevent the elusive 'upward' movement from development to Western immigration from becoming a reality. Thus, international education networks may be irrelevant. Recent geopolitical challenges include the increased focus on internationalism and globalization, which may come at the cost of diplomacy and trade. Although Brock (1988) identified the arcane notions of achievement before the boom of the knowledge economy, increased dependence on Western certificates at the tertiary level may be seen to be a geopolitical threat leading to 'brain drain' and thus may pose as a threat to identity and internal development. In light of the pressure for small 
states to establish status in a globalized world, a larger geopolitical concern of sustainability and survival emerges. Recent developments such as the Caribbean Single Market provide a platform for increased regional movement in the form of rights to abode and work in participating island states. This is facilitated by the common school leaving certificates made available through the creation of the Caribbean Examination Council (CXC). The boom and increased accessibility of the internet also eases communication between islands and reduces reliance on postal services. Distance learning is also made possible and thus local education institutions are able to provide for regional needs.

However, small states still exist on the periphery of world order which is dominated by larger English speaking countries such as the USA and UK. One of the key challenges for small states as identified earlier by Williams (1951, cited in Brock, 1988) is the gap between the curriculum and context as small states may be more concerned about providing 'high quality' by world standards rather than local standards. While education may be a victim of globalization, Gooch (1995) points to the reliance of other institutions on foreign models. Barbados boasts of having the $3^{\text {rd }}$ oldest parliamentary system in the Commonwealth and has created a national media centre modeled after the BBC in the United Kingdom, "a design which Barbadian officials promote as the most promising for social development" (Gooch, 1995: 118). Gooch (1995) also provides an analysis of the influence of foreign media powers over Barbadian society and alludes to a dependence on the United States and the IMF, which have, on occasion, influenced television programming decisions. She further argues that the proximity of Anglophone Caribbean islands to the United States places them in a position of interest as American political and commercial interest have expanded in the region throughout the $20^{\text {th }}$ century (Gooch, 1995). The United States Department of Commerce (1990) has described the influence of media programs as "economic growth and political stability in a nearby strategically important region, which enhances 'our country's security"' (cited in Gooch 1995: 117). Lashley (1995) argues that the United States is the greatest supplier of programming to the rest of the world. Certainly, many developing countries view American and other programming from 'The West' as threatening as media dominance may drag countries back into dependency (Sterling and Head, 1987 cited in Lashley, 1995). Emery and Smythe (1986) express concern that the spread of standards and style of American media is more 
likely to contribute to a global 'American media village' by dominating world communications (cited in Lashley, 1995).

Beyond the realm of media influence, Cuthbert (1986) explains the security intentions of the United States in this region: "the Monroe Doctrine of the US gave way to the Good Neighbour policy of the $30 \mathrm{~s}$ and 40 s which have given way, since the $50 \mathrm{~s}$, to the cold war policy of keeping the region free of Soviet influence" (cited in Gooch, 1995: 117). Philip Hughes, a US Ambassador to Barbados noted that some CARICOM countries were less aligned with the United States at UN assemblies, and stated the following: "In the international community there is no more valuable commodity than the practical evidence of friendship based on shared values and common purpose of historical record of cooperation is a good building block of friendship" (The Nation, 1992 cited in Gooch, 1995: 118). Gooch (1995: 109) concludes “( $t$ )here is little question that Barbados' colonial past and its continued affiliation with the West has had a great impact on its economic, political and social institutions". This need to align with North America may also be reflected in the sensitivity surrounding news media, as the 'bad' reporting may hurt the image of Barbados and affect the vulnerable industry of tourism. Gooch (1995) reports a June 1973 edict called 'The Positive Side of News' in which one Caribbean Broadcasting Cooperation (CBC) staff member recalls "The positive side of news meant that we should only spotlight the government ministers and anything the government was doing. Anything critical was considered the negative side of news" (Gooch, 1995: 113). Another case involved the topic of the IMF. According to the director of the non-profit group Caribbean Policy Development Centre (CPDC), they proposed a programme on the process of structural readjustment, which was reviewed by the CBC (Gooch, 1995). However, the CPDC director was told there was inadequate space to show the documentary despite the fact that the $\mathrm{CBC}$ aired a video provided by the IMF regarding structural readjustment that same week (Gooch, 1995). Certainly, the media context of Barbados reveals its conservative nature and its reluctance to appear critical. 


\subsection{Social context}

\subsubsection{Race}

Although ethnicities such as the Chinese, Irish, Portuguese and Syrians live in the Caribbean (Donnell and Welsh, 1996), the majority of the population is of African origin (Leo-Rhynie, 1996). Slaves were from various parts of West Africa and originated from different tribes and power statuses. Communities of former indentured slaves from India remained in Caribbean island states such as Trinidad and Tobago and Guyana, and are typically referred to as 'East Indian'. 'West Indians' on the other hand, is the collective term for Caribbean peoples living in the former British island colonies. While the term 'creole' is often used to refer to a linguistic system, the term 'Creole' is often used in reference to race. Both the linguistic term 'creole' and ethnic reference 'Creole' derive from the Spanish word criollo "which denotes "born in, native to, committed to the area of living" (Braithwaite, 1971 cited in Donnell and Welsh, 1996: 10). The term 'Creole' is used to "describe those of predominantly European descent who regard the Caribbean as home, or those who are "functionally white"" (Saakana, 1987 cited in Donnell and Welsh, 1996: 10). Jean Rhys, in her novel Wide Sargasso Sea (1966) uses the metaphor of "white cockroaches". Donnell and Welsh (1996) also identify the range of names for residents of European or white descent in the Caribbean: white West Indians, Creoles, Euro-Creoles, expatriates and 'red legs' (Donnell and Welsh, 1996). They argue for the existence of a 'Creole continuum' of cultural involvement and colonial allegiance of residents of European or white descent (Donnell and Welsh, 1996). Aspects of colonialism will be further discussed in section 3.4.1.

While race is a significant issue in the Caribbean, Leo-Rhynie (1997: 26) asserts that this is not a simplistic matter as other factors play a role: "The personal status, relationship and conduct of the members of these groups are significantly influenced by gender, race, and cultural/sub-cultural practice". The history of slavery and the resulting identity issues play an important role in perceptions of race. The older work of Miller (1969) found conflict among girls of African origin who were dissatisfied with their own physical attributes and instead selected typical Caucasian features as the ideal. While similar body dissatisfaction was identified among East Indian and Chinese girls, more self acceptance was noted among the latter two groups (cited in Leo-Rhynie, 1997). Beyond perceptions of physical 
appearance, Leo-Rhynie (1997: 34) also argues that this desired 'whiteness' plays a role in the overall process of socialization: "The value system of the European ideal, and the cultural traditions of people of different ethnic origins - particularly those of African and Indian heritage, whose traditions were suppressed during slavery and indentureship, respectively, create difficulties for the socialization process". One respondent notes a conflict between East Indians and Afro-Caribbeans in Trinidad and Tobago as religious and racial divide persists. There is the perception that East Indians are "taking over Blacks" (fieldwork interview, April 2007) While the racial conflict among white West Indians and Afro-Caribbeans is less pronounced in Trinidad and Tobago, there is a milder form of conflict between white West Indians and Afro-Caribbeans in Barbados: "I would say the most marked difference is in Trinidad. Barbados has more of a White-Black division but this is subtle, you have to be there for a while to pick it up. It's more blended than Trinidad society" (fieldwork interview, April 2007). This may be supported by data on violence between East Indians and Afro-Caribbeans in Trinidad and Tobago. Yet Brock (1984) argues that the historic relationships of race, colour, class and education emerge peculiarly from a stratified socioeconomic context. He identifies three groups:

1. A white/creole elite educated in metropolitan countries or in the local private and/or denominational secondary sector.

2. A creole or mulatto 'middle class' which has emerged alongside the provision of public education systems, and is characteristically urban-based, professionally employed and interested in the maintenance or the selective principle.

3. Negro peasantry or proletariat subsisting on a ceiling of primary education (in some countries this stratum may include large number of Indians (Brock, 1984: 166).

Brock (1984: 166) recognizes adjustments to this stratification in places such as Jamaica, Trinidad and Barbados: "In Trinidad, the most striking adjustment is the emergence of a significant section of the Indian component into the professional middle classes". On the other hand, Barbados has seen enhanced access and provision for early education, translating into the notion that all peoples are accessible to education services. This is due to the diversification of the economy and existing geographical compactness of the country (Brock, 1984). 


\subsubsection{Gender roles}

Issues surrounding gender roles, motherhood, families and childrearing appear to be largely connected in the Caribbean. This may stem from the circular nature of the socialization process, in which children are raised in families where messages regarding gender roles are strongly enforced. As the region has the largest percentage of female headed households, the possibility of similar childrearing practices seems highly possible. The following section pertains to issues raised in 2.2 .4 on childrearing due to the interconnected nature of gender, motherhood and families in the Caribbean. Although the child care provided is largely determined by both race and class, it is clear that boys and girls are usually treated differently from birth (Leo-Rhynie, 1997). Play and toys are also gendered (Leo-Rhynie, 1997), and parents believe that even at the ages of birth to three, girls and boys should behave differently (Grant, 1983 cited in Leo-Rhynie, 1997).

Evans and Davies (1997) assert that the status of becoming a mother is highly valued in the Caribbean. Motherhood is tied to female sexuality, as Hodge (1977) states the common perception that "the childless woman is an abomination, a pitiable creature" (cited in LeoRhynie, 1997: 39). As a result, "the emergence of a strong self-image and a sense of womanhood...serves as a rite of passage" (Durant-Gonzales, 1982 cited in Evans and Davies, 1997: 5). Yet early pregnancy and motherhood may impede young women from developing a full identity and self confidence, as well as establishing healthy relationships with members of both sexes and behaving in morally responsible ways (Evans and Davies, 1997). Durant-Gonzales (1982) also argues that teenage pregnancy creates a cycle of motherhood, low wage jobs and poverty (cited in Evans and Davies, 1997). Yet positive self-worth and strong self-images may not be highly valued in the Caribbean where traits of obedience and docility are particularly valued for girls (Brown, 1984; Payne, 1989 both cited in Evans and Davies, 1997). Aspects of sexuality are also not discussed: "At puberty, girls are warned by their mothers to 'stay away from men' but very often no explanation is given for this warning" (Leo-Rhynie, 1997: 39). To protect girls from harmful relationships with boys, they are often kept at home. Although the involvement of children in household work varies among social classes and urban/rural divides, tasks are assigned differently for boys and girls in all classes and generally girls are expected to help in the house (Evans and Davies, 1997). This has an impact on a girl's perception of herself. Many mothers have 
learned to become self-sufficient out of necessity and without complaining - an approach that has enabled Caribbean families to persist through challenges in relationships (Evans and Davies, 1997). As a result of their own experience as single mothers, Caribbean women may encourage these qualities in their daughters (Evans and Davies, 1997).

Boys, on the other hand, are assigned a very different gender role. At both home and school, boys receive harsher corporal punishment than girls. While this may be a result of the independence displayed by the offending boy, paradoxically, "it may be a way of 'toughening up' the boy as part of his survival skills" (Evans and Davies, 1997: 5). In general, boys are freed from ongoing demands of domestic chores in the house and Senior (1991) reports the perception that boys are pampered and catered to in the home (cited in Evans and Davies, 1997). This may be a direct result of the role assigned to men as breadwinners. Leo-Rhynie (1997: 35) concludes that "in all social class groups, respect for and status of men in the community are gained through their ability to provide for their families". When fathers are present, they tend to be detached from the child rearing process as they are expected to provide economic support and act as the final authority (LeoRhynie, 1997). However, this may create ambivalence among children who live in families headed by women and young males may not have a clear understanding of their roles in the home and society due to the absence of a father. Children are taught "to defer and give greater respect to their fathers or stepfathers - who may be irresponsible, unreliable, and authoritarian" rather than "their mothers, whose management of the home and family earn their respect" (Leo-Rhynie, 1997: 37). Thus, boys may hold a marginal position at home and school and "this makes the boy more vulnerable to the demands of peer groups and gangs, groups that may not adhere to prosocial values and beliefs" (Evans and Davies, 1997: 19). This has long term effects on male participation in education and society. Gender roles in the Caribbean will be discussed further in the literature review.

\subsubsection{Family Structures}

Evans and Davies (1997) found that the extended family has become dispersed and, as a result, roles of child rearing are changing as members of the community no longer express a sense of responsibility towards adolescents. Further, traditional values such as “... a belief in education, hard work, and respect for elders" and "education for social mobility" may be shifted to make way for the "adoption of materialism and individualism by a significant 
number of middle class youth" (Evans and Davies, 1997: 11). Evans and Davies (1997: 12) also discuss the factors such as school dropout and youth unemployment as well as breakdown of traditional family structures as contributing to the rise of social problems: "This social situation, coupled with the weakening family structure and community influence, as well as the absence of organized social activities for the young, makes it easy, especially for young males, to be inducted into antisocial activities such as crime". This may be strongly related to various factors in the socialization process. While this section does not attempt to explain social phenomena in the diverse region of the Caribbean, there will be a focus on several aspects that have been raised in research, such as the large number of female headed households, child shifting, child rearing and parental attitudes.

The family unit of a husband, wife and biological children as the religious and social ideal exists mostly in the upper and middle classes of society and within East Indian and Chinese ethnic groups (Leo-Rhynie, 1997). The family structure in the rest of the society may appear to be quite different from this ideal despite the fact that many children grow up with a male resident in the form of a partner, relative or natural father (Leo-Rhynie, 1997). It has been estimated by Massiah (1982 cited in Evans and Davies, 1997) that around 30-50\% of families are headed by females, varying from Jamaica at $33.8 \%$ to Barbados and Grenada at $42.9 \%$ and $45.3 \%$ respectively. While this data is dated, the prevalence of female headed households produce a matrifocal society in which females are not necessarily matriarchs but are regarded as a main aspect of family and social life. The high proportion of female headed households may be attributed to the fact that children most often stay with their mothers if either the mother or the father selects another partner (Brown et al., 1997). While women do not remain single throughout their lives as mothers, there is a pattern that seems to emerge among Caribbean adults: "Parents often progress from a visiting union to a common-law union or a marriage union. Thus children born later to a parent or a couple are likely to be reared in a two-parent household" (Powell, 1986 cited in Evans and Davies, 1997: 4). More specifically, visiting unions are common among women up to age 25 after which there is gradual movement to common-law or legal union, and by age 45 commonlaw or marital unions become the norm (Leo-Rhynie, 1997). However, it is important to note that common-law and visiting unions are less prevalent among East Indian families in Guyana and Trinidad and Tobago (Evans and Davies, 1997). Fewer female headed households are found among this ethnic group with East Indians in Guyana at $22.4 \%$ and 
Trinidad and Tobago East Indian women at 27.0\% (Massiah, 1982 cited in Evans and Davies, 1997). The process of motherhood is further complicated by the practice of child shifting. Evans and Davies (1997) approximate $15-30 \%$ of children raised by relatives or neighbours, usually due to a new relationship or 'visiting union' with another partner. A child may also be shifted if the mother moves to another city, town or country for work and there are also instances in which a mother will transfer the child to another home in hope that her child will receive a better life (Evans and Davies, 1997).

\subsubsection{Child Rearing}

The preferences for sons and daughters may be linked to perceptions of boys and girls. Middle-class parents may prefer a boy to carry on the family name, but lower class mothers often prefer girls, perhaps due to the feeling that boys are more troublesome and the expectation that girls will look after them in their old age (Leo-Rhynie, 1997). However, the work of Brown et al. (1997) concluded that the mother-son bond in Caribbean culture is significant. There may be competing demands from their families of origin and their own partners and children (Brown et al., 1997). Bonds between mothers and sons are seen by partners and wives as a diversion from a man's emotional and financial commitments to his own families of procreation (Brown et al., 1997). In fact, Brown et al. (1997: 94) comment that this culturally sanctioned bond stems from the feeling that "Caribbean mothers raise daughters to be independent and/or resourceful helpmates to eventual partners, but raise sons to remain sons". This may be a result of the mother's need for financial support in her old age as this may not be guaranteed from a partner (Brown et al., 1997). Evans and Davies (1997: 5) also identified another common child rearing notion that children "should be seen and not heard". They found that middle class parents complained about their children asking too many questions or talking too much, "ignoring the value of such interchange for the development of language and the understanding of concepts" (Evans and Davies, 1997: 5). In general, conversing and reasoning with children is limited and in low-income homes, it was found that children have few opportunities for extended conversations with parents or guardians, although there were plenty of opportunities to play with their peers (Evans and Davies, 1997). In fact, Evans and Davies (1997) found that the majority of parents and guardians talk to their school age children only once or twice a week. 
While the scope of socialization processes is beyond the realm of this dissertation, it is clear that there are some common child rearing practices in the Caribbean. Evans and Davies (1997: 5) point to the embedded nature of cultural beliefs such as the biblical injunction not to "spare the rod and spoil the child". Further, they found that parents across all socioeconomic groups value a "punitive, restrictive approach to discipline and child rearing" (Evans and Davies, 1997: 5). Leo-Rhynie (1997: 48) also identified the common belief that "a mother can 'beat the badness' out of her child". Corporal punishment is not combined with any aspect of loving father-child contact as Arnold (1992) states that children are expected to understand their punishment because they are loved and cared by their parents (cited in Leo-Rhynie, 1997). As such, "(t)he control-love dimension in the Caribbean setting is therefore often characterized by mixed messages authoritarian/punitive control, alternating with indulgence and protectiveness" (LeoRhynie, 1997: 45). Corporal punishment is also used in schools as a means of discipline. This belief in corporal punishment may be a result of several perceptions regarding characteristics that children were expected to have in Caribbean families. Certainly, sociocultural factors impact many aspects of education in complex ways. More information is available on context in Appendix B. While it is not possible to explore relationships between sociocultural values and the thesis fieldwork, this short section on geopolitical and sociocultural context helps contextualize studies and policies in the region relating to views of children and pedagogy. The next section will focus on horizontal and vertical 'education borrowing' literature as well as particular studies on the Caribbean. As the literature on 'education borrowing' is not specific to the Caribbean as there has yet to be a strong example of 'borrowing' in the region, context is central for understanding the potential benefits, disadvantages, possibilities and limitations for both types of 'borrowing'. 


\section{Literature Review of 'Education Borrowing' and Research in the Caribbean: The state of an under researched field}

As 'education borrowing' in the Caribbean is an under researched topic, this chapter examines literature of 'education borrowing' as well as academic writing on the Caribbean. Reviewing current literature helps to capture ecological validity for the research topic as all areas will be given some attention. The aim of this chapter is to situate findings in a larger academic landscape to provide the reader with a richer understanding of the notion of 'borrowing', review cases of 'borrowing' and identify the unique concerns of the Caribbean. By juxtaposing the larger theoretical nature of 'borrowing' with particular cases of policy transfer and the specific situation of the Caribbean, an overview of the current state of this relatively hidden field is portrayed. The chapter also moves from theory to documentation of other cases to the context and concerns of research in the Caribbean, transitioning towards a narrower focus to probe the possibilities and limitations of 'horizontal' and 'vertical borrowing'. Considerations of motives and views on the process on the process of 'borrowing' are first outlined, followed by a discussion of the model proposed by Phillips and Ochs (2004). Cases in the 'first' and 'third' world are then described as examples of the theoretical perspectives. Finally, the chapter finishes with an overview of current literature in the Caribbean to highlight considerations and context of the region. Unfortunately, there is very little written specifically on Barbados and Trinidad and Tobago; moreover, literature on the Caribbean region as a whole is also limited.

As the research indicated in this chapter has implications for both horizontal and vertical borrowing, the general term 'education borrowing' will refer to both types of directions. It is also used to ensure consistency with the perspectives of the writers referenced, as they may refer to the general term without specifying the direction of influence. The field of 'education borrowing' is a recognized academic field, and the terms 'horizontal' and 'vertical borrowing' are unique to this thesis, conceived to help describe findings.

\subsection{Theoretical considerations for 'education borrowing'}




\subsubsection{Reasons and Motives}

At first glance, it is possible to conceive 'education borrowing' as an activity with 'good' intentions where policymakers aim to improve systems by introducing a successful idea elsewhere and wholeheartedly advocating it for the sole purpose of delivering quality education. Yet Ochs (2006: 602, italics hers) outlines four different reasons why foreign examples may be borrowed through her own conceptions and the work of other writers in the field:

1. To caution against educational reform;

2. To glorify current education at home in comparison to other nations...

3. To legitimate the adoption or reform of educational policy at home...or

4. To scandalize policy and practices at home, substantiating and validating the need for reform...

Ochs (2006) also classifies examples of foreign policy text into four other categories in which each of the motivations above influence the 'borrowing' of both discourse and text. It is suggested that examples of foreign policy are used as "an exemplar for innovation of new practices at home" (Schriewer, 1990; Turbin, 2001; Ochs and Philips, 2002a, b cited in Ochs, 2006, italics hers). Policy text is also employed as an inspiration for policy reform, including the termination of current policies as well as to converge education reform with global aid initiatives such as Education for All (Ochs, 2006). Finally it may be borrowed to improve the country's international standing (Ochs, 2006). The face of 'education borrowing' is indeed political. The process is not as straightforward as seeing a new idea elsewhere and 'borrowing' it as the reform may already exist in some form in the home context. Thus, the act or appearance of 'education borrowing' is actually a form of political legitimatization.

Legitimization is explained by Steiner-Khamsi (2004) who builds on Schriewer's (1990) work on externalization in which he recognizes that 'international standards' may be from an 'imagined' international community to legitimate policies. Halpin and Troyna (1995: 304) further state that policy transfer is not about the success of the policy in their nation of origin but rather "...much more to do with legitimating other related policies". Examples 
from another country become a resource for politicians to "demonstrate that desirable reforms are workable as well as right" (Whitty and Edwards 1998: 223). It is not always about new policies but also the justification for old policies to continue to persist as Silvona (2004: 76) argues that education policy transfer is used to "legitimize the maintenance of 'old' institutional structures to be used for 'new' purposes in a postsocialist context". Regardless of whether or not the foreign policy was transferred, political discourse associated with the ideas may be transferred (Steiner-Khamsi, 2000 cited in Silvona, 2004). In fact, Spreen (2004a: 105) argues that "the mere mention of borrowed concepts helps contested ideas gain credibility even before they are ever implemented" based on Schriewer's (1992) argument that the language of reform programmes are borrowed as a "self-referential discursive act" (Spreen, 2004a: 105) to build support for policies promoted in the home context without 'borrowing' the actual initiative itself. This is consistent with Lynch's (1998) phrase "flags of convenience" which denote buzzwords to attract funding or attention (cited in Spreen, 2004a).

The use of these 'flags of convenience' is shown in the examples described by SteinerKhamsi (2006) who asserts that countries that adopted aspects of New Zealand's Outcomes Based Education (OBE) such as Britain, Australia, Canada and South Africa referred to experiences in the other countries when widespread criticism arose in their own nations. In the case of South Africa, Spreen (2004a, 2004b) argues that transitional states attempting to reposition their international standing use reforms to signal global participation in the modern society. Spreen (2004b: 221) asserts the following:

In the field of education, circulating reforms internationally serves to reify the notion of international education relatedness and to legitimize the use of international competition and world-class standards in education. This is a bandwagon that most governments do not want to miss jumping on

Steiner-Khamsi and Quist (2000) also explain the necessity of timing of justifying home reforms during times of contestation with external references to legitimate current practices or new reforms (cited in Luschei, 2004). However, the use of external references is not straightforward as timing is everything for the justification of 'borrowing' which may appear invasive after the policy has been accepted into the country. Legitimization will be discussed further in relation to the fieldwork data in 7.2.3. Certainly, 'education borrowing' as legitimization may appear successful as it creates an enclosure around the policy idea as 
it seems to show there is some agreement elsewhere for the reform in question. Shore and Wright (1997, cited in Vavrus, 2004: 151) assert that consensus closes off alternative ways of thinking as described by Vavrus: "The tighter the referential web, the stronger the consensus and the more difficult it becomes to speak up..."

There are other reasons proposed by writers on why 'borrowing' occurs. Luschei (2004) refers to a discussion by Robertson and Waltman (1993, cited in Luschei, 2004: 161) on Plato's argument for looking elsewhere to confirm and improve policies at home: "It is always right for one who dwells in a well-ordered State to go forth on a voyage of enquiry by land and sea, if so be that he himself is incorruptible, so as to confirm thereby such of his native laws as are rightly enacted, and to amend any that are deficient". Robertson and Waltman (1993, cited in Luschei, 2004: 161) thus question Plato's notion of policy 'borrowing' and conclude that "in contrast to Plato's ideal state, most nations resort to copying others' solutions when easier alternatives are in short supply". Robertson and Waltman (1993, cited in Luschei, 2004: 161) offer a less cynical view of policy 'borrowing' as they assert that policymakers first search their own past for solutions before looking abroad, and when conflicts arise among parties, "they are likely to search for solutions that can achieve a consensus among the participants".

\subsubsection{Views on the Process}

Views on how 'education borrowing' occurs are varied and much of the work on 'education borrowing' involves the use of examples to support the findings by researchers. There are two problematic notions associated with 'education borrowing' according to Noah and Eckstein (1969: 21): "It was one thing to assert that the study of foreign education was a valuable enterprise; it is quite another to believe that foreign examples could be imported and domesticated". The problematic assumptions of 'education borrowing' have been pointed out in the use of linear models to highlight the fallacy of such straightforward discussions. Ochs and Phillips (2004) use an illustration by Bray (2004, cited in Ochs and Phillips, 2004: 7) to show how economics and policy 'borrowing' are naively collapsed:

- Country A is an economic basket case (high levels of unemployment and low levels of economic growth) - this is portrayed as largely the result of the educational system which is not producing workers with appropriate skills 
- Country B is economically successful (low levels of unemployment and high levels of economic growth) - this is to a large degree the result of its possessing a welleducated workforce

- Therefore, if country A adopts some of the features of the educational system of Country B it will improve the state of Country A's economy

However, these simple representations of 'borrowing' are in circulation as education is heavily entrenched in the world of politics. Context is of little importance, as discussed by Whitty and Edwards (1998: 223) in the case of justifying decisions of marketization of schools in the United States with examples of grant maintained schools, "despite the risks of ignoring large differences in history, culture and structure and the possibility that some necessary conditions for implementation may be absent in the setting to which the 'lesson' is applied...". As noted by former civil servant Ponting (1986, cited in Halpin and Troyna, 1995: 308), it is evident that politicians are not viewed in a positive light:

...Inside Whitehall is a seedy world of half-truth, ignorance and botched decisiontaking... The instinctive reaction of most Ministers when confronted by an issue is not to think in terms of analyzing a complex problem to seek out the optimum solution but instead to see it in political terms.

Whitty and Edwards (1998) also show the ignorance of advisors to the "education borrowing' process through the example of Sexton (1991, cited in Whitty and Edwards, 1998) who advised New Zealand on how to reform its education system after a few weeks of visiting the country without any prior knowledge of the system. Although Spreen $(2004 a, 2004 b)$ argues that the global movement of ideas and people creates difficulty in pinpointing the time and mode of entry of a policy into another context, she also points out that 'education borrowing' processes and strategies are contingent on time as well as the status, legitimacy and position of the policy maker spearheading the reform. SteinerKhamsi (2004) further argues the importance of key policy personnel in 'education borrowing' through the example 'bridges'. Steiner-Khamsi draws on the example of New Zealander Maris O'Rourke who was central to the Outcomes Based Education (OBE) reforms in New Zealand. In 1995, O'Rourke was hired by the World Bank. Through the appointment of O'Rourke, aspects of OBE then experienced an exponential growth through the Bank's funding initiatives to low-income countries (Steiner-Khamsi, 2004). Individuals such O'Rourke are able to maintain 'weak ties' and elevate ideas globally through institutions that disseminate education policy as shown in social network theory (SteinerKhamsi, 2004: 215). Yet both Steiner-Khamsi (2004) and Chisholm (2007) agree that 
education ideas circulate in other ways. Steiner-Khamsi (2004: 215) lists institutionalized issue networks in education policy such as "associations, journals, newsletters, list-serves and conferences". Chisholm (2007) acknowledges the power of conferences as ideas are put into circulation and enables their absorption and wider dissemination into networks regardless whether or not the ideas are accepted or not. In short, "(n)umbers count, both for mobilization and for survival" (Steiner-Khamsi, 2004: 215). These concepts will be discussed in relation to the thesis data in 7.2.3.

There is also the notion that similar political ideas contribute to the development of parallel reforms such as those associated with neoliberalism. Individuals such as Bruce Cooper, a neoliberalist academic in New York, had links on both sides of the Atlantic that may have helped shape some ideas and act as a medium for exchanging examples (Whitty and Edwards, 1998). Yet while these neoliberal policy networks may exist, the study of similar neoliberalist policies in the UK and USA by Whitty and Edwards (1998: 211) found "...more evidence of the use of overseas examples to legitimate policies at home than it does of direct policy borrowing". Whitty and Edwards provide examples of individuals giving attention to identical reforms across the Atlantic: Kenneth Baker cited the success of American magnet schools during his famous visit to several American cities in 1987 and American state politicians visited British grant-maintained schools to justify charter school legislation in the United States. Yet while examples of British policies were used in discussions at the government level such as publications of league tables, there was less evidence of detailed 'borrowing' as some respondents went as far as to claim that American politicians are "too insular in attitude to be aware of the detail of what was happening in Britain" (Whitty and Edwards, 1992 cited in Halpin and Troyna, 1995: 307).

\subsection{Towards a Model for 'Education borrowing'}

The model purposed by Phillips and Ochs (2004) and Ochs and Phillips (2004) will be presented in this section. A copy of Phillips and Ochs' Model is in Appendix C. While other writers have offered views of how 'borrowing' and transfer occur, the work of these two writers marks a systematic approach to understanding the process. In another article, Phillips and Ochs (2003) note the diverse needs of developing small states and raise 
questions for countries to consider based on their 4 stages of 'education borrowing'. This model will be used to discuss fieldwork data in 7.2.2.

\subsubsection{Phillips and Ochs' Model (2004)}

The first stage of Phillips and Ochs' (2004) model is cross-national attraction, which is defined as impulses or 'externalizing potential'. It may be argued that cases of education policy transfer or the use of foreign examples are simply part of the first stage of 'borrowing' and do not continue to gestation. Cross-national attraction may begin with internal dissatisfaction by members of an education system such as pupils, parents, teachers and/or ministry officials (Phillips and Ochs, 2004). The two writers also identify the aspects of potential policy to be borrowed such as the following: a 'guiding philosophy' such as equality in education opportunities; ambitions and goals such as Education for All or increasing participation in higher education; strategies such as additional funding or training; enabling structures such as new types of school or general education reform; processes such as assessment procedures or grade repetition (Ochs and Phillips 2002a, cited in Phillips and Ochs, 2004). The second stage in the model involves the decision making process. Phillips and Ochs (2004) categorize types of decisions as theoretical, realistic and/or practical, 'quick fix' and 'phoney'. Theoretical decisions are instances where policies such as 'choice and diversity' may be borrowed but may remain generally ambiguous ambitions that do not lead to direct or effective implementation (Phillips and Ochs, 2004). Realistic and/or practical decisions are more genuine than the last two types of 'quick fix' and 'phoney'. Phillips and Ochs (2004) define a 'quick fix' as a dangerous decision in times of political necessity and provide examples such as those introduced in East Europe from external sources following the changes of 1989. The final category of 'phoney' consists of enthusiastic decisions that lack further action.

The third stage in the Phillips and Ochs (2004) model is implementation, which they note will be contingent on the conditions of the country where the reforms are being introduced. They point to the importance of 'significant actors' whose attitudes determine the speed of transformation as they have the power to support or resist change, particularly in decentralized systems. As a result, "(r)esistence might take the form of delayed decision, or simply of non-decision" (Phillips and Ochs, 2004: 780). The fourth stage in the process is 
then internalization/indigenization where the policy is contextualized into the system of the borrower country and it is possible to see how it affects pre-existing structures (Phillips and Ochs, 2004). There are four steps in this stage: impact on existing modus operandi where the motives and objectives can be seen in the larger system; absorption of external features and the extent to which features from the other system have been adopted; synthesis where the policy becomes part of the whole strategy of the 'borrower' nation which is supported by Cornoy and Rhoten's (2002, cited in Phillips and Ochs, 2004) concept of 'recontextualization', acknowledging the interpretation of the policy; and finally evaluation where reflection discerns the realism of the expectations of 'borrowing' (Phillips and Ochs, 2004).

Phillips and Ochs (2004) recognize the difficulties associated with the creation of their model, and raise questions regarding definitions and setting parameters, analyzing and identifying the processes and assessments in terms of judging the outcomes. Thus they regard the model as preliminary "since it will inevitably change as a result of future attempts to apply it to instances of policy 'borrowing' in various contexts" (Phillips and Ochs, 2004: 781). Through a historical approach to analyzing the process of the UK 'borrowing' from Germany, they show how this model fits. Ochs (2006) also uses the model in her examination of the borough of Barking and Dagenham and its 'borrowing' of the Zurich approach to primary Maths. She concludes that the case of Barking and Dagenham highlights best practices from each of the stages:

1. A continued commitment to the objective (improving achievement) and understanding across the LEA of the motives for cross-national attraction;

2. The development of key partnerships to collect data, provide resources, and raise awareness during the decision-making process;

3. Awareness of success and challenges through evaluation during implementation;

4. Recognition that internalization was an iterative process, which could lead to more investigations; more decisions, and continued assessment; and

5. Careful consideration of the local and national context across all four stages. (Ochs, 2006: 616)

\subsubsection{From Practice to Adaptation}


The actual reform that is the object of the process may be transformed through 'education borrowing' as the interpretation of policy officials and the need to indigenize the concept take hold of the original reform viewed in the 'borrower' country. Ochs and Phillips (2004) articulate the presence of filters or lenses in this process where perceptions of the reform pass through to metamorphosis. The first filter is interpretation which depicts the varying ways that actors and organizations understand the reform or idea (Ochs and Phillips, 2006: 10). The second filter or lens is transmission, explained by Ochs (2006: 17) as follows:

(T)he agents whose interpretation of aspects of education 'elsewhere' will result in its being given a particular slant will initiate processes of policy transmission which will involve complex agencies...that in turn will filter the policy through the lens of their own agenda and expectations.

Public forms of commentary and analysis such as the media, academic and scholarly discourse and debate will also affect transmission (Ochs and Phillips, 2004).

The third filter proposed by Ochs and Phillips is reception, where practitioners scrutinize the practice. The two writers narrow the outcome of this filter down to "a significant element of chance" in which practitioners either "will misunderstand the ideas behind a particular innovation" or "training will be inadequate or will produce distortion of the 'borrowed' ideas" (Ochs and Phillips, 2004: 17). Implementation is the next filter, affected by what is practically possible and acceptable. Ochs and Phillips (2004: 17) explain that enthusiasm and resistance "...will further mould the idea which has started out as a clearly identified element of practice within one observable location and at one particular time".

The process of adaptation of the reform is heavily dependent on individual actors. Consistent with the notion of filters, Dolowitz and Marsh (2000) created a list of nine types of actors involved in the process from importing a borrowed idea to implementation: "elected officials, political parties, bureaucrats/civil servants, pressure groups, policy entrepreneurs and experts, trans-national corporations, think tanks, supra-national government and non-governmental institutions and consultants' (cited in Ochs, 2006: 611). These actors play a central role in the filtration process of the reform or idea in question. On the other hand, it is not simply the adaptation process that is centrally shaped by individuals, but also the importation stage. Tanaka (2003) makes a clear distinction 
between 'transmitters' - those who move ideas from one context to another through the act of 'translational indigenization' and 'receivers' who put the concepts into practice through ‘implementational indigenization' (cited in Ochs and Phillips, 2004: 18). Tanaka makes a further distinction between types of transmitters - importing and exporting - and whether or not they have authoritarian or liberal approaches. Import transmitters attempt to import educational concepts and ideas from a different context (Tanaka, 2003 cited in Ochs and Phillips, 2004). Authoritarian importing transmitters "execute a translational indigenization of educational concepts and practices', and exercise their authority to arrest receivers' attempts to undertake implementational indigenization of these concepts and practices" (Ochs and Phillips, 2004: 18). Liberal importing transmitters, on the other hand include receivers in the implementation and indigenization of the concepts, either because these transmitters wish to include receivers or lack the power to exclude them (Tanaka, 2003 cited in Ochs and Phillips, 2004). Exporting transmitters include "colonizers, occupiers, educationalists and transnational agencies" (Tanaka, 2003 cited in Ochs and Phillips, 2004: 18) who engage in both authoritarian and liberal export. Both groups of exporting transmitters seek support in different cultural contexts for foreign concepts and practice. Authoritarian exporting is "analogous" to authoritarian importing and liberal exporting is much the same as liberal importing but permits local actors to perform the implementation of the education concepts that have been exported to them (Ochs and Phillips, 2004).

\subsubsection{Beyond the Model: De-territoralization}

Phillips and Ochs' (2004) model is viewed in a circular fashion where the reform is evaluated and, if further dissatisfaction is present, the process may begin again to remedy the deficiencies. This 'end point' of 'education borrowing' and/or policy transfer may take the form of a re-generation (as suggested by Phillips and Ochs) until the country is satisfied with the 'solution' to its 'problem', or other processes may occur. Tyack and Cuban (1995, cited in Chisholm, 2007: 303) illustrate the three outcomes for reforms introduced with much attention: they can either "take root, or wither away and die, forgotten, or are grafted onto existing institutions as add-ons..." If the reform does survive, it may lose its heritage as a 'borrowed' concept. Ochs (2006: 612) in her work on Swiss ideas in the borough of Barking and Dagenham found that the ideas became internalized and were "rebranded" and “stopped being 'Swiss' and became 'unique' to Barking and Dagenham". Ochs (2006) 
attributes this to 'institutional amnesia', a phrase coined by Steiner-Khamsi (2004). In order for the borrowed idea to become part of the system, it seems it must be owned by the context. Steiner-Khamsi (2004) refers to this whole process as de-territorialization, using the example of Outcomes Based Education (OBE) and its de-association with New Zealand and its 1980s school reforms. This has helped in the export of OBE, as "few reforms claim to be twins, triplets or even quadruplets of the original reform idea. Most of them, however, are likely to claim to be improved versions of the original" (Steiner-Khamsi, 2004: 215). In cases of policy epidemics such as OBE, the model is perceived and traded as a global transnational model (Steiner Khamsi, 2004).

Spreen (2004a) points out the obvious irony of this in light of the initial use of foreign examples to legitimize home policies. The power of foreign models in creating a 'consensus' that a reform idea is successful loses its power during the process of transfer. Spreen (2004a: 112) refers to the onset of foreign policy discourse as "international contemplation" in the beginning stages of planning and notes the lack of cross-cultural examination. However, “...once concepts and approaches hit the ground and come into conflict with local nuances and cultural understandings, its international applicability is called into question" (Spreen, 2004a: 112). This occurs exactly when ideas begin to develop and become nationalized as they "...must confront cultural beliefs, practices, and local understandings; then the international argument loses weight". (Spreen, 2004a: 112). As indigenization occurs, the original foreign appeal withers away and the borrowed framework, reform or idea is adapted to the cultural context in order for it to be accepted by a wider audience and be implemented with some success. Otherwise, it may be aborted.

\section{$\underline{3.3 \text { Cases of 'Borrowing' }}$}

Werning Rivera (2004 cited in Steiner-Khamsi, 2006) outlines three choices countries may consider when looking for a reference society to borrow lessons. They consist of comparability in terms of geographical, historical or cultural proximity; prestige (such as prominence in geo-strategy) and performance in economics and politics. Steiner-Khamsi (2006: 674) notes the absence of "economic considerations, that is, countries that are actively involved as 'donors' and engage in external funding assistance". This is particularly true for developing countries dependent on aid, and as such this section will 
highlight examples of 'borrowing' in both first world countries and those in a development context. It is beyond the scope of this chapter to examine all cases of 'borrowing' and the use of foreign examples as there are many cases and the summary provided here does not do justice to the findings of each case. Additionally, there are certainly cases of 'borrowing' that may not be documented as writers in this field are typically from the 'West. It is also difficult to pinpoint exactly how foreign models were used in the formation of home policies. However, a few important examples will be cited with a slight bias towards those in the developing country context as findings may have stronger implications for the island states of Barbados and Trinidad and Tobago. The cases in the 'first world' and Brazil's adoption of the Escuela Nueva Colombian model appear to be 'horizontal borrowing', while the case of Rwanda reveals several directions of borrowed ideas, notably from returning individuals and the aid agencies, which indicates the direction is mostly 'vertical'. The spread of OBE in Central Asian countries also appears to be 'vertical borrowing'.

Regardless of which cases are studied, there is perhaps little evidence of highly successful 'borrowing' or policy transfer in which countries wholeheartedly adopted a reform that took root and adapted smoothly into the existing system. Thus there is no perfect process and exemplars of 'borrowing' and policy transfer are in short supply. Cowen (2006: 14) cites examples of 'borrowing' and concludes the following:

All these examples illustrate specific routes of international influence, and mark specific crises which the supposed 'transfer' was supposed to resolve - normally within a naïve (or political) over-confidence that such transfers will work in their new domestic contexts.

The third part of this section will examine 'borrowing' between the 'First World' and developing countries. New Zealand's Outcomes Based Education received much attention as it has been linked to World Bank loans after the appointment to Washington of one of its chief architects - New Zealander Maris O'Rourke - who brought the ideas with her (Dale, 2001) and into the developing context (see section 3.3.3 and Appendix D).

\subsubsection{Cases in the 'first world'}


Phillips (1995, 2000a, 2000b, 2002, and 2004) discusses in detail British interest in Germany from approximately the $19^{\text {th }}$ century onwards and uses the case of Germany as example in his work with Ochs on policy 'borrowing' modeling. The work of Phillips on Germany is beyond the scope of this chapter; however it is important to note that the main interest of the English revolved around primary and secondary achievement. Indeed the tripartite system of Germany, in particular their technical and vocational system, has a strong reputation. As mentioned previously, Ochs (2006) examined 'borrowing' between Zurich, Switzerland and the London borough of Barking and Dagenham, which resulted in a rise in children's confidence and achievement. Swiss Maths teaching methods as observed in Zurich include whole class instruction where children were required to use precise mathematical language in explanations (Ochs, 2006). Other famous cases include the transatlantic mutual interest between America and the UK as highlighted by Whitty and Edwards, as well as interest in the neoliberal reforms of New Zealand, which is discussed at length later. Links within Europe have been long standing, perhaps due to proximity and competition such as British interest in France and Scandinavia. In particular, due to the high achievement scores of Finland in international achievement tests such as PISA, there has been widespread interest in the Finnish system to the point where 'policy tourism' includes organized itineraries to deal with the demand among visiting officials (personal conversation with doctoral candidate studying Finland). There has also been interest in Asia, in particular Japan and the high achieving four Asian tiger economies of Hong Kong, Taiwan, Singapore and South Korea (see Stevenson and Stigler, 1992; Green, 2000). The gaze of the borrower has not always come from 'the West' as the American comprehensive school has been viewed as a model as well as their competency-based teacher training (Cowen, 2006). As discussed previously, the marketization of education in the UK has also been the object of interest. Japan has shown interest in 'borrowing' UK pedagogical approaches as well (see Green, 2000).

The work of Hufton and Elliott (2000) proposes the strength of a 'pedagogical nexus' in the Russian system. Russia has always been a strong focal point as it has influenced the systems of Eastern European countries - although remnants of the system remain in varying degrees across the former states. However, Russia, despite historical transitions, has remained steadfast in its pedagogical methods. The historical and cultural weight of the 
Russian system has reinforced support among teachers and parents who were educated much of the same way as their children. Russia has also been of interest to America and China as Cowen (2006: 14) writes: "This sort of political foolishness is not a monopoly of Americans, who wanted at one point to know 'why Ivan can read and Johnny cannot' and then embraced a model of teaching drawn from the English infant school.... Such international errors are widespread in space and in time". 'Borrowing' from others to improve education systems is not a recent activity and is not limited simply to the countries in the west. After 1949, China borrowed Soviet practices to help create a socialist society and exact translations of Soviet textbooks were introduced into the People's Republic (Cowen, 2006).

\subsubsection{Cases in the 'Third World'}

Steiner-Khamsi (2006: 666) believes that research in the developing context not only pays attention to regional and South-South transfer but also points out “...the limitations of policy borrowing research focusing exclusively on cultural, social and political dimensions of transfer, and neglect the economics of policy borrowing". Countries dependent on aid are impacted by the "donor logic" of both development banks motivated by finance and bilateral agencies which "selectively export 'best practices' from their own education systems, supposedly missing or 'underdeveloped' in low-income countries (SteinerKhamsi, 2006: 675). Steiner-Khamsi (2006) uses the example of the decision of the Japanese government to export their 'lesson study' after pressure to direct investments towards basic education initiatives as part of international agreements rather than 'hard' type funding for school buildings. With the rise of competition for national branding of 'best practices', Japan exported its 'lesson study', a reflective teacher development sharing practice in Maths and Science as part of its funding agreements (Steiner-Khamsi, 2006).

'Borrowing' in developing countries is an enormous task considering the financial cost of changing classroom practice. Further, every society has particular sociocultural beliefs towards education and these may be severely immutable, especially when faced with the prospect of adopting a foreign model. The notion of education reform in developing countries through 'education borrowing' or policy transfer is described bleakly by Jansen (1998) who claims that despite 80 years of curriculum change research, there is no evidence 
to suggest changing the curriculum will lead to changes in a nation's economy. He states that even the most optimistic study by the World Bank on experimental research on economically responsive curriculum in Tanzania and Colombia simply concludes there is no significant social or private benefit for the countries (Psacharopoulos and Woodhall, 1986 cited in Jansen 1998). Although Jansen's (1998: 324) work is in reference to South Africa, he concludes the following for developing countries:

This is particularly the case in developing countries, where economic problems have little to do with what happens inside schools and much more to do with the economics and politics of a third-world state, e.g. sustained high unemployment... What official documents therefore claim is at best misleading since they offer an economic development panacea to benefit those alienated from education and training...in the name of a complex curriculum reform policy. To make such connections between curriculum and society has understandable political goals, but these connections have no foundation in the accumulated research on curriculum change.

'Education borrowing' and policy transfer in developing countries are under-researched areas as the discussions surrounding the problematic impact of aid organizations often detract from the process itself. Two studies of 'education borrowing' and policy transfer will be discussed in this section. While this is a limited snapshot of the process occurring in developing countries, the cases of Brazil and Rwanda have some interesting implications for further analysis. Brazil adopted Escuela Nueva from the Southern country of Colombia and enjoyed minimal success due to problems of implementation. On the other hand, Rwanda experienced the varying agendas of international influence in its post conflict phase. Both are interesting cases of 'borrowing' and transfer to contrast with the larger epidemic that hit many developing countries - the New Zealand model of Outcomes Based Education which will be discussed in 3.3.3.

\subsubsection{Brazil: South-South 'borrowing'}

Brazilian education has been of interest to other countries in both the north and the south since the early 1970s with the radical ideas of Paulo Freire. In America, Freire's ideas caught enthusiasm with students and, in particular, specialists in adult education (Cowen, 2006). Brazil has been both the borrower and the lender. In the 1990s it was interested in the quality control systems of the English university as it believed it would prepare their 
students for a globalized world (Cowen, 2006). However, a more famous case of 'borrowing' is that of Escuela Nueva, a Colombian model of a unitary school that consists of the following key features: inservice teacher training; community involvement; creation of self instructional learning guides for pupils complete with learning objectives and guided activities including creative exploration, application of region-specific knowledge; and supposedly requires students to construct their own knowledge (McEwan and Beneviste, 2001). The idea of a unitary school was not new. In fact, unitary schools are common in developing countries and thus the Escuela Nueva model was a way of improving quality (McEwan and Beneviste, 2001). Yet this Colombian initiative was 'horizontally' introduced into Brazil at a time when there were increasing doubts about the programme (Luschei, 2004). Disappointingly, Beneviste and McEwan (2000 cited in Luschei, 2004) found only one of three workshops for teachers had a statistically significant effect on the use of more active pedagogy for pupils. Local will from community members and teachers is a key element in the success, perhaps due to Schiefelbein's (1992) caution for adaptation rather than replication: "Planners must realize that the term replication does not mean mechanical reproduction, but rather adaptive implementation that remains true to the project's core philosophy and central strategies" (cited in Luschei, 2004: 157). Further, this large variation of the implementation by teachers of the Escuela Nueva model and pedagogy prompted a caution to education planners: "Even if the requisite program inputs are developed and capacity is provided, the core of educational practice may remain only slightly altered" (Schiefelbein, 1992 cited in Luschei, 2004: 157). Clearly, adaptation to local context and the local will of actors needs to be taken into serious consideration before enthusiastic 'borrowing' of models.

\subsubsection{Rwanda: International influences}

According to the analysis by Schweisfurth (2006), Rwanda did not borrow a specific model during its time of reconstruction, but 'education borrowing' or policy transfer took the form of 'second generation colonialism', as it was "carried through returning refugees in postcolonial contexts, who have a comparative perspective and acclimatization in foreign ways of working" (Schweisfurth, 2006: 704). Returning individuals brought back ideas from

other former British colonies such as Tanzania and Uganda (Schweisfurth, 2006). As Rwanda had already inherited aspects of the Belgian school during colonial rule; the 
resulting scenario in education was the "the co-existence of A levels and Upper Secondary examinations; the modeling of the Kigali Institute of Education to the parallel Ugandan institution; and the implementation of the Ugandan-style inspection by the Inspectorate General". (Schweisfurth, 2006: 704). Those in the new key positions such as the Minister of Education, the head of education research and planning and current director of examinations had spent extended time working elsewhere during the period of conflict (Schweisfurth, 2006). Schweisfurth (2006: 704) explains the positions of power available to these individuals:

This is obviously not to say that individuals have been granted the sole power to formulate and implement policy; the influence is more subtle than that. However, in a state suffering from serious capacity problems, in a post-conflict situation, individuals can find themselves in positions of considerable authority...

Some indication of 'vertical borrowing' may be evidenced in the presence of aid agencies, which varied in their intentions and goals, from agencies that worked with targeted agendas to other NGOs in a more ad hoc basis (Schweisfurth, 2006). There was also a diversity of goals, with some placing emphasis on "the genocide and imperatives of 'never again' at the heart of the education agenda" others focused on Education for All, Millennium Development Goals with the basis of poverty reduction, "either because this is seen as the essential prerequisite to lasting peace, or because the global nature of this agenda raises its profile and feeds its resource base" (Schweisfurth, 2006: 707). While it may be argued that the experiences of returnees in power, the emphasis on ensuring genocide does not happen again and goals of international agencies are not in direct conflict, the different imperatives of each of these three forms of international influence may impede the necessity to build peace through schools (Schweisfurth, 2006). The case of Rwanda points to the complicated picture of 'education borrowing' or policy transfer as it is difficult to distinguish the impact of international influence and how reforms are introduced. Schweisfurth (2006: 707) thus concludes the following:

What emerges bears little resemblance to the traditional Comparative Education domain of policy 'borrowing' or policy 'transfer', which is relatively tame and linear; the extent of challenges, and the diversity of global and cross-national currents has created a much more turbulent picture.

\subsubsection{OBE as a model}


The rapid dissemination of Outcomes Based Education (OBE) is likened to an epidemic that afflicted systems particularly at the stage of policy formation by Steiner-Khamsi (2006). She points out the popularity of adopting such a reform: “... global diffusion as ultimate proof that this particular reform strategy is effective and accelerates change in schools" (Steiner-Khamsi, 2006: 665). OBE apparently originated in New Zealand yet has become 'de-territorialized' to the extent that referring to OBE requires a precise geographical context. OBE was greeted with much fanfare in South Africa and also impacted foreign aid in the Central Asian countries of Mongolia, the Kyrgyzstan and Kazakhstan. The interest in OBE still exists despite the stagnation of the movement as countries such as Germany and Switzerland are considered 'laggards' of the reform (Steiner-Khamsi, 2006). Steiner-Khamsi (2006: 670) also refers to such reforms as "an octopus with several arms" which begs her question "which element(s) of OBE reform traveled to the different national contexts?" However, there is an attempt to describe some of its key features as seen in New Zealand's Curriculum Framework in which individual students and their learning outcomes are at the centre of teaching and learning (SteinerKhamsi, 2006). Content, then is dissociated from specific grades and teachers establish benchmarks for students who are regularly tested (Steiner-Khamsi, 2006). The performance of a teacher is reflected in the meeting of learning outcomes and thus OBE "has been propagated as a tool for quality enhancement in education, and aptly referred to as the New Contractualism or New Accountability" (Steiner-Khamsi, 2006: 668). Steiner-Khamsi (2006) asserts that the introduction of teacher bonuses accompanied OBE in many countries along with teacher monitoring, salary schemes and in some cases, school choice. Other aspects occasionally appeared such as curriculum and assessment reform and public accountability for school quality (Steiner-Khamsi, 2006). OBE was not adopted as a package and at times only a few features appeared; in fact respondents in Steiner-Khamsi's (2006) study disliked the other features to the extent that they questioned how the aspects could be associated with OBE. Yet, as Jansen (1998) points out, the international experience does not mirror the intentions of OBE. Citing the case of American adoption of OBE, Brandt (1994, cited in Jansen 1998) found that the reforms do not actualize in the classroom context as curriculum and assessment schemes are rarely overhauled. 
In fact, Dale (2001: 499) argues that the model owes its popularity to its political support: "The career of the New Zealand model began under a very particular set of conditions and could only proceed with the backing of powerful sponsors, both inside and outside the country". Thus, OBE as an idea is not inherently 'good', but was certainly popular as a model. Its shortcomings were later realized both inside and outside New Zealand at a time when it was still being exported to 'late adopters' (Steiner-Khamsi, 2006). Not only did it appeal to countries in similar positions, it was also popular with rich OECD nations, perhaps due to its similar roots with the Washington Consensus (Dale, 2001). The Washington Consensus as explained by Chan (2007) was a pact during the Thatcher and Reagan era between the US government, economic agencies, international financial institutions and think tanks that promoted pro-market policies based on public expenditure cuts, deregulation and foreign direct investment, taking the form of structural adjustment programmes at the World Bank. Thus, OBE had strong roots in the notion of a fiscal management approach to education.

Initially, the New Zealand model may have been popular because it was unassuming: it did not point out existing 'best' practices or demand specific conditions only found in New Zealand (Dale, 2001). Dale (2001: 498) further explains why the New Zealand origins of OBE helped with its exportation:

New Zealand is not a large, powerful or rich country; indeed, it had been gradually slipping down the OECD league tables from its high point in the early 1950s. Nor did it have a history of neo-liberal economic policies. On the contrary, it had been previously seen as a laboratory for the welfare state. Further, while it is clearly in the Western bloc, New Zealand cannot be seen as representative of it, or acting on its behalf. Associated with this, it did not represent a threat of American hegemony or takeover...

Interest in New Zealand was found in interviews with respondents (see 4.3.1), which will be discussed in 4.3.2 and 7.3.4.

\subsection{Education in the Caribbean}

While the first four sections of this literature review focused on wider theoretical perspectives for 'education borrowing', policy transfer, and alternative lenses to understand the influence of foreign examples in policy formation, the last and largest section will focus 
on the context of the Caribbean. To date, no case of 'horizontal borrowing' in the Caribbean has been noted, but the cases of Brazil, Rwanda and OBE serve as examples of developing country 'borrowing'. This section is divided up into three parts, starting with discussion of education in colonial times, followed by a present day critique of teaching and learning, exams, teachers and inclusion. The final part paves a way forward for the Caribbean as envisioned by writers in the field. See 2.1.1 and 2.1.3 for research on small states and the impact of multilateralism.

\subsubsection{Colonial Education}

Insight into the present education systems of the West Indies may be aided by a short discussion on education in the colonial era as the present model of schooling owes much to European colonial history. Jules (2008: 205) describes education in the Caribbean slave society: "... it was reserved for the children of the planter class and documents of the period explicitly assert that to educate the children of the lower classes would be to 'unfit them for that role in life that must necessarily be theirs'. Although London (2002: 117) concludes that major developments have been made to ensure an education that serves the needs of the postcolonial politics, economy and society, sadly, "the transformation has been glacially slow". Hickling-Hudson (2004: 296) argues that it is indeed this model that "contributes to the devastating class tensions across the region. If we cannot reshape the model, there is little possibility of improvement of quality, the range of skills competencies, values and other attributes. Yet Louisy (2001: 191) argues that colonial education “...can best be described as ad hoc and segregated.... except to say that mainstreaming of the now significantly large African population was absolutely opposed..." In addition, education for the colonial elite was much different from the indigenes (Louisy, 2001). Willinsky (1998, cited in London 2002) agrees, as his work on education administration found differences between territories despite some common denominator in policies. In light of inconsistencies in colonial education, the main aim according to Bacchus $(1994$, cited in London, 2002: 100) was to instill in the subalterns "a world view that would develop in them [the colonized] a voluntary subservience to the white ruling groups and a willingness to continue to occupy their positions on the lowest rungs of the occupational and social ladder". This view of education reflects upon the view of the colonizers of their subjects. London (2001: 403) points to the myth of the lazy native and the view that "the colonized 
were seen as 'indolent and sun-loving', a group of people easier to dominate than 'those nurtured in a colder climate'..." Thus, the school was viewed to be a better agent in the socialization process than the home to ensure "the habits of obedience to an external law" (Ross, 1901 cited in London, 2002: 108). London (2001) argues that this was made possible with the establishment of the English language in the colonies which forced a bond with British Empire. Thus, the diffusion of the language "ensured a special bond with things English and with 'all things white' to this day" (London, 2001: 394). In the case of Trinidad and Tobago, all other languages are defunct including Hindi as "English has become an asset as Trinidad and Tobago arrives to modernize its economy and society, and to harmonize its cultural diversity, goals for which effective participation in the global economy of today becomes mandatory" (London, 2001: 418). Thus, English in Trinidad and Tobago and the death of indigenous languages has created a colonized bond to the British Empire. Palmer (1967, cited in London, 2001: 420) asserts that language shapes the way one sees as "For more than man realizes he channels through language the various facets of his living - his worshipping, loving, social behaviour, even the shape of his feelings is conformed to language." London (2001: 407-408) asserts the bond between Englishness and the Empire was solidified in the teaching of English:

The content, instructional methods, administrative and surveillance techniques used were designed for the purpose, as well as to guarantee use even after the rhetoric of de-anglocentrification had infiltrated many spheres of public life during the early post-colonial era. The Trinidad and Tobago 'buy local' and 'go-local' campaigns of the 1960s and 1990s were part of the new dispensation, but they did not enjoy any degree of success.

The work of London $(2001,2002)$ also provides insight into education during colonial Trinidad and Tobago, which is reflected in the present day education system. He identifies four ideological positions borrowed from Imperial Britain, namely "mental disciplinarity, humanism, child study and social efficiency" (London, 2002: 103). Mental discipline is based on the notion that aspects of the mind such as memory, attention, observation, reasoning and will could be trained as muscles to function more effectively (London, 2002) which may be likened to Brookfield's (1975, cited in London, 2002: 105) description of colonization as a "struggle for the mind". Humanism, on the other hand, contributed to the content studied as it placed emphasis on promoting western values in the curriculum such as "(k)nowledge of 'the truth', love of 'beauty' and cultivating the habit of doing 'good"' 
(London, 2002: 105). Humanism also involved the 'five windows of the soul (Harris, 1886 cited in London, 2002) namely "arithmetic, geography, history, grammar, literature and art" to facilitate the shaping of norms and traits for the subjects (London, 2002: 105). Child study was another movement that was popular in early $20^{\text {th }}$ century Britain, which focused on play and activity. Yet the principles of child study were not so faithfully followed in the colonial world as the "aspects of the doctrine selected for implementation could not yield the liberation or conscientization that observers...claim would provide a panacea for the oppressed "other"' (London, 2002: 115). Curriculum individualism was yet another feature that was based on variations such as achievement and gender, which determined the limits of the child's capacities (London, 2002). Similar to the present day situation in the Caribbean, colonial notions of curriculum individualism lead to curricular and instructional differentiation and as a result to streaming" (London, 2002: 107). Finally, social efficiency dictated that the aim of the curriculum was to include all activities in life and as such colonial education aimed to connect activities in school with those that the child would be required to perform in their adult (colonized) life (London, 2002). These tenets of colonial education are still evident in Caribbean societies today, despite some efforts to liberalize education. A post-colonial analysis of the data collected in this study is found in 7.3.3.

\subsubsection{Critiques of Education in the Caribbean}

Most of the criticism of education in the Caribbean centres around the problems of provision and the inequalities produced. While there will be specific discussion regarding aspects of the system such as teaching and learning, examinations, teachers and inclusion, the critique offered by Hickling-Hudson (2004: 296) sums up the central concerns:

Education systems like those in the Anglophone Caribbean are underdeveloped in terms of the quantity of provision and maldeveloped in terms of its stratification and unevenness of quality. They match the logic of the capitalist underdevelopment found in many post-colonial countries ...preparing a minority of the population with advanced levels of education to participate in the complex economic activities of the very small modern sector.

Hickling-Hudson (2004: 298) asserts the need for schools to "...shed their $19^{\text {th }}$ century characteristics of stratification, didactism, authoritarianism, competitiveness and selfish individualism". She also describes schools in the Caribbean as "custodial and often 
humiliating institutions" despite some top quality schools that are comparable to those in the West (Hickling-Hudson, 2004: 298). As a result, large populations of Caribbean citizenry have been subjected to badly endowed schools and thus are victims of education injustice (Hickling-Hudson, 2004). Any attempt to enter back into education unfortunately is wrought with the similar problems of quality, resulting in little opportunity to improve one's quality of life. Hickling-Hudson (2004: 296) paints a bleak picture for re-entry into education: “...(A)dult basic and popular education is often too underdeveloped to provide adequate opportunity for poorly schooled adults to gain the qualifications necessary for well-paid employment, social mobility or the political skills to press for democratic change". See 6.3 and 6.4 for respondent perspectives on teaching and learning, exams and lower-achieving pupils.

\subsubsection{Teaching and Learning}

Torres (1996, cited in Hickling-Hudson 2004: 298) declared "(w)ithout the reform of teacher education, there will be no reform of education". Teacher training is often seen as key to all other changes in the schooling system. Despite a dearth of research in teacher training in the Caribbean, Coultas and Lewin (2002) provide some insights into teacher training in Trinidad and Tobago with strong implications for the Caribbean. Coultas and Lewin (2002) surveyed teacher trainees with varying teaching experience in their study of four developing countries including Trinidad and Tobago. As teachers in Trinidad and Tobago need to have completed two to three years of teaching and be currently in teaching posts during their study, they were contrasted with teachers from Malawi, Ghana and Lesotho who were pre-service trainees. The cohort of 700-800 teachers was awarded full scholarships for their study (Coultas and Lewin, 2002). Student teachers in Trinidad and Tobago held high qualifications compared to training teachers from the three African countries, as each Trinibagonian needed to have five CXC passes to enter the profession (Coultas and Lewin, 2002). Other interesting findings for the Trinibagonian trainees from this study include the following: Trinibagonian trainees found teaching difficult and twothirds of them were in favour of corporal punishment (Coultas and Lewin, 2002). Yet perhaps the most significant findings from this study are those that pertain to teacher training in developing country contexts. Coultas and Lewin (2002: 256) found no clear indication "that training programmes and the experience of being an NQT have 
dramatically transformed the responses trainees give to the common items". Thus, training does not cause significantly large shifts in the perspectives of the different groups of teachers (Coultas and Lewin, 2002). The two researchers explain this finding:

This might be considered disappointing, or perhaps an indication that the task teacher educators have is a very difficult one. It may also suggest that the perceptions represented by the items are deeply entrenched, and/or they are strongly influenced by factors exogenous to the training process (Coultas and Lewin, 2002: 256).

Coultas and Lewin (2002: 256) conclude that factors such as “...age, religious affiliation, home background, prior educational qualifications, and amount of teaching experience new trainees have, vary widely". Further, these characteristics are not the same as those found in American and British student teachers, "from where much of the theorizing and advice on teacher education reform in Anglophone countries originates" (Coultas and Lewin, 2002: 256). More worrying is the finding that Education tutors are surprisingly unaware of the characteristics of their training cohorts and even of the teaching and school contexts they enter after training programmes (Coultas and Lewin, 2002). This study shows that models of teacher training from America and Britain may have compounded the poor quality of education found in teaching and learning in the Caribbean. These models of teacher training may also contribute to the beliefs of teachers.

Bell-Hutchinson's (2004) doctoral thesis from the Mona Campus of the University of the West Indies provides some insights into teachers' beliefs, classroom pedagogy and practice. She notes three key components of Mathematics teaching in Jamaica based on her fieldwork observations and previous experience as a teacher:

1. The teacher is always at the centre-stage,

2. Rote teaching is the norm, and

3. Students are very dependent on the teacher (Bell-Hutchinson, 2004: 7)

Even when difficulties arose in the learning process, questioning the students would sometimes occur, "seemingly to have the students think about the problem" but "teachers ended up answering the questions themselves" in many cases (Bell-Hutchinson, 2004: 8). Bell-Hutchinson (2004: 10) also provides an example of a lesson on fractions in which "(a)nyone passing this classroom would have witnessed a learning environment abuzz with activity" as students were excitedly completing activities. Yet upon closer examination, 
significant ideas lacked discussion and development, as discussed by Bell-Hutchinson (2004: 10):

The definition of a fraction, for example, which as given by one student, was taken as correct by the teacher and 'handed' to the students without any attempt to clarify, add meaning to or determine the nature of the understanding that had been developed by the students concerning this definition. There was no attempt throughout the discussion to link the activities which the students had done with the questions which the teacher subsequently asked, and there as, similarly, no indication that the students had made any such connection. In addition, the student who answered ' 5 ' was not probed any further in order to unearth the reasons for his answer.

However, Bell-Hutchinson's (2004) thesis work queried the approach of teaching-forthinking in two classrooms by two separate teachers and was able to report changes within students in their confidence levels and attitudes towards school Maths. This deeper approach emphasizes students' understanding and experience of a concept and aims to provide opportunities for thinking. Teachers also reported that "...students had begun to develop enquiring minds, and were becoming more independent learners" (BellHutchinson, 2004: 272). Further developments in teacher training with focus on teachingfor-thinking approaches may pave a promising avenue for improving quality.

Yet Lee (2002, cited in Bell-Hutchinson, 2004) addressed the resistance among teachers towards implementing new Maths curriculum and found that success in the implementation process was linked to the extent of changing beliefs about multiple aspects of the teaching process such as the nature of Mathematics, how pupils learn Maths, and assessment strategies. Mathematics is unanimously viewed as vitally important to parents, teachers and employers in Jamaica (Bell-Hutchinson, 2004) - and probably the whole Caribbean. While the 'usefulness' of Mathematics has been queried by Devlin $(2000$, cited in BellHutchinson, 2004) who argues that few people need to use Maths beyond what they have acquired by the age of 12, Bell-Hutchinson (2004: 57) argues that this perspective begs two further questions: "Firstly does the fact that most of school mathematics is not used by the average citizen suggest that we should reduce the content of school mathematics? And secondly, is the attainment of quantitative competence the only reason for teaching mathematics?" Bell-Hutchinson (2004: 63) provides several generally agreed purposes for the teaching of Maths: 
- Mathematics facilitates the development of thinking (including spatial thinking) and reasoning skills, and ideas of proof

- Mathematics can be use to predict, explain and describe phenomena;

- Mathematics is the foundation for science and technology

- Mathematics provides opportunities to promote cultural development;

- Mathematics provides a powerful means of communication.

Regardless of whether or not parents, teachers and employers in the Caribbean agree with each of these, the main belief that Maths is viewed as important cannot be ignored. Thus there needs to be some reconciliation between curriculum reform, teachers' beliefs and the beliefs of wider society in order for changes to be made in the classroom. The thesis work of Bell-Hutchinson (2004) provides a platform to explore teachers' beliefs further. She identifies the key factor for success of thinking-focused pedagogy as teacher beliefs in the methodology of teaching-for-thinking and further to this, "reflects this belief in his/her practice" (Bell-Hutchinson, 2004: 272). With regards to the students, Bell-Hutchinson (2004: 292) found the following: despite the little attention paid to affective needs of students, the attitude of the teacher matters to children and "...can make the difference between alienation and participation". The notion of quality, however, may begin with teachers' attitudes but is also inextricably linked to other aspects of the school system such as exams.

\subsubsection{Exams}

One of the more important education developments was the establishment of the Caribbean Examinations Council. Exams created by educationalists in the region replaced the Oxford Cambridge GCE and Advanced level exams, yielding outcomes such as increasing control over assessments, ensuring contextual relevance to pupils and introducing school based assessments. Yet Hickling-Hudson (2004) reveals that access continues to be problematic due to high entry fees and demanding standards that require well-qualified teachers and resourceful schools. Poverty remains a problem on a regional level, resulting in only a small portion of students sitting the exams, and further, the majority fails (HicklingHudson, 2004). The majority of schools are poor and denied the opportunity to "...acquire the dominant epistemic and technical literacy necessary to gain at least four strong passes in this regional, highly respected Caribbean examination system" (Hickling-Hudson, 2004: 
298). Any education change, argues Hickling-Hudson (2004), may include abolishing selective exams that stake access to schools of varying quality and status. This is not simply an exercise of eliminating a procedural test. Rather, this would involve a momentous societal value shift: "This would mean a challenge to the economic privilege now exercised by the minority of families across the region, who send their children to the high-status preparatory and secondary schools which remain an entrenched legacy of British colonialism"(Hickling-Hudson 2004: 298). Hickling-Hudson (2004) aptly concludes that it would take a "revolution" to bring out such changes to the conservative norm in a cashstrapped region. And yet, school leaving exams need to be changed. Although Barbados has achieved universal secondary education and a good participation rate of $23 \%$ in higher education (Peters and Best, 2005), a large number of students leave school without relevant qualifications. Peters and Best (2005) suggest that quality outputs at secondary level and remediation in the non-compulsory schooling context needs to improve to allow individuals to access higher education. In the context of improving tertiary level participation, the current pathways of passes at CXC level or 2 passes at CAPE level are "inadequate for the sustained growth in the enrolment that is required" (Peters and Best, 2005: 15).

Attempts to change the landscape of exams have not been implemented favourably. BellHutchinson (2004) outlines the introduction of the Secondary School Certificate in Jamaica, which had the purpose of providing certification for all school leaving students. However, SSC exams are only taken by students in new secondary schools and "carry very little currency in the wider society" (Bell-Hutchinson, 2004: 36). Further, candidates need to wait a whole year for their results (Bell-Hutchinson. 2004). Although examination results have strong implications for a child's future, they also strongly direct the course of teaching within the Caribbean system. Bell-Hutchinson (2004: 3) notes that many of her in-service and pre-service teachers admitted their key aim was to "get students through the examinations" through a methodology of rote memorization, practice, drill and repetition. There is perhaps a further issue of teacher awareness of the aims of the curriculum. Many teachers were not aware of the aims of the CSEC examination which moves away from rote knowledge of the curriculum (Caribbean Examinations Council, 2001) and as a result, their teaching does not reflect the aims put forth by CXC (Bell-Hutchinson, 2004). This is probably due to the fact that many of Bell-Hutchinson's (2004: 32) students admitted they have never seen a CSEC syllabus, "because, more often than not, they are provided with 
their schools' mathematics syllabus, already divided into 'Years' and 'Terms', rather like a ready-made package". This was confirmed by the fieldwork interviews and observations of this thesis study. On the other hand, even if they did, the important factor of beliefs may remain unchanged (see Lee, 2002 in 3.4.2.1). While exams continue to dictate many aspects of societal values and teacher perspectives, the next part of this section will look at inclusion.

\subsubsection{Inclusion}

Lavia's (2007: 190) work is a rare study on the issue of inclusion in the West Indies as "...the notion of the role of special education in development terms is a recent formulation for the region". Yet the creation of difference and normalization of practices are not new (Lavia, 2007). While Education for All plans have provided universal and in most cases, secondary education, the "...quick-paced implementation of 'inclusion' has resulted in educational turbulence" (Lavia, 2007: 193). New hybrid forms of inclusion emerge such as changing the role of special schools to resource centres, decentralizing special needs provision through support services meant to be interdisciplinary and the ambitious goal to "...construct systems of access for all to participate in seamless education provision from early childhood to tertiary education" (Lavia, 2007: 193). The development of increased special needs provision is certainly an area for growth as participation continues to expand at the secondary level and further research in this area may reveal the 'borrowing' of inclusion models.

A more commonly researched area is that of gender. As discussed in 2.2 , the Caribbean is a matrifocal society where generally girls have higher achievement levels in compulsory schooling. Lavia (2007: 194) explains the structural relationships governing this:

...(G)eography and proximity to the learning site; existing levels of participation within the family and general family ethos about schooling and learning; attitudes about who should be educated and their potential for economic involvement; choices about allocation of (limited) resource: and bureaucratic and quality factors in schooling arrangements, curricula and teaching ... as have been exemplified in the previous life history accounts. 
Although the work of Parry (1996) is dated, her work in Jamaica, Barbados and St. Vincent reveals gender dynamics between teachers and students in the classroom (see 2.2.2 for more information on gender). She found male students, especially in Jamaica, slumped over their desks and wandering around. Males were described as "“lazy', 'disruptive', 'noisy' and 'rude" (Parry, 1996: 8). If they sat at the front of the class, it was either because they were interested in a subject or because they were 'making a point' (Parry, 1996: 8). On the other hand, females asked more questions, raised their hands and provided answers. In the single sex classrooms that Parry (1996) visited, they were cleaner and quieter than all-male classrooms. To help explain this marked difference among the genders in both single and mixed sex classes, Parry (1996: 11) discusses the construction of masculinity in the Caribbean where "cultural expectations of male behaviour are informed by an extremely hard, macho, masculine sex/gender identity which is associated with maleness". Thus male students are expected to show specific responses informed by a cultural interpretation of masculinity by both their classmates and teachers (Parry, 1996: 11). This disruptive 'acting out' has strong implications for their education performance. Parry (1996: 12) also links this version of masculinity to the notion of homosocial enactment - "driven by the fear of being exposed as 'not a real male' by one's peers" which impacts behaviour, motivation and performance in the classroom. She explains as follows:

The enactment involves classroom behavior, motivation and education performance... the enactment of male sex/sex gender identity in this respect relegates any aspects of education to the female side of the male/female dichotomy and consequently educational efforts and achievements are devalued (Parry, 1996: 12)

When asked about the low levels of participation from males in mixed sex classes, teachers mainly mentioned the fear of failure (Parry, 1996). Yet Parry (1996: 9) also noted "...the unwillingness of respondents to acknowledge how their own expectations might inform gender responses". Teachers' perceptions of gender may also strongly contribute to their behaviour in the classroom. Although girls were described as "“attentive', 'applied', 'serious' and 'encouraging"' (Parry, 1996: 8), teachers from Jamaica preferred to teach males as "...males responded to verbal chastisement like 'water off a duck's back"” (Parry, 1996: 9). This may be due to the way that female teachers treated their students, resorting to sarcasm and ridicule more frequently than male teachers who rarely used these 'strategies' as a way of disciplining their students. While female teachers stated that girls "... responded 
to verbal discipline by 'sulking, 'bearing grudges' and 'giving you a look'", none of the male respondents experienced these responses and preferred teaching girls as they were better behaved (Parry, 1996: 9). In fact, male teachers criticized the treatment of female pupils by female teachers (Parry, 1996). There may also be a slight correlation between teachers' level of training and gendered responses to verbal discipline. Jamaican teachers were the least trained as $36.9 \%$ did not have teaching qualifications and gender responses to verbal discipline were the most marked in Jamaican respondents. The situation was certainly less marked in Barbados where $82.1 \%$ of the sample was teacher-trained graduates and $17.9 \%$ were non-teacher trained graduates. Parry's (1996) study may support the benefits of teacher training in improving perceptions of gender despite Coultas and Lewin's (2002) finding of little relationship between teacher training and transforming beliefs. While gender and education is not discussed further in the next part on priorities of the region, other plans related to education quality will be examined.

\subsubsection{Moving Forward}

\subsubsection{Ideals in the Caribbean}

In their analysis of education in the Caribbean and visions for the future, Louisy (2004) and Hickling-Hudson (2004) provide their readers with proposals for the ideal Caribbean citizen. Hayhoe (2007: 203) supports the use of ideals in comparative education as she refers directly to the examples given by Louisy and Hickling-Hudson and writes the following:

It is refreshing to see ideal types used in this way to sketch out the vision of a preferred future, and to highlight the cultural and social values which will define that future, thus defying the homogenizing forces of globalization or shaping them in new ways...bringing about a sense of empowerment for education as an important means of cultural and social transformation.

Louisy's (2004: 288) ideal type is a profile endorsed by other Caribbean Heads of Government for the ideal Caribbean citizen worker. Some traits are listed below:

- Demonstrates multiple literacies, including foreign language skills, independent and critical thinking;

- Has developed the capacity to create and take advantage of opportunities to control, improve, maintain and promote physical, emotional, social and spiritual well-being, and contribute to the health and welfare of the community and country; 
- Has informed respect for our cultural heritage and that of others

Despite Hayhoe's (2007) comments on the using types to defy the homogeneous forces of globalization, Louisy (2004) recognizes her description of the ideal Caribbean person is not necessarily context specific. She admits: "(g)iven the universality of these skills and attributes, it is not difficult to recognize in this profile an 'Ideal World Citizen"' (Louisy, 2004: 288). Louisy (2004: 289) argues that any worthwhile education in the global world is one that prepares students for uncertainty through "nurturing an entrepreneurial spirit and developing a business-like approach to life" with multi skills such as flexibility and adaptability. Louisy's (2004) vision is consistent with many of the dominant discourses of Education for All which emphasizes ICT, languages spoken in the home context and multiple literacies.

On the other hand, Hickling-Hudson's (2004: 295) discussion of an ideal type is more critical. Her ideal is as follows:

The 'Ideal' person is not only highly educated but an ethicist; not just an entrepreneur but a civic activist; not just a citizen-worker with 'multiple literacies', but one with critical and highly-developed intellectual competencies, across epistemic, humanist, technical and public spheres of knowledge. ... If such a range of attributes is beyond the reach of any one person, there is the hope that each individual might exemplify some of them.

Hickling-Hudson (2004) also sets out a vision made possible through civic movements throughout the region where women will make up half of the government. Countries in the Caribbean will support each other and as well "...encourage pressure groups to challenge the galloping impoverishment resulting from 'free market' practices of the late $20^{\text {th }}$ and early $21^{\text {st }}$ century" (Hickling-Hudson, 2004: 295). Her vision for the Caribbean future is as follows:

The people have won integrated regional trade, inter-country labour mobility, social structures promoting greater levels of justice for the poor and those with disabilities, and governmental and institutional reforms facilitating and supporting equity and creativity. Among their proudest achievements are sophisticated education institutions and practices. ... Between 2010 and 2050, the education systems of the region were transformed. Primary, secondary, tertiary and adult education increased access and equity. The majority are no longer shut out of high quality education. Universities and colleges expanded and now offer flexible degree and diploma programmes that blend a strong Caribbean character and selected global principals. 
Activist educators throughout the region and in its dynamic diasporas of Caribbean people - particularly in the UK and North America (Patterson 2000) - have contributed to the breaking down of the neo-colonial barriers which kept the Caribbean societies insular - trapped in the language and isolationist education traditions of the former colonizing powers. Collaborating with communities, governments and global, diasporic and local business, they are working closely with counterparts in Cuba, the Dominican Republic and Haiti to improve the region's economy and society (Hickling-Hudson, 2004: 294).

Hickling-Hudson's Caribbean future is consistent with a vision of stability, peace, prosperity and regional cooperation. She approaches her ideal type with criticism of the current rhetoric of global education and requests an approach beyond humanist values towards ideals of active citizenship. It is refreshing to see the proposals of such empowering ideal types in light of discussions on the vulnerability of the region and the challenges faced by education to deliver a quality system.

\subsubsection{Towards a Framework}

While it is not specific to the Caribbean but rather to the entire area of small states, Crossley and Holmes (1999) set out plans for the future of the Commonwealth Secretariat's work. They set out three different categories of themes. At the end of each list of themes is the word 'other' followed by a question mark as Crossley and Holmes (1999) approach this framework with openness for more themes. The mandate they propose is wide and varied, involving many aspects of the small states' capacity beyond the education sector. There is an obvious stress on collaboration. Each of the themes groups together topics that are related to each other and builds on existing work, already completed in some cases, and other works in progress. The first category comprises conceptual and theoretical issues related to definitions of some of the following: “"small states' concept; globalization, localization, regionalization...use of 'small states' concept by agencies and policy makers; human resource development...'resistance', 'resilience'; work with agencies" (Crossley and Holmes, 1999: 55). Under this same category of themes is "Organization and Management of Ministries of Education", which lists items such as: "further training activities... preparation of new materials; financing of education; strategic management planning; quality assurance; gender and education management...advice on the production of curriculum materials". While there has been much early work on these concepts, more may be needed at another time. The other two further categories of themes reflect agenda 
items which need to be build upon in the Secretariat such as a Commonwealth Network of Tertiary Institutions, Association of Commonwealth Examination and Accreditation Bodies (ACEAB), community access to ICT, understanding local needs and lifelong learning. An integrated approach is seen as a necessary direction for the development of small states. In particular, there is a dearth of research in this area and more is certainly welcome (as discussed in 3.4.3). Education in small states requires a coordinated effort supported by ongoing knowledge building to ensure a critical approach to development that is not easily thrown by the waves of globalization. Criticality, as informed by reflective research, will help small states understand the challenges they face.

There is also large gap in education research for teacher practitioners who need resources to draw upon and those who work on policy. In the area of teaching, particularly Maths, educationalists in the Caribbean have a knowledge base that stems from research carried out in the UK and the USA (Bell-Hutchinson, 2004). Certainly research and resources on teaching in the Caribbean island states context would be more appropriate and indigenous knowledge building for teachers would create a more critical approach to pedagogy, thereby hopefully facilitating room for self-reflection of practice. As evidenced in this literature review, there is need for more research in the island states of the Caribbean as published academic discussion has a short history. While the characteristics of small states are indeed unique, and much has been achieved with regards to development, "but, with characteristic modesty, we have treated it almost like a family affair and kept it to ourselves" (Louisy, 1999: xii). Louisy (2001) points to the under-representation of the Caribbean in comparative education studies based on the articles that appear in journals in first world countries. She argues that the Caribbean states would benefit "tremendously from the ready availability of a sound, well-researched body of knowledge on the social, economic, political and cultural realities of the region" (Louisy, 2001:430) that is in-depth and grounded strongly in context (Louisy, 1999). This would speed up the time it takes for island states to "... respond to the ever-changing international landscape" and "... allow the international community...to take timely informed action in its relations with the region without having to wait for time-consuming, usually protracted feasibility studies, country reports or sectoral development plans" (Louisy, 2001: 430). 
From the above statements, there is certainly a clear focus for more work on the part of international researchers. Yet Louisy (2001) also calls for more work on behalf of insiders and Caribbean locals who have distinctive perspectives and "are in a strong position to define the framework within which these developments and initiatives can be executed" (Louisy, 1999: xii). Louisy (2001: 436) also hints at partnerships, calling for study centres in comparative and international education to "...perhaps offer to collaborate more with regional or national institutions in carrying out studies or research projects within these institutions' sphere of operation or influence". Perhaps this is an acknowledgement that help from the international community is better than no help at all, as Louisy (2001: 436) admits the following:

Such an offer would be readily accepted given the islands' acknowledgement that they probably would not have much success if they were to bid for research funding in a field heavily dominated by the larger institutions, research institutions and internationally recognized researchers. The odds are so heavily stacked against the small states of the Caribbean!

Louisy's (2001) call for international researchers is tied closely to 'education borrowing'. She points out that it is difficult to avoid the dangers of uncritical transfers if island states lack the institutional capacity to investigate the notion of " "customis(ing)' the experience of others" (Louisy, 2001: 436). This is particularly important as the Caribbean continues to depend on development aid, which further builds the bond between the small states and development agencies "many of whom find it easier to adopt a one size fits all' policy" (Louisy, 2001: 436). This adds to the difficulty of asserting the perspectives of island states on decisions made. Louisy (2001: 436) notes the difficulty in persuading agencies “...that the contests and circumstances of Sub-Saharan Africa or Latin America, for example, do not necessarily apply in their totality to the Caribbean region".

While most of Louisy's (2001) support for international research is a seen as a call for help for the region, she also argues that comparative education has much to benefit from the West Indies. She refers to Sadler's work and asks “...whether the practical value of studying the workings of the education systems of others in this twenty-first century lies only in our being better fitted to study and understand our own" (Louisy, 2001: 437). Rather, she questions her audience about the notion of living together: "Should it not be primarily because it would enable us to better understand these 'foreign' systems so that we 
could more fruitfully live and work with others?" (Louisy, 2001: 437). Thus, the Caribbean is worthy of attention as it is a good example of groups of people who have historically had to learn to live and work together regardless of their backgrounds, which is a key response called upon by globalization (Louisy, 2001). The notion of 'living and working together' is a central concern of this thesis, which will be distilled into many smaller questions and three different methods of obtaining data to understand the extent to which 'borrowing' or 'sharing best practices' exists. The next section on methodology will provide a rationale for probing the possibilities and limitations for 'borrowing', as well as specific methods used in this thesis study. 


\section{The Research Journey: Methodological considerations for investigating pulses for 'horizontal' and 'vertical borrowing'}

The research journey of this doctoral work began with a serious look at methodological approaches. Quantitative and qualitative approaches were considered, with the arrival of a decision to focus largely on a qualitative methodology. Ethical issues played a large part in this decision. The data gathering tools were based on the particular context of the two islands as well as the 'outsider' status of the candidate. As a woman of visible Chinese ethnicity in the Caribbean, there was a need to be accepted by the education community to gain trust and access to other potential respondents. A large number of pilot interviews were undertaken to ensure appropriateness of questions and strengthen validity and reliability of the research project. Lessons from the pilot interviews are discussed, followed by an analysis of methodology. The research journey is outlined in sequential order, providing insight into the process of being an 'outsider', piloting the interview tool, immersing in data collection, debriefing and verifying findings and reflecting on the process. The chapter will begin with a rationale for the qualitative approaches used, followed by an outline of ethical considerations which formed a framework for approaching data collection and the pilot. Section 4.2 provides details of the methodology, including sampling and description of the three methods employed in this study, namely the policy review, interviews and observations. The following section describes and reflects on the pilot. Finally, 4.4 provides an analysis of the methodology, with a discussion of validity, reliability, generalizability and consideration of ethical issues.

\subsection{Rationale and considerations}

\subsubsection{Rationale for qualitative methods}

While Ozga (2000) argues that debates concerning qualitative and quantitative data involve two views of the world rather than any innate difference between the two types of research, she highlights some of the traditional benefits of quantitative work:"[It is] a view of educational enquiry that understands 'objective' data as real, and subjective data as illustrative. Only hard, concrete, real data have status in this view, and they may be 
subjected to analysis by "statistical machinery" (Ozga 2000: 92). Despite their reputation as objective and mechanical, quantitative methods have benefits. Ozga argues that large sample size and statistical technique enable findings to be valid and reliable and thus used to inform policy because they tangibly describe results (Ozga, 2000). They can provide testable propositions and can be used to make generalizations (Cohen, Manion and Morrison, 2000). Yet quantitative research is more than the application of methods for the purpose of securing a faith in data. Medawar (1972, cited in Cohen, Manion and Morrison, 2000: 14) writes on the speculative process of the scientific method, which begins with an imaginative preconceptuation of what might be true: "Scientific reasoning is therefore at all levels an interaction between two episodes of thought - a dialogue between two voices, the one imaginative and the other critical; a dialogue...between the possible and the actual, between proposal and disposal, conjecture and criticism, between what might be true and what is in fact the case".

Although quantitative methods may be seen to be robust due to the ability to measure the effect of variables, calculate correlation and produce probability, validity and reliability figures that mathematically state the limitations of the research, there are drawbacks as well. Yates (2004: 22) discusses the claim that "quality education research must be scientifically based research". She argues that education is not akin to medical research and "It is not the same as simply finding the mechanism that causes a disease" (Yates, 2004: 31, italics hers). This is in accordance to the assertions put forth by Riddell (1995: 186) who argues against simple production models that "...neither answer questions about school effectiveness nor shed light on the narrower issues of educational efficiency because the effects that purportedly are related to the identified inputs cannot be separated from the preexisting conditions of student populations". Jansen (1995) concurs, and argues that effective schools research has suffered from a long list of quantitative problems, including the following: sample bias, definitional concerns, outcome measures, control for background characteristics, inappropriate comparisons and methodological limitations and aggregation of achievement data. Odden (1991, cited in Jansen, 1995: 196) agrees with Riddell's argument as he calls for a "shift towards understanding the 'why' and 'how' of implementation at the classroom level rather than simple quantifiable outcomes [such as] the 'what and 'how much' of conventional implementation studies". Classrooms, schools 
and island states are complex places worthy of multi-level analysis rather than simple correlation models that investigate the effect of one input to explain one output.

On the other hand, Fairbrother (2007: 60) describes qualitative studies as those that tend to be based on the views of the subjects as they are not limited to particular variables and "tend to be exploratory and expository, with reports of the research not following a fixed structure or stating questions or hypotheses at the outset". Detailed descriptions are provided and infused with both theory and interpretation. He concludes the following for the purpose of comparative studies: "Qualitative researchers in comparative education share a strong belief in the importance of cultural, political and social contexts, and the position that education cannot be decontextualized from its local culture" (Fairbrother, 2007: 46). $\mathrm{He}$ further argues that the benefits of qualitative research include an awareness of the shortcomings of large bodies of cross-national statistical data which fail to consider the potential bias as local context and internal variation are absent from the analysis of the nation-states (Fairbrother, 2007). Scott and Usher (1999) point to the implication that quantitative research is seen as 'better' and more 'legitimate' as qualitative work was discounted as being soft, unrigorous and subjective until recently. Qualitative researchers had won battles to justify their methodology and work to prove the validity of their outcomes to arrive at the present argument of the comparability of qualitative and quantitative approaches despite their diverging assumptions of epistemology (Scott and Usher, 1999).

Due to the nature of small states, the impact of scale is significant for both infrastructure and policy (see 2.1.1). As the populations of both Barbados and Trinidad and Tobago are isolated due to the island geography of both places, human resources between countries is restricted due to fewer opportunities for population movement. With regards to the smallness of scale, particular caution needs to be taken against statistical analysis of these nation states. Internal variation may also be weighed too heavily in small sample sizes without a focused analysis of why differences exist. Although quantitative information exists on school leaving exams and university admissions, the cautionary needs for "sensitivity to the greater potential for bias and unquestioned assumptions" (Fairbrother, 2007: 46) are not met with existing data on more implicit aspects of education such as the process of learning, the affective dimension and the impact of policies. Qualitative methods 
allow for a sensitive approach to the voices of subjects as they do not set out variables to be measured. This is particularly important in small states as presumptions may be interpreted as unfounded, leading subjects to reject the role of the researcher. As the Ph.D candidate does not have prior ethnographic experience teaching in either of the island states in this study, it is particularly important to approach the work without a fixed structure or hypothesis. A strong agenda may be perceived as overly assertive. Thus, this study aims to ensure a strong focus on the subject with a lesser focus, where possible, on Fairbrother's (2007) aspects of quantitative methods such as structured questions, direct assessments and detached observations. Access is another issue that requires the call for qualitative methods. As classrooms, schools and systems are not laboratories, this is particularly true for small states where the presence of an outsider does not go unnoticed. Gaining access to policymakers, curriculum developers, teacher trainers and teachers necessitates recommendations as participants may be wary of foreign researchers without a good reference. A rigid structure, set variables and assertive agenda may deter participation of respondents. Qualitative approaches appear to be more flexible for the smaller resource pool of small states.

However, there are limitations and criticisms of qualitative approaches as they may often be seen as lacking in certifiable conclusions. They may also appear to be less rigorous and robust as they do not follow a set method of definition, measurement and evaluation. Yet, in the words of one respondent, the question remains "by whose standards will you be measuring our system?" (Informal Caribbean respondent, personal conversation, Jan 2007). Qualitative methods can yield results which set out the parameters for discussion and focus on the judgments that subjects make about their own system which may include a high degree of analysis, as Fairbrother (2007: 60) argues that qualitative methods are "... detailed and infused with interpretation and theorization". Ozga (2000:113) offers a further consideration of the meanings behind methodological choices:

(I)t is insufficient to think of methodology as concerned only with technical procedures and data-gathering processes. Methodologies...reflect choices that are based on orientation to policy research, and that in turn influences the topic and the resources brought to bear on the research problem.

While methodological choices must be appropriate for the subject and context of the research, Phillips and Schweisfurth (2008: 101) who note the broad area of comparative 
education topics, conclude: "There can be no single approach to comparison that will agreed upon or that will be appropriate even to the majority of circumstances". Yet it seems most appropriate to approach the study without prior expectations or hypotheses. Scott and Usher (1999) describe four different approaches to hypothesis modeling: induction, deduction, retroduction and abduction. While the first two involve testing and creating a theory, the third involves identifying structures which underpin irregularities, devising a model and then testing it to see if the casual powers are in existence (Scott and Usher, 1999). Neither of these three appear to be appropriate for the purpose of this Ph.D study as the candidate is not a member of the local context and should remain open to observations without a particular model in mind, although there may be some comparisons made with case studies of 'education borrowing'. While Phillips and Ochs' (2003) model of 'education borrowing' will be examined, a clear induction or deduction strategy will not be used. There will be a stronger focus on the process of abduction, which is defined as a strategy that is "generally used by hermeneutic or interpretive researchers and focuses on drawing out meanings used by social actors as they live their daily lives" (Scott and Usher, 1999: 47). This perspective gives authority to the descriptions that participants provide of their intentions, plans and projects to avoid conceptualizing actors as "the 'unwitting dupe' of structural forces beyond their control and thus not able to act intentionally" (Scott and Usher, 1999: 47). This view emphasizes the "active and intentional flow of social life" and "recognize(s) the central importance of the social actor in their descriptions of social life" (Scott and Usher, 1999: 47). However, there are some criticisms as "the stress on descriptions of the intentions and plans of social actors fails to position and locate these activities within the enabling and constraining contexts of life" (Scott and Usher, 1999: 48). Scott and Usher (1999) further argue:

The hermeutic process always involves closure at some arbitrary point by the researcher. This closure takes the form of a 'going beyond' the way of understanding developed by the social actors under scrutiny. Abduction therefore comprises this movement from lay to technical accounts of social processes and lives, and is an alternative to inductive, deductive and retroductive strategies (Scott and Usher, 1999: 49). 


\subsubsection{Ethical considerations}

It is important to consider the intended outcomes and ensure the methods for collecting data will be effective for answering research questions. However, there needs to be some parameter for measuring the value of the potential findings. Ethical considerations will be discussed here and referred to again in 4.4.4. Yates (2004: 17) highlights some common claims about the value of education research. The first is the claim that "we can measure 'good education research' by its contribution to learning". She argues that there is a consequence of treating 'improvement to learning' as the sole or ultimate criterion for defining 'good' research as this is often not the case with some powerful studies which examine phenomenon rather than deliver improvement strategies. The concept of 'improvement to learning' is in itself contentious. Second, she takes apart the claim that "good education research must make sense to be usable by teachers (or instructors or parents or the lay reader)" (Yates, 2004: 20) as it is perceived to be otherwise irrelevant as it does not produce 'new knowledge' that is easily communicated to teachers or instructors. She argues this is in fact an issue that involves the field of education itself as large resource allocations, accountability and institutional processes occur at a system level which affects participants in the system. Teachers are often not directly involved in policy processes despite being key actors in the implementations of reforms. Thus, educational research is symptomatic of the divide between teachers and policy and the value of research should not be measured on how 'practical' and 'achievable' it is for teachers. Research is often the result of what individuals feel is needed or desirable and should not be judged on its merits of usability.

One of the central intentions of the work is to create new knowledge and draw attention to the possibilities of 'horizontal borrowing' and the existence of 'vertical borrowing' in small states. While the candidate does not intend to test a theory of 'borrowing' or suggest participant countries borrow from each other, these may be subsequent implications in the findings. The key focus is one of inquiry and investigation rather than ensuring effectiveness across nations and schools. While larger states are not insulated from global interdependency, small states often suffer from a low identity status and risk dissolving into a 'Fourth World' of the unknown and forgotten. Thus research on small states such as the Caribbean islands is particularly important to ensure the sharing of knowledge and 
understand global forces. Louisy (2001) argues that the Caribbean islands are an interesting cultural milieu and the region has much to contribute to comparative education. Although Jamaica has been the focus of some comparative studies in the geopolitical area of Latin America and the Caribbean, smaller island states such as Barbados and Trinidad and Tobago have been neglected from education research. This Ph.D study will not only be examining an under-researched area, but also an under-researched topic. There has been little comparative education research in the region as a whole. Studies on Caribbean education have focused on topics such as teacher training (see Coultas and Lewin, 2002 in 3.4.2) and masculinities in the classroom (see Parry, 1996 in 3.4.2). Specific sampling of Mathematics classrooms, teachers and curriculum will be undertaken. It appears that Mathematics curriculum and neither 'horizontal' nor 'vertical borrowing' have been a strong focus of research in the region. While large scale studies on Mathematics attainment have involved countries such as Japan, the United States, European states and Mexico, there has been little written about Mathematics education in the Caribbean. Although this $\mathrm{Ph}$.D study does not aim to be definitive in shaping policy reform, it may shed light upon aspects of the Mathematics education, contribute to research in this neglected region and lead to further enquiry, thus generating new knowledge

It was important to ensure that an ethnographic approach was taken with sensitivity to the cultural context. The project is focused on the issues of modeling and the direction of 'borrowing', and aims to reduce potential for a voyeuristic and/or critical colonial gaze. As Barbados and Trinidad and Tobago are both small states, it is important to ensure that the work is not viewed as intrusive or judgmental by the community. As an outside observer, it is important to take all appropriate measures to reduce bias and include the perspectives of those who work and study in these countries. There is a possibility that the $\mathrm{Ph} . \mathrm{D}$ candidate may be viewed as a principal researcher in the area of Mathematics education in Barbados and Trinidad and Tobago. Findings may be interpreted as recommendations and thus there is a risk of impacting opinions, policies and pedagogical practices without further research. McKeever (2000) points to her personal experience as a white researcher in South Africa where Troyna and Carrington's (1989) warning about the potential for white researchers to unassumingly enable the state to increase control over communities. This needs to be taken into consideration. As this is a single study in a small state, there is a danger of premature intervention if the study appears to be conclusive. The candidate must be cautious of the 
tone used in communicating research findings. The final document should not be communicated in an assertive fashion and the limitations of the findings are stated. The smallness of scale and the unique context of each of the island states are explicitly discussed. While research methods are robust, the degree of generalizability is noted in 4.4.3. Although results have a potential to be interesting, they should never appear to be overly rigorous as this is a qualitative study that focuses on similarities, differences and a discussion on possibilities for 'horizontal' and 'vertical borrowing'.

Although anonymity is difficult to achieve, confidentiality must be preserved to the highest degree. Cohen, Manion and Morrison (2000) state the limitations of anonymity: "A subject agreeing to a face-to-face interview, on the other hand, can in no way expect anonymity. At most, the interviewer can promise confidentiality" (Cohen, Manion and Morrison, 2000: 62). However, the three researchers concur with the importance of non-traceability and suggest aggregating data in some cases to prevent individual responses from being specifically identified. Where possible, data from interviews are aggregated where subjects share the same profession or work in similar levels of education. While every effort will be made to ensure the confidentiality of participants, there are instances in which a particular individual is the only post holder in the West Indies, such as a head of a ministry department on an island state or the post holder is potentially recognizable, such as a reputable Maths teacher in one of the island states. Such posts are described in a way that preserves as much confidentiality as possible. As casual conversation about the progress of the study (either in the Caribbean countries or in the UK) may lead to breaches of confidentiality as colleagues of the candidate may be somehow acquainted directly or with other colleagues of the participants, there is no discussion of identifying details.

McKeever's (2000: 102) work on the considerations of ethnical issues in post colonial research points to the necessity to learn about the history of colonialism and "study the systems that were developed to resist colonialism and the various forms this resistance took". She argues this is important as postcolonial societies are not monolithic. Although McKeever highlights issues based on her personal experience as a white researcher in apartheid South Africa, there are implications for the candidate who is of Chinese descent. Also, McKeever (2000) discusses Troyna and Carrington's (1989) criticism that the power differentials between white researchers and black subjects impedes the elicitation of 
meaningful data, and when such data is available, it may be misinterpreted to pathologize black communities. However, McKeever (2000) also raises the point that the disadvantages of her color needed to be weighed against the advantages of highlighting aspects of her work on working-class black South African educational history. Similarly, it may be argued that the disadvantages of being of Chinese descent need to be taken into account, but may not necessarily devalue the findings of this work. During fieldwork, respondents were often puzzled by the presence of a Chinese-Canadian lecturer from the United Kingdom in the Caribbean as most of the Chinese national on the islands were imported for building construction projects. While there was not an element of post-colonial power relationships, there was certainly the necessity to build relationships in order to be accepted into educational communities. McKeever (2000) notes "it is possible to build honest relationships across race, class, gender and culture. This can be facilitated by working together on a jointly defined task" (McKeever, 2000: 109). She concludes the following:

... (T)here does seem to be a real danger of perpetuating racism when researching it and making assumptions about how the research respondents see the world - and that applies to any researcher, whether researching their own or another culture... It is important to foreground these as much as possible so that the reader can make a judgment about how these may affect the research (McKeever, 2000: 109).

There are considerations that must also be taken in understanding the relationships between environment, knowledge and culture as the researcher must be aware of the juxtaposition of local knowledge and the knowledge inherited by colonialism (McKeever, 2000). There should be an awareness of the literature available on the 'subjects' as "the researcher at the Western power-knowledge institution is given access to all that the colonial system has produced by the way of intellectual resources, and the knowledge systems of the colonized, if they appear at all, are rewritten into the text of Western science or literature" (McKeever, 2000: 110). She also draws a parallel to the process of annexation and warns "it is no longer acceptable to annex or totally rewrite other peoples' discourses" (McKeever, 2000: 110). Further, Scott and Usher (1999: 49) write: “(T)he researcher's biography imposes an order on how the social actor [sic] understands their life. When this is inscribed in a text of some sort, a further process of intrusion takes place". To counteract this, Wellington (2000: 42) argues that "(b)eing reflective involves thinking critically about the research process; how it was done and why, and how it could have been improved". Yet a subset of this is 'reflexivity' which involves reflecting on the self - the researcher. Wellington (2000: 
43) also points out that being reflexive "does not merit an excessively long, confessional, autobiographic account... A statement of the researcher's position can be brief and should include relevant information only". Thus, a brief description of the candidate is in Appendix E. This is supported by Phillips and Schweisfurth's (2008) assertion that comparativists face ethnocentricity at every stage of the research process and note the importance of recognizing preconceptions based on personal experiences of education.

\subsection{Detailed Methodology}

\subsubsection{Sampling}

Wellington (2000) outlines three types of 'purposive' sampling used in qualitative research such as maximum variation sampling, which includes a wide range of differences of a phenomenon and typical case sample involves selecting units which are believed to be fairly typical. On the other hand, critical case sampling involves the selection of special characteristic cases, such as schools that are seen to be effective: "Indeed, schools, colleges or employers exhibiting 'good practice' in a certain field are often chosen for case-study sites for evaluations, especially if the aim is to study 'good practice', analyze it and disseminate its key features to a wider audience" (Wellington, 2000: 61). The snowball method of purposive sampling is defined by Wellington (2000: 62) where "one case suggests another who suggests another" will be used in this study for specific sampling with the countries, where as critical sampling was used to select the two countries of Barbados and Trinidad and Tobago for this study. The snowball method also involves local educationalists, which in turn may create some aspects of ownership and involvement on the part of the participants. McKeever (2004: 115) writes: "If researchers can work with rather than for communities, and conduct research with them into initiatives that they themselves have taken to try to address some of their problems, then I think that research may be able to play a truly progressive role".

Two types of sampling will be used for this study. The first involves the larger choice of island states for study. Many different island states are included in this region, all of which have unique sociocultural and historical traits. Although Phillips and Schweisfurth (2008: 96) caution against regional groupings on the basis of geography, former allegiances and 
colonial powers, as it denies cultural individuality and creates a spurious comparison, they suggest that "...comparativists should seek out units of analysis that are intrinsically appropriate to the task in hand". While this thesis is interested in 'horizontal borrowing' in Caribbean small states, the sampling of islands necessitates careful consideration. In this instance, purposive sampling will be used as the study will be looking at the possibility of 'horizontal borrowing', in which 'lender' and 'recipient' roles need to be filled. Thus, the 'lender' needs to be an exemplar according to achievements and reputation, and the 'recipient' should be an improving nation. Purposive sampling involves handpicking cases to build up a sample that is satisfactory to the specific need of the study regardless of particularity or bias: "Whilst it may satisfy the researcher's needs to take this type of sample, it does not pretend to represent the wider population; it is deliberately and unashamedly selective and biased" (Cohen, Manion and Morrison, 2000: 104). Due to its achievements (see Chapter 1), Barbados will be examined for characteristics leading to a 'lender' for the purpose of 'horizontal borrowing' and other islands will be examined for characteristics leading to 'recipient' features. The island of Barbados has achieved UPE, gender parity in primary and secondary education as well as an adult literacy rate above 99.7\% (UNESCO, 2006a). It has also devoted $7.2 \%$ of its GNP to education (UNESCO, 2009). While the Global Monitoring Report 2009 asserts that "(i)mproving the quality of education constitutes a major challenge for school systems in Latin America and the Caribbean" (UNESCO, 2009), the quality of education in Barbados may be evaluated differently due to its achievement of EFA indicators. Some preliminary research has indicated that there are a few possible 'recipient' countries, such as Trinidad and Tobago, Jamaica and Guyana, which share a political past as part of the failed Federation of the Caribbean. Today, Trinidad and Tobago is seen as a competitor to Barbados as it is smaller than Jamaica, which has a superiority complex over the region due to its size (Caribbean researcher, interview Feb 2007). Trinidad and Tobago was selected over Guyana for comparison with Barbados as Trinidad and Tobago has a University of West Indies campus and has dedicated the recommended GDP towards the Education for All initiative. Although convenience sampling may be useful for case studies, there are limitations to this type of sampling as it can only comment on the sample itself. Convenience sampling cannot not seek to generalize about the wider population (Cohen, Manion and Morrison, 2000). 
Individuals selected for interviews and schools selected for observations will be based on convenience sampling as the candidate is not a local resident or citizen of the region. Convenience sampling may be particularly useful for small states studies as recommendations may aid mobility among the education community. As suggested by one Caribbean researcher, it is important to bear in mind the geography of each of the island states, which range from urban metropolises to sprawling countrysides. Brock (1984) notes there is less of a divide between urban and rural society in both Trinidad and Barbados, as "Barbados is a city where sugar grows in the suburbs" (Lowenthal, 1957 cited in Brock, 1984: 172). Schools were sampled in the capital cities and surrounding areas of Bridgetown, Barbados and Port of Spain, Trinidad and Tobago. Four schools were sampled via convenience sampling in Barbados and an application was put forth with approval from the Ministry. One interview and one hour of observation took place in a lower achieving school which was added as a supplement to the study after a member of the Ministry of Education in Barbados was interviewed as the respondent felt it was an interesting case. In Trinidad and Tobago, research access was granted and the Ministry assigned four schools to examine in the Port of Spain area. To reduce the number of confounding factors, Maths teachers and classes were sampled. The Ph.D candidate is a former Maths teacher and completed a master's dissertation in teachers' perspectives of indigenous pupils in Maths classrooms.

\subsubsection{Methods used}

\subsubsection{Policy Review}

The first method is policy analysis. This will be mostly limited by access and availability. Principal sources include written materials such as curriculum documents, CXC past Mathematics examinations, policies and government reform papers. Ozga (2000: 95) expands the category of policy texts to include "documentary or other materials that can be read as significant within the discursive parameters of an investigation, provided that detailed justification is given for their inclusion". She makes a particular distinction between policy as text and discourse, alluding to Derrida's (1978) notions: 
Policy as text is the element of policy that can be worked on, interpreted and contextualized, and stands in contradiction to assumptions that policy works in a straight line from formulation to implementation. Policy as discourse understands policy as part of the dominant system of social relations; policy as discourse frames what can be said or thought. Policy as text addresses agency, policy as discourse addresses structure (Ozga, 2000: 94).

Although analysis of policy will examine the larger framework of policy as discourse, the documents examined will be taken as texts. They will be examined for their depictions, intentions and aims of education policy. Ozga (2000: 95) draws a parallel between reading texts and other written narratives: "they may be scrutinized for their portrayal of character and plot, for their use of particular forms of language in order to produce impressions or responses; they may have an authorial 'voice' or seek to convey the impression of multiple viewpoints".

Ozga (2000: 95) also offers three particular issues that should be addressed in the analysis of policy documents and the messages they seek to convey:

- The source of the policy: whose interests it serves; its relationship to global, national and local imperatives

- The scope of the policy: what it is assumed it is able to do; how it frames the issues; the policy relationships embedded in it

- The pattern of the policy: what it builds on or alters in terms of relationships, what organization and institutional changes or developments it requires.

This framework will be taken into consideration in the process of policy analysis and will be evaluated in 4.4.1.

\subsubsection{Interviews}

Ethnographic research in the form of interviews took place. There were three aims for the questions: 1) obtain respondents' perspectives of their own education system, and any perceptions they may have about the other island's system to identify areas of strengths and weaknesses; 2) understand the degree of implementation of national initiatives to discern resistance or enthusiasm towards reform; 3) probe possibilities for sharing, 'horizontal borrowing' or external influence to discern resistance or enthusiasm towards international policies. A copy of the interview question bank is found in Appendix F. Wellington (2000) sets forth stages in preparing and carrying out interviews, in which the first stage is 
preparing the interview schedule by translating the research objectives into interview questions, deciding the degree of structure, ordering the questions and deciding how the responses will be collected. The second stage is the pilot, in which a small sample is used and as a result ambiguous, confusing or insensitive questions are removed (Wellington, 2000). Thirdly, the subjects are chosen and access is negotiated. Finally, the interview itself takes place, in which the steps of preparation, briefing, questioning and feedback are undertaken (Wellington, 2000). Respondents were briefed orally about the project and an additional information sheet regarding the aims of the project and personal details about the researcher was also prepared (See Appendix G). Using Wellington's stages, this study involved interviews with teachers, academics, policy makers, and international respondents. As the application to undertake research needed to be approved by the Ministries of Education in both countries, pupil access was not requested out of fear that the research proposal would be rejected. As the research question is focused on possibilities for 'horizontal borrowing' and the presence of 'vertical borrowing', pupils' perspectives would have been interesting but may have only made a minor contribution to the findings. Cannell and Kahn (1968, cited in Cohen, Manion and Morrison, 2000) found that when interviews were used, validity was a chronic problem. Cohen, Manion and Morrison (2000) argue that the most practical way to increase validity is to minimize bias which may stem from the attitudes and expectations of the interviewer, misconceptions and misunderstandings as well as the tendency for the interviewer to see the respondent in their own image and/or seek answers that support preconceived ideas (Cohen, Manion and Morrison, 2000). Highly structured interviews with the same format and sequence of words is supported by Silverman (1993, cited in Cohen, Manion and Morrison, 2000) although Scheurich (1995, cited in Cohen, Manion and Morrison, 2000) argues that controlling the wording does not guarantee controlling the interview. Silverman (1993, cited in Cohen, Manion and Morrison, 2000) also suggests reliability can be increased by careful piloting, training of interviewers, inter-rater reliability in coding responses and extended use of closed questions. However, Silverman also argues that open-ended interviews allow for unanticipated questions to be raised and recognizes that the sequencing of questions may differ from one respondent to another.

There is also the issue of power that is significant in an interview situation as "the interview is not simply a data collection situation but a social and frequently a political situation" 
(Cohen, Manion and Morrison, 2000). Although there is an asymmetry of power with the interviewer generating questions through defining the situation, topics and course of the interview (Kvale, 1996 cited in Cohen, Manion and Morrison, 2000), there is also the potential for powerful people to maintain their reputation by using well-chosen, articulate phrases (Cohen, Manion and Morrison, 2000). Kvale (1996, cited in Cohen, Manion and Morrison, 2000) outlines a range of characteristics of an effective interviewer: knowledgeable, structuring, clear, gentle, sensitive, open, steering, critical, remembering and interpreting. There is also the issue of 'transcriber selectivity' in interviews as transcripts remain selective as they are interpretations of social situations despite the provision of details (Lee, 1993 and Kvale, 1996 cited in Cohen, Manion and Morrison, 2000). One method of reducing this bias is summarizing responses in the course of the interview; however this may result in further bias if the interviewer unconsciously emphasizes responses that are consistent with personal expectations (Cohen, Manion and Morrison, 2000). To ensure consistency of verbatim responses, responses were repeated back to the respondents for verification. Selected statements were touch typed and then repeated back to respondents verbatim. Respondents were asked to confirm the documentation of their statement. On almost all occasions, respondents agreed fully with the written documentation of their verbal statements and at times further elaborated on their statements. See 4.4.1 for a critique of this method.

\subsubsection{Classroom Observations}

For the purpose of triangulation, non-participant observations provided data for the Ph.D study. To ensure consistency of sampling, only Mathematics classrooms taught by respondents were observed across all levels. Field notes were kept for 87 hours of observations in nine schools, eight of which formed the main body of the study and one that was added as a case study for a lower achieving Barbadian school. Notes were taken regarding the classroom context, behaviour of children and teaching practices for the purpose of validating the data from the policy review and interviews. Non-participant observations were also used to understand socio-cultural contexts and were carried out with sensitivity to culture. The writer struggled to reduce outsider observer bias as pupils found it difficult to adjust to a foreign visitor's active presence in the classroom. Pupils were frequently curious but teachers answered their questions. A strong effort was made to 
ensure comfort from both pupils and the teacher in observation methods by sitting at the back of the classroom. To avoid the perception by teachers that judgments were made about their teaching, they had the opportunity to discuss their reactions to the findings of this study after observations and were debriefed (see 4.4.2). This transparent approach to data collection attempted to provide a balanced voice and reduce outside observer bias. Cohen, Manion and Morrison (2000) further highlight threats to validity and reliability such as the potential unawareness of important antecedent events, the risk of the observed situation as unrepresentative of the sample in the study, the presence of the observer on the participants' actions and the possibility that the researcher may become too attached to the group to be objective. As observations were used along with two other sources of data, validity concerns are minimized. However, a critique of this method is found in 4.4.1.

\subsection{Lessons from the pilot}

From 29 January to 1 February 2007, pilot interviews took place in Barbados with two Maths Heads of Department and two lecturers. In addition, one group interview for teachers took place at a top performing school for information purposes only and data was not used in the pilot. A similar pilot study took place in Port of Spain, Trinidad and Tobago from 21 May to 24 May 2007 in which one Maths Head of Department was interviewed, one Maths teacher, two policymakers, and four Education Studies lecturers. Three members of regional organizations were also interviewed during fieldwork in the region.

\section{Barbados}

Teachers:

Heads of Maths: B1, B2

Policymakers:

Members of regional and international affiliations: I1, I2, I3

Academics: B3, B4

Total: 15

As different questions were asked during the interviews, it is not possible to provide a numerical breakdown of the different responses to each question asked. In some cases, questions were worded differently depending on the participant. Although some participants clearly stated that they could not answer some questions due to unfamiliarity with the topic, the large majority of questions yielded fruitful responses. After the first pilot

\section{Trinidad and Tobago}

T1

$\mathrm{T} 2$

T3, T4
T5, T6, T7, T8 
in Barbados, it appeared there was resistance to 'horizontal borrowing' between island states. However, the research continued in an attempt to understand the reasons behind resistance between the two island states to investigate why countries resist cross-national attraction and regionalism. It was also interesting to identify countries of interest to the two island states, and the pulses behind foreign curiosity. A few changes to questions were made as result of the pilot to reflect the realities of policy interest as well as the classroom. Questions were reworded to reduce ambiguity following recommendations by pilot respondents. The interviews were very helpful for gathering data and strongly informed the fieldwork findings.

\subsubsection{Findings from the pilot}

\subsubsection{Reactions to notions of 'horizontal borrowing'}

Educationalists in both countries appeared ambivalent about the idea of 'horizontal borrowing'. This notion was faced with much greater criticism in Trinidad and Tobago, in which educationalists preferred the term 'sharing best practices' rather than the seemingly institutionalized wide scale notion of 'horizontal borrowing' which was accepted in Barbados. The idea of 'borrowing' was certainly contentious in Trinidad and Tobago. Two Trinibagonian academics strongly opposed the idea of 'borrowing' from anywhere. One of these academics discussed at length the resistance to foreign in ideas in light of culture and the history of the education system while the other noted "we lend, we don't borrow" (T7). T6 agreed, referring to the Caribbean as a "hinterland of exploitation". As Trinibagonians seemed to resist 'horizontal borrowing' in the pilot, further interviews in the main data collection investigated the possibilities of both 'horizontal' and 'vertical borrowing' between island states and uncover reasons why there is resistance to it. However, policymaker T3 asserts a significant difference: "we are the capitalists in the Caribbean because oil has driven us through the years. That is why it is difficult to make comparisons between Trinidad and any other country". 11 states: "Trinidad seems to be different because of the money - others are similar because of tourism but Trinidad doesn't need to rely on tourism". Conversely, T8, another academic from the same country disagrees, noting that pupils write the same exam. T8 offers the perspective of mobility, while mentioning the differences between island states such as languages, expressions and history, but concludes 
that a student would probably be able to move from Trinidad to Dominica with ease. B4 argues that "...for most of the Caribbean, the British islands all have the same sauce" and are similar because they "grew up in the same pattern". The perception of similarities and differences is interesting and seems to have a profound impact on possibilities for 'horizontal borrowing' and this was probed further in the fieldwork. It also appears that aspects of access create differences between the two countries. One respondent sums up the similarities and differences between the two countries in this way: "from my experience, we're all essentially the same. Maths education maintains the same flavour. In some countries, there is a difference in access such as Barbados and Trinidad and Tobago, but that doesn't mean difference in quality" (I3). Aspects of quality were probed further in the main data collection as a result of this assertion to ascertain similarities and differences in teaching practices and accommodations for lower achieving pupils.

Perhaps there is a cultural resistance to 'horizontal borrowing' as sharing and cooperation may be limited by societal views. One respondent notes that the idea of 'sharing' is problematic: “...every single political leader wants to keep his kingdom, so every one of them wants to keep its own. It will feel it will lead to federation. They won't want to unite it's so good to be king despite things like CARICOM, etc." (I1). Further, the participant mentions the element of competition on an individual level and its impact on learning: "People have a tendency in the Caribbean to pull down others - why do you want to be there? Why be teacher's pet?" (I1). More data was needed from fieldwork interviews to support pilot data which seemed to show strong resistance to 'horizontal borrowing'. See 6.5 for more data collected on both 'horizontal' and 'vertical borrowing'. When asked if there were opportunities for information sharing between schools, both teachers in Barbados and Trinidad and Tobago note these are not available on a systematic level. In fact, one informal teacher respondent asserts the following: "Sharing is not part of the culture here. This is why I'm interested in your study and will be interested in what you find". This particular teacher attempted to share best practices with schools in one island in the Caribbean but did not find much interest among colleagues. Out of the teachers interviewed, only one appears enthusiastic about 'borrowing': "I would love to have best practices with other teachers, on other islands, in the world!" (T2). However, this teacher is highly motivated to improve pedagogy: "I am interested in delivering and making Maths associated with real life. I am really interested. I do research the net, I read books" (T2). 
There may be other confounding factors which may make this teacher more willing to borrow ideas. By interviewing many more teachers in the main data collection, factors such as gender and age may show an influence towards perceptions of teachers.

\subsubsection{Perceptions of national systems}

Barbadian educationalists were generally proud of the accomplishments of their education systems. However, they were quick to recognize that the system was successful for helping children pass exams: "For the students that are capable they are well prepared and pass the exams" (B4). B4 is also critical: "For the ones who are not so clever, there are some weaknesses. Our system at the moment is not geared towards bringing the slower ones along as fully as they should be" One teacher remarks that the strength of their school was down to the individual level of the teacher and textbooks: "A main contributory success is the teacher. We also have contribution made by the textbooks we have chosen. Some teachers seem to do so much better regardless of the same material on hand" (B2). On the other hand, respondents point out that the notion of success is rooted in societal differences among children: "For a child to do well in school, you need to listen and hear the value of listening...you have to have disposition to want to learn" (I1). This need to prepare children to learn has been a strong focus of the 2007 EFA Global Monitoring Report and is spearheaded by several Early Years lecturers in Trinidad and Tobago. However, the perception of both systems seems to vary. Educationalists from both regions seemed to identify strengths of the system. At times they link to economic success, such as Trinidad and Tobago's ability to build schools and train teachers over a short period of time (I1). Trinibagonian teacher T2 concludes: "A lot of it depends on the teacher and how they want to deliver the lesson - and realize that they are going to learn more by investigation instead of, I know it, you write it down". T8 offers a further perspective on teachers, asserting that teachers would probably agree there are other ways of teaching, whether or not they actually use them. Apparently the Ministry of Education offers workshops to support teachers (T8). Observations of classroom teaching would help to consolidate findings on pedagogical approaches of teachers. Further fieldwork interviews were also required to understand resistance to new pedagogies as these are strongly advocated in the new Barbados and Trinidad and Tobago curricula. See 6.3 for data collected on the new syllabuses. 
Pilot interviews also served as a way of gathering information about the system. The pilot study revealed other initiatives such as the new University of Trinidad and Tobago, which offers courses with a focus on Trinibagonian economy, such as industries, mechanics and a teacher training programme. Respondents from both countries acknowledge the presence of a spectrum of achievement across schools and a hierarchy in status. In Barbados, pupils enter secondary schools based on results from the $11+$ and Trinibagonian pupils write a similar exam. However, the difference lies in types of schools available to pupils. High achieving Barbadian schools tend to be those that are reputable. One particularly strong school attributes its standing to the pupils and the recruitment and training of former pupils as teachers: "...when [the teachers] come in, they already have an ingrained loyalty to the school and that is what makes the school successful" (B1). Further research is required to determine the successfulness of Barbadian schools beyond factors such as pupil selfselection into reputable schools. However, Trinibagonian educators generally acknowledge the strong nature of denominational schools. Despite efforts by the government to distribute 'good' teachers among government and denominational schools, it appears the perception of prestige in denominational schools is difficult to dissolve: "What may have contributed to that perception is that the top $10 \%$ of students and teachers together create certain cultures that are established so that the perception of the environment is created by the school" (T3). T2 is quick to point out that there are many good teachers at lower performing schools.

Further, Trinibagonian junior comprehensive schools, which cater to the 12-15 cohort, are seen as low performing whereas schools that provide education for the 12-18 age range are stronger schools (T2). I1 comments on junior comprehensives: "you have a large absentee rate...they say they were too weak to go to prestige schools... we tell them they are not good enough, then they turn to crime, you can hardly blame that for what happens". However, junior comprehensive schools are in the process of phasing out. While Barbadian and Trinibagonian school achievement seems to be attributed to the power of reputation and a polarization of students with good entrance results, the difference lies in the distinction between types of schools in Trinidad and Tobago, while such a distinction does not seem apparent in Barbados. There is also the acknowledgement that a wider variation of socioeconomic status exists in Trinidad and Tobago, perhaps as a result of the wealth 
reaped from oil. However, the benefits of national wealth may not have translated to all citizens. Yet changes are occurring to reform the system despite criticism on the ground of the new National Certificate of Secondary Education (NCSE) as part of the Secondary Education Modernization Plan (SEMP). While some supported NCSE, one informal respondent of a successful traditional school argues that the curriculum did not adequately prepare students for CXCs and CAPEs (advanced level subjects). T2 agrees, stating: "It's something for Trinidad; it's how it's rated in the country as such... I don't really find it's given a lot of importance". As the NCSE is now part of the mainstream policy in education, a review of the aims of the NCSE was undertaken as part of the data collection. During fieldwork interviews, participants were asked about whether or not new curriculum changes were happening in Barbados. The pilot interviews did not reveal large scale Barbadian curriculum changes but further interviews were necessary to uncover pulses of reform, which were revealed by one of the pilot respondents in a follow up conversation. Barbados is piloting a new syllabus among some of the schools which focuses mostly on content changes.

More inquiry into the isomorphism of these two states needs to be made with the policy review and fieldwork interviews. Perhaps the two countries are more similar than different, and the differences lie in outside-school factors such as socioeconomic aspects and new national directives such as Trinidad's Vision 2020 and the NSCE. Examining the national documents of both countries will reveal directions and objectives. One respondent notes the following:

You've chosen two strong ones in education. They are both moving towards their own universities and it seems to me they are the least likely to borrow from each other as they are firm on creating their own education... But both places have traditions of their own education system, and 1 wondered how much borrowing they would need from another system. They are both working to be capacity... But perhaps because they are moving in the same direction, it is a reason for the borrowing because they are both in strong positions (I3).

However, 'horizontal borrowing' may be possible among the Windward Islands. These Eastern Caribbean islands are often perceived as similar to each other. One respondent remarks the similarity to Jamaica: "In St. Lucia, St. Vincent, and Grenada, pretty similar to Jamaica, not a strong flavour" (13). Another respondent concurs: "If you have been to St. Lucia and Dominique, St. Vincent, so similar it's not funny. Trinidad seems to be different 
because of the money - others are similar because of tourism..." (I1). As such, these islands may be better suited to 'borrowing' but this alternative hypothesis needs probing with further research which is beyond the scope of this thesis study.

\subsubsection{Perceptions of Maths education}

Through the interviews, the writer gained some insights for further consideration. First, both Barbadian Maths teachers interviewed had a strong passion for the subject, a sentiment that was mirrored in subsequent conversations with other Maths teachers. Although they regarded $\mathrm{CXC}$ examinations as rigorous, they felt it was important for pupils to love the subject and perform well on the exams. All four Maths teachers interviewed in both countries had a very strong knowledge base in Mathematics. None of the Maths teachers, however, feel there was a strong emphasis on interactive learning: "I think its something that certainly needs to be extended" (B1), although one teacher mentions there were possibilities for this the CAPE Mathematics curriculum: "The government body has realized that students need to be involved in projects where the application of the Maths is necessary rather then doing routine problems and the syllabus is geared towards projects" (T1). There appears to be agreement among academics (B3, T5) that Mathematical ideas may relate to a Caribbean context; however ethnomathematical ideas are not prevalent in the Caribbean: "The concepts are essentially the same - it is just a question of how to get students to apply it in their own environment. Trigonometry in Australia is the same in Barbados" (B4). Thus, the EFA goal of quality education may not centre on culturally appropriate curriculum as much as improving teaching practices. Yet there were other respondents who stress the importance of a global awareness:

Yes - I think it should be done...but I have a problem of how far can we get with this kind of approach in light of globalization. We may try that approach then find ourselves limited and the quality limited and unable to produce that kind of students who can make it on a global market. (T1, teacher)

This notion of a global curriculum was probed further in interviews to uncover why these countries looked to certain places for innovation. In other words, the notion of what constitutes 'global' was probed. Teachers certainly express the desire to link students' experiences to Mathematical concepts. B2 provides an extended example of teaching integration by asking students questions, yet when discussing the degree to which hands-on 
learning of Mathematics is available for students, they reply: "I don't know if I can say that is emphasized a lot - I don't think there is a lot". As the four teachers interviewed are either heads of Maths departments or senior Maths teachers, their responses may be on an individual level rather than reflective of a stereotypically rote learning system as suggested by T5 who notes that "Secondary schools are probably very traditional still. The teacher teaches to the test". One of these Maths teachers describes her teaching methods as heavily teacher centred and remarks that education in Barbados appears to be "how England was 20 years ago" (B1). B1 shares: "Because of the intake that we have we tend to use a similar approach for all of the children, assuming that their needs are roughly the same. It's basically chalk and talk..." T3, a policymaker, offers an explanation for the high emphasis on traditional methods of teaching and starts at the level of university lecturers who do not have exposure to education training and are content specialists. Thus, T3 notes "you can imagine what is going to be the type of education through secondary school - everything was an attempt to transfer content - whatever you were going to regurgitate right through to the school system". A former chief examiner of Maths seems to concur that the weakest area is problem solving: "The weakest area is problem solving... this is as a region because of reliance on rote learning, the idea that "you've got to get this to pass the exam' " (I3). Observations of participants in the pilot study helped to validate the responses regarding rote teaching. Further interviews with non-senior Maths teachers revealed the variation of opinions of teachers in Barbados and Trinidad and Tobago. See 6.4.2 and 6.4.3 for more data collected in the main fieldwork research.

\subsubsection{Areas of innovation and influence}

When asked about the influences of other countries on educational ideas, it was evident that both the USA and UK were key players. One respondent notes the contribution of the British examination system in the creation process of the CXCs, although American perspectives were also sought to a lesser degree (I2). I2 confirms the continuing similarities of the CXC exams with those of the British: "Our standards are on par with the British exams...normally we tag with the British system, at least $60 \%$ of the core". However $\mathrm{I} 2$ is also quick to point out "but now it's our own standards - we've been setting exams for 30 years". 12 discusses the international recognition that CXCs have gained due to its rigorous standards, while also mentioning the potential criticism from local islanders about the high 
benchmarks: "they may say our standards are too high. We have always had to be a little higher than the rest on an international level to be recognized in the first place" (I2). The creation of the CXC exams also involved international acceptance from tertiary education: "this would have been sent out to universities and colleges overseas...to ensure this was at standard because we didn't want them to be lower - we needed some comparability" (B4, academic). On a policy level, there was some consultation with New Zealand for the new curricula of the NCSE due to the perception that "seemed to be aligned to what we were thinking and some ideas on how to move forward... also it's a British model and also more closely with the British based system we have" (T3, Trinibagonian policymaker). Singapore was also examined for its economic success (T6). With regards to educational research literature, the UK, USA and Australia were easily accessible via the internet and were popular among researchers. There is certainly the tendency to look abroad for inspiration, as Trinibagonian policymaker T4 states, "we look to a large extent outside the region, the New Zealand model, what's happening in the UK and USA and pulling together 'best practices' together and seeing how the ideas work together". T4 points to the research from the UK, USA and New Zealand as a reason these countries are examined. Yet, the pull of the 'west' or 'global' trends is not necessarily positive: "Indirectly I would say that we are influenced by what happens in other places - not necessarily for the better. We tend to follow a trend which...people have complained about in the States such as the lowering of standards" (B4, Barbadian academic). From the pilot study alone, it seemed apparent that 'horizontal borrowing' did not occur between the two island states; however, patterns of foreign innovation and possibilities for 'vertical borrowing' were areas for further consideration.

However, T4 also states the use of international consultants for a wide range of ideas and gives the example of the TechVoc programme from Jamaica and the CXC headquarters in Barbados for the NCSE marking systems. This was probed further in interviews and policy documents. However, T4 is also quick to point out that the government works with UWI staff as well as personnel from the Caribbean and Trinidad and Tobago. Along with the EFA report in which officials from each island are required to report on best practices, regional collaboration appears limited to the examples provided by $\mathrm{T} 4$. All respondents seemed to agree that the CXCs are culturally appropriate and this is one of the key aims of NCSE: "When I was on CXC panel I tried to do that, but it was hard to find things common 
for everyone... With the national curriculum we are trying to do that through [the goals of] citizenship and also aesthetics" (T3). One respondent feels that the CXCs are able to account for cultural differences across the islands as representatives from each participating island sit on the panel for the syllabus and marking procedures: "You have to account for how a Trinibagonian student compared to how a Barbadian student would address an issue. For example in Barbados, the fruit 'akee' is called 'gillip' which is a bigger fruit in Jamaica - then it can become ambiguous" (12). See 6.5 for further perspectives expressed by respondents in the main data collection.

\subsubsection{Discussion}

The selective nature of secondary education in both countries has led to certain strengths and problems. For those who are able to succeed in the traditional exam-driven system, they are able to gain currency and thus mobility in the Knowledge Economy. If Barbadian and Trinibagonian students are able to navigate a curriculum based on rote learning and strong teacher relationships, they will achieve school leaving certificates with international currency. As there are sufficient numbers of places for Barbadian children, there is a sense of equality in the system and thus the goal of access to universal secondary education is achieved. As the literature review on educational quality does not separate access from quality, further interviews and observations were required in the data collection process to validate this notion of 'equality' in the Barbadian system. In the case of Trinidad and Tobago, the supply of secondary school places cannot meet the demand and class sizes appear very large. Further, as students enter secondary school at age 12 and complete their CXCs and CAPEs at ages 15-17, children who drop out of secondary school are left without qualifications. Hence, the NCSE appears to be an attempt to promote the completion - and hopefully the retention - of secondary school attendees. A thorough review of the NCSE as well as further interviews to query the implementation of the national curriculum is needed to determine effectiveness. Similarly, it is necessary to investigate the process of curriculum reform in Barbados and the actualization of such changes.

Teaching in both countries seems to be similar as respondents suggested the absence of interactive learning and hands-on approaches in Mathematics classrooms. This follows 
Evans' and Davies' (1997: 17) observation of secondary schools in the Caribbean: "Since schools are not publicly evaluated on any criteria other than performance in examinations, such decline [of emotional and affective development] goes unmeasured, though the effect can be quite significant". The movement away from rote learning appears to be a desire for all educationalists in both countries and both the CAPE and NCSE seem to recognize the need for student inquiry. However, the degree to which student-centred approaches persist in classroom teaching needs to be verified by classroom observations. According to a pilot interview with a lecturer, the teacher training college in Barbados covered topics such as sociology and psychology of education, classroom practice and research methods (B3) with the mandate "to raise the performance of teachers who will then help students and this has implications for development and the economy" (B3). This shows promise of critical reflection of curriculum, but further data collection will reveal the effectiveness of teacher training.

However, dependence on exams and certificates worthy of international recognition appears to be a more pertinent issue for respondents. From the perspective of the $\mathrm{CXC}$, one of the key benefits is the following: "By having common Maths exams, we can track deficiencies in terms of teachers and students; there are some areas...where there are weaker students and teachers" (I2). Yet the NCSE provides a certificate for students who do not plan on participating in international higher education. This is particularly important as there is a small elite who attend reputable international universities and thus international education networks may be irrelevant. The force of multilaterals, however, should not be ignored. T8, a Trinibagonian academic mentions one example of an initiative that has been implemented all over the world, including the Caribbean. Large scale assessments at the primary level took place as part of a reform process. As part of a loan agreement, agencies may require the compliance of certain criteria (T8).

Yet the importance of local standards must not be neglected. The strong identities of the island states - particularly Barbados and Trinidad and Tobago - seem to make 'horizontal borrowing' or 'sharing of best practices' a difficult task. While some respondents feel that the histories, cultures and ethnic demographics are factors that must be taken into account in collaborative initiatives, the international community may view all the islands in the Caribbean the same. The perceptions and encouragements of the international community 
need to be investigated in the review of policy. Yet it is clear that the island states are looking for ideas as Barbados has a strong link to the UK and the NCSE was inspired by New Zealand. Education literature from the UK, USA and Australia is widely accessible via the internet. However, some respondents identified possible areas that they would be interested in discussing further, such as gender and achievement (T4, policymaker), drawing out creative abilities within the formal education system (T8), developing methods for improving results and discipline (T4).

From the experience of completing the pilot, there was a stronger understanding of context and the difficulties with conducting interviews in small states. Anonymity was difficult to preserve as other teachers in the schools were aware of respondents' identity. Further, the reality of gaining access to key personnel in government ministries forced a reconsideration of the sampling methods as policymakers were difficult to reach and access to most of the policy respondents was achieved through contacts. Thus, more time was spent on networking before the main data collection to develop stronger relationships with gatekeepers on both countries. However, the experiences of teachers in the pilot varied considerably as some were former chief examiners or worked very closely with policies. As such, more questions on the experience of training, policy implementation and the role of examinations were added to the interview question bank. It also became apparent that teachers are extremely busy and school space is limited. Therefore, requests and arrangements for interviews had to be flexible. During the fieldwork visits in October and November 2007, some half day visits were made and several schools were visited in a week as the experience from the pilot proved that full days and weeks of research were difficult to achieve in schools. Initially, the thesis sample aimed to interview as many policy personnel as possible, as well as a substantial sample of teachers and academics. However, limited access to policymakers and the influential positions held by teachers was not taken into account. Access to teacher respondents proved to be easier to access than policymakers. After access was negotiated with headteachers, schools were welcoming and Maths teachers readily participated. On the other hand, access to policymakers required much negotiation and was often limited. Policymakers tended to restrict their networks and usually did not provide contact details for other potential respondents. Academics, on the other hand, were willing to share their contacts and were the easiest to access. As some teachers had strong experience in policy, the sample for the main data collection was 
revised to include more teachers. Teachers were also willing to talk and appeared to enjoy sharing their experiences in person. Although surveys were initially planned to sample a larger number of teachers, this method was removed in place of more interviews as they are more personable and can be completed within a set amount of time.

The pilot provided updated information on education in Barbados and Trinidad as there is a dearth of literature on education policies in both countries. In particular, pilot interviews with academics provided a stronger context for the main data collection as a deeper understanding of curricula developments and the hierarchical nature of the education system. Academic respondents provided resources such as theses, conference proceedings, unpublished papers and documents outlining structural aspects of the system. It was clear that more reading on regional and international policies was necessary. There appeared to be resistance to global education policies, but at the same time, respondents were interested in the latest reforms in the UK and Canada and often asked about the candidate's experience of teaching in these countries. The pilot left questions regarding the susceptibility and impact of foreign ideas and the origins of resistance to 'horizontal borrowing' from each other. It also generated further questions regarding classroom practices such teachers' perceptions of chalk and talk and the degree to which national and international policies were implemented. These were subsequently answered with interviews and observations in the main fieldwork collection.

\subsection{Analysis of methodology}

This section will provide a review of the research question and methods and discuss the validity and reliability of the findings and methods, as well as generalizability and ethical concerns related to the study. The findings of this research provided answers to the research questions raised initially, such as those related to the identification of values espoused in the Maths curriculum, best practices exported elsewhere, the openness of Trinidad and Tobago, the uniqueness of the Caribbean, the limitations of Phillips and Ochs' (2004) model, the barriers of culture, and the reproduction of social stratification through Maths. The largest and most overarching question regarding the possibilities of 'horizontal borrowing' was answered. While it is possible and encouraged, the power of tradition and the gaze towards the 'centre' prevents the necessary impulses towards 'horizontal 
borrowing' and 'vertical borrowing' is a sharper reality. The initial assertion of Barbados as a model may still hold true as it is viewed in this manner by policy documents and some teacher respondents. There is a sufficient degree of openness in Trinidad and Tobago and it fits the role of recipient; however cultural and social views of sharing limit possibilities of 'horizontal borrowing' from within the Caribbean Sea.

The policy review and the fieldwork revealed there are large gaps between policy and practice. Despite the existence of policies advocating 'horizontal borrowing', they are not realized due to resistance at the local level. Interviews with respondents revealed their perspectives on 'horizontal borrowing' and the policy review highlighted the ambitions of documents. While regional organizations exist, and formal and informal opportunities arise, there is still resistance among local actors for implementing the best practices from elsewhere. Thus the perspectives of local actors are valuable for understanding the limitations of 'horizontal borrowing' of policies. Possibilities are certainly available but if ownership by local actors is the necessary link, they may not be actualized. Therefore, the next question may involve the link between opinions and actions. While the strength of this link was only investigated for teachers' perspectives and their classroom behaviour, the observations revealed the inconsistencies between terms such as 'group work' and 'real life' Mathematics. Further discussion regarding reliability will be discussed in this section.

\subsubsection{Effectiveness of methods}

Three key methods were used to gather data (see 4.2.2). The policy review provided a vision of Barbados, Trinidad and Tobago and the Caribbean by multilaterals and regional associations. The advocacy of 'horizontal borrowing' by international policy documents affirmed the researcher's interest in the topic for the region. The examination of national documents charted a picture of the island governments, providing both a context of local policy as well as a counterexample to 'horizontal borrowing' as the documents appeared to be nationalistic. Further, reading national documents helped to confirm the choice of selecting Barbados and Trinidad and Tobago as the two Caribbean countries of study in this thesis. Both nations are heading in similar directions in education reform and are leaders in the region. Yet they are not interested in 'horizontal borrowing' from each other despite the somewhat forced notion of regionalism by multilaterals and regional organizations. It is 
clear that the encouragement of 'horizontal borrowing' is mostly limited to international documents. Yet the notion of a Caribbean identity is present in international, regional and national documents. The extent to which this is implemented in practice was probed in the interviews and classroom observations. In short, the policy review provided written evidence of 'horizontal borrowing' as a key strategy and raised further questions about the extent to which this was possible in Barbados and Trinidad and Tobago. Through the counterexamples of the national documents, gaps between multilaterals and the individual island states became evident. The contrast of the two types of documents served as a test to determine the extent to which policies are difficult to implement because they are international and from 'elsewhere', or if policy actualization is generally a challenge due to resistance from the ground.

Interviews helped to answer these questions. Teachers, policymakers and academics provided their perspectives on both the current state of education on the islands as well as future plans. Although the data collected from this fieldwork is based on experiences, narrative and perspectives, which may appear less quantitative than other types of data, the weight of educators' perspectives is significant in small states where the smallness of scale impacts implementation of polices. Interviews and observations were focused on understanding resistance to the ideas of international, regional and national policies. Interviews were largely semi-structured as questions were prepared from a question bank beforehand. Qualitative approaches were necessary as the researcher was not familiar with the context and needed to appear as flexible as possible. Although qualitative methods have been criticized for lacking in certifiable conclusions, the use of three methods in this thesis helped to strengthen the reliability and validity of the work. Further, the emphasis of the fieldwork is on understanding phenomenon and examining the gaps between policy and practice - both of which are difficult to capture using quantitative methods. Deductive and inductive methods were absent in the place of abduction to reduce bias and invasiveness of the research. A large pilot study was carried out in two separate trips to Barbados and Trinidad and Tobago, with a four month break between the trips to ensure sufficient time to reflect upon methodology. Discussion regarding the pilot study and lessons learned is found in 4.3 . 
Thirdly, classroom observations served as triangulation for the study. No indicators were used initially as the observations were intended to inform the researcher about classroom culture in the two island states. The observations revealed gaps between teacher responses and actual practice. While teachers claimed to use group work and student led discussions (see 6.4.1), these were absent from the observations, perhaps due to disagreement between the researcher and teachers over these terms, or perhaps due to the need to impress the researcher. Certainly, classroom observations served as a very useful method of triangulation as they helped to identify aspects of reliability and validity. They also provided a strong context for education system, thereby situating the findings in a live context. Additionally, observations increased dependability for the research and confirmed the choice for selecting Barbados and Trinidad and Tobago. As 87 hours of observation were taken over three and a half months as recorded through field notes and reflexive journals, the researcher is able to claim a substantial engagement in the field along with other markers of dependability such as respondent validation and debriefing by peers. Through the feedback sessions, verification of transcripts and a written summary of findings, respondents were given opportunities to validate fieldwork. Further debriefing by peers took place through conferences in both the UK and abroad. Finally, the observations further confirmed the choice of selecting Barbados and Trinidad and Tobago as the classroom culture and pedagogy are remarkably similar. The main difference between the two countries thus appeared to be on the ground and in some aspects of the national documents. While other Caribbean islands would have served as interesting subjects of comparison, the strong identities of Barbados and Trinidad and Tobago are distinct despite similar histories. The four islands of Jamaica, Guyana, Barbados and Trinidad and Tobago have always been major players in the region; however Barbados and Trinidad and Tobago are arguably the most developed due to their achievement of Education for All goals.

Despite overall satisfaction with the methods selected, there are some criticisms of the research. Respondents may have been distracted by the researcher's touch typing during the interviews, and some would have preferred standard note-taking. While almost all respondents spoke freely and enthusiastically responded to questions, standard note-taking may have increased the comfort level for some respondents, particularly younger female teachers who appeared reluctant to speak and policymakers who may not have wanted to have their comments recorded verbatim. Although respondents were briefed before 
interviews, oral consent was granted in all cases and respondents were offered opportunities to withdraw from the study, written consent could have been obtained. However, this may have intimidated some of the respondents as they may felt it the environment was too formal. Some of the teacher interviews could have taken place in less chaotic environments, as crowded staff rooms and noisy classrooms may have been distractive for the respondents. The presence of other people may have limited respondents' willingness to share perspectives. Another criticism lies in the method of classroom observations. Videotaping classroom activities would have helped with analysis of observations, as field notes may suffer from bias, fatigue and difficulty concentrating on teacher instruction, blackboard notes and pupil reactions at the same time.

Further interviews with local policymakers could have taken place (see 6.1). Although there were three more interviews with respondents involved in policy in the past (B4, T6 and I1), only four were current postholders in the Caribbean (B17, T3, T4 and I2,). One interview took place outside the Caribbean with a respondent who worked with international organizations either in the past or present (I5). A further interview took place with a respondent who worked for an international organization but preferred to be classed as an academic with no affiliations. While there were eight interviews in total with past or present policymakers both inside and outside the Caribbean, more could have been done, particularly with policymakers in regional organizations as they could have provided insight on Caribbean cooperation. This, however, was limited by access. Despite emails, phone calls and written letters, further contact with policymakers could not be made. Yet the interviews with policymaker respondents revealed similar perspectives. Additional interviews may have only provided more examples of looking elsewhere for foreign ideas as none of the interviews with policymakers centred on 'borrowing' within the region. Those that participated were representative of key policy positions despite the lack of dignitaries interviewed. While two respondents (T4 and 12) provided ambivalent answers and did not reveal much about the impulses of either 'horizontal' or 'vertical borrowing', others such as B4, B17, T3, T6, I1 and 15 were eager to talk and very helpful. None of the eight respondents mentioned above were able to pinpoint an exact example of 'horizontal borrowing' in the Caribbean, other than one pilot respondent who mentioned 'horizontal borrowing' aspects of the TechVoc programme from Jamaica. However, further information on this example was not found in later interviews and there appeared to be a 
lack of information on this instance of 'horizontal borrowing' in policy documents. On the whole, policymaker respondents were only able to mention foreign examples in policymaking from 'elsewhere' - and at best, discussions lacked detail and were limited to a few statements. It is also important to note that policymakers often referred to written documents to support their answers as they needed to continue to tow the ministry line on a given topic. As such, the policy review covered many of the topics that would have been otherwise discussed in interviews. 1t would have been helpful to have more interviews if access was permitted; however the findings based on the interviews completed and the policy review compensate for this shortcoming.

As academics served as a valuable resource of information, advice was sought throughout the fieldwork process. However, individual recorded interviews were limited to the pilot mostly due to timing. Academics were the first group of respondents approached on the islands as they were easily accessible. Key academics on Maths education and education policy were approached via email and most responded quickly to the request for interviews. In order to maintain their interest in the study and willingness to help access policymakers and schools, arrangements were made quickly for interviews. Thus, with the exception of one academic in the study, all academic respondents were interviewed during the pilot. There was the intention to interview more academics; however most had already been interviewed. Three potential academics remained; one was accessed through a personal contact, and the other two did not respond to emails or phone calls. If there was an opportunity to replicate the study, one or two pilot interviews with academics would have been helpful, but it would be more advantageous to carry informal conversations with academics for the purpose of accessing gatekeepers, followed by formal interviews in the main data collection. Prolonged engagement in the field may have aided issues of access as networks would have been developed further. In total, 12 weeks were spent completing interviews and observations. While the break between the pilot study and main data collection helped consolidate ideas, understand policy documents and finalize methodology, the same preparatory work could have been completed in Barbados and Trinidad to meet gatekeepers.

As a result of accessibility, the sample size was heavily focused on teachers. Emphasis on teachers in the sample was made after completion of the pilot study (see section 4.3.2). 
While this bias towards the teacher experience may be viewed as a criticism, it is essential to note that some of the teachers had experiences outside the classroom such as former roles as chief examiners for CXC. Others had taught on neighbouring Caribbean islands. Further, the findings revealed that teachers play a role in the slow actualization of policy as resistance is on the ground for national initiatives. There is also a cultural resistance to sharing among teachers and schools. Despite criticism from teachers regarding the hierarchal, achievement based state systems, they also subscribed to their inherent values. All of these findings are fascinating and strongly added to the findings on the dynamics of education in Barbados and Trinidad and Tobago. The sheer sample size of teacher responses also increased the validity and reliability, along with other techniques to ensure the robustness of the study as discussed in the next subsection.

\subsubsection{Reliability and validity}

While it is difficult to objectively review policy and literature, close readings and citing examples verbatim from documents helps to increase the reliability of Chapters 3 and 5 . These chapters used methods as suggested by prominent researchers in the field. Jansen's (2004, cited in Ochs and Phillips, 2004: 21) four points on contextual aspects of 'borrowing' were used to investigate the scope of 'horizontal' and 'vertical borrowing':

1. Describe social, economic and political contexts that make policy borrowing possible; - see 2.1 and 2.2

2. Demonstrate complex ways in which borrowed policies make their way into national education systems (acknowledging the roles of persons and context); see $3.3,6.5$ and 7.3

3. Describe changes of policy through the process of local adoption; - see 5.2 and 5.3

4. Show effects of borrowing in the schools and classrooms - see 6.3, 6.4, 7.1.2, 7.2.2 and 7.2.3.

This helps to increase the validity of the research process on the topic as it follows Jansen's process. Similarly, the policy review has covered Ogza's (2000) steps for reviewing policy (see 4.2) which were used to frame the policy review. This helped to create criteria of examining policy and ensured an established lens for viewing data. By using both of these frameworks, the otherwise subjective review of policy was kept under closer analysis, thereby increasing validity of the findings. 
Teachers generally agreed on many of the perspectives expressed through the debriefing process. Between December 3 and 13, 2007, a selected group of participants were invited for feedback meetings in Barbados and Trinidad and Tobago. A cross section of participants was selected. However, many of these participants selected were teachers as classroom observations formed a part of the research process and these follow up sessions also served the purpose for debriefing. Headteachers and Heads of Departments were contacted. They were asked to invite any teachers who participated in the interviews or observations to attend as well. All nine schools were contacted and eight responded. Upon arriving at one school, the headteacher described a damaging theft and vandalism to school property and thus teachers had been dismissed for the day. As such, a very brief session was held for the headteacher (who did not participate in the interviews) and teachers from this particular school were not debriefed in person. Six educationalists who worked in policy or academic settings were invited and five responded. Follow up emails and phone calls were made to the two non responding participants but no response was elicited. In total, 17 respondents were formally debriefed through the feedback sessions. Interview transcripts were returned to participants for verification purposes. Notes of conversations were sent back to informal respondents if verbatim quotes were used. One respondent asked for her transcript to be paraphrased only and quoted verbatim only if notified. A few others submitted changes. A two page summary of findings was mailed to all interview respondents regardless of whether or not they attended the feedback sessions (see Appendix I). Participants were given the opportunity to withdraw from the study during this debriefing process. One participant retired from teaching and was not able to be reached via telephone and thus did not receive feedback or the interview transcript. A list of participants who took part in the feedback sessions and their roles is available in Appendix $\mathrm{J}$.

Although teachers did not express the same opinion all the time, and often disagreed with each other, clusters of teachers voiced the same opinion. While teachers expanded on ideas and explained opinions with different examples, no outliers of data were found. The sample size and the similarity of opinions expressed by clusters of teachers from different countries and different schools shows a substantial robustness of the findings. If this study was replicated again, opinions would be similar to those indicated in the study as teachers 
spanning the ranges of age, race, gender, teacher engagement and years of teaching experience were interviewed. If different respondents were selected, there may be very slight deviations from some of the perspectives expressed; however the range of opinions noted in this thesis should cover the contrasting perspectives expressed. Subjects were generally reliable, although there were discrepancies in the terms used. This may have been due to ambiguity of phrases such as 'group work' which was interpreted as opportunities in which pupils were permitted to participate opposed to children working in groups to complete an open ended task. Phrases such as 'student-led' often referred to the manner in which students worked on the board, or helped to generate answers to a question rather than the more innovative teaching strategy of children generating their own questions to their peers and leading discussions among the class. This is not unusual, as Phillips and Schweisfurth (2008: 95) explain: "Differences in language use are associated with differences in conceptual approach to the kinds of issues with which comparativists deal". Despite confusion surrounding the phrases, teachers openly admitted to strong emphasis on rote methods although the extent to which they claimed to use 'group work' and 'student led' pedagogy differed. In this way, subjects were reliable as they were able to describe their teaching styles accurately despite questionable reliability in the responses of questions with ambiguous terms. The researcher takes ownership for the confusion experienced and feels this is a valid criticism of the study. However, it is also important to note that teachers were not always the best informed with regards to policy. There was disagreement over the intentions of the NCSE as some felt it was a certificate awarding exercise rather than a national assessment to identify discrepancies in the system. In this way, the reliability of teacher criticisms of the system is called into question.

Interpretive and evaluative validity were also fulfilled as much as possible. Interpretative validity is defined as follows: "the ability of the research to catch the meaning, interpretations, terms, intentions that situations and events have for the participants/subjects themselves, in their terms" (Cohen, Manion and Morrison, 2000: 105). This was fulfilled through the unstructured observations and the follow up conversations that often took place after the observations to allow the teacher to highlight any aspect of the lesson that they wished to comment on. The semi-structured nature of the interviews also allowed participants to provide input on issues that they felt were important. As mentioned previously, respondents were issued their transcripts for verification to ensure that they 
were satisfied with the transcription process. By comparing the interviews to the classroom observations, differences of interpretation of terms such as 'group work' were caught to help increase interpretative validity. In addition, the classroom observations also revealed the strong relationships between teachers and pupils, and the high participation of the students in some instances, thus capturing the student centred intentions of the teachers. Evaluative validity was also captured through the use of evaluative frameworks for the thesis (see 3.1 and 3.2). Cohen, Manion and Morrison (2000: 105) describe evaluative validity as "the application of an evaluative framework, judgmental of that which is being researched, rather than a descriptive, explanatory or interpretive one". The application of Phillips and Ochs (2004) framework evaluated the extent of both "horizontal and 'vertical borrowing', thus reducing researcher bias of blind measurement of a phenomenon. By comparing the data of this thesis against set criteria, validity of findings is increased as it is difficult to evaluate findings if it is described through the interpretative eyes of the researcher.

\subsubsection{Generalizability}

The sampling of interview respondents was mostly opportunistic. Confounding factors such as differences by subject matter were reduced as there was a focus on secondary mathematics. Yet despite the lack of a random sample, the schools and teachers that participated were representative of different achievement levels and types of schools. Although there were two lower performing schools out of the nine sampled (one of which did not form a main part of the study), it is possible to generalize the results from the nine schools to represent the islands of Barbados and Trinidad and Tobago. However, the extent to which the conclusions regarding both types of 'borrowing' can be generalized to the whole region is questionable. In some ways, Barbados and Trinidad and Tobago have similar histories and share some aspects of cultural and societal values with each other and other English speaking Caribbean islands (see 2.2 for literature on sociocultural context of the region). On the other hand, the two countries see themselves as distinct. This dynamic is present throughout the Caribbean as islands are homogenously perceived despite sentiments of difference. The notion of the Caribbean as a unified region is highly disputed and discussions regarding the region in this thesis are limited to the English speaking Commonwealth Caribbean. On the one hand, the policies advocated by multilaterals pertain 
to the whole region, and in this way, the ideal of 'horizontal borrowing' of policies holds true. Yet the individual policy documents of Barbados and Trinidad and Tobago and the subsequent views of 'horizontal and 'vertical borrowing' are unique to the islands. Certainly, there is the argument that if the two island states are heading in very similar directions, other islands may be heading in the same direction as well due to the unilateral forces of aid agencies, the knowledge economy and the desire to converge to the 'centre'. Thus the findings regarding 'borrowing' may be extrapolated for the rest of the English speaking Commonwealth Caribbean. Although there may be variations of strength, some of the aspects of forces of tradition are present in all of the English speaking Commonwealth Caribbean islands such as the importance placed on the $11+$, rote teaching and the esteem held for international study. The relationship between Barbados and Trinidad and Tobago may not be generalizable as the islands have different idiosyncratic relationships with each other, which may be a barrier or incentive to 'horizontal borrowing'.

Perhaps one certainty is that the findings from this thesis cannot be fully extrapolated for the entire Caribbean, small states, or developing countries. The idiosyncrasies are simply too diverse despite the ubiquitous treatment of these groups by the 'international community'. However, the notion of 'horizontal borrowing' in this thesis is centred on regionalism and encouraging relationships to share best practices. In this way, the discussion in 7.2 may be extrapolated. As many of the countries within these regional groupings are former colonies who have yet to reach developed nation status, there is often the perception from the 'centre' that they are all the same and should borrow from each other. In this way, there may be some aspects of the ideal 'horizontal borrowing' as envisioned by the 'international community' which may be representative of ideal SouthSouth collaboration. The impact of forces of tradition and the gaze towards the 'centre' on policy implementation may be a concern for other developing nations, as tradition is present in all societies, particularly developing ones. Gazing towards the 'centre' is a byproduct of Eurocentrism for post colonial countries and a necessary survival mechanism for all vulnerable countries in the knowledge economy. 


\subsubsection{Considerations of ethics}

As discussed in 4.1.2, ethical considerations are essential for the smallness of scale and outsider approach. Anonymity and confidentiality were difficult to preserve in Barbados and Trinidad and Tobago. As the islands were small, teachers were curious to find out the other schools involved. In the beginning of the study when access to subjects was a concern, Maths headteachers asked about other schools who had agreed to the study and potential names of schools were released. Teachers were also cognizant of other teachers who were being interviewed and observed, as schools were small and it was difficult to hold interviews in private areas. Although all interviews were held in quiet places and without participation of other colleagues except otherwise noted, the researcher did not blend into the school environment and it was clear that a study was being carried out. However, responses and observed teaching practices were not released to other respondents. The identity of participants remains confidential as well as participating schools. Although the Ministries of Education in both countries have records of participating schools, the data will not reveal the source of responses. It is important to note the social connections among teachers in the islands as well as the difficulties faced by the researcher in blending into the school environment. There are very few researchers who visit the islands, and hardly any of Chinese origin.

In an effort to reduce the attitudes and expectations of the researcher during interviews and classroom observations, there was a briefing before the interviews begin. Often, participants appeared more relaxed after the briefing as they were reassured that their responses and any notes on their classroom teaching would remain confidential. The feedback sessions in December 2007 were particularly helpful in confirming the confidential nature of the findings. Respondents appeared much more relaxed and many offered further help if necessary. As the researcher knew little about the topic initially, and a fixed hypothesis was absent, there were few expectations on the part of the researcher. It is hoped that the respondents did not feel pressured to respond in a certain way. However, discrepancies between verbal responses and the realities of the classroom were picked up by examining gaps between interview transcripts and subsequent observations. Triangulation helped to increase reliability of responses. 
The schools and teaching environments in Barbados and Trinidad and Tobago were very busy. In Trinidad and Tobago, teacher timetabling was often chaotic as some teachers were absent from lessons and cover needed to be found among existing staff. In some instances, the researcher experienced a conflict of interest as participants proceeded to give interviews despite teacher absence. In these instances, interviews were cut short by the researcher to facilitate time for cover. In order to reduce the invasive nature of research, interviews and observations were carried out without specific time or place requirements. As a result, the interviews range in length and privacy. Some were carried out over 15 minutes in busy classrooms while children worked; others were held in quieter environments for hours. The interviews were all recorded by touch typing, eliminating the need for tape recorders. As all interviewees had the opportunity to verify their transcripts, there was much transparency to the process which heavily aided satisfactory feelings of trust. One asked that their transcript to be paraphrased only and quoted verbatim only if notified. A few others (B1, T3, T17 and I5) submitted minor changes. One retired from the teaching profession and could not be reached via mobile phone. All others were contacted.

Initially, there was a concern that respondents would feel scrutinized as they were participating in a study from the 'centre'. The Ph.D study was registered in the UK and the candidate was a former teacher from Canada. With the possibility that respondents were fearful of being criticized, friendly relationships were built between the researcher and the interviewees in an attempt to show little judgment on their practices. Many respondents noted they enjoyed participating in this research project. Further, all respondents stated that they agreed with the findings. A cross section of 19 participants was selected to participate in debriefing sessions. Many of these participants selected were teachers, as classroom observations formed a large part of the research process and these follow up sessions also served the purpose for debriefing. The debriefing sessions helped to reassure participants that the study was focused on higher country level comparisons rather than individual assessments. Respondents enjoyed the debriefing sessions and appreciated the written follow up briefing document. Although they were welcome to provide verbal or written feedback, only positive comments were sent to the researcher.

The final ethical concern involves publishing information that may tarnish the esteem of the countries. Despite several attempts to uncover the percentage of students in the Caribbean 
leaving without secondary school certification from the island governments and the CXC, the researcher decided to cease investigation into this data. There were other questions from the interviews that remained unanswered, most of them revolving around the effectiveness of the school systems and the intentions behind the aims of the national documents. These seemed to make the respondents uncomfortable as they did not provide answers. While the researcher attempted to follow up on these questions through light emails and phone calls, it appeared to be unethical to continue to investigate these areas. As respondents have the right to withdraw from interviews at any time, their experience of the fieldwork process is a paramount concern. After all, as evidenced by the interviews and observations, the direction of policy is molded by their involvement in national initiatives and attention paid to the 'centre' through the use of foreign examples. The policy review adds a further perspective to the study, providing details of the national and international initiatives that operate within the education spaces of the respondents. Attention will now be paid to the findings from the policy review, followed by a full discussion of respondent findings. 


\section{Policy Review of International and National Documents: \\ Investigating encouragement and responses towards notions of 'horizontal borrowing', regionalism and improving quality}

This chapter focuses on findings from the policy review, one of the central data collection methods. International documents from UNESCO and the Commonwealth Secretariat were examined to analyze the promotion of 'horizontal borrowing' and the related notion of regionalism. Improving quality is an impetus for these policies and thus was examined as well. The response of the governments of Barbados and Trinidad and Tobago, illustrated in national policy documents and curricula, was also examined to ascertain a government response to these policies. In particular, Mathematics curricula are discussed in this chapter as a specific example of the responses to concerns of improving quality and adopting a regional focus. The close exploration of Mathematics curriculum documents helps to situate the respondents' perspectives in the following chapter on fieldwork findings. It also provides a critical reading of one aspect of secondary schooling to illustrate examples of curricular response to international initiatives, such as UNESCO's Four Pillars (see 5.1.1). The analysis of Mathematics curriculum documents also provides a counter-perspective to criticisms from the academic community on teaching and learning in the Caribbean (see 3.4.2). The chapter moves from providing an overview of large scale international initiatives to the specific response of governments in one subject area, providing a full range account of policy recommendations and national responses. The focus on both global and national policy perspectives will illustrate the gap between policy and practice, which will be further probed and discussed in Chapter 7.

\subsection{International documents}

While CARICOM and the Caribbean Development Bank are independent regional organizations, they do not produce policy documents on education quality as they are primarily concerned with economics and trade. In fact, one of the criticisms of CARICOM is its failure to contribute to regional education initiatives. Jules (2008: 206) writes the following: 
Although paying lip-service to human resource development and recognizing the centrality of people to any integration process, and even while establishing the bureaucratic infrastructure for a Caribbean Single Market and Economy, the absence of a harmonized agenda for education across the entire region remains one of the developmental lacuna of the initiative.

Discussion will be limited to the policies of UNESCO and the Commonwealth Secretariat. It is important to note that the Commonwealth Secretariat has parallel values as the United Nations and shares some allegiance: "The Commonwealth way is to seek consensus through consultation and the sharing of experience. 1t is uniquely placed to serve as a model and as a catalyst for new forms of friendship and co-operation to all in the spirit of the Charter of the United Nations" (Commonwealth Secretariat, 1991). Although collaboration and networking is encouraged between nation-states, there is also the implication that these must be in tandem within the global order of multilaterals. Howe (2003: 47), in his report for the International Bureau of Education, recommends a permanent small states network in close collaboration with the World Bank and Commonwealth Secretariat, but "such a networking system would not substitute for the work of the World Bank, Commonwealth Secretariat and other donors..." As illustrated in this policy review, UNESCO, regional arms of UNESCO and the Commonwealth Secretariat share similar goals and initiatives which shape the movement of countries. The national policy documents of Barbados and Trinidad and Tobago are thus remarkably similar and use much of the same rhetoric dictated by the agencies and may be considered a form of neo-colonialism to shape the course of 'development', convergence or globalization, as discussed further in 7.3.4.

\subsubsection{Education for All: An international initiative on quality}

The largest and most influential policy document is the Jomtien pledge signed by the world's leaders declaring Education for All (EFA) in 1990. This declaration was renewed in Dakar in 2000 and has been extended to 2015. The goals are listed in Appendix H. The failure to reach these goals by the original target date of 2000 and the anticipated failure of reaching the extended end date of 2010 have been due to several key reasons as outlined by UNESCO: “...weak political will, insufficient financial resources and the inefficient use of those available, the burden of debt, inadequate attention to the learning needs of the poor and the excluded, a lack of attention to the quality of learning and an absence of 
commitment to overcoming gender disparities" (UNESCO, 2000: 12). The Millennium Development Goals (MDGs) created a larger framework for development and included EFA goals to ensure a more multi-sectoral and varied agenda for development. Two of the eight MDGs relate directly to EFA: achieve universal primary education and promote gender equality and empower women. While Jules (2008) agrees that EFA focuses on the problem of illiteracy and the social exclusion of children from education, he argues that EFA can become "...a hegemonic construct that constitutes the measure of all educational advancement in developing countries and on the basis of which international aid and lending will be prioritized". In particular, he asserts that the initiative can become "...a fetter to those countries that have gone beyond the elemental prescriptions of the EFA" (Jules, 2008: 206). Jules (2008) notes that Caribbean countries argued in 1990 that basic education should include secondary education to cater to the knowledge economy, yet this was rejected for its expansive and expensive approach. In the 2009 Global Monitoring Report for Education for All, most of the region has achieved universal primary education (UNESCO, 2009). Further, both Barbados and Trinidad and Tobago are close to achieving EFA goals as measured by the EFA Development Index (EDI). EDI is a measure of four quantifiable EFA goals: total primary net enrolment ratio (NER); the literacy rate of those aged 15 and above; the average of the gross participation indexes (GPI) for primary and secondary gross enrolment ratio (GER) and the adult literacy rate; and the survival rate to Grade 5. Each of these aspects is weighted equally to yield a ratio between 0 and 1 , where 1 represents full achievement of EFA. Barbados has an EDI of 0.943 and Trinidad and Tobago has an EDI of 0.941 (UNESCO, 2009). However, the central concern for education in the Caribbean remains that of education quality - a goal which is less quantifiable to measure.

UNESCO makes it clear that quality and access are inextricably linked and raises the concern that the education programs tend to reproduce pre-existing social inequalities. Further, education quality is viewed from a human rights approach by UNESCO as it must be relevant in order to be universal and equitable (UNESCO Santiago, 2007). Despite the achievement of access, quality education is paramount to continued progress towards improving the education systems of developing countries. Instruction remains uniform in the region, marginalizing children who may lack the cultural and social capital to participate in singular perspectives of teaching and learning (UNESCO Santiago, 2007). 
This in turn causes education to reproduce social inequalities (UNESCO Santiago, 2007). From the perspective of small states, education quality is viewed as a necessity for being functional in preparing citizens for work. In a report written for the Commonwealth Secretariat, Briguglio, Persaud and Stern (2006: iv) argue that although small states generally have highly educated populations than larger developing countries, "it is essential that they invest in and further improve the quality of their educational systems, if they are to exploit effectively the current and emerging service opportunities". The report also concludes that relative to the amount spent on education, "the quality of school graduates is often disappointing" (Briguglio, Persaud and Stern, 2006: 19). They cite the following as key reasons: "accountability, efficiency, school management, teacher training and motivation, community involvement and education culture appear to be key quality determinants" (Briguglio, Persaud and Stern, 2006: 19). Although UNESCO advocates the importance of raising quality to ensure sufficient access among other reasons listed below, there is also support for secondary education as a necessity for national development: "No country can be expected to develop into a modern and open economy without a certain proportion of its work force having completed secondary education" (UNESCO, 2000: 16). It is mostly within the context of small states and education for national development that education is posited as functional. In the majority of policy documents, including those produced by national governments themselves, education quality is viewed as being important in its own right. However, access and quality are not described as interconnected. Barbados, for example, writes the following: "The challenge for Barbadian education is therefore one of quality rather than access" (Government of Barbados, 1995: 6, italics theirs). There is the notion within education quality discourse that access, quality and equality are inextricably linked. Without access, quality cannot develop; without quality, access is restricted. Both tenets impact equality.

Expanding on the overall goal of achieving quality education for all, the Report on the International Commission on Education for the XXI Century (UNESCO 1996, cited in UNESCO Santiago, 2007) advocates the four pillars of learning related to knowledge development, training, understanding and values education. They are as follows:

- learn to know, in order to acquire a broad cultural repertory and the specific knowledge that stimulates the curiosity in order to continue learning and developing in the knowledge society; 
- learn to do, developing competencies that train people to deal with unexpected situations, work in teams, and develop themselves in different social and working contexts as well as develop enterprising capacities;

- learn to live together, fostering the understanding of and valuing others through the perception of the forms of inter-dependence and respect for the values of pluralism, mutual understanding, and peace

- learn to be, in order to know and value oneself, construct one's own identity, and act with a growing capacity for autonomy, judgment, and personal responsibility in different life situations" (UNESCO, 1996 cited in UNESCO Santiago, 2007: 29, italics theirs).

Learning to know and learning to live together are considered well developed in the curricula of Latin America and the Caribbean but learning to do and learning to be are not explicitly implemented (UNESCO Santiago, 2007). These two pillars are key, “... since it is not sufficient for students to manage information and be able to analyze and summarize it if they are not also taught to make well-founded judgments and interpretations for decision making" (UNESCO Santiago, 2007: 14). Creativity, developing diverse alternatives for problem solving and encouraging meta-cognitive processes are other related tenets which are found to be lacking (UNESCO Santiago, 2007). There is certainly room for further improvement in actualizing this framework as the delivery of these curriculum documents needs to be reinforced through mechanisms and procedures to ensure activity on the classroom level (UNESCO Santiago, 2007). Similarly, Howe (2003) in his study for the International Bureau of Education concludes there is room for more development in the area of citizenship education despite emphasis on pertinent topics such as human rights, conflict resolution, respect for self and peaceful co-existence: "There is currently a severe weakness and limitation in human, financial and teaching/learning materials resources necessary to significantly enhance the scope and quality of citizenship education programmes which are currently in place or being contemplated for implementation" (Howe, 2003: 8). Jules and Panneflek (2000) in their assessment for UNESCO on EFA in the Caribbean, concur with this view, pointing to the shortfall between the necessity for Caribbean children to develop into self-learners and the lack of academic qualifications of teachers to ensure appropriate mechanisms are in place. Equally important is the issue of assessment. UNESCO writes: "Assessment of learning should include an evaluation of environments, processes and outcomes. Learning outcomes must be well-defined in both cognitive and non-cognitive domains, and be continually assessed as an integral part of the teaching and learning process" (UNESCO, 2000: 20). Reliance on traditional modes of 
assessment will be discussed further in 6.3.2. The Caribbean Examinations Council is the regional organization responsible for creating, facilitating and executing school leaving exams.

Documents related to education quality include a large focus on teachers. UNESCO writes of their key position in transforming education and developing student values, noting that: "Teachers at all levels of the education system should be respected and adequately remunerated; have access to training and ongoing professional development and support... and be able to participate, locally and nationally, in decisions affecting their professional levels and teaching environments". (UNESCO, 2000: 20). Subsequently, in the same document, countries pledge to "offer teachers high quality academic training that is linked to research and ability to produce innovations, and that prepares them for carrying out their duties in diverse social, economic, cultural and technological contexts" (UNESCO, 2000: 40). This is particularly important in the region, less than $25 \%$ of teachers in states such as the British Virgin Islands and Trinidad and Tobago have received teaching training (UNESCO, 2008). To ensure this is achieved, UNESCO pledges an "increase in the quality of teaching and of curriculum development, and the use of more effective pedagogies - with attention to pre-service teacher training institutes, in-service training opportunities, and open and distance learning (UNESCO, 2006b: Annex 1, p13). Howe (2003) in his review for the International Bureau of Education also notes that training needs to be extended to Ministry of Education staff to ensure strong curriculum development. However, this global mandate may be difficult for small states to implement due to capacity issues. See 2.1.3 for further discussion on the impact of multilateralism.

\subsubsection{Possibilities for regionalism and 'sharing best practices'}

Both UNESCO and the Commonwealth Secretariat encourage working together as a region and 'sharing best practices' for the purpose of improving education systems. In fact, part of UNESCO's mandate is as a 'standard setter' (UNESCO, 2002: 6) and the Commonwealth Secretariat recently launched a new division devoted to sharing the experiences of education and learning. This section will outline the initiatives taken by both of these organizations in fulfilling these aims. 


\subsubsection{Regional networks}

Regional networks consist of countries in the same geographical context, defined as proximal geography or similar sizes with respect to population, space or GDP. The Caribbean states form a proximal network and are part of the Commonwealth small states network. Regional activities are intended to fulfill the following functions:

Co-ordination with all relevant networks, setting and monitoring regional/subregional targets; advocacy, policy dialogue; the promotion of partnerships and technical co-operation; the sharing of best practices, and lessons learned; monitoring and reporting for accountability; and promoting resource mobilization (UNESCO, 2000: 10)

Briguglio, Persaud and Stern (2006: 46) write in their document for the International Bureau of Education that "(e)nhanced regional cooperation is needed not only to better provide for domestic needs, but also increase engagement with a globalizing world". UNESCO supports regional networks as well as they "provide platforms for strengthening cooperation in EFA" (UNESCO, 2006b: Annex 1, p18). Such networks are welcomed by Commonwealth Heads, as they welcomed the Small States Network for Economic Development under the coordination of the Government of Malta and the World Bank (Commonwealth Secretariat, 2007). Current regional organizations such as the Caribbean Development Bank, the Caribbean Community (CARICOM), the Eastern Caribbean Central Bank and the Organization of Eastern Caribbean States show the desire for states to form collaborations within the Caribbean Sea. The networking of small states may be a necessary alliance as they share many of the same challenges such as "remoteness and insularity, susceptibility to natural disasters, limited institutional capacity, limited diversification, and a high degree of openness" as well as "a rising concerns with respect to youth unemployment, security and crime; and the HIV/AIDS pandemic" (Briguglio Persaud and Stern, 2006: iii-iv). Further, their ability to deliver all of the functions of a modern state creates the necessity to seek collaboration with other countries facing the same capacity challenges in the areas of health and disease control, higher education, secondary school examinations and foreign representation (Briguglio, Persaud and Stern, 2006). 
To this end, regional representation is a powerful force for establishing solidarity in a global arena where larger and richer countries may dominate dialogue. One area in which this is particularly acute concerns the GATS (General Agreement on Trade in Services) framework. The Commonwealth ministers have expressed "widespread concern that the inclusion of education under the WTO and GATS as a service could lead to its commodification" (Commonwealth Secretariat, 2003: 41). Through the Commonwealth Secretariat, the Heads of Governments assert the need to "affirm the paramount importance of safeguarding the values, standards and quality of education" (Commonwealth Secretariat, 2003: 41). The Protocol for the Recruitment of Commonwealth Teachers is an example of a regional agreement in which "(g)overnments of both source and recruiting countries represented by Ministers of Education and their senior officials, as well as representatives from civil society engaged in frank and open dialogue to understand and reconcile differences and arrive at a morally binding consensus" (Commonwealth Secretariat, 2004: foreword).

The potential for regionalism is strongly supported by the Caribbean Single Market and Economy initiated by CARICOM. This creates freer movement between citizens of participating states and paves the way for a deeper regional connection. Initiatives in national documents of Barbados and Trinidad and Tobago also reinforce regionalism. The report to the International Bureau of Education also recommends the following:

- Ensure that Caribbean citizens understand the ties that bind them and the common destiny they share as a people (Howe, 2003: 10)

- Ensure that citizenship education curriculum and programmes utilize readily recognizable and understood Caribbean examples, case studies, stories and scenarios and folklore to convey the ideal and lessons to be learnt though the various citizenship education programmes, exercises and initiatives (Howe, 2003: 16).

Further, Jules (2008) in his review of recent policy documents argues for a regional harmonization of education systems, recalling findings from policy studies (Miller et al., 1991, Jules et al., 2000, World Bank, 2001 cited in Jules, 2008). He argues that harmonization does not equate to uniformity but rather establishes minimum standards. Jules believes harmonization is essential as "... it will facilitate the realization of economies of scale in the provision of education; it will ensure some comparability between the education systems that would further facilitate the free movement of persons" (Jules, 2008: 
210). However, harmonization between the systems in Barbados and Trinidad, beyond the existing CXC examinations, appears elusive. Despite the lack of a sense of regionalism and Caribbean identity in the thesis fieldwork, regionalism is one of the main themes in the policy documents and may be considered as part of the 'borrowing' process. However, as illustrated in 5.1.2.1, the notion of 'sharing best practices' is not well defined or described although it appears to be supported in policy rhetoric.

\subsubsection{1 'Sharing best practices'}

With regards to education, UNESCO's key focus appears to be capacity building, information exchange and international cooperation. Although the phrase 'education borrowing' is not explicitly mentioned, some of its functions include:

...(G)athering, transferring, disseminating and sharing available information, knowledge and best practices in its fields of competence, identifying innovative solutions and testing them through pilot projects (UNESCO, 2002: 16).

Through national, regional and subregional EFA forums, it also aims to foster "cooperation and sharing of experience" (UNESCO, 2002: 18). Both the UNESCO policy documents of 2000 and 2006 reinforce this notion of 'horizontal borrowing' through the rhetoric of 'international cooperation' (UNESCO, 2000: 42) which is not recognized as problematic. There is also the implication that there is some pressure for countries to cooperate in this practice, as one of the artion points contains a call for governments and societies "to make every effort to co-operate in the development of policies, strategies and action plans that will give a new thrust to polices that guarantee to all people the right of access to basic quality education and to reap its benefits" (UNESCO, 2000: 42). The complexities around 'cooperation' are neglected and simply framed as a "(c)onvergence of strategies: sharing what works and what has not worked in a spirit of mutual learning and concern to adopt and disseminate good practice" (UNESCO, 2006b: Annex 1, p11). Further, UNESCO is self-positioned as the nucleus of directives. It calls itself "a laboratory of ideas" (UNESCO, 2002: 24). It sees itself as providing "intellectual support to policy-makers and practitioners in the identification of priorities, best practices and innovations with a view to buttressing education strategies and policy reforms" (UNESCO, 2002: 24). Through "innovation, effective intervention and wise practices", UNESCO seeks "to ensure that the 
objectives, principles and priorities it promotes are followed suit by other multi- and bilateral programmes and that projects are implemented" (UNESCO, 2002: 6). The policy agenda dictated by UNESCO is of great interest as it commands much power over states and the policy discourse shows the level of pride it takes in this position.

While the geographical scope of UNESCO is much larger than the Commonwealth Secretariat, Commonwealth networks are perhaps more closely knit for the Caribbean as many of the island states belong to the Secretariat and are involved in the work on small states. Education falls under the jurisdiction of the Social Transformation Programmes Division (STPD). Among other aims, it will "facilitate the sharing of knowledge with Ministries of Education to keep them up to date on latest issues, and trends, related to MDGs" in order to "better promote and publicize innovative examples of educational practices" (Commonwealth Secretariat, 2003: 25). Further, by sharing best practices, it hopes to "stimulate faster and wider replication across the Commonwealth" (Commonwealth Secretariat, 2003: 26). The sharing of such practices is ongoing through the publications of documents which describe examples of programmes and innovative projects for replication. Past topics include Early Childhood Education, Education in Difficult Circumstances and HIV/AIDS (see Burke-Ramsay and Degazon-Johnson, 2005; Williams, 2006 on behalf of the Commonwealth Secretariat).

To develop the initiative of sharing best practices, the Centre for Commonwealth Education was established for primary and secondary education as well as the training of teachers through disseminating expertise, research and consultancy projects: "It will assist in the delivery of knowledge so as to deliver best practice in individual countries... CI/CEE will position itself as a key player as a catalyst for action" (Commonwealth Secretariat, 2003: 31). This follows the recommendations made at the same 2003 meeting in which Heads of Government recommended that accessible media should be established by the Commonwealth to facilitate networking and discussions on knowledge of "“what works" and 'good practice"" (single quotations theirs, Commonwealth Secretariat, 2003: 16). Further development of the World Bank and Commonwealth Secretariat websites on data and reports is supported by Briguglio, Persaud and Stern (2006) in his report to the Commonwealth on small states as many of the lessons are not available to other small states. He asserts that small states are the best source of expertise as some countries have 
developed sophisticated policies and regulations which meet the needs of small states (Briguglio, Persaud and Stern, 2006). Examples of successful policies are listed from various sectors:

Samoa has successfully managed to reduce their cost of air transportation through innovative selection of foreign carriers, the Maldives has developed a vibrant tourism sector from meager beginnings... and Singapore's experience in 'bonding' emigrants to recover the cost of higher education is potentially useful to other small states seeking to enhance their human resource base (Briguglio, Persaud and Stern, 2006: 42).

While the notion of 'borrowing' is not always universally defined (see Chapter 1), the problematic nature of 'sharing best practices' is addressed minimally within the Commonwealth policy documents. One document notes that during the Heads of Government meeting, "( $(t)$ he potential value of sharing knowledge and understanding of best practice raised questions (Commonwealth Secretariat, 2003: 11). The parameters and purposes of 'sharing' are discussed and described with limited clarity in the publication on best practices of education in difficult circumstances (Williams, 2006). On the one hand, it is stated that the report is primarily intended for Commonwealth African countries, but also notes "in the same way as the burgeoning literature from all over the world on the role of education in emergencies, conflict situations and difficult circumstances contains many pointers from which Africa can learn". The global implications for the document perhaps arise from the purpose of the publication to provoke discussion. It also "aims to help policy-makers and others reach a better understanding of the complex issues at stake and of the options which face them, and to share best practices in addressing the serious situations arising from conflict, emergencies and difficult circumstances" (Commonwealth Secretariat, 2006: 10). The process of 'sharing best practices' appears to be catalyst with a large global mandate in this context. 'Horizontal borrowing' is not viewed critically but 'best practices' appear to have universal relevancy.

Perhaps the clearest definition of a 'best practice' can be found in the pamphlet for the Commonwealth Good Practice Awards: “An Education Good Practice is a programme, project, policy strategy or significant intervention which has made a positive difference to the status or condition of primary school children, their teachers or the education system of a country in respect of one or more of the Six Action Areas" (Commonwealth Secretariat, 
2005: 2). The six action areas refer to those of the Commonwealth Secretariat's Social Transformation Programmes Division with respect to education. The criteria for the Good Practice Awards include relevance, as demonstrated through "a socio-culturally sensitive and economically appropriate response to the context and challenge of education delivery in a specific country" (Commonwealth Secretariat, 2005: 3); measurable impact and effect, as projected to have a positive, long term effect; efficiency and effectiveness through demonstrated cost effectiveness in resource use; community participation and contribution, whereby the success of the practice is enriched through participation, ownership or contribution of the civil society and finally, replication, defined as "(g)iven similar conditions and circumstances, the Good Practice has the potential to be replicated in the Education systems of other Commonwealth countries" (Commonwealth Secretariat, 2005: 4).

The last criterion of replicability is particularly interesting for the purpose of this $\mathrm{Ph} . \mathrm{D}$ study as it outlines one of the key intentions of 'sharing best practices'. The Commonwealth is clear on the direction that 'best practices' should take, stating: “... quality in education within existing systems should be identified and recognized, with a view to replicating it on a regional or global basis" (Commonwealth Secretariat, 2005: 30). This idea of replication is not further discussed in other Commonwealth Secretariat documents or any of the regional documents. The notion of 'sharing best practices' appears limited to examples of successful policies or programmes (such as those listed above by Briguglio, Persaud and Stern, 2006) in which other countries may benefit from reflection or discussion, or as information gathering. UNESCO uses the phrases "adopt and disseminate good practice" (UNESCO, 2006b: Annex 1, p11) and on a more subtle but powerful level, provides support to policy-makers by identifying best practices “...with a view to buttressing education strategies..." (UNESCO, 2002: 24). The phrases used to describe the action taken on 'best practices' by UNESCO and the Commonwealth Secretariat indicates implementation through adoption and buttressing strategies.

While replication appears to be an explicit and invasive concept, two other phrases used in relation to dialogue are 'peer review' and 'South-South cooperation'. Peer review involves examining the political, institutional and implementation frameworks of EFA. As the practice necessitates willing and engaged participating countries, there is also the 
expectation that peer review will result in change as this process includes "...commitment to use the results of peer review to re-orientate polices and improve practices" (UNESCO, 2006b: Annex 1, p16). South-South cooperation has a broader focus and "offers opportunities for exchange and mutual learning through a range of fora and mechanisms" (UNESCO, 2006b: Annex 1, p18). UNESCO believes that cooperation among developing nations of the South benefits from similar challenges, opportunities, constraints and context (UNESCO, 2006b: Annex 1). Through South-South partnerships across the wide range of developing country needs, "beginning with those who are most in need", there will be support for learning best practices, strengthening institutions such as financing developing capacity, and technological innovations (UNESCO, 2006b: Annex 1). Finally, "lessons from existing experience of South-South cooperation will inform specific measures in promoting collaboration to achieve the EFA goals" (UNESCO, 2006b: Annex 1, p 18). This process is not necessarily organic. Mid-2007 was set as benchmark for EFA conveners to make specific measures to strengthen and bring together existing links of South-South cooperation (UNESCO, 2006b: Annex 1). The 2006 document states: "a more deliberate and expanded approach will turn this into specific input and investment, in part supported by donor countries" (UNESCO, 2006b: Annex 1, p18).

As illustrated in the next section, one of the key themes in these policy documents is the agenda shaped by multilaterals to ensure a specific perspective on 'development'. Countries are left to their own autonomy with regards to contextualized implementation. Goals, however, are set forth by the agencies and insular views are discouraged.

\subsubsection{Local context, global agenda, outward view}

The policy documents reviewed promote a three-pronged message to nation states that show respect for the local context and thus national autonomy, but at the same time are direct about following a global agenda and limiting insularity. Through analysis of the documents it appears that despite the presence of a global agenda, policies appear to assert protection against the threats of globalization. The documents reviewed attempt to appreciate local context and respect for diversity among nations by spending time ensuring nation states that policies can be adaptable. By implementing global policies, nation states may be viewed as adopting an outward stance. This may be seen as a necessary reaction to 
a globalized world to bring countries out from the periphery of existence. International policy documents may communicate that allegiances are key to survival in a seemingly neoliberal global world. Advocacy for a local approach and adaptation policy is seen in the regional framework for action of EFA in the Americas. The Dakar document (UNESCO, 2000) recognizes the gap between the heterogeneous conditions of the countries and the homogenous strategies for reaching objectives: "This means that countries must convert regional commitments into national goals, according to their own capabilities" (UNESCO, 2000: 36). In a later document, it is recommended that EFA plans are embedded within an overall national strategy for education and poverty reduction, in which "(m)ember states must be the prime movers..." (UNESCO, 2002: 18). The focus on the country context shows that the policies must be adapted but remain within the parameters of reaching the same objectives. Autonomy is limited as guidance is provided by UNESCO. The focus on the 'local' stems from a reactionary defense against globalization: "UNESCO can also help reinforce a growing trend towards localization and empowerment at local levels... This will enable people to operate on a platform of their own when dealing with globalization (UNESCO, 2002: 5)

In the same document, UNESCO also positions itself as the following:

A standard setter: ... fostering multidisciplinary exchange and mutual understanding working - where possible and desirable - towards universal agreements on these issues, benchmarking targets and mobilizing international opinion (UNESCO, 2002: 6)

Despite some respect for nation-states and their heterogeneous contexts, there is the understanding that the agendas are global. The movement towards the agreed upon frameworks stems from UNESCO's function to benchmark targets and mobilize international views. The same document also states that one of the functions during the period 2002-2007 is to develop "universal principles and norms based on shared values. In order to meet emerging challenges in education, science, culture and communication to protect and strengthen the "common public good"" (UNESCO, 2002: 5). Although 'shared values' and 'common public good' may be aspects decided by member states through consensus building practices, it is not possible to include voices that are marginalized by government elites who are represented at these meetings. The global agenda extends also beyond values as there are key directions in which UNESCO aims to take in the area of 
education, such as system renewal of secondary education, promotion of interdisciplinary approaches, and technical and vocational education (UNESCO, 2002). While these reforms may be beneficial to students, they may not be appropriate priorities for the countries with regards to budgeting and capacity constraints. The agenda is global in nature and has homogenous objectives. Similarly, the Commonwealth operates on such principles. There is the promotion of values such as tolerance, combating injustice, peace, progress in the modern world, understanding among nations and eliminating discrimination (Commonwealth Secretariat, 1971). One of the Commonwealth's education goals are in six action areas including "Using Distance Learning to Overcome Barriers" (capitals theirs, Commonwealth Secretariat, 2003). While this may be a successful, innovative approach, it is nevertheless a global directive that may allow for local adaptation. Yet the direction of global agendas relative to local approach appears to be from the top down rather than the bottom up in the policy structures of UNESCO, the Commonwealth Secretariat and their member states. However, as evidenced in 2.1.3, the Commonwealth Secretariat is praised by several academics on its work with small states.

Despite encouraging adaptation at the local level, the necessity to participate in a global world is illustrated in the values and directives by multilaterals as well as the outward view that countries are required to pursue. This is particularly pertinent for small states: "Heads of Government encouraged small states to continue to implement outward-orientated development strategies that would assist them to overcome their vulnerabilities" (Commonwealth Secretariat, 2007: 11-12). While this may be a necessary perspective to adopt, this is problematic for the Caribbean Single Market and Economy (CSME) initiative by CARICOM. Briguglio, Persaud and Stern (2006: 17) for the Commonwealth Secretariat write the following on the CSME:

This is welcome progress but, because of limited opportunities even in a fully integrated regional market, these efforts should be seen as a step towards global market integration. It is important they do not detract from seeking opportunities in world markets.

Insularity is not promoted in the context of local adaptation and global values but rather small states are directed towards regional cooperation (see section 5.1.2) and creating a "comparative and competitive advantage in the service sectors, including...health, education..." (Briguglio, Persaud and Stern, 2006: iv). The message is thus clear that a 
strong outward view will assist small states in progression towards 'development' along with following a global agenda and values and ensuring a local context. Thus, one key finding from the policy review is as follows: the dissemination of policies is a stronger explanation of similarities between the two countries and will continue to dictate national policies rather than any interest in cross national attraction.

\subsection{National Documents: Barbados}

\subsubsection{Self-modeling}

Policy documents in Barbados show a great deal of national pride. While there are some nationalistic aspects in the documents of Trinidad and Tobago, there is a clear difference between the approaches taken by the two countries. In the 1995 White Paper, Barbados articulates the success of its social, economic and political growth through a focus on human resource development (Government of Barbados, 1995: i):

Barbados, like other great societies, has always placed a premium on the education of its people, whether it was for performing basic tasks well or for higher pursuits... That this philosophy has served this country well can be clearly seen by our position as the Number One developing nation and as twentieth among all sovereign states.

There is further description of this success in a publication produced to describe the history of education in Barbados, due to "much interest in the education system of Barbados, locally, regionally and internationally" (Government of Barbados, 2000a: 3). The current Chief Education Officer writes of the system:

Our success as a developing country is demonstrated in the fact that during the 1970 s and 1980s Barbados boasted a literacy rate of over $95 \%$. The factors responsible for this have been: - a) the development of a comprehensive network of primary schools during the twentieth century; b) after the 1950s greater access to post-primary education, resulting in a secondary place for every child in the 1990s; c) a professional, trained cadre of teachers; d) at least $18 \%$ or more of Government annual budget earmarked for the education sector (Government of Barbados, 2000a: $3)$.

In another document, the Government also demonstrates its successful performance by reminding readers of its $99.7 \%$ literacy rate, life expectancy of 74.9 years, $100 \%$ access to safe drinking water, comprehensive health and social security system and low levels of 
poverty and crime (Government of Barbados, 2007). Barbados points out its recognition on an international level, listing achievements such as receiving the $30^{\text {th }}$ rank in the UNDP Human Development Index, $31^{\text {st }}$ in the Global Competitiveness Index, the least corrupt Caribbean island by Transparency International (Government of Barbados, 2007: 11).

The Government of Barbados takes this a step further by aiming to market itself as 'the Barbados model'. It begins by reminding the reader that "Barbados is recognized internationally, as United Nations' Secretary General Kofi Annan observed as 'punching above its weight"' (Government of Barbados, 2007: 39). In this nation building document, which charts out the direction for the country until 2025, one of the goals is to ensure that the country is branded and recognized internationally through branding. It implies that this is already happening on some level, stating that it is "celebrated domestically as the "Bajan Way' and recognized regionally and internationally as the 'Barbados Model' (Government of Barbados, 2007: 39). This is an interesting approach that Barbados has taken as it shows the pride of the nation and the rhetoric seems to imply that it is a leader in the area of development from which other countries may learn. The implication is that the country needs now to be recognized through marketing, as a "duty to show the world how a small country may be successful yet retain its identity" (Government of Barbados, 2007: 39). Perhaps this is a necessary step to develop a niche within the arena of globalization and to ensure existence of its identity as a successful small state. The value placed on human resource development can be seen in the aim of the model to "establish Barbadian leaders as intellectual pioneers" (Government of Barbados, 2007: 39).

The government of Barbados exhibits its pride in the education system through setting high benchmarks. Below are some examples of the ambitious targets:

- Increase access to, and enrolment in, tertiary education using appropriate modalities such as distance and e-learning to facilitate the achievement of a graduate in every Barbadian household

- $\quad 75 \%$ certification of all students leaving secondary school by 2012 (Government of Barbados, 2007: 59)

Further, the government aims to obtain "universal recognition of the Barbados Brand by 2025 " and to become the "number one nation of peace, security, political and social stability in the world" (Government of Barbados, 2007: 106). These aims form a part of a 
larger framework for the nation's growth and development, in which curriculum reform plays a large part as illustrated in the next section.

\subsubsection{Curriculum Change: guiding principles}

Following on the premise of human resource development, one of the key aims of the education system is to create a workforce: “...every child should have educational opportunities of a kind which would allow him [sic] to make the most of his abilities and to contribute to the social and economic growth of the country" (Government of Barbados, 2000b: 31). The curriculum in Barbados is infused with several other key principles, one of which is nation building. The national goals outlined in the above section underpin two of the key objectives preparing citizens with the "responsibility of nation building", "revaluing the role of education in the sphere of national development" and helping the population "develop positive attitudes, values and beliefs to enhance the individual and his/her position in the family, community and nation (Government of Barbados, 1995: 3). Curriculum reform is thus described by the Government of Barbados as the "sine qua non of nation building" (Government of Barbados, 2000b: 51). It is viewed as a way of effecting social, economic and political changes to develop its people (Government of Barbados 2000b). At the same time, the government sees the curriculum as dynamic as it "seeks to respond to socio-economic forces in the society, and to new findings in the field of education" (Government of Barbados, 2000b: 51). It is clear that the curriculum holds high expectations for the nations, and the following reforms both currently in progress and forthcoming shows the intentions of the government. While the objectives of ensuring citizens imbued with responsibility of nation building, revaluing the role of education and facilitating the development of positive attitudes is not explicitly clear in the reforms, teacher training, certification and new modes of instruction are viewed as key points.

While curriculum change is a seen as a nation building exercise, it also has some regional focus. These two tenets are held loosely together and can be seen in specific activities as recommended in curriculum documents although this relationship between the national and regional are not discussed in any of the policy documents. By focusing on regionalism as a guiding principle, this meets the desire for the government of Barbados to be "A society that is an integral part of the Caribbean family of nations" (Government of Barbados, 2007: 
24). The 2000 curriculum document describes necessary skills for the Caribbean citizen of the $21^{\text {st }}$ century, some of which are listed below:

- Have an informed respect for cultural heritage

- Demonstrate multiple literacies, independent and critical thinking, question the beliefs and practices of past and present and bring this to bear on the innovative application of science and technology to problem solving

- Value and display the creative imagination in its various manifestations and nurture its development in the economic and entrepreneurial spheres in all other areas of life (Government of Barbados, 2000b: 4)

These skills did not appear to be critically important in classroom observations, although some respondents paid some attention to these aims in their responses. Through the curriculum documents, it is possible to see how skills related to Caribbean citizenry are met through suggested curriculum activities and assessment exercises. These skills are consistent with the four pillars of UNESCO listed in Section 2.1 as well as the key skills that Barbadian students should have at the end of secondary school such as accessing and analyzing information, developing positive relationships, becoming aware of career opportunities, and fostering positive attitudes (Government of Barbados, 1995: 45-46). Both the new certification and teaching methodologies attempt to recognize and foster these skills. See 6.3 for respondent perspectives of this new curriculum.

\subsubsection{New certification, same problems?}

The most recognizable school leaving certificates are those under the jurisdiction of the Caribbean Examinations Council. While this caters for the upper 25\% who are academically able (Government of Barbados, 1995), many children leave without "independent indicators of their achievement" (Government of Barbados, 1995: 80). The other less recognized options for students are the CXC Basic Examinations or the Barbados Secondary School Examination, written by "some who could not pass CXC examinations" (Government of Barbados, 1995: 80). However, both the CXC Basic Examinations and BSSE are not readily accepted for the purposes of further training or the job market (Government of Barbados, 1995). The remedy proposed by the 1995 document is a national secondary school certificate to measure the skills and competencies of students. Two key reasons for this change include the disparity between to the large investment of resources placed in education and the vast amount of children disadvantaged leaving school without a 
measure of their academic achievements (Government of Barbados, 1995). The new certificate will show that the student has completed an approved program with an acceptable level of competency. The implementation of the national certificate indicates that it will mark a paradigm shift in the way in which education tends to advantage the academic. It will attempt to “...correct the present untenable situation where about $60 \%$ of the graduates of secondary schools complete secondary education without having an appropriate measure of the competencies attained" (Government of Barbados, 1995: 11).

The government of Barbados also recognizes that the national certificate will have its limitations. With regards to the Barbados National Diploma of Secondary Education, the government writes:

...(T)he BNDSE in and of itself will be sufficient to constitute a final high school qualification reflecting the necessary skills and competencies for entry into certain forms of post-secondary training. Students who want to fast track their access to university education soon after leaving school are recommended to continue their pursuit of CXC general proficiency (Government of Barbados, 2000b: 36)

At the same time, any curriculum change may need to ensure that students are able to leave school with either CXC examinations or the new national certificate. In the 2000 policy introducing the new curriculum, it is written that "(o)ur curriculum will be developed so that from the time students enter secondary school they will begin to acquire the prerequisite knowledge and skills required for CXC examinations" (Government of Barbados, 2000b: 36).

It may be argued that the provision of a new certificate to replace the CXC Basic or BSSE will suffer from the deeper problems stemming from those who may be perceived to have lesser 'academic' ability. The division between those who are able to secure places in reputable secondary schools begins with the secondary school entrance exam, also known as the $11+$. In the past, students whose scores fell below the range for secondary school places were sent to senior and composite schools, where "(p)upils attending these schools are often treated like primary school pupils, even though they are similar in size and maturity to their peers in secondary schools" (Government of Barbados, 1995: 75). The new curriculum aims to place such students into a senior school where they will receive remedial and technical programmes on education and life skills. While certification may 
aim to remedy this problem, it may not be able to solve the larger problems of schooling by ability. However, an overhaul of the ways in which teaching and learning may work only in tandem with certification change.

The curriculum document of 2000 also includes a chart comparing traditional curriculum with the new revised curriculum. The crux of the change, according to the Ministry of Education is as follows: "In other words, it is the child's interaction with the curriculum rather than the curriculum dictating the pace of learning that will be the focus of attention" (Government of Barbados, 2000b: 13, bold letters theirs). Teaching methodologies will need to be changed to view students as active participants "who are able to formulate thoughts independently of each other" (Government of Barbados, 1995: 49). Further, teachers must change the way in which they interact with pupils and their view towards learning: "( $\mathrm{t}$ )he teacher must now become a facilitator of pupils' learning and thus organize activities which will optimize this process (Government of Barbados, 1995: 49). As a result of changes in instructional methodology, there will be a movement away from traditional modes of assessment which have consisted of norm-referenced testing: "more authentic assessments which are based on a combination of both process and product methods (orals, interviews, peer and self-assessment, performance assessment, exhibitions, portfolios, project-based work, written achievement tests and norm-referenced tests)" (Government of Barbados, 2000b: 11). Further the student-centred focus will lead to the movement away from automatic promotion "towards developmentally appropriate learning levels; children will be promoted in the main only after they have demonstrated satisfactory performance in their subject disciplines" (Government of Barbados, 2000b: 13, bold and underlined letters theirs). These aims are not apparent in fieldwork data and are not mentioned in subsequent policy documents. The perpetuation of rote teaching methods may be due to mixed messages. The government notes that constructivist philosophy should not replace current best practices; instead teaching methods should be infused with the constructivist approach (Government of Barbados, 2000b). This may lead to justification for perpetuating traditional teaching practices which are considered effective by teachers. See 6.4 .1 for more discussion. 


\subsection{National Documents: Trinidad and Tobago}

One of the major undertakings by the Trinidad and Tobago government continues to be the Secondary Education Modernization Plan (SEMP):

The goal of the SEMP is to strengthen the nation's productivity and competitiveness by ensuring that young citizens from all backgrounds are prepared, through a modern education system, to participate in, and contribute to, the development of a technologically driven and skills-based economy (Government of Trinidad and Tobago, 2002a: 12).

SEMP encompasses the following objectives of reforming and expanding the secondary system to ensure five years of quality education for Trinibagonians, creating a dynamic and relevant curriculum and developing teaching technologies that will ensure graduates will be able to adapt with advances and globalization (Government of Trinidad and Tobago, 2004). Modernizing the secondary education system appears to be of strong urgency as there are insufficient places at state secondary schools and places at private schools have been purchased in the past for 7,766 students to sustain commitment to universal secondary education (Government of Trinidad and Tobago, 2004: 25). In addition, there are not enough places at ' $A$ ' level (Government of Trinidad and Tobago, 2007). By constructing new sixth form colleges, upgrading some secondary schools and purchasing places in the private sector, the present need should be met and there is potential to reach the target of $60 \%$ participation at ' $A$ ' level (Government of Trinidad and Tobago, 2007). There is certainly the need to ensure that secondary and further education opportunities are readily available for students and provision is sustainable by the Ministry of Education.

SEMP may also be seen as one aspect of the Government's plan to reach developed nation status by 2020 in an overall national document titled Vision2020. Similarly, Barbados aims to reach developed nation status by 2025 and both of these nation building documents are similar in their aims to ensure domestic development through education. In particular, a multisectoral approach is taken by the Ministry of Education as it works with other ministries such as "...Social Development, Health, Youth and Gender Affairs and National Security, to address specific needs of students" (Government of Trinidad and Tobago, 2004: 6). In this section, documents will be discussed relative to SEMP and Vision2020. 


\subsubsection{Viewing itself: a critical but ambitious approach}

While Barbados asserts itself as a model through stating its achievements and plans to market itself as the 'Bajan Model', the Government of Trinidad and Tobago takes an opposite approach. In policy documents, it points out some of the past failures and challenges in the current education system. In the 1993 document, there is recognition that education has not produced enough quality graduates nor served the needs of children:

Our learning systems, over the last two decades have not generated the expected quality of graduates in the proportions which our levels of educational expenditure per pupil have led us to hope for, and it is generally recognized that they do not cater as efficiently as they might for those who are 'educationally at risk' broadly speaking, as well as more particular for those individuals in our community with special needs" (Government of Trinidad and Tobago, 1993a: Sec.1, p3)

Over the period $2000-2005,51 \%$ of students attained five or more subjects (Government of Trinidad and Tobago, 2007: 25). In the 2007 document, the government outlines the need to address the problems of illiteracy at the secondary school level, "ambivalence to scholastic effort, lack of motivation and ambition", disruptive behaviour and violence in schools (Government of Trinidad and Tobago, 2007: 9). The new National Curriculum document also identifies "deficiencies" which include

...(A)n unacceptably low level of academic achievement, unsatisfactory personal and social development outcomes; and curricular arrangements whose major outcomes were linked to the attainment of a minimum of five General passes in the Caribbean Examination Council (CXC) examination (Government of Trinidad and Tobago, 2002a: 1).

Conversely, the government of Trinidad and Tobago asserts the achievement of the system as a means of reducing reproduction of social inequalities: “...the education system in this country has been the channel through which the working class has been able to achieve social mobility, an achievement that is now enjoyed by the children and grandchildren of our forefathers" (Government of Trinidad and Tobago, 2004: 32). This may be a result of the efforts made to 'deshift' some of the less reputable state secondary schools to ensure that children attended classes throughout the day and thus reduce the stigma attached to shift structure schools. This initiative is ongoing and is mentioned in both the 1993 and 2002 documents. Despite appearing critical, there is the acknowledgement that education must change in order to prevent "further deterioration in [the] levels of learning 
achievement" (Government of Trinidad and Tobago, 1993a: Sec.1, p4). The policies discussed are ambitious and show a commitment to the sector. One of the key aims is to “...broaden access and improve quality simultaneously in accordance with social demand (Government of Trinidad and Tobago, 1993a: Sec.1, p4). Education standards are to be globally competitive and the curriculum will undergo significant changes to ensure mastery of academic skills, critical thinking and social skills through new teaching methodologies and testing and evaluation (Government of Trinidad and Tobago, 2007). To this end, a process-oriented approach is emphasized to encourage students"...to develop enquiring minds and question existing paradigms and the very assumptions on which they are based" (Government of Trinidad and Tobago, 2007: 7). Further, the document asserts that from early childhood education, an atmosphere of creativity, technical learning and entrepreneurship needs to be fostered to provide children with different ways of learning (Government of Trinidad and Tobago, 2007). These listed aims are not consistent with classrooms observed in the thesis fieldwork.

Vision2020 sets out an ambitious plan and charts the future of the nation until developed nation status in 2020 . There are four main goals, all of which are interrelated to innovation and human resource development. Goal 2 directly involves education: "Trinidad and Tobago will have a seamless, self-renewing, high quality education system" (Government of Trinidad and Tobago, 2007: 2). Vision2020 includes the following benchmarks: $60 \%$ of students leaving with full certificates, $45 \%$ of all primary schools and $80 \%$ of all secondary schools equipped with one Guidance Officer, Special Needs Teacher and Social Worker (Government of Trinidad and Tobago, 2007: 35). While both of these goals are ambitious, the capacity for the education system to provide specialist teachers trained in the area of guidance, special needs and social work may lead to a significant strain on current training programmes. Similarly, the four year plan of 2002-2006 contains goals which require much movement within both policy and necessitate leadership and training on behalf of those leading the initiatives. The 2002-2006 plan includes Education for All goals as such as accessibility and delivering quality education, as well as policy development and alignment of education strategy with national development objectives (Government of Trinidad and Tobago, 2004: Sec. Strategic Plan 2002-2006). Key qualitative priorities are also listed such as reviewing the curriculum for teachers' college and setting up a new vision for teaching training, building capacity for continuous assessment, "complete transformation" 
of the early childhood education system and strengthening student support services (Government of Trinidad and Tobago, 2004: Sec. Strategic Plan 2002-2006, p17). Fieldwork data shows little evidence of the achievement of these goals, with the exception of some indication of building capacity for continuous assessment and teacher training. See 6.2 for respondent perspectives.

\subsubsection{Education for development}

Education is seen as "...fundamental to the overall development of Trinidad and Tobago" (Government of Trinidad and Tobago, 2002a: 32). The importance of the curriculum for instilling national values must not be underestimated. The alignment of curriculum reform to national development is "...imperative for the creation of people who respond to the rapidly changing social and economic environment (Government of Trinidad and Tobago, 2007: 24). New curricula which “...go well beyond pedagogy and take account of instilling values and attitudes to create responsible citizens will be continuously developed" (Government of Trinidad and Tobago, 2007: 28). Further, the government of Trinidad and Tobago asserts the need for education to be focused on building human resources for the purpose of national development. Changes to the teaching paradigm “...must be complemented by efforts to instill a sense of national pride to all our citizens and an understanding and appreciate for what is uniquely ours" (Government of Trinidad and Tobago, 2007: 8).

One of the main reasons for positing education as a key aim for development stems from the smallness of scale. The government recognizes that the population in Trinidad and Tobago will most likely remain stable for the next 14 years and thus increasing productivity is necessary to meet growth targets (Government of Trinidad and Tobago, 2007). Thus heavily subsidized, universal education to age 16 “.... is the greatest safeguard of the freedom of our people and is the best guarantee of their social, political and economic wellbeing at this stage in our development" (Government of Trinidad and Tobago, 2002a: 3). Education is essential to participate in the "new production paradigm, which will replace the demand for qualification with the demand for skills" (Government of Trinidad and Tobago, 2007: 4). Individuals with secondary education who can multi-task and are flexible will receive the fastest growing and paid jobs as they can adapt to changing environments 
(Government of Trinidad and Tobago, 2007: 4). Globalization is also a key concern particularly for the growth of small states. Survival "in a pluralistic, global village" requires competencies of higher-order literacy, problem solving, self confidence and social skills associated with action (Government of Trinidad and Tobago, 1993a: Sec.3, p9). Innovation in its citizenry is also seen as pivotal (Government of Trinidad and Tobago, 2007).

\subsubsection{A holistic approach: Aims of the NCSE}

As the school is viewed as "a microcosm of society" (Government of Trinidad and Tobago, 2004: 7), it is imperative that the needs of children are addressed within the sector. Beyond functional purposes of education to train up generations of workers to sustain the growth of the country, one of the central purposes of the curriculum is to provide "sound and accessible education" as this is "...central for the achievement of social equity" (Government of Trinidad and Tobago, 1993a: Sec.1, p3). One of the philosophical underpinnings of the 1993 white paper includes the conviction that "...Trinidad and Tobago must endeavour to develop a spiritually, morally, physically, intellectually and emotionally sound individual" (Government of Trinidad and Tobago, 1993b: 2). This is supported by the global policies related to Education for All, which advocates "school management through curriculum interventions" that target social skills, character building, survival skills and conflict resolution (Jules and Panneflek, 2000: 39). Further, these aims are actualized in the new curriculum document.

The National Certificate of Secondary Education (NCSE) aims to "address the deficiencies identified in the system" which include

...(T)he absence of a common core curriculum in all secondary schools, fragmentation of information and skills provided to students, a lack of connection to the real world and a wide variation in the teaching time accorded to various subjects from school to school (Government of Trinidad and Tobago, 2002b: Sec. Note to Teachers, p.iii).

Shaping the curriculum are four tenets: philosophy and nature of knowledge; society and culture; the learner and learning theories (Government of Trinidad and Tobago, 2002b) in order to construct the development of a moral, spiritual, intellectual and emotional student (Government of Trinidad and Tobago, 2002b: Sec. Note to Teachers, p.iii). Through the 
adoption of more child-centred approaches to teaching and learning and providing opportunities for holistic development, the new curriculum aims to achieve six key learning outcomes which the government of Trinidad and Tobago claims to be universally accepted (Government of Trinidad and Tobago, 2002b). These six areas are as follows: aesthetic expression, citizenship, communication, personal development, problem solving and technical competence (Government of Trinidad and Tobago, 2002a: 6). These six areas will be emphasized in the eight core curriculum areas of English, Science, Spanish, Social Studies, Mathematics, Physical Education, Technology Education, and Visual and Performing Arts in forms 1-3 (Government of Trinidad and Tobago 2002b). Students are permitted to select subjects in forms 4-6, most likely due to their aspirations to complete CXC exams. In all subject areas, critical thinking should be infused as well as special emphasis on technology education (Government of Trinidad and Tobago, 2007). This probably follows the government's national directives on innovation and human resource development. While one of the main purposes for the NCSE is to provide national assessment with an intention of improving the system of education, it is also certification for students in academic, vocational and aesthetic education (Government of Trinidad and Tobago, 2007).

The main emphasis of the new curriculum appears to be the core academic subjects and concurrently the promotion of personal and social development and ensuring a technological focus (Government of Trinidad and Tobago, 1993a). The shared focus of academic, personal and social development and technology may stem from the "learnercentred design" of the curriculum as it is "...based on 'man-centred' [sic] philosophical assumptions employing constructivist theory" in which the major orientation is selfactualization (Government of Trinidad and Tobago, 2002a: 11). By providing "personally satisfying experiences for each student", the student is able to move from one level to the next through activities which expand to allow for new insights and approaches to integrating new knowledge (Government of Trinidad and Tobago, 2002a: 11). This is certainly a large mandate for a curriculum which replaces traditional modes of teaching and assessment. Impetus for the paradigm shift in the curriculum intentions may have stemmed from interest in reform elsewhere, in particular through the involvement of the international consultant from Nova Scotia, Canada who guided the design and development of the curriculum. Influence from other countries is discussed further in 6.5 and 7.2.3. 


\subsubsection{Building a workforce of teachers}

Delivery of the new curriculum certainly requires the capacity development of teachers. Training the workforce has been a key aim for the past decade and continues to occupy themes in policy reform documents. The 1993 document indicates a need to demonstrate "improvement of teacher competencies through pre-service and in-service programmes of training" (Government of Trinidad and Tobago, 1993a: Sec.3, p11). In fact, it set out to achieve:

...(T)he goal of a fully trained teaching service at the early childhood, primary, secondary levels with policies for recruitment, promotion and performance appraisal and remuneration which would ensure adequate development and maximum utilization of the skills and abilities of such a teacher corps (Government of Trinidad and Tobago, 1993b: 8).

This has not yet been realized. The current programme in place for teacher training for graduates with first degrees (amounting to $5 \%$ per school per year) consists of a mandatory 60 hour programme introducing "relevant concepts and practice" (Government of Trinidad and Tobago, 2004: 39). In 1993, 40\% of teachers did not hold degrees (Government of Trinidad and Tobago, 1993b). The government instead aspires to transform the system of teacher education by reviewing the curriculum of teachers' colleges and setting a new vision in teacher training (Government of Trinidad and Tobago, 2002a). In addition, the process of recruitment will be reviewed to build a professional service (Government of Trinidad and Tobago, 2002a). Although this has been benchmarked for Dec 2003, the change was not apparent in the interviews. The 2007 document states that a working group recommended the formation of a Bachelor of Education pre-service programme which subsequently began in September 2006 (Government of Trinidad and Tobago, 2007). This course is provided by the University of Trinidad and Tobago (UTT website). The government also prioritizes "(r)evision of the present system of assigning teachers to entrant classes" (Government of Trinidad and Tobago, 2005: 78). Respondent perspectives on the current state of the Trinibagonian teaching force is discussed in 6.2.3. 


\subsection{Analysis of Mathematics Curriculum Documents}

This section is based on the two most recent curriculum documents of Barbados and Trinidad. Although the Barbados government is piloting a new national curriculum, this has not yet been fully developed. The only available document was a syllabus created by one of the schools piloted showing the different aspects of mathematical knowledge teachers were asked to cover in the new curriculum. The values of the new curriculum were not made explicit. Thus, the analysis below pertains to the 2001 curriculum of Barbados and the 2002 national curriculum of Trinidad and Tobago.

\subsubsection{Barbados}

\subsubsection{Vague teaching directions}

One of the key aims of the secondary school Mathematics curriculum is to ensure that children "face the challenges of the twenty-first century with confidence" (Government of Barbados, 2001: iii). As Mathematics is seen as encouraging local thinking and problemsolving, it is described as providing a platform for the development of analytical skills and critical decision making (Government of Barbados, 2000b: 15). Thus students must be in a school environment that enables them to think, reason and solve problems via resources and technologies as these competencies, as well as Mathematical skills such as estimation, computation and data handling form the basis of the Barbados syllabus (Government of Barbados, 2001). Although Mathematics is often seen as a subject area for those more academically inclined, the government sees it " ...as a tool that is utilized by persons in all spheres of society - a tool without which it is impossible to function" (Government of Barbados 2001: iii). In this statement, Maths is posited as functional. One of the general objectives of the curriculum is to ensure that children "acquire the mathematical skills, understandings and attitudes that are necessary to be successful in their chosen careers" (Government of Barbados, 2001: v). However the view of mathematics as utility is not discussed further as the other general objectives provide a wider understanding of Mathematics education. These include the following:

- Develop an awareness of the importance of mathematics 
- Recognize the presence of Mathematics in their environment

- Apply mathematical knowledge to the solutions of problems in their daily lives

- Foster the ability to think logically, creativity and critically (Government of Barbados, 2001: v)

Despite findings of this study that suggest a lack of connection of Mathematics to students' out-of-classroom knowledge, the content of the syllabus is “...designed to ensure that all students acquire a range of mathematical skills and competencies, while recognizing the application of Mathematics is in their environment" (Government of Barbados, 2001: iii). This is supported by further discussion of the initiatives of the Ministry of Education, Youth Affairs and Culture which include problem solving rather than memorization and practicing procedures, promoting the use of manipulatives, using Mathematics to develop critical, creative and decision making skills in pupils, making connections to other subject areas and pupils' experiences, using technology, multi-media instruction and multifaceted assessment to evaluate what children know (Government of Barbados, 2001: iv). There is some discussion regarding these aspects of teaching and learning; however the bulk of the document is focused on content knowledge and the levels in which material needs to be introduced. While the syllabus professes some new innovations to teaching and learning Mathematics, these are perhaps most evident in the suggested activities linked to each topic and benchmark.

While there is an understanding that children have "varying abilities and aptitudes", the syllabus seems to indicate that students will subsequently develop different levels of understanding of these topics: “...some pupils might be able to achieve a higher standard than that which is set, while on the other hand, others may not achieve the standard set". Although this appears to take on a deficit approach implying that children who do not meet the targets are lacking in ability, the syllabus attempts to justify this position by stating: "It is hoped that the needs of every pupil would be met under these circumstances" (Government of Barbados, 2001: vi). Further description, discussion and direction on aspects of ensuring inclusion is absent and multi-intelligence perspectives on Mathematics education are not mentioned. In addition, development of critical thinking and problem solving skills remains vague. While the syllabus is clear that the teaching and learning of Mathematics must focus on these skills, the document lacks a clear rationale on why teachers should change their approaches to teaching. It does not outline nor critique the 
notion of constructivism which is emphasized in the 2000 national curriculum document. Instead, the syllabus simply encourages teachers to "use strategies and methodologies" (Government of Barbados, 2001: viii) to develop these skills and repeats its assertion that "(t)he mathematics classroom must provide the opportunity for pupils to formulate problems from everyday situations, use concrete materials, reason logically and use a variety of problem solving strategies" (Government of Barbados, 2001: vii).

\subsubsection{Strong emphasis on content}

The rest of the document provides a strong emphasis on introducing and building upon mathematical knowledge as the syllabus asserts the following: "The nature of mathematics instruction requires that concepts are introduced in the earlier stages and developed in the later stages" (Government of Barbados, 2001: vi). Mathematics education is viewed as a linear progression of topics which increase in knowledge and understanding through the years. It is not viewed holistically. A large focus of the curriculum lies in the section titled Scope and Sequence which provides a long chart outlining when topics are to be introduced and developed. The representation of content as a focal point of the curriculum emphasizes the importance of understanding the 'canon' of Mathematics. While the aims of the curriculum stress skills, this is not evident in the way in which the topics are dissected and listed similar to a checklist. There is little rationale for why these strands are viewed as central to the curriculum and how they link to each other. Instead they appear removed and are presented as strands which will be developed subsequently in each year of secondary school in a linear and stepwise fashion. The strands themselves are conventional. They are as follows: the calculator, number theory, computation, measurement, consumer arithmetic, stats and probability, geometry, set theory, relations, functions and graphs, algebra (Government of Barbados, 2001). The strands are heavily emphasized and details are provided to ensure teachers develop similar concepts which form a traditional academic approach to mathematics. With the exception of consumer arithmetic, there is little relevance to mathematical approaches which take the breadth of mathematics outside of the conventional curriculum. While it may be argued that consumer arithmetic is the most 'useful' unit for children, it stereotypes mathematics education as removed from life and pigeonholes mathematics as simply being a set of calculations related to counting. 
Through the list of suggested activities, there is some more attention paid to the aim of the Barbados curriculum to connect Maths to everyday situations, use manipulatives, learn to reason logically and employ various problem-solving strategies (Government of Barbados, 2001). Although group work was not noted during fieldwork observations, these proposed tasks aim to "...meet both the individual needs of the pupils as well as provide activities for group work, thereby facilitating collaboration between pupils, teachers and parents, while consolidating instruction and developing the necessary skills" (Government of Barbados, 2001: vi). The suggested activities include examples situated in a cultural context such as "Students will use cricket score sheets to calculate the fraction of the total runs scored by particular batsmen [sic]. Use the results to write a report of the team's performance" (Government of Barbados, 2001: 36). They also focus on the school community thereby involving some scope of relevance for the students: "Create a bus schedule for buses in a given area. Write a letter to the Transport Board outlining the present schedule and making suggestions for improvements" (Government of Barbados, 2001: 41). Examples from their present environment are encouraged: "Identify angles seen in the classroom and in photographs" (Government of Barbados, 2001: 46) as well as those within the geographic region: "Compare prices of airline tickets to a selected destination at various times of the week (weekday vs. weekend) and different time of the year. Plan a trip for the class to at least three Caribbean destinations" (Government of Barbados, 2001: 54). This activity also provides some exposure to the tourism industry. There are activities that involve some aspects of art and design: "Construct kites from indigenous materials" (Government of Barbados, 2001: 47) and "Photograph buildings that illustrate triangles, quadrilaterals and circles. Produce a booklet that contains a description and at least examples of each shape (Government of Barbados, 2001: 47, bold letters theirs). These activities indicate the movement of the curriculum away from 'chalk and talk' and are consistent with the intention of the curriculum to "focus on the practical application of mathematical skills and concepts" (Government of Barbados, 2000b: 15). As these types of activities were not observed in the thesis fieldwork, they may need to justify them to teachers in order for the activities to reach the sphere of the classroom. See 6.4 .2 for respondents' perspectives on Maths education. 


\subsubsection{Trinidad and Tobago}

\subsubsection{Trinidad and Tobago: A remedy to its dissatisfaction?}

On the other hand, the curriculum document of Trinidad and Tobago is lengthier and spends time justifying the choices within the curriculum. This may be a result of dissatisfaction with the system and the self critical stance taken by the government. The curriculum document begins by stating the following:

The teaching and learning of mathematics has been under constant scrutiny over the last fifty years. Reports from external examination bodies, the Ministry of Education, employers and public and private agencies on mathematical achievement, have all concluded that the majority of our students at the primary and secondary levels lack basic skills in numeracy (Government of Trinidad and Tobago, 2002b: Sec.2, p2)

A national indicator for the Ministry of Education is the high proportion of students who are not certified as proficient in Maths (Government of Trinidad and Tobago, 2002). Thus the government feels that the most important change "...will be the design of a mathematics curriculum that is relevant to the individual and needs of the society (Government of Trinidad and Tobago, 2002b: Sec. 2, p2).

In the 2005 annual report of the national test, it is reported that $53.9 \%$ are functioning at Level 3 or 4 at Standard 1 in Maths and decreases to $40.7 \%$ functioning at the same levels in Standard 3 (Government of Trinidad and Tobago, 2005). There are four levels with Level 4 as the top mark allotted. Students attending private schools achieved higher percentages in Maths at Level 3 or 4 with 76\% reaching these levels at Standard 1 and $66 \%$ at Standard 3 (Government of Trinidad and Tobago, 2005). Despite the stronger reputation accorded to denominational schools at the secondary level, "( $\mathrm{t}$ )he results indicate that more students at Level 1 and 2 attend denominational schools compared to government and private schools (Government of Trinidad and Tobago, 2005: iv). As a result of these findings, the annual test report of 2005 recommends the development of a national numeracy strategy, guidance in the appropriate use of instructional strategies and schools need to be given clearer directives to emphasize numeracy in the early years education (Government of Trinidad and Tobago, 2005). There are further initiatives listed to improve 
Maths education such as the Vocation Remedial Camp in Mathematics and Physics, a hands-on experience for secondary school students (Government of Trinidad and Tobago, 2007: 16).

\subsubsection{Aims of the Mathematics Curriculum}

The vision statement of the curriculum asserts the functionality of Mathematics. The curriculum aims to develop "mathematically empowered students who can make an effective contribution to our society in an increasingly technological world" (Government of Trinidad and Tobago, 2002b: Sec.2, p1). Whereas Barbados constructs Maths education as the development of strands, Trinidad and Tobago's curriculum defines Maths as "essentially an abstract subject" and posits it as the "study of the properties of number and its relation to measurement, space, shape, statistics and probability" (Government of Trinidad and Tobago, 2002b: Sec.2, p2). Similar to the assertions of the Barbados curriculum, Trinidad and Tobago views Maths as a platform for enabling critical, creative, logical, investigative and problem solving skills (Government of Trinidad and Tobago, 2002b). While the Barbados document is much shorter in its rationale, the Trinibagonian document explains in further detail the ways in which Maths contributes to the goals of education through wider goals of making connections, representation and recognition of patterns. The curriculum states the commonly asserted notion that Maths must be relevant to the environment in which children live (Government of Trinidad and Tobago, 2002b). The curriculum asserts that "Mathematics is essential to the study of all other subjects in the curriculum" (Government of Trinidad and Tobago, 2002b: Sec.2, p2), a theme that is followed by the recommendation that teachers should integrate Maths with other subject areas where possible as "...the learner will observe how mathematics is used in daily life and be provided with opportunities to practice mathematical skills while enhancing a better understanding of mathematical concepts". This discussion is followed by a section listing the different subjects and how Mathematics is connected to them (Government of Trinidad and Tobago, 2002b: Sec.2, p5). While the curriculum is clear on the linkages between Maths and other subject areas, these connections were rarely seen in the fieldwork observations. 
Yet the goals of the Trinibagonian Maths curriculum attempt to widen the scope of conventional ways of seeing Maths education. While relevancy and critical thinking are included in this list, there is also the goal to "to promote appreciation of the role of mathematics in the aesthetics and to make mathematics fun" (Government of Trinidad and Tobago, 2002b: Sec.2, p3). Through the study of Mathematics, the curriculum aims to develop personal and social attributes in its students, as there are goals to "develop selfreliance, honesty, open-mindedness, confidence and perseverance by cultivating a method of studying Mathematics that results in success" and "to encourage collaboration among students and to promote positive attitudes and values in students through the completion of mathematical tasks" (Government of Trinidad and Tobago 2002b: Sec.2, p3). Other goals include enabling students to communicate effectively using mathematical jargon, provide opportunities for students to experience the structure, elegance and power of Maths and to provide students with a range of knowledge skills and techniques related to traditionally mathematical concepts such as number, geometry, algebra, measurement, statistics, functions and relations in a way that is relevant to the $21^{\text {st }}$ century (Government of Trinidad and Tobago, 2002b).

\subsubsection{Curriculum content}

In particular, the curriculum explains directly to teachers the necessity for change:

The mathematics classroom needs to be one in which students are actively engaged in doing mathematics. It is no longer acceptable to view mathematics as a set of isolated rules and procedures that the teacher transmits to the student (Government of Trinidad and Tobago, 2002b: Sec.3, p1).

The national document recommends that classroom activities and student assignments must provide opportunities for students to see mathematics as a useful tool for processing the world (Government of Trinidad and Tobago, 2002b). Similar to Barbados, there is the notion of Mathematics as functional. There is also a heavy emphasis on problem solving and it is thus suggested that a safe and comfortable learning environment must be fostered to help students and teachers discuss problems, share solutions and value multiple approaches (Government of Trinidad and Tobago, 2002b). Yet the document attempts to convince teachers that mathematics is not simply "acquiring a body of knowledge" (Government of Trinidad and Tobago, 2002b: Sec.3, p1) and uses the term "mathematical 
literacy" and "mathematical thinking" (Government of Trinidad and Tobago, 2002b: Sec.3, p1) to group the skills of formulating questions, developing and employing algorithms, making connections and communication (Government of Trinidad and Tobago, 2002b). It tries to balance this newer way of thinking with traditional modes by stating " $(t)$ eachers need to balance the acquisition of procedural skills with the attainment of conceptual understanding. (Government of Trinidad and Tobago, 2002b: Sec.3, p1). However, this contrasts the opinions of teachers on the use of outside knowledge as discussed in 6.4.2 and 6.4.3.

The document mostly provides some good guidance and justification for these suggested activities which are intended to promote the values of the curriculum document. However, there is some support for routine problems as they "promote convergent thinking" and thus the student learns to operate convergently and "seeks the correct answer in one way only" (Government of Trinidad and Tobago 2002b: Sec.3, p5). This seems to justify the continued use of problem solving approaches which are teacher-centred and expository. The curriculum document attempts to hold both approaches in tandem as it also argues "(o)n the other hand, creative thinking skills can be developed using non-routine problems which promote divergent thinking" (Government of Trinidad and Tobago 2002b: Sec.3, p5). A definition is then provided for 'challenging tasks' which depict a real life issue, uses manipulatives, has a mathematical base, is accessible to all students, allows for extensions and can be solved in a variety of ways (Government of Trinidad and Tobago, 2002b). These challenging tasks contain four essential elements of communication, representation, reasoning, connection and problem solving (Government of Trinidad and Tobago, 2002b), all of which are outlined for the reader.

Sample activities are listed on the next six pages such as generating "examples of sets from the likes and dislikes of students on various issues and other information collected from students" (Government of Trinidad and Tobago, 2002b: Sec.3, p11), "outline the place value table for the denary system up to several places" in pairs and decide on the quantitative relationship between each column (Government of Trinidad and Tobago, 2002b: Sec.3, p7). Students express these orally and then state as many relationships between the subunits of the metric system individually (Government of Trinidad and Tobago, 2002b). These tasks, although involving group work and student contribution to 
the activity may be viewed as limited in potential for elements of communication, representation, reasoning, connection and problem solving. Problem solving activities are also suggested, such as the following task: "Given a rectangular card of length $30 \mathrm{~cm}$ and width $20 \mathrm{~cm}$, determine the isosceles triangle with the largest possible area and perimeter which can be cut from the card (Government of Trinidad and Tobago, 2002b: Sec.3, p12). Other problems such as riddles from foreign sources are suggested: "The census taker asked Mr. Riddle how many children he had, and their ages. Mr. Riddle answered "1 have 3 children. The product of their ages is 36 . The sum of their ages is today's date". The census taker thought awhile and then said "I need more information". "Okay", said Mr. Riddle. "The youngest is a boy". What are the ages of the 3 children?"(Government of Trinidad and Tobago, 2002b: Sec.3, p12).

\section{$\underline{\text { 5.5 Discussion }}$}

\subsubsection{Similarities in policies}

The documents of Barbados and Trinidad and Tobago focus strongly on national and economic development. The government of Barbados aspires to be a "(a) truly literate society whose people are educated, rounded human beings, possessed of sophisticated skills and so imbued with social justice and equity that no one is left by the wayside". Similarly, Trinidad and Tobago notes that the goal of the secondary education reform is to strengthen productivity and competitiveness of the country by ensuring youths of all backgrounds are prepared "...through a modern education system, to participate in, and contribute to, the development of a technologically driven and skills-based economy" (Government of Trinidad and Tobago, 2002: 12). Perhaps this is due to the challenges faced by globalization, which are viewed mostly in a resource development perspective rather than the effects of abuse of the environment or sexually transmitted infections. The government of Trinidad and Tobago (2002a: 3) expresses its concerns about globalization:

Our very survival as a people and as a nation depends on how we face the challenges of life in this global village where we must compete for space in the international market place; in a global economy that is knowledge-based and technologically-driven, particularly by the information and communication technologies. 
Indeed, the similarities between Barbados and Trinidad and Tobago in the quest for survival in a globalized world are expected as they are both small states with similar contexts, both physically and socially. Jules and Panneflek (2000) argue that each country contains capital cities and main towns in the densest areas of settlements which are linked together by coastal main roads as these cities and towns serve as ports. They point out that most of these populations have the same ancestral origins which lead to similarities in appearances, religions and the arts (Jules and Panneflek, 2000). With regards to education, most countries have standardized tests for admission to secondary schools based on Language Arts, Maths, Science and Social Studies (Jules and Panneflek, 2000). In the eyes of international organizations and initiatives such as EFA, the countries in the Caribbean are seen as more similar than different. Both countries also view ability in the same way. In Barbados, children who do not pass the secondary school entrance exam are placed in technical and vocational schools (see 5.2.3). Finally, both countries have very similar challenges. Youth unemployment rates in both Barbados and Trinidad and Tobago are disconcertingly high (Briguglio, Persaud and Stern, 2006). HIV/AIDS is a serious threat to gains made by the development process. Briguglio, Persaud and Stern (2006: 31$)$ report that in the Western world, the Caribbean small states are the most affected countries and "(i)n the English speaking Caribbean, AIDS is now the largest cause of death among young men between the ages of 15 and $44 "$ ".

Despite the encouragement of 'horizontal borrowing' by multilaterals, cross national attraction between the two countries does not occur. National initiatives also face implementation problems in both states, either as a result of poor actualization, or common grounds of resistance among actors. Further discussion of the resistance to policy initiatives will be covered in 7.2 and 7.3. Other similarities between initiatives taken by both island states exist in the areas of constructivist approaches to curriculum, continuous assessment and magnet schools (see Government of Barbados, 2007: 200 and Government of Trinidad and Tobago, 2007: 30). Both Barbados and Trinidad and Tobago have based their curriculum on constructivist philosophy as it gives “...students the opportunity to operate at different levels within the classroom, experience multiple methods of learning and assessment, think divergently, and apply the knowledge gained to real-life situations" (Government of Barbados, 2001: 3). Education is also constructed as a national directive to ensure that children conform to "positive attributes and values (that) will make him/her a 
productive member of society" (Government of Barbados, 2001: 3). The documents from Trinidad and Tobago indicate similar aims (see 5.3.3). Information technology and continuous assessment are also emphasized in both curriculum documents (Government of Barbados, 2000b; Government of Trinidad and Tobago, 2002a). Key themes such as openness and flexibility seem to permeate some of the reforms in both countries. The push for continuous assessment seems to arise from a quality of education perspective, possibly through the EFA initiative. Certainly Jules and Panneflek (2000: 38, italics theirs) who reviewed the Caribbean region's progress on EFA advocate this approach as it is vital in "upgrading students competencies, reducing repetition, and increasing survival rates". Jules and Panneflek (2000) also argue that this practice is written as an aim in many national plans in the Caribbean and now must be implemented in the systems.

The coordination and concurrent development of curriculum is not a chance occurrence but a movement from within the region with influence from global sources. The degree to which these are coincidences based on 'best practices' globally, encouraged by international organizations or isomorphism is difficult to distinguish. Certainly the two island states are committed to international and regional agreements. Both governments have divisions or departments that are involved in international work. The mission of Barbados' International Relations Division is to liaise with UNESCO, OAS, CARICOM, Commonwealth Secretariat, Association of Caribbean States and Commonwealth of Learning (Government of Barbados, 2000a), Further, the unit is responsible for ensuring “...that projects sponsored by these organizations, especially UNSECO are implemented and funds expended according to their requirements" (Government of Barbados, 2000a: 27). Lastly, they must "co-ordinate bilateral agreements and educational exchanges between Barbados and other countries" (Government of Barbados, 2000a: 27). Similarly, Trinidad and Tobago has the Department of Education Research and Evaluation (DERE) which is responsible for "(c)ollaboration with other local, regional and international educational institutions and agencies engaged in educational research" and " $(\mathrm{t}) \mathrm{he}$ identification of strategic partners for undertaking research an evaluation activities" (Government of Trinidad and Tobago, 2002a: 24). Trinidad and Tobago sees the commitments made to these organizations as part of opportunities of the system rather than weaknesses or threats (Government of Trinidad and Tobago, 2002a) despite the mandatory requirements from such multilaterals, such as the development of country reports according 
to set guidelines set by UNESCO. The executive summary of the 2004 policy document states that the report was developed according to such guidelines.

\subsubsection{Differences in policies}

Despite facing similar challenges as small states and developing nations, there are some key areas in which the two island states differ. They have some distinct cultural values which converge, such as the importance placed on diversity. This is probably due to the differences in cultural demographics as Barbados has a predominant Afro-Caribbean population whereas Trinidad and Tobago is home to Afro-Caribbean peoples, IndoCaribbean groups as well as those from European, Syrian and Chinese heritages (see 2.2.1). Barbados aims to "(p)romote a greater awareness of African cultural heritage among all Barbadians in such a way as to build social cohesiveness and strengthen national unity and identity" (Government of Barbados, 2007: 42). Barbados is also a very Anglican society and this is recognized in policy: "It must be stated that our abiding FAITH IN GOD has been the bedrock foundation upon which our values have been nurtured across generations" (capital letters theirs, Government of Barbados, 2007: 21). On the other hand, Trinidad and Tobago have been recognized for providing programmes on harmony and peaceful living among groups (see Introduction). Instead, the divisions within education and social economic status are evident through the different types of schools. The privileges enjoyed by denominational schools are outlined in the Concordat which provides "assurances for the preservation and character of Denominational schools" (Government of Trinidad and Tobago, 1960: 1). As a further point of contrast, the core values listed by Barbados include the following:

Patriotism, Loyalty, Tolerance, Compassion, Empathy, Trustworthiness, Respect, Industry, Steadfastness, Discipline, Resourcefulness, Self-reliance, Thriftiness, Community Mindedness, Fairness, Adaptability, Resilience (Government of Barbados, 2007: 21).

On the other hand, the government of Trinidad and Tobago list the following constructs as fundamental: “' decency', 'justice', 'respect', 'kindness', 'equality', 'love', 'honesty' and "sensitivity" (1993b: 2) and state these are the "major determinants of the survival of our multi-cultural society (1993b: 2). 
These differences between the two countries may be seen as being self-identified. Small island states such Barbados and Trinidad and Tobago may feel the need to carve out a separate identity in order to survive, or these differences may be 'real' rather than imagined. Both countries separately identified a set of strengths and weaknesses which differ from each other. Perhaps as a result of delayed success on reaching quantifiable benchmarks in education quality, Trinidad and Tobago identifies its strengths all of which are related to human resources or knowledge within the ministry:

- An education policy framework to transform the education system and sustain continuous improvement

- Organizational knowledge and experience in managing the conduct of examinations at both the primary and secondary level

- Development of a strategic management culture in the ministry

- Highly compensated teaching corp who are de-linked from the Public Service (Government of Trinidad and Tobago, 2002a: 37-38)

While Trinidad and Tobago claims to have a strong knowledge and resource base in the Ministry of Education, one of the weaknesses that Barbados identifies is "(p)aucity of research, development and innovation" (Government of Barbados, 2007: 16). On the other hand, Trinidad and Tobago may assert a strong nucleus for reform, it also recognizes the "ineffective and inefficient organizational structural arrangements in the Ministry of Education" (Government of Trinidad and Tobago, 2002a: 38) as a weakness. Although there are some highly trained teachers, there is also "(a)n under-developed human resource management system which hinders manpower [sic] planning in respect of teachers" (Government of Trinidad and Tobago, 2002a: 38). In addition, despite strong policy frameworks, one of the listed threats to the system is "( $t$ )he lack of synergy which may exist in the reform implementation agenda for the wider social sector and that of the educational sector (Government of Trinidad and Tobago, 2002a: 40). Yet these weaknesses alone do not limit the 'horizontal borrowing' advocated in international policy documents rather it is the perspective of difference between the island states and the gaze towards the 'centre' that impedes transfer and regionalism. The next chapter summarizes fieldwork interviews and illustrates the gap between policy and ground perspectives. 


\section{Fieldwork Findings: Voices of respondents on the school system, pedagogy and 'borrowing'}

As the voices of respondents are key to understanding the possibilities of 'horizontal borrowing' and the presence of 'vertical borrowing', this chapter focuses exclusively on their narratives. It is divided up into sections topics and subsections on themes. The sections follow the focus of interview questions. The chapter will begin with a description of respondents, followed by their perspectives of similarities and differences between Barbados and Trinidad and Tobago. This was investigated as a starting point to uncover sentiments and perceptions of respondents on the two islands and to provide data on areas of strengths and weaknesses. Respondents were also asked about the curriculum and examinations, two areas of concern for education quality (see 3.4.2). As teaching and learning is a focus of international policy documents (see 5.1.1), the opinions of interviewees were sought. Finally, respondents were asked to identify instances of 'horizontal' or 'vertical borrowing', and their opinions about this notion. Most of this section is narrative and does not contain exact numbers of respondents who agreed or disagreed with statements as the interview schedule differed for respondents (see 4.2.2.2). However, for each perspective noted, there is also an indication of respondents who agreed or disagreed. As the narrative responses of interviews contain rich data for analysis, the focus of this chapter will remain on their voices. A thorough treatment of the empirical work will follow in the next chapter.

\subsection{The respondents}

After completing the pilot of 15 interviews, 35 further interviews took place between September 11 and October 19, 2007. Interview transcripts are available to other researchers at the discretion of the Ph.D candidate. The following chart shows the positions held by the respondents. Some of the respondents have worked in various positions and the current position held may not fully represent their expertise. Several academics worked extensively on national curriculum items and some of the senior teachers were former chief examiners for CXC. Bold respondent numbers denote participants from the pilot study. Their responses are discussed separately in section 4.3. 


\section{Barbados}

Teachers: B5, B6, B7, B8, B9, B10

$\mathrm{B} 11, \mathrm{~B} 12$

Heads of Maths: B1, B2, B13, B14, B15

Senior School Management: B16

State Policymakers:

B17

Local Academics: B3, B4, B18

Regional and international respondents: I1, I2, I3, I4, I5, I6
Trinidad and Tobago

T1, T9, T10, T11, T12, T13, T15, T16, T17, T18, T19, T20, T21, $\mathrm{T} 22, \mathrm{~T} 23$

T2, T24, T25

T26

T3, T4

T5, T6, T7, T8

Total: 50

Some of the pertinent information garnered from the pilot involved aspects of the system previously not noted in literature, such as the recent developments in both countries and the weight of current policies. As such, respondents were asked for their perspectives on new government initiatives such as the creation of new curricula as well as the reasons behind differences between the two countries. As teachers formed the largest cohort of respondents, an interview question bank was prepared before the pilot and used throughout the pilot interviews. Following the pilot, the questions were amended to include further perspectives on aspects of teaching and learning. Although education policy is a key focus of this study, aspects of classroom activity and teachers' perspectives of their own teaching often reflects the process of implementation of policy and may reveal gaps between policy and practice. See 4.2 for information on methods and 4.4 for a critique of the research process.

\subsection{Perceived similarities and differences}

As this study is rooted in the field of comparative education, the identification of similarities and differences may be a beginning point for analysis. By looking at similarities and differences, the scope for 'sharing' may be uncovered. By asking respondents about the degree to which they feel differences exist between island states, T6 
and T7's assertion in the pilot that history and sociocultural makeup impede 'horizontal borrowing' was also tested. In order to help respondents consider features of their own education system, one of the initial questions in the interviews was the identification of strengths and weaknesses of their own education system. This follows from the perspective that 'education borrowing' may begin with the interest of sharing 'best practices' or interest to improve on aspects of one's own system. Both of these perspectives are described and problematized in 3.1. In the case of Barbados and Trinidad and Tobago, this includes aspects that the countries themselves see as areas for improvement.

\subsubsection{Barbados: Identified areas of strengths and weaknesses}

Respondents in Barbados had varied responses when asked to identify the strengths and weaknesses of the education system. Many of the respondents were able to provide answers, such as B10 who provides a list of positive aspects such as moving at the same pace as children, students who enjoy Maths, the CXC exams, involvement of teachers in setting questions and marking exams, ability to choose books and the computerization of the system. B17, a policymaker mentions accessibility from early years to tertiary education, trained teachers and provision for textbooks and school meals. Others such as B9 point out the difficulty of the question, stating, "I don't know what to compare to". Some respondents are supportive of the system, while others feel that the system produces strong students and leaves others behind. There seems to be agreement that high achievers are successful. B7 points to the portability of the education in Barbados:

I think we have a pretty good system, it allows children to fit into different cultures pretty easily, they tend to do well in the American system, perform well in Britain. Our students will tend to study in England, Scotland, Canada, USA, they will adapt there because of the foundation.

B11 offers a similar response, stating that students are able to perform well on American SATs and "(a) large number of the population has grasped basic mathematical computation". Another teacher feels that Barbadian students are better than their North American counterparts: "When people go to Canada or States, they always seem to be ahead of those students in those places and usually have a better approach" (B15). This may be a result of the emphasis placed on Maths: "to be truthful, it is a fairly high level.... 1 think a lot of importance is attached to Mathematics from the early age of primary school 
so people see it as something you must do" (B18, academic respondent). However, the necessity to achieve in Maths may create an environment geared towards the exams. Thus, the system may work well due to its ability to help students obtain qualifications.

Although responses to the question regarding weaknesses of the system varied, there was some attention paid to those who are not successful. While B7 identifies free education to the tertiary level as a strength of the system, they also state that "...the attitudes of our people seem that they are not making the most of the situation". B7 points to the issue of low achieving pupils:

There are too many people who are leaving our system who have not mastered basic concepts at Math.... After being in this system for so long, there is nothing that comes that shows me it's being looked at. Every year at the common entrance, we see people who are not performing, but I don't know if they are doing anything of it.

B12 raises the same weakness and offers a solution: “...we don't have an alternative yet to the present Maths course....like a Maths for business course. We need something like that, especially for people who are yes, not necessarily experts in Maths..." B16 points to a similar weakness when describing the quality of teaching and learning in Barbados: "I think we have a reasonably good quality of teaching and learning. I think the problem is that the curriculum used is not appropriate with the children we're dealing with, but where there is appropriate curriculum for the needs of the child, the quality is fine". B9 provides a similar comment but placed emphasis on the lack of technology: "the technology not what it should be, so the learning depends on the student to grasp the concept.... So the stronger students, those who are analytically minded will get through". B14 offers a suggestion:

Well, should I call this a strength? It is a strength in that everybody has to follow Maths as at one time when students could drop Maths... although if I could recommend, I would say that some should do arithmetic while others can do geometry and algebra.

Other responses focus on other aspects. B10 identifies the problem of not liking Maths and attributes this to primary school teachers: “...there are children from primary school who do not like Maths but have negative attitudes and that is something we have to fight against". On the other hand, B8 claims there are no problems with the syllabus, but "the main problem of education is simply the numbers, our classes are too large". B16 also comments on the need for a greater integration of technology, which is echoed in the 
general comments of both Barbadian and Trinibagonian teachers. B11 suggests "maybe we could incorporate more technology like some schools in other parts of the world where they have a whole Maths lab, which is not prevalent here". B11 also states the need for more aids. B15 shares that the inability for some teachers to embrace new technology is a weakness.

\subsubsection{Trinidad and Tobago: Identified areas of strengths and weaknesses}

Trinibagonian respondents found it difficult to answer the question "What are the strong features of education in Trinidad?". T12 notes: "I can't think of any. That tells me that there are few, if any" while T9 responds with: "You can move on and I'll come back to that". Other teachers such as T18 use this question as an opportunity to talk about the weaknesses of the system instead. However, T12 attempts to answer the question by pointing out the benefit of having free tertiary education: "It has allowed free education up until tertiary level, that is a general point but I think the quality of education needs to be worked on". T21 responds with a similar positive point. T24 initially needed some time to think about the question but later answers the following:

I think if students are serious, any child graduating from form 6 or university should be literate and competent enough to go into the job market and be very confident that they can accomplish what they set out to do. If taken seriously, the education system is very strong. But a lot of work is needed within the system, within the schools, to fulfill the necessary requirements.

T11 also responds to the ability of the system to produce high achieving students: "The strong features are that it is convergent, because students can become experts in a certain area. This is different from places like Canada where it is quite divergent". This may be in reference to the high level of mastery required for CAPE level exams, for which students select the topics they would like to pursue. Conversely, T25 feels that students who were pursuing vocational subjects need Maths lessons that are more suitable to their vocations.

Through the interviews, it is revealed that there is little provision for low achieving pupils, although various terms were used to describe the 'problem'. A few teachers identify free secondary education while others point to the lack of special needs provision as a source of the 'problem'. T19 and T18 both feel that the provision of free secondary education led to 
the marginalization of lower achieving pupils: "there is a lot of access to the education but the only problem is, that because of the system you find that the children are just being moved from primary school to secondary school level with no thought about if they are academically inclined". T18 concurs, stating "We want society to realize that no matter how rich or poor they are, they have some opportunity. Tertiary education was made free, you don't have to pay, it's free but I'm worried that by making things free and cost effective, we are sacrificing the quality of education that is being produced". T24 also blames primary schools:

Within recent times, schools were given enough funds to implement or provide additional materials needed to help these students. Basically, I feel it stems from the primary schools; principals and teachers in the primary schools are responsible to a large extent.

T12 also identifies several learning disabilities in his comments: "You can tweak a system to make it for different levels, but if a child is coming into a school with ADD or learning disabilities, they are going to get left behind because nothing is set up".

Overcrowded classrooms are seen as a weakness (T13) and perhaps this leads to lower quality of student pupil relationships. T26 suggests there is a relationship between teacher relationships and success in the school: "Our students need teachers who will understand and develop relationships with them. Our teachers who do that will have no problems with the students". Parents and socioeconomic factors are attributed to differences in education outcomes as well. T24 states: "Parents also have a role to play and they are not doing it. They see school as babysitting, where to leave your child during the day, no reinforcement, no emphasis given to teachers and the schools". T19, a teacher at a senior comprehensive school, describes the background of her students: "a lot of children come from single parent families; some are even on their own. And they somehow...don't recognize the value of the education, they don't know that education can bring them out of the position they're in". Conversely, T13 complains of the school culture, “....it's a battle to get them to do what we want in class time, because they will cover it in private lessons, which is because of the overcrowded classes that they enroll in private classes" Indeed, in the section below on aspects of teaching and learning, it is clear that teaching techniques are rote and may not engage students. Real life examples and less traditional modes of learning are absent from classrooms in both Barbados and Trinidad and Tobago. See 6.4.2 for further discussion. 


\subsubsection{Teachers}

Almost all secondary school teachers sampled in Barbados hold a first degree and a teacher training certificate and are thus more qualified than their Trinibagonian counterparts. This may be due to the sample of respondents in Barbados as subjects tend to be senior teachers, whereas several new teachers were surveyed in Trinidad and Tobago. B5, a recent graduate, was satisfied with the course and felt the most memorable aspect of the programme was the emphasis on the importance of planning. There are, however, areas for improvement. B17, a policymaker points to how Maths education may be improved in Barbados:

We now have greater knowledge of how children learn Maths; there is a need for teachers to be retrained to how to teach Maths... Teachers need to be aware of what research is saying so they can have innovative ways of how children are learning.

As there are very few comments related to teachers in Barbados, the following section is a lengthy description of the concerns relating to the teaching profession in Trinidad and Tobago.

With the exception of one respondent who feels that a positive feature of education in Trinidad and Tobago is the teaching force, one area of weakness was frequently discussed in the interviews: teaching staff. In general, while most teachers in Barbados are qualified, many teachers sampled in Trinidad and Tobago do not hold teaching qualifications although many have first degrees in Maths. However, the link between teacher training and quality of instruction may not be linear as teachers who hold qualifications in teaching are not necessarily more engaged. In fact, one qualified teacher was frequently late for classroom observations and their lessons did not appear challenging as the students apparently mastered the material already. Yet as a whole, further training is viewed as necessary. T25 points out the gap between effort and training: "On the other hand, even though some of them are willing, they may not have the adequate teaching skills". A few new teachers were interviewed and asked about the type of training they received. While T14 participated in two training sessions after being appointed to a teaching post, consisting of a four week session prepared by the Ministry and an induction hosted by their own school, T9 and T10 summed up their training as a series of conversations with other teachers in the department and the department head. T20 did not receive any training as a 
letter of confirmation appointment was received the day before the commencement of the contract. This scenario may be indicative of teacher shortages. All three of the government schools visited in Trinidad and Tobago are currently experiencing a shortfall of Maths teachers. In turn, other members of staff either cover classes or classes are left temporarily without instruction. This is a result of the centralized structure of hiring subject teachers by the ministry (T24). However T26 offers another opinion regarding the quality of teacher recruits:

Teaching in this country should attract the best people in the various disciplines. I'm not sure to what extent that prevails. You can get a degree in the lowest degree standing and apply to teach and more likely than not, you will become a teacher.

It is also easier to ask a teacher to leave from a denominational school as the governing bodies have more control over the human resource decisions. Another international respondent expresses a similar sentiment: "we have been losing teachers both in number and quality and there is no question in my mind that if we focus on building and restoring in teacher quality we would be going a far way in having quality education in the Caribbean" (15). Yet T14 argues this is may be true for teachers in other subjects and Mathematics is an exception: “... a lot of them aren't qualified... But for Math I would say the opposite though, people who actually teach Math love it and are highly qualified". It appears to be a profession that is not difficult to enter, as one respondent noted that they became a teacher because "It was honestly the easiest thing to get into after UWI" (T20).

Several teachers comment on the problem of teacher commitment: "There are some teachers who are in the system for a number of years and they're not as effective as they used to be, when they were younger - if they were ever effective, so they can have a negative effect on those coming into the system" (T15). T25 describes the problem: "teacher absenteeism, not attending classes on time, not attending classes at all even though they may be reported for duty, they're here but not attending the class". Although T17 points to the difficulties some teachers experienced in receiving their pay, this is not seen as a sole reason for teacher disengagement: "I've heard people use it as an excuse, they don't get paid enough to not take their holiday". T17, along with another respondent, points to the difference between teacher absenteeism and the legal allowances teachers are permitted to take. T17 states "So I think the problem is that really and truly we are allotted too much, 
we are given as much as anyone who works 12 months a year but over nine months... So what they see as an absenteeism problem is what you're allotted". However, T17 also explains: "I say yes, just because we have sick leave, we shouldn't use it up, but there's no incentive not to take it, it's not like it rolls over or you can save it up and retire early". T17 continues to state that the 'problem' of teacher 'absenteeism' is multifaceted: “...there are bigger reasons, low pay and not feeling appreciated and frustrated, so not wanting to deal with students, you really have to come feeling refreshed, and hard to come here feeling frustrated about salary and be productive". T24 offers a different perspective, stating that the administration has a responsibility to follow up: "If I do that [don't come to class], the administration has the authority to pull up or speak to me. If it is not done one time after one time or two times, I develop the habit of not going to class, and that is the problem". T26 refers to this problem as one of teacher enculturation and summarizes the experience of teachers at T26's school:

If teachers have families with values and morals and community, that is going to shape their values and thinking. Then they come to [this school] and the history of the school, that is going to impact on the teacher and the willingness of the teacher to transform their behavior to what the school needs from them.

The personnel problems are not only associated with teachers as T25 points to the wider political picture of education in Trinidad and Tobago: "Well, what you have to remember is that the Minister of Education is a political post... You may also have people there who are incompetent but because they have some political affiliation or know someone who is already in the system...but not best suited for the job so by virtue their incompetence is spread throughout the system". Similarly, T19 refers to the poor management of education and but also teacher training as well: "it's not managed properly... we know we have problems but need somebody to come and help us, we don't have that at all". T18 agrees, stating "the most important rung in the ladder is the one at the bottom; you can't do it from the top. But people think management is most important. But if you pull out the teachers, we are the bottom rung, along with the students and the parents". However, T24 disagrees: "I think schools are supported fully in most cases. I think it is administration and teaching staff who are not fulfilling their roles in the profession.... And if administration would pull out these teachers then things would be better". On the other hand, commitment on behalf of the administration to facilitate teacher engagement is also a necessary component as some of the physical conditions in which teachers worked are in need of improvement. 
These include administration-teacher relationships, building maintenance, plumbing and temperature control, all of which appeared to be at various stages of progress at the schools visited.

\subsubsection{Hierarchy of secondary schools}

Although both Barbados and Trinidad and Tobago continue to use equivalent 11+ exams to determine secondary school places, criticism is expressed by respondents regarding the differences in status of schools. In Barbados, schools are ranked according to achievement at $\mathrm{CXC}$ exams, while the denominational schools in Trinidad and Tobago are seen as prestigious institutions compared to government secondary schools. Both countries have top schools and those which were known to be poor achieving. These divisions created a hierarchy. Referring to the education system in Barbados, B13, a teacher at a lower performing Barbadian school stated "lt's good but it leaves students behind if you're not at the top end. It serves those at the top end well, but with schools like this, we're too small to have elitist schools in this country..." When asked to what degree Barbadian schools are egalitarian, one respondent notes they are equal in sense that they follow common criteria: "...once you show the ability, you can write your exams at any school, of course the way the system is now, this set to [name of school], this set to [name of school]... So it depends on the ability that the child shows in a particular setting..." Teachers such as B7 are concerned about this aspect of the system: "we have the crème of the crop, they get through the exams but at other schools I know they are not getting through".

Trinibagonian teachers are also critical of the resulting hierarchy of the secondary school system. T12 states: "It has produced a definite class structure, students that come out of prestigious schools, seven year schools, will have more opportunities available to them, those from five year, a little less, and three year, obviously less". When asked about the extent to which the hierarchy in Trinibagonian schools mirrors the social divisions within Trinibagonian society, T26 responds: "It is there alive, prominent; unfortunately that is what drives the society. Because if you are an old boy or old girl from these denominational schools, doors are open to you much more readily than students from this school". T12 feels that parental investment occurred prior to entering secondary school as parents invested in private primary schools to ensure successful outcomes on the exam "...they will 
do everything possible from age 8 or 7 to ensure they are progressing in that point to do the exam in order to get the highest percentage possible... So that is where the spending the money comes in. Not afterwards, because it's already paid for" (T12). However, T14 regards enrolment at the prestigious denominational schools as somewhat of a necessity for children from more prominent backgrounds: "By out of necessity sometimes we take them. Some children wouldn't last with the kidnapping situation... they would be harassed". T17 concurs with this view, stating that if children of expatriates were to go to public schools, "certainly not if they're white, and not a government school" referring to denominational non-fee paying schools as a suitable choice.

Both T12 and T23 describe in detail the reasons why low achieving students are found in government schools, predominately those which are now in the process of being converted from junior secondary schools to full five year secondary schools. See 6.4.4 for more perspectives on lower-achieving pupils. T23 explains that junior secondary schools contribute to the low performing scores of their respective senior comprehensive schools, giving an example from teaching experience:

I'm doing Cartesian graphs and they are saying, 'Miss, we haven't had a teacher' so the form $4 \mathrm{~s}$ are not at $4^{\text {th }}$ level but basically doing form 1 work with them because they have come from three different schools so we have to start at a lower spot to make sure they all come up. So we have a shorter time to get them to CSec so this has been the challenge.

However, some feel that the centralized process of placing teachers across government schools creates a fairly equal system: "I could have been placed in [name of school], [name of town], wherever you are placed, you are expected to fulfill your role, so we are equal but over the years people get away with all sorts of things, so the problems continue" (T24).

\section{$\underline{6.3 \text { Syllabuses and Examinations }}$}

\subsubsection{National Syllabuses}

The section below outlines perspectives on the syllabuses for each country. It is important to note that the CXC exams are the outward qualifications in both countries and completing the syllabus is an internal exercise. Barbadian respondents are generally satisfied with the 
syllabus. Teachers such as B7 feel the students handle it well. B11 agrees, "Yes, I think the syllabus is quite appropriate, it has been reviewed recently and it is ongoing as well, it covers a full range of topics and you can use it when they go to other universities". Students are required to write internal exams every year, which some teachers such as B6 feel are beneficial: "If there's no exam, the student would relax, the exam helps them to focus on the task at hand". Continuous assessment was also in the process of being widespread at the secondary level. B13, a teacher at a lower performing school, reveals how the school organizes the syllabus over a longer period to ensure students were able to complete it. Questions to Barbadian respondents regarding the syllabus usually led to discussions regarding the $\mathrm{CXC}$ exams.

On the other hand, respondents from Trinidad and Tobago have varied opinions on the new National Certification of Secondary Education (see 5.3.3 for more information on the NCSE initiative). This section highlights some of the perspectives on the NCSE from the point of view of Trinibagonian educators. One teacher, T26, feels the general population does not understand the purposes of the NCSE: "they still think it's a certificate exercise". This may be reflected in the responses from teachers such as T9 who states it is "Form three assessed so they can use to show they have been educated up to the form 3 level". T11 believes the certificate had no currency "... what good is that certificate going to be, just to get a job as a garbage collector but you won't have the O levels". T20 also agrees, stating: “...it has no relevance, it doesn't have an impact. With the CXC you get a certificate afterwards and you can get a job with them, but you can't really get a job afterwards with it". T14 feel that it has low standards, arguing: "It's a moot point here because it's below the standard of the school. We don't have to think about it because we already cater for it with the syllabus". Instead, T26 argues it is "an initial step to test the quality of the education system... which is a step in the right direction". Others such as T25 feel that "if implemented in the proper way, it is an extremely good idea. However, you need the resources.... If you don't have that, it falls flat on the face and defeats the purpose for it to work. Also you need teachers who are qualified and experienced in teaching, not only in subject but qualified in teaching of the subject who are committed to the process". T24 finds schools need to be more involved: "If it is fully developed, if schools support the program, I think it has a lot of meaning, it can get us very far, but schools are not fulfilling 
their roles with respect to continuous assessment, with respect to registration of students, with respect to submission of data required by the Ministry".

\subsubsection{Perspectives on CXC exams}

While both teachers and policymakers find the standard of the CXC exams to be high, there is a concern among educators in both countries about students who fail to achieve passing grades in the Maths examinations, both on a national and regional level. There is also the critique that the exams are an exercise at the end of a training period, rather than a measure of intelligence. B19 expresses concern that these exams dictate too much of the Maths education system in Barbados: "The Mathematics education is basically tied a lot to the exam bodies and until the exam is set in a way that Mathematics is more practical then we're not going to get very much done". T11, a teacher, is also critical of the lack of creativity within the Caribbean exams: "There isn't a lot of creative thinkers. This is the way the CAPE syllabus is, it's a linear approach where you do step a b, c and then $d$ you get the answer". T5, an academic, offers a critique of the Mathematics in the CXC exam as being "dull". Further, T5 states, "It's easy to train a student who wants to do well - but what I see is that students don't opt in, it's not exciting...it's how its presented - doesn't seem to be a useful skill".

B6, however, offers a different perspective when asked about how the situation of low numbers passing the Maths exams:

We find at the primary level, they are more untrained, inexperienced persons at the classroom and sometimes you have persons teaching mathematics at the primary level who don't understand mathematical concepts, so you have someone who doesn't understand some mathematical concepts teaching someone else, so false concepts are being reinforced at primary level.

Clearly, the examinations are an important part of the school systems as they are the outward benchmarks needed to obtain the currency of knowledge required by international institutions. B7 states "the exam is the proof that they have mastered certain competencies". They may also serve as markers of a good education system in the region as CXC reports focus on the number of student entries and passes - two 'indicators' of a successful national system. The entire system is geared towards exams: "from the time they do school 
they do exams" (B7). High failure rates also indicate a flaw in the system as a linear approach to schooling suggests that school leaving exams are the apex of education. B7 feels the exams reflect their abilities: “...I base my final evaluation on what the exams are like". B17, a policymaker in Barbados agrees that the system is geared towards these assessments: "Yes, we are presently driven by exams but also looking at other forms of assessments. We are piloting continuous assessments...moving away from just the final exam". T25 expresses a concern about this dependence on exams: "But we find Maths is problematic because we have a high failure rate for what the national exam qualifies them to do". Yet perspectives on the CXC exams appear mixed, with some teachers complaining about the lowering of standards. However both B7 and B8 do not agree, stating that the exam questions are too easy: "they are pitching the standard of the region which I think is wrong. You may be setting a wrong example by setting the standard low and then they do CAPE and they get the shock of their life" (B8).

\subsection{Aspects of teaching and learning}

The above section on areas of strengths and weaknesses highlights the respondents' answers to questions related to systemic aspects of their own education systems. The following section summarizes discussions on aspects of teaching and learning that were prompted by the researcher to gauge teachers' perspectives of their pedagogical approaches and understand why traditional teaching persists despite policy changes. As these responses are remarkably similar in both island-states, in some cases the interviewees' comments are not separated by country. While the focus of this thesis is not limited to aspects of teaching and learning, dynamics of the classroom inform policy processes. In order to investigate the possibilities of 'horizontal borrowing' and the presence of 'vertical borrowing', it may be helpful to identify the challenges that the education system faces from the ground. Identifying the context in which teaching and learning takes place may determine the extent to which the countries are similar and perhaps uncover the influences. While similar aspects of teaching and learning do not necessarily provide feasible circumstances for 'horizontal borrowing' - either from each other or elsewhere - it will inform the impact of both colonization and globalization. These two tenets may better describe and answer the research question of whether or not 'horizontal borrowing' is possible as the concept may 
be masked in the two stronger pulses of historical colonization and current forms of globalization (see 7.3.3 and 7.3.4).

\subsubsection{Rote methods}

In general, teachers from both countries have mixed responses regarding less traditional modes of teaching such as problem solving, group work, cultural contexts of Mathematics and real life examples. Some teachers stress the necessity and frequency of use of these techniques while others state they do not use them. While teachers are critical of 'chalk and talk' methods, they often admit they teach in this style: "I think I try but I know sometimes it's too much chalk and talk" (T23). Another teacher notes the use of chalk and talk and then shares: “. .. it should be much more modern; 1 would think it's a bit archaic". Another Barbadian teacher states: "I would agree it's true but we can't get away from chalk and talk. We would have to revamp our whole system.... We have seen the group thing, but they have teaching assistants" (B14).

Some teachers, however, feel that teacher centred methods are not only effective, but also ideal. B11 shares:

...I think chalk and talk is a good way of getting over concepts although persons like to use technology, but I think students still grasp the theory behind it because even though you use lots of manipulatives, they don't get the theory. It makes it more enjoyable, do they still understand the concepts better is still up in the air.... Yes there is lots of chalk and talk but if the person delivering it is still good, it is still effective.

When asked how students best learn Maths, one Barbadian teacher replies, "by watching very carefully what the teacher is doing, and once they have the basics, you can apply that in different settings. It's fairly teacher based" (B8). This finding is consistent with the observations. Several teachers were asked to identify the benefits and drawbacks of this teaching method by the researcher as a way of trying to overcome bias against traditional methods of teaching. T9 explains reasons for choosing this instructional method: "You are able to explain....and if they didn't follow a step, you can erase it and go over it again". However, T9 is not able to identify the drawbacks of chalk and talk, simply stating: "I don't see any". T10, another Trinibagonian asserts that the only downfall was not being able to 
face the class and gives the following example: "when your back is turned, they can have a little snack so you can't see it". Similarly, B5, a Barbadian teacher feels the only drawbacks of dictation might arise if a child is absent during dictation or if there is a child with a hearing difficulty.

Other teachers have mixed feelings. T12 agrees it is easy to put up questions but admits it limits student engagement. However, B6 suggests it helps teachers guide students: "The teacher can pick up any errors that students are making.... For me one of the benefits is that you get immediate responses from students to see the concepts practiced in the lesson". Barbadian teachers such as B15 also feel it is effective but dated: “... we have not changed that much from the chalk and board/talk teaching and I still find it works for us in the Caribbean although with the influence of the outside world it is probably going to change". A further perspective is that chalk and talk is perhaps one step beyond simply 'talk'. T10 explains the experience of having a teacher who did not write on the board: "So working on the board helps, not just explaining and not being on the board". The following conclusion of an international respondent appears to reflect the interviews:

The teaching... that informs the pedagogy is pretty traditional - teacher is knowledge, needs to push class along, a curriculum timetable to get through things in the school year. Not child centred, not participatory, not very experimental (I4).

Teachers such as B6, however, are also able to see the limitations of chalk and talk: "One of the drawbacks is that it usually pigeonholes the students into adopting specific approaches to particular problems.... We are directing the course of the lesson instead of students having their input to the lesson". Administrators such as T26 are working on improving teaching through collaborative planning and argue that schools must be professional research communities. T26 feels that teachers must learn to sit together and talk: "Instructional strategies - those used presently may be obsolete and chalk and talk does not embrace the students, not in the least bit".

Others insisted they used group work and stressed problem solving techniques. For the most part, respondents are able to identify the limitations in this area, stating "I think a lot more can be done with respect to Maths" (T24). Teachers cite both lack of time and the exam oriented system (B10) as restraining factors for dependence on chalk and talk. 
Barbadian teachers feel the same way and offer similar perspectives. B15 highlights the need to cover the syllabus and "the way we teach cannot always promote problem solving as we call it". Some of the reasons include size of the class and length of the syllabus. Yet B10 notes that the CXC exam contains this element of Maths education: "the exam has included mathematical problems with...the emphasis on problem solving to ensure teachers do this at the school..." Curricular documents outlined in 5.4 also reflect such skills. B11 argues that problem solving is emphasized to a large extent but also states: "I try to show them how to go through the steps, A, B, C, and not just focusing on the answer", revealing a level of dependence on the teacher. Yet T24 asserts that problem solving skills are emphasized all the time. T24 appears to be in the minority as others argue that "the system does not focus on the thinking questions... We know the reason why students are weak and we don't focus on that, we focus on the strong points" (T15). On the other hand, T11 attributes weak emphasis on problem solving skills to the reliance on past papers: "They all want to see past exam papers and...they want to see it all, so if they see it worded in a different way, they can't solve it". However, teachers such as B6 express concern over this issue:

I am interested in how they would approach it rather than the answer. I emphasize that in my classes where appropriate. Sometimes I will hear, I know the answer but 1 can't tell you how I got the answer, I find that is a problem where they can't articulate how they got it.

Although not witnessed in the observations, some teachers describe their styles as interactive. This may be a result of the differences in definitions of word 'interactive'. It is possible that respondents feel that interactive learning involves participation on the part of students during teacher led activities such as showing steps to a Mathematical exercise, dictation or repetition of concepts. Some teachers claim to use group work (such as B12); however this was only seen once in the six weeks of fieldwork. Through the interviews, some respondents express the view of group work as chaotic:

It's something we try but because of the restrictions of classrooms and moving the furniture about and because there is much chaos going on, the class may have classrooms beside it, so you need to minimize the noise level...but I don't want to spend too much time on it because I don't want things to get out of hand (T18).

T11 experiences the same school cultural norms: "if you're talking about it here and the convent and most of the Catholic schools, discipline is important and they don't like to see 
talking as making commotions, or level of noise is high". This may explain why classes were minimally participatory and followed traditional modes of learning. However, participatory approaches are supported by the Ministries of Education in both countries (see review of NCSE and the Barbadian syllabus in 5.2, 5.3 and 5.4).

\subsection{2 'Real life' Mathematics}

As a whole, teachers in both countries express some interest in 'real life' Mathematics. Questions were asked to discern attitudes towards non-traditional approaches to teaching. Barbadian teachers such as B15 recognize the need to make it interesting: "... a lot of students say Maths is so boring and that is something we as Maths teachers need to do, find ways to make it ore interesting to the students that students would actually encounter". In particular, B10 recalls a national competition involving different subject areas such as Home Economics, Social Studies, Maths and Science. Each subject had to show relevancy to the chosen topic: "it brought out the different problems of every day life as it related to children's experiences". Other teachers such as T12 feel if schools have the right resources and building space, ideally students "would be learning from around them, even before they get to school, I suppose they can learn in any other environment, at the movies... whatever the student calls their natural habitat". B9 notes the necessity of explaining the relevancy of Maths: "That is always the first question, 'Ma'am, when am I going to use it?' So you try to find how they can use it in life, what they can use it for". B17, a policymaker, feels that students need to be aware of the relevance of Maths in order to overcome fear: "they encounter it every day; it isn't anything to be afraid of... Relate Maths to what they're doing in real life situation, when you see the importance of it, they can...pay attention to it because they see the relevance of it".

Some of the respondents state they use 'real life' examples and attempt to emphasize the relevance of Maths to real life; however this was not noted in the classroom observations. Barbadian teacher B14 expresses both the necessity and the feasibility to avoid it: "Real life? I don't think they can emphasize enough. Some people can teach Maths without once drawing attention to real life. I think it needs to be done whenever possible". B18, an academic, expresses concern over this issue: "How many Mathematics classes go outside... and actually measure the angle to show the angle of the tree, we can do it on 
paper but can't actually see it's done'. However, teachers are able to identify 'real life' topics such as consumer arithmetic and interest. Beyond stereotypical constructions of Mathematics as 'useful' in counting and business, the wider context of Mathematics is not explicitly discussed.

In particular, the Mathematics associated with the students' own culture - that of their home environment or out of classroom culture - is not identified within lessons with the exception of one teacher T18, who points out the Maths involved in drug dealing. While this may vilify the practice of building upon out-of-classroom experiences, other aspects of children's lives such as media, cultural practices, the arts and nature are not identified as possible breeding grounds for exploring Mathematics beyond the 'academic' curriculum. Most teachers recognize the presence of Maths in pupils' out of school experiences, and cite examples in their interviews of how "Maths is all around us" (B14), but do not appear to build on it in their lessons. This may be a result of the poor reputation of pupils' environments as inappropriate and invaluable to the school experience. When asked if outside school knowledge was built upon in the classroom, a few respondents note that the communities in which some of these children live carry out practices that are not approved by teachers. They cited drugs, media and over excitement about Carnival. One teacher shares: "...some of them have wrong concepts out there, you know you don't want to emphasize too much of the negative things... their teen life may not be the correct examples. We try to impose our right ideals" (T23).

\subsubsection{Mathematics and Caribbean culture}

Questions were posed about the importance of regional or local Caribbean culture to discern the degree to which a regional identity is shared. While respondents did not oppose the idea, none of them were passionate and appear mildly supportive at best. A few respondents asked for examples while others agree with the idea but did not express enthusiasm. B9 is supportive and provides an example in her response to the question:

...(I)f you're doing vector questions, is it faster to fly from Barbados to Jamaica straight or via Trinidad using vector. So they can visualize it because they know geometry and they can draw out the triangle and calculate the vector. 
Others recognize the importance of cultural context. B14 responds: "...if they can see and get it to relate to things they do culturally they should have a better attitude towards the subject". Yet there were other respondents who stress the importance of a global awareness:

I, however feel that we should not go from one extreme to another. When I was at school, all my questions were on English settings. Now that we have gone the other way, we should recognize the world is the world, so not just the Caribbean but expose them to other things out there (B7).

A few teachers question the effectiveness of these techniques, such as T11: "They talk about cricket scores and so on, they relate well to it. 1 don't know. I'm not sure if it works, theoretically it should work, but I haven't seen evidence". Yet B15 notes the importance of context: “...not saying you shouldn't learn about trains and snow but more relevant to the student if they're learning about things in their own world". One academic offers various ways in which Maths is present in the local Trinibagonian context through examples of patterns on steel pans and trapezium motifs, flutes in Hosay festivals, wing spans of carnival costumes and several others in an unpublished paper. The perspective of T14 may sum up how Maths teachers from both countries feel: "It's important, how much time devoted to it is another question. History is probably more able to do it than Math class but I think it's important for them to learn about Trinidad". On the other hand, academics such as $\mathrm{B} 18$ argue that a cultural conflict only exists up to a point:

If you get a British or American textbook, some of the examples used in the book, the Caribbean children might have no knowledge of what they're talking about. An area like bus schedule or timetable - you come to Barbados and you don't even know that a bus schedule exists sometimes because the buses come ad hoc. Even that kind of thing, the cultural difference is only in terms of using text.

However, cultural identity in education is emphasized in international and regional documents. See 7.1.2 for more discussion on gaps between fieldwork and policy.

\subsubsection{Accommodations for Lower Achieving Pupils}

As respondents voice concern about lower achieving pupils and the provision of quality education is a concern in the Caribbean, this section focuses on responses to questions regarding accommodation of lower achieving pupils. It appears that a systematic approach is lacking and teachers from both countries use a variety of different methods to cater to 
lower achieving pupils. Schools are divided by achievement as the $11+$ equivalent exam ensures that pupils with high scores attend the most reputable schools. B14 agrees, stating "A lot of students have not had a good foundation coming up from primary school...some students, they make it very difficult for you to teach them when they are in the secondary school so you will get students telling you they hate Mathematics". When asked why pupils struggle with CSec Maths, policymaker B17 points to the fear of Maths, problems with reading and a poor foundation of Maths when entering secondary school. Other reasons are raised such as students having short memories and needing to re-teach previous lessons. Children who are not able to write the $\mathrm{CXC}$ examinations are permitted to complete the Barbados Secondary School Certificate at the third and fourth form level (B17).

Although there is not a systematic approach to supporting lower achieving pupils, teachers appear to have techniques to accommodate students. B18 sums up one construction of how schools may accommodate different levels: "most schools have accelerated groups, those who move on faster and the slower ones who take a little more time to come". One example of a school initiative is the development of a peer tutoring programme at one Barbadian school which is in the process of being widened in scope (B15, B16). Teachers such as B8 cater to lower achieving pupils by doing more examples with them and questions on worksheets while B7 suggests more practical activities. B15 offers free private lessons for students writing the CXC. B18 points to the problem of teachers and the need to become more sensitized to lower achieving pupils and concludes: "I think generally we are an exam oriented society, and everybody does things for the exam, so you teach for the test, so if we teach the subject and forget the exam, we can do a little more". B15 also mentions form level teaching, where students' problems are discussed and how to 'solve' the problems of low achievers. On the other hand, B8 sees the problem of low achievement as resulting from large classes. When asked about recommendations to help more students pass the Maths exam, B8 points to the problem of pupils' lack of enthusiasm, large classes and discipline. Only one teacher recognizes the possibility that students may not be achieving due to method of instruction: "I would meet with them on a one-to-one basis, of course if you have a lot of people who have a lot of difficulty, it might be my teaching style rather than them" (B5). 
One of the schools at the bottom end of the achievement scale was included later in the study after the researcher was able to obtain permission to visit the school with a policymaker. The Maths department organizes the syllabus over the span of seven years rather than the traditional use of four years by other schools. This is possible as the school did not have a sixth form and students who complete the syllabus receive a scroll at graduation. B13 describes the methods used at the school:

The pace...is a gentle, slow pace. We use a lot of activities; we do a lot of our own preparation of our own exercises versus textbook exercises, so we can tailor questions to what we have taught and the understanding of the students at that point in time.... The language we use in the classroom, it is modified... we try not to go over their head; we try to use examples that relate to their own experience.

B13 also discusses professional development activities for teachers, in which five or six teachers coordinate the different year levels within the school to help share information and ideas. Assessment instruments are also "designed to benefit students in most respects and...we try to set precedents in terms of their difficulty so they will feel some sort of accomplishment" (B13). However, it is apparent that materials need to be developed on a larger scale that is appropriate to the learning styles, achievement levels and age of these pupils. During the interview, another educationalist suggested a book for the students at the school which is aimed at primary school pupils, noting: “...it is at the primary level, so you can't show it...so you have to use it as a teacher resource". The linear focus on the CXC exams may be a result of the lack of development for lower achieving students in both Barbados and Trinidad and Tobago.

In Trinidad and Tobago, this issue was also raised. Teacher T12 notes that accommodations for lower achieving pupils are "up to the individual teacher, see how far they want to go with them to spend that time. Other than that, they have to resort to lessons or outside tuition to get other small classes". Some teachers such as T14 share their methods: "I usually engage them more in class, once I recognize. I also recommend extra one-on-one with me". T25 suggests the use of concrete experiences, as "they must be able to relate what is being taught to them". T13 identifies some methods: "Try to bring them to the front of the class so you can monitor them a bit better, get them to sit next to a brighter student to help them to impart knowledge, walk around, stand next to them, and help them, and after class you can help them out..." 
While these methods may work, alternative styles of teaching are not mentioned and these techniques are seen as specific accommodations to traditional modes of teaching. Similarly, in classroom observations, teachers treated lower achieving pupils as needing more enforcement with basic concepts. The notion of going beyond chalk and talk does not seem apparent. This may be a result of the hierarchical divisions among secondary schools in both Barbados and Trinidad and Tobago, in which the rhetoric of the system may be based on divisions rooted on $11+$ exam scores. As such, the notion of catering to different achievement levels may be perceived to be less of an issue as students of similar levels are placed in the same school. However, educationalists did not appear to be strong proponents of the notion of natural ability as teachers in higher performing schools complained about the lack of critical thinkers and the over subscription of students to private lessons. This may imply that teachers believe to some degree that pupils who worked hard would be able to achieve passes in CXC exams. Some teachers point to the social problems in lower performing schools, while others point to the problem of illiteracy: "Maybe it's because their foundation is weak, their reading and writing skills are bad". Teacher respondents feel that primary schools were not preparing students for secondary education in this respect: "they must address the literacy problem early on in primary school; they shouldn't be coming into secondary school with reading problems" (T23).

\subsection{Perspectives on 'Horizontal' and 'Vertical Borrowing'}

Schools in both countries appear to work mostly in isolation, although teachers from different schools discuss education topics informally at workshops hosted by the Ministry. The recognition of similar problems across schools may be a preliminary step for collaboration. Some of these problems include the belief that Maths is difficult. Barbadian academics such as B18 believed this would be a way forward: "There is something called sharing. What we need is for teachers to get together". However, teachers such as B11 offer an explanation on why this does not happen: "...the schools are so different from each other. Some are board run; you have the newer and older secondary schools". A few instances of dialogue and collaboration are mentioned by the respondents, such as the coordination of information on early years work for the EFA initiative, regional conferences on aspects of education and politics and one of the schools in Barbados was 
visited by a group of teachers from another island as they were beginning to implement the CAPE level exams. When asked about interest in other Caribbean countries, the response is mostly positive although there were some mixed perspectives. Teacher T15 shares: “....if it is with the Caribbean exam, which or whatever region or country is doing well, I would like to know feedback from the country on how they have good grades, but checking out the statistics it seems that Trinidad has the best pass grades so they should come to us". T11 simply replies, "Not really" and B8 responds ambivalently "I don't think any teacher would have a problem at looking at other territories or other parts of the world". B9 concurs: "I have no problems with that. It's all for the greater good of the students". Others welcome the idea, T25 agrees with the premise: "well it would be welcome; it would help the situation, certainly", while T22 states, "of course, yes, of course". One respondent recalls the biennial meetings of the Caribbean Association of Headteachers as an example of an opportunity for discussion.

Teachers also refer to the CXC marking sessions as a time to meet other Maths teachers in the Caribbean. B10 explains the experience: “...you are transported to different marking centres and we have a chance to talk, and you can share with other islands, sometimes you find a problem is not unique and you can see the approach they take and deal with it in other islands". Within the Ministry, there are a few key members of staff from other islands and thus innovations from the region are highlighted. There was some interest in a Jamaican vocational education program. However, academic B18 points out the possibility of universal, rather than regional problems: “...from my readings, we all have the same type of problems. I went to a conference - the [name of American organization] three years ago and some of the problems which were discussed were the same ones we meet here in Barbados".

There is certainly a push towards the same goals within the Caribbean by international initiatives - particularly raising the quality of education through the Education for All initiative. This is relevant within Mathematics education due to the heavy emphasis within the students' timetables as Maths is mandatory in secondary school. Non-attendance is high in poorly performing schools in both countries. The necessity of relevant Maths curriculum for secondary school students beyond the linear focus of school leaving exams is necessary, as many of secondary school leavers will not attend tertiary education. In this regard, there 
are certainly common problems within the region. Yet with the exception of some examples of collaboration, it appears that the individual island states tend to look to each other minimally for inspiration, best practices or 'horizontal borrowing' of policies. I6, an international respondent, offers an interesting analysis of the constructed aspect of regionalism:

The question is, are these bodies home grown? Is it that they look to each other to work together? And the question is, are these driven by the interests of developed countries or is it that developing countries are preferring this way to organize the world, preferring them to solve their own problems....?

This is perhaps contrary to the beliefs of others in the international community. Another respondent argues the following: "lt is important that we treat the Caribbean as a region moving on the basis of greater cohesion and greater cross fertilization, and common benefit to all players, meaning all islands..." (I5). Yet the tendency to look towards the 'West' may be a result of assumptions that countries such as those in South East Asia and UK and USA have managed to achieve a success in particular aspects of education. In particular, one respondent suggests the lack of expertise in the Caribbean with regards to education success:

...(W)e would look in countries with status in industry and technology perhaps as a habit, perhaps as a tradition but I don't think the Caribbean, perhaps tourism, is the only thing we have international recognition in, because of our climate, our food and culture, as a Caribbean community. But in other areas, I don't think we have that status just yet (T26, headteacher).

Indeed, this is consistent with the interview findings in which educationalists reveal interest in areas such as South East Asia due to their performance in TIMSS and thus "certainly those countries would be doing something right" (T26). Academics refer to research in online journals from Australia, the USA and UK. A Canadian consultant also worked on the NCSE curriculum document. Although Phillips and Ochs (2003) note 'borrowing' from a Canadian project on instilling responsibility on communities for raising children in Trinidad and Tobago, respondents were not aware of this initiative. Yet this process of 'sharing' is supported by one international respondent: "If you are a small state operating in a specific context, then sharing with other small states is of great advantage" (I5). Yet another international respondent wrote the following in an email: "The introduction of CARICOM and the very new Caribbean Single Market are two initiatives aimed at bringing 
us closer to together as a region (which makes sense), but we struggle with the need to be ONE while maintaining our individual independence...." (I3). However, the element of competition between the two countries may be an impediment to sharing and collaboration. B2, in an informal conversation during the main data collection, shares the following: "I don't think that everyone having qualifications is a good thing. We have good rates of passes at this school $-93 \%$. We wouldn't have such high rates, - and Barbados does have good passes - it's just that places like Jamaica and Guyana do not". In response to a discussion about sharing on a school level, one teacher also states, "people are reluctant to use things created by others, some of that is jealousy or envy, and some of it is wanting to use their own things". This notion of jealousy is similar to comments by pilot respondents (see 4.3.1) and confirms the possibility of cultural resistance to sharing.

Respondents identify possible areas of interest for improvement such as the problem of pupils disliking Maths. This issue is prevalent in many countries, and may be seen as possible area of collaboration for the region - or may be perceived as universal Mathematics education problems in which solutions may be found by looking 'globally'. Respondents at the policy development level seem more interested in participating on a global scale rather than a regional level. This is evident in the description of the curriculum content as relatively 'universal'. B17, a policymaker believes "Maths is universal. You can pretty much use [the Barbadian curriculum] anywhere. I looked up the National Council of Teachers of Mathematics and it fits their frameworks. It's universal". In the same vein, B6 suggests the existence of a 'canon': "I don't think the cultural aspect should become too important in a Maths programme. I believe that there is a certain body of Math knowledge out there, that the average person should attempt to acquire". When asked what is included in this body of Maths, B6 replies the following:

Ability to make reasonable estimates in terms of measurement, somebody should be able to estimate the size of the room, how many people can occupy the room, in terms of how much air and space they require, the ability to deal with buying and selling, the ability to deal with wages, bills, consumer mathematics. Everybody should be familiar with that type of mathematics.

Teacher T23 states that the teaching of Maths and culture had the potential to make global Maths 'local': "I would think it's part of global Maths... maybe it's the teacher, they may impose the culture into the Math with examples but the actual syllabus could be used 
anywhere". Yet this acceptance of the constructed 'global' Maths curriculum may be a result of dependence on international recognition of the curriculum in place of a more culturally relevant curriculum.

I6 discusses the gap between the needs of the individuals and the constructs currently in place by identifying the presence of an elite within the Caribbean. I6 shares: "the challenges to...small states is to move to education organization management to a strong connection to dialogue with policymakers and the majority of learners who are...primarily Creole in language and culture". However, this movement towards prioritizing the needs of the local may be further complicated by the changing nature of aid in which multilaterals tend to align themselves to the Millennium Development Goals: "To be an active donor, you have to adopt the same discourse, especially with respect to education and development". The universal approach to aid, therefore, may result in an increasingly 'global' picture of education and development that may manifest itself in similar approaches to policy.

Thus, is 'horizontal borrowing' possible? Within the small states of the Caribbean, one respondent believes it is: "Yes. Because I've seen it happen, effectively because of the size of the Caribbean and the proximity of the countries to each other and already from the standpoint of officials and ministers, there is a lot of cross fertilization and learning that goes on" (I5). There is also the suggestion that 'horizontal borrowing' may be better suited for the smaller Windward Islands. One respondent mentions the reliance of these islands on Barbados for teacher training in the eastern Caribbean:

...(S)maller islands have had their own initial teacher training courses or in service training and those islands have been connected to Barbados. The curriculum had to be accepted by Barbados to take it - initial exams had to be marked and then brought back to Barbados to monitor it (14).

However, the same respondent notes some tension in this relationship:

Really, the islands are advanced so they could set up teaching training profiles and not under auspices of Barbados. There is some tension because some of them are more advanced and others less advanced. Some, like St. Lucia, are trying to lead the way to more advanced approach. 
This may be considered imposition but needs to be analyzed further to see if the OECS countries are facing different forces in 'horizontal' or 'vertical borrowing' impulses. In Barbados and Trinidad and Tobago, 'vertical borrowing' as a concept may be a result of the process from colonization to globalization (see 7.3.3 and 7.3.4). The possibilities for 'horizontal borrowing' between the two island states may be limited as a result of the directions in which both countries are headed with regards to development. The key agenda appears to be the same, yet the results appear closely aligned with a global process of 'horizontal borrowing' from a constructed commonality - whether real or imagined. I6, an international respondent uses the example of private schools as a potential 'mask' of 'horizontal borrowing' - when indeed it may be part of a neoliberal agenda that may be of interest to countries. In this perspective, the expansion of private schools may be something the two countries have in common due to global pulses rather than 'horizontal borrowing' between each other. The individual identities of the countries and the similar directions may be impulses for 'horizontal borrowing' - but the key ingredient as identified by Phillips and Ochs (2004) of cross-national attraction does not appear to exist. Instead, the desire to participate in the knowledge economy may be of greater importance. Further, it appears that many aspects of teaching and learning in both countries have not moved towards the new curriculum approaches created by the countries themselves and thus rote and traditional perspectives on teaching and learning persist. The success of Barbados in achieving its Education for All goals may lie in its strengthened priority on teacher training. Trinidad and Tobago may be able to learn lessons on how the government implemented this initiative; however, this again may be a result of both donor agendas and a worldwide push in literature to increase the training capacity of educators. The intention of keeping up with the world is expressed in Barbadian academic B18's response to where reform is headed in Barbados: “...l don't know. What happens here happens in the wider world, a global thing. So we try to keep up with the global changes, wherever it is, and that will be the influence for whatever is going on". Research from the 'west' may have a stronger influence than findings from neighbouring islands. There appears to be several important reasons for this, one of which stems from electronic journals which are easily accessible. One academic pointed to the benefits of low cost and physical access of both North American and Australian journals. Larger forces such as globalization, convergence, colonialism and the movement of people as 'bridges' for ideas provide explanations for the findings and will be outlined in the next chapter. 


\section{Analysis of Research Data: Examining the gaps between theory, policy and practice}

The chapter begins by examining interview responses, followed by a larger consideration of the policy review and observations, which were used for the purpose of triangulation (see 4.2.2.3). It is clear there are some clear gaps between theory, policy and practice of 'education borrowing'. The following section attempts to understand these gaps by outlining ways to conceptualize data. Specifically, the current realities and ideal dynamics as proposed by policy documents are described. Phillips and Ochs' (2004) model is assessed against the state of policy and practice in Barbados and Trinidad and Tobago to evaluate the gap between theoretical approaches to borrowing and the specific case of these two island states. Other theoretical perspectives are also assessed to draw conclusions on the gap between theory, policy and practice. Finally, the chapter moves towards proposing other explanations for fieldwork data, particularly resistance to borrowing (7.3.1); forces of tradition reinforcing existing pedagogies (7.3.2); impact of colonialism on patterns of 'vertical borrowing' rather than 'horizontal borrowing' (7.3.3); similarities of policy and pedagogy due to globalization and convergence (7.3.4) and the slow realization of global policies (7.3.5). Each of these subsections proposes a way of understanding the data of this research, bringing together literature from Chapter 3, policies reviewed in Chapter 5 and the voices of interview respondents in Chapter 6.

\subsection{Analysis of Data}

\subsubsection{Discussion of Data}

\subsubsection{Differences between Barbadian and Trinibagonian responses}

Barbadians respondents were proud of the achievements of their system due to its high standing in CXC and in the region as Barbados is viewed as having a strong system in the Caribbean. While some teachers were careful to qualify that the achievements were due to the pupils' ability to pass exams, others took pride in the system and attributed it to the number of qualified teachers on the island. Only one respondent felt that the system was 
better than the UK. Despite the level of pride for the national system, teachers did not note anything inherently strong about the curriculum. The notes from the classroom observations are consistent with the finding that teachers know very little about the aims of the syllabus and most of the pedagogical aims were founded on exam preparation. It is important to note that there was very little justification for the aims of the syllabus in the actual curriculum document. Further, as Barbadian teachers were briefed about the intentions of the study, they may have felt they needed to highlight aspects worthy of being 'horizontal' lenders. While several male Barbadian teacher respondents were very proud of their system, other males were slightly more critical. In particular, B13, a teacher from a lower achieving school noted the support needed to assist lower achieving pupils (see 6.4.4). Yet this criticism seemed to support the mainstream rhetoric of the system based on merit and the notion that they are not able to participate in the system. Thus, criticism was not aimed at the values or problems inherent in the system but rather the support needed to help students to navigate education. Further, the department under the care of B13 did not use drastically different methods or approaches to teaching - rather an amended four year curriculum spread out over seven years to fulfil the national scheme using a slower pace. Despite B13's criticism, the methods used are not system subversive or innovative, but appear to be a watered down version of traditional linear methods. The hierarchy of schools and the elitist system were certainly subscribed to despite the criticism expressed by B13.

On the other hand, all Trinibagonian respondents found it difficult to speak at length about positive features of the system. Although they were not able to identify strong features of the school system, young, female Trinibagonian teachers were the less willing to critically discuss education in Trinidad and Tobago. Older Trinibagonian teachers, particularly males or females in positions of power spoke passionately about their experiences and perspectives of the system. The difference in willingness to engage critically in the interviews between the young female Trinibagonian teachers and males and females in positions of power may be a result of power dynamics. Young teachers may experience less exposure to the system and may not feel comfortable speaking up. In addition, the interviews with these younger female teachers took place under awkward circumstances as observations were cancelled due to teacher absenteeism. Thus, the Head of Maths asked available teachers to participate in interviews. Three out of four of the interviewees were young females. Perhaps interviewees felt uneasy about the researcher's expectations. 
Similarly, the one Trinibagonian male teacher who did not offer strong responses was held up as an exemplar for his use of teaching with technology and thus may have felt that he needed to limit his opinions about the system.

While teachers in both countries were critical of the system, they were also proud of their work with the students and their ability to help students 'get through' the exams. Responses varied among teachers in the same school. The achievement level and social standing of the school had little bearing on the responses provided by teachers. There was a strong recognition of the expository pedagogical approach of 'chalk and talk' by all teachers. While teachers mentioned techniques used to make rote teaching more student-centred, little effort was made to depart from the realm of traditional Victorian teaching. On the one hand, teachers felt the system was elitist and rote but on the other hand, they also subscribed to the values inherent in the system. Teachers and academics in Barbados and Trinidad and Tobago noted that at best, children who were able access education and the rote pedagogic methods, were able to benefit greatly from the system.

Although three teachers noted resistance to sharing and cooperation among colleagues, other teachers did not mention competition. Between high achieving schools, there was a pressing need to ensure top scores in both countries. Schools were proud of their standing on their island due to the number of national scholarships awarded to their students achieving high CAPE examination results. As noted in the pilot, Barbadian teachers such as B2 took pride in the lack of achievement of other places. Regardless of the achievement level of their schools, all teachers were equally concerned about low achieving students and the cohort of secondary school aged children leaving without certification.

\subsubsection{Differences by respondent positions}

There was widespread agreement among teachers, policymakers and academics that rote teaching methods persisted. Academics and policymakers felt that the teaching profession needed to be improved, and this was also recognized among teachers in Trinidad and Tobago only. Respondents in all positions were eager to talk; however willingness to engage was highest among Maths heads of departments and academics. This is probably due to the way in which contacts were made. As the initial contact in each school was the 
Maths head of department, they were key gatekeepers of the fieldwork process. While their willingness to share their opinions may be due to their age and experience with the system, their interest in the study was evident in their interviews and in the coordination of subsequent interviews with their staff.

There was agreement among teachers from both countries on several topics: chalk and talk, relating Maths to outside classroom knowledge and low achieving pupils. Academics and policymakers had differing views from teachers on all three of these topics. In both countries, teachers of all levels of experience acknowledged their use of rote methods. Predictably, there was widespread agreement on the general notion that connections to real life Maths was important among teachers, academics and policymakers. As this is a very loose and often superficial concept, there is often a large amount of ambiguity surrounding the phrase. Teachers were able to identify topics and types of questions such as consumer arithmetic and interest. Beyond stereotypical constructions of Mathematics as 'useful' in counting and business, the wider context of Mathematics was not explicitly discussed. When asked about the degree to which they emphasized this in their classrooms, some teachers responded positively; however this was not noted in the classroom observations. Other aspects of children's lives such as media, cultural practices, the arts and nature were not identified as possible breeding grounds for both examples and exploring the Mathematics beyond 'academic' curriculum. Most teachers recognized this, and cited examples in their interviews of using real life examples, but did not appear to build on it in their lessons and this notion appeared to be rhetoric rather than a deep pedagogical conviction. This may be a result of the reputation that out-of-classroom environments have as inappropriate and invaluable to the school experience. When asked if outside school knowledge was built upon in the classroom, a few respondents noted that the communities in which some of these children live carry out practices that are not approved by the teachers.

The sentiment on both countries was the 'problem' of low achievement appears to begin from primary school and continues into secondary school. Despite the onus placed on individual teachers in both countries to accommodate lower achieving pupils, a systematic approach was lacking apart from the division of schools by ability level. Teachers in both countries listed techniques they used to help students. While these methods may work, 
alternative styles of teaching were not mentioned and these techniques were seen as add on approaches to traditional modes of teaching. Some teachers pointed to the social problems in lower performing schools, while others pointed to the problem of illiteracy. B8, a Barbadian teacher saw the problem of low achievement as resulting from the students and large classes. When asked about recommendations to help more students pass the Maths exam, B8 pointed to a lack of enthusiasm, large classes and discipline. Only one teacher (B5) recognized the possibility that students may not be achieving due to method of instruction. Despite their beliefs, a need for stronger inclusion for lower achieving pupils was evident in both teacher interviews and observations.

Yet policymakers and academics were critical of teachers. B17, a Barbadian policymaker was well aware of the pedagogical situation and highlights the problem of teacher beliefs:

We are encouraging them to use guided discovery, expository way of learning Maths. As for does [chalk and talk] work? The older teachers will say it worked in older times; they followed the teacher and did what they're told...

$\mathrm{B} 18$, a Barbadian academic points to the problem of teachers and the need to become more sensitized to lower achieving pupils. Policymakers also recognized the need to improve the teaching profession, including the state of teaching in Barbados. However, there was little recognition at the teacher level that the pedagogy may be impacting student achievement. Although it is interesting that both policymakers and teachers pointed to the lack of commitment in the teaching profession, the majority of teachers who participated in the study did not attend a teaching development day hosted by one of the teaching unions. While the union may not have direct access to plans put forth by the ministry, the low attendance at such meetings may be indicative of problems with communicating to the teaching population. For example, teachers were critical of the NSCE but there was inconsistency of perspectives with regards to its aims and intentions. This may be a result of the lack of ownership felt by teachers. With regards to the NCSE, teacher T24 argues that schools need to fulfill their roles of assessing pupils and submitting data to the Ministry. Although there was some agreement among respondents from both nations that teacher training is a strength in Barbados, this is probably not a possible avenue for 'horizontal borrowing' as the government has few plans in place for expanding training and more engagement is needed by the teaching workforce. 
Unsurprisingly, academics were vocal about their opinions especially when it involved their subject area. Only one academic appeared reserved and did not critically engage with system problems but only discussed topics related to the faculty of education, perhaps due to a conflict of interest of holding a temporary position of power and the vulnerability of appearing too critical of those in higher positions. Maths education academics were critical of teachers and their approach to 'real life' Maths. With the exception of one respondent, academics were generally critical of the system. This respondent may not have been critical due to the high recognition of teacher training in Barbados and may have felt there were expectations to provide information and not personal perspectives. A student teacher was also present at the interview. Despite attempts to reach the respondent and the head of the education department for further interviews to query the approaches used by the college, there was no further contact with members of the college. Yet the area of teacher training is particularly interesting as it may indicate the level of critique they are expected to engage with. One academic noted the weak critical nature of teacher training in Barbados despite its strong development in ensuring teachers received adequate preparation for their roles. In a debriefing interview, this respondent expressed a need for a stronger push towards helping student teachers examine and reflect upon their own experiences in order to change their pedagogy.

\subsubsection{Consistencies and gaps between fieldwork and policy review}

This subsection will mostly examine two large gaps between fieldwork responses and policy: the relationship between culture and curriculum and the notions of 'horizontal' and 'vertical borrowing'. Other gaps will also be identified at the end of the subsection.

\subsubsection{Culture and curriculum}

Teachers, academics and policymakers in the two island states found it difficult to link together Caribbean identity with curriculum content. Yet initiatives from the island governments appeared to be met with ambivalence (see 6.3). While respondents were not pessimistic about national initiatives, there was little enthusiasm for NCSE and the new Barbados curriculum. Knowledge seemed to neither develop from the region nor become 
indigenized. When asked about the importance of regional or local Caribbean culture, teachers seemed ambivalent to the idea. A few respondents asked for examples while others agreed but did not express enthusiasm. One teacher was skeptical of the effectiveness of linking culture to teaching content while another teacher was supportive and provided an example in her response to the question. Yet others such as Trinibagonian T23 simply note: "Maybe we are just not thinking along those lines". This statement is indicative of the general feelings towards regionalism and the lack of indigenous identity attributed to both teaching and subject knowledge. Yet there were other respondents who stressed the importance of a global awareness to "...recognize the world is the world, so not just the Caribbean but expose them to other things out there" (B7, teacher). Definitions of "the world' and the notion of 'global' usually refer to 'the West'. All of these terms are ambiguous, left undefined and uncritically approached. This results in further vulnerability of the islands as it perpetuates Eurocentrism and continues to posit the Caribbean as 'Other'. The perception that Maths is 'global' is prevalent whereas subjects such as history and geography appear to be responsible for instilling a sense of Caribbean culture. Teacher B11 certainly concurred, stating, "Once you have the concepts you can use them in any situation... I don't think it makes a big difference". The necessity to participate in the knowledge economy thus overrides the need to strengthen cultural identity and to take pride in education as knowledge that organically develops from a national pulse. Rather it appears to be viewed as a system that has evolved from the outside and contains knowledge that must be transported into the minds of students in order to gain currency in the wider world. Education knowledge is viewed as being static and at best, user-friendly to those who can access it.

Although only two Maths lecturers were interviewed, there was some agreement at the academic level. While both academics felt connections to 'real life' were important, they differed on their approach to the intersection of Maths and Caribbean culture. Interestingly, one of the policymakers was enlightened by the notion of marrying Maths with Caribbean culture. Perhaps this will be further implemented in pedagogical aims of the ministry although it is mentioned in the syllabus and falls under the overarching aims of the CXC. Certainly a Caribbean identity in curriculum and pedagogy is encouraged in policy documents such as Howe's (2003) report to the International Bureau of Education (see 5.1.2). Despite continued practice of culture-free traditional pedagogical approaches 
evident in the interviews and classroom observations, policies on the island, regional and international level advocate a paradigm shift in teaching. One of the founding pillars of the NCSE aims to ensure citizenship through the curriculum. The syllabus of Barbados also includes many examples of integrating outside classroom knowledge into teaching. This is consistent with the aims of the Barbados syllabus. While the syllabus in Barbados is laid out as a checklist of competencies, the document also includes general objectives which provide a wider understanding of Mathematics education (see 5.2.2).

Similar to the assertions of the Barbados curriculum, Trinidad and Tobago views Maths as a platform for enabling critical, creative, logical, investigative and problem solving skills (Government of Trinidad and Tobago, 2002b). While the Barbados document is much shorter in its rationale, the Trinibagonian document explains in further detail the ways in which Maths contributes to the goals of education through wider goals of making connections, representation and recognition of patterns. The curriculum states the commonly asserted notion that Maths must be relevant to the environment in which children live (Government of Trinidad and Tobago, 2002b). The curricula of both Barbados and Trinidad and Tobago are removed from the realities at the classroom level. The subject specific intentions of $\mathrm{CXC}$ advocate a deeper approach to thinking about Mathematics. The CSEC syllabus operates on three guiding principles:

1. Relevant to the existing and anticipated needs of Caribbean society

2. Related to the ability and interest of Caribbean students

3. Aligned to the philosophy of the educational system (Caribbean Examinations Council, 2001: 1)

While there is no further discussion of the philosophy that underpins the education system (nor reference to specific education systems), the document states that the principles focus on Maths education as problem solving tool and assert that Maths is a study of coherent subjects which form a body of knowledge "rather than a set of unrelated topics" (Caribbean Examinations Council, 2001: 1). While Maths topics were linked together, the way in which the lessons were delivered did not weave together the relevancy of the topics to the needs of Caribbean society nor cater to the interests of students. Similar to most of the region, the first two UNESCO pillars of learn to know and learn to do were evident but the latter two of learn to live together and learn to be were sadly absent. The gaps between the aims of these documents and teacher practice may be attributed to poor communication of 
these aims, perhaps stemming from weak reflective study of the syllabuses in teacher training colleges.

\subsubsection{2 'Horizontal borrowing' of ideas}

The notion of the Caribbean as a region appears to be posited as a geographical entity rather than a dynamic partnership from which innovation and strength may be drawn. While 'horizontal borrowing' is strongly advocated in both the policies of Education for All and the Commonwealth Secretariat through the encouragement of sharing best practices, SouthSouth collaboration, and forming regional associations, these notions seemed far removed from the realities at the teacher, academic and policymaker levels. This may stem from the limited view of regionalism. Policymakers in Trinidad and Tobago such as T3 were critical of their home system but were also reluctant to 'borrow' from the Caribbean despite noting that there was previously interest in Canada. Another policymaker identified some interest in Jamaica and the CXC but was not specific about experiences of 'horizontal borrowing'. The ambiguity expressed may be due to a lack of knowledge of the foreign examples examined or respondent reservation. When asked about similarities, respondents from Trinidad and Tobago felt that their twin isle state was unique. At the level of academics, there was some resistance, although the perspective varied. Respondents often pointed to the differences between islands and noted the systemic and historical differences in the ways in which education has evolved on the islands. On the other hand, international respondents who had been involved with policy saw the islands as being relatively similar. Certainly, the challenges of traditional pedagogy, cultural values and the linkages created by CXC were evident in the interviews. International respondents varied in their opinions and approaches to 'horizontal borrowing'. Some international academics were skeptical of 'horizontal borrowing' while only one international policymaker was strongly enthusiastic while others were less than enthusiastic about regional sharing, although one mentioned some of the best practices in a regional EFA document. However, the extent to which these regional practices were implemented was not discussed. While there were a few respondents who felt that the two countries were able to borrow from each other, the vast majority of respondents did not show enthusiasm. Generally speaking, teachers were ambivalent or resistant towards sharing and academics were critical of it. On the other hand, heads of schools welcomed 'horizontal borrowing' and policy makers embraced it. It 
is interesting to note that Barbados felt it was in a strong position to be a model through the policy review and the interview responses in the policymaker, school management and teacher level. However, Barbadian academics were more critical of the system, with one academic stating that it could not be a model.

All of the above views contrast the support for 'horizontal borrowing' by multilaterals such as the Commonwealth Secretariat and UNESCO who heavily advocate regional sharing, replication and cooperation among states (see 5.1.2). The intentions of policy seem far removed from the sentiments among local actors. UNESCO supports regional networks as well as they "provide platforms for strengthening cooperation in EFA" (UNESCO, 2006b: Annex 1, p18). Through national, regional and subregional EFA forums, UNESCO also aims to foster "cooperation and sharing of experience" (UNESCO, 2002: 18). Both the UNESCO policy documents of 2000 and 2006 reinforce this notion of 'horizontal borrowing' through the rhetoric of 'international cooperation' (UNESCO, 2000: 42) which is not recognized as problematic. Yet there is also the implication that there is some pressure for countries to cooperate in this practice, as one of the action points contains a call for governments and societies "to make every effort to co-operate in the development of policies, strategies and action plans that will give a new thrust to polices that guarantee to all people the right of access to basic quality education and to reap its benefits" (UNESCO 2000: 42). By sharing best practices, the Commonwealth Secretariat hopes to "stimulate faster and wider replication across the Commonwealth" (Commonwealth Secretariat, 2003: 26). The sharing of such practices is ongoing through the publications of documents that describe examples of programmes and innovative projects for replication. Regional cooperation ensures that small states can deliver all of the functions of a modern state. The smallness of scale leads to the necessity to seek collaboration with other countries facing the same capacity challenges in the areas of health and disease control, higher education, secondary school examinations and foreign representation (Briguglio, Persaud and Stern, 2006). Not only is such geographical cooperation supported by international documents, the potential for regionalism is strongly supported by the Caribbean Single Market and Economy initiated by CARICOM. Thus, the notion of sharing among Caribbean islands seems to be limited to regional organizations such as CXC and CARICOM which provide a collective infrastructure. At the national level, there is little interest in 'horizontal borrowing' from other islands. Rather, national documents 
seem to focus on developing a stronger awareness of both a Caribbean identity and community. This is evident in both the national documents aimed towards developed nation status for Barbados and Trinidad and Tobago as well as the curriculum documents. Unfortunately, initiatives even at the national level are not implemented at the local level.

\subsubsection{Other gaps}

There is also a gap between the policy review and the literature review. Phillips and Ochs' notion of 'borrowing' is far narrower than those espoused by the policy documents. While 'borrowing' is not explicitly used as policy buzzword, other phrases used in relation to dialogue are 'peer review', 'South-South cooperation' and 'good practice'. Peer review involves examining the political, institutional and implementation frameworks of EFA. As the practice necessitates willing and engaged participating countries, there is also the expectation that peer review will result in changes in policy and South-South partnerships are expected to encompass the wide range of developing country needs. Finally, the Commonwealth uses the term 'replication' without much discussion. 1t is mentioned with reference to the Good Practice Awards and is not approached critically. The notion of 'sharing best practices' appears limited to examples of successful policies or programmes (such as those listed above by Briguglio, Persaud and Stern, 2006) in which other countries may benefit from reflection or discussion, or as information gathering. UNESCO uses the phrases "adopt and disseminate good practice" (UNESCO, 2006b: Annex 1, p11) and on a more subtle but powerful level, provides support to policy-makers by identifying best practices “... with a view to buttressing education strategies..." (UNESCO 2002: 24). The phrases used to describe the action taken on 'best practices' by UNESCO and the Commonwealth Secretariat indicates implementation through adoption and buttressing strategies. Perhaps this is due to the 'phoney' nature of 'horizontal borrowing', to use Phillips and Ochs' (2004) phrase. While it may be easy to classify all of the encouragement of 'borrowing' in the international documents as simply rhetoric, more research into the intentions and challenges of regionalism may be needed, particularly in the area of developing countries. Most of the cases reviewed by academics in the field involved 'horizontal borrowing' in the 'West' and the epidemic of OBE. There was little written on cases of South-South collaboration or the benefits or disadvantages of regionalism apart from the work on small states. Perhaps the focus on 'horizontal 
borrowing' has yet to involve smaller partnerships or cases of implementing policies to encourage sharing best practices among developing countries. While the rhetoric of SouthSouth collaboration is relatively new in the area of development, there is a weak basis of literature to build a stronger foundation for the field. Although such policies to encourage sharing are in place, and there is a good body of literature on the use of foreign ideas, it is difficult to use ideas from the larger body of literature to critique policies.

\section{$\underline{7.2 \text { Conceptions of Data }}$}

\subsubsection{Current realities and ideal dynamics}

International policy documents implicate an ideal Caribbean dynamic in which islands work together with minimal hierarchy (see 5.1.2 and 5.1.3). As a result of regional cooperation, the goals of 'horizontal borrowing' and sharing good practices and ideas among islands are reached. In this ideal, global agendas are disseminated and indigenized into national initiatives of similar but not identical scope. International policies also aim to replace the islands' colonial gaze towards the metropole with a stronger focus on the 'international community' to ensure a euphemistic change of perception over the colonial notion of 'centre'/periphery. In the ideal situation, the 'international community' remains present in the region and supervises opportunities for sharing, such as involvement in agencies such as the Caribbean Development Bank. The power of tradition is absent from the ideal as imagined by policy documents, either through naïveté of the local context or ignorance. Yet the reality of the situation differs greatly from this 'harmonious' ideal. Dissemination of global initiatives not only confronts cultural differences, but also the competing priorities of national initiatives and forces of tradition. Instead of looking towards each other, islands look to the 'centre', an ambiguous 'global education' that islands follow, usually referring to the information they receive about education in North America and Europe, in particular the USA and UK. The 'centre' is impersonal does not have a direct relationship with the islands but affects the 'world economy' and 'order'. Barbados and Trinidad and Tobago are vulnerable to outside forces, to both the benefit and detriment of the islands. The notion of a national identity is difficult to foster as the islands gaze outwards and at the same time other nations look towards less industrialized countries for development opportunities, exploitation and control. Vulnerability thus acts as a double- 
edged sword. One informal respondent from Barbados views the influence from the outside as a process of 'reacting' rather than planning, swaying in the midst of changes in the 'world' and thus results in the illusion of control. The respondent states: "When something goes wrong, it is due to outside forces; when it turns out well, it is a national idea".

It is important to note that teachers, academics and policymakers recognized some aspects of sharing and regional cooperation, such as informal camaraderie, during the CXC marking sessions. There are also some formal associations such as the Caribbean Association of Headteachers although formal documents have yet to be found. Regional 'horizontal borrowing' is at best limited to informal discussions in which islanders hear about developments in neighbouring states through word of mouth. In other words, networks of traveling information exist but do not appear to be significant, as substantial evidence of effective informal networks is lacking. Although there are regional forums such as those initiated by EFA, UNESCO and the Commonwealth Secretariat, they are imposed and agenda driven. Despite these opportunities for 'horizontal borrowing', little sharing occurs between the islands in the current situation. However, the ideal is simply not in line with the realities of the islands. EFA has faced challenges for a few key reasons at the national level such as weak political will and inadequate attention to the needs of the poor and excluded (UNESCO, 2000). Despite EFA regional working groups and panCommonwealth meetings, teachers in both countries were not strongly convicted about possible avenues for 'horizontal borrowing'. Although teachers in both countries identified teacher training in Barbados as a strength, there appeared to be little motivation by the Trinibagonian government to improve training. Further, teacher engagement is an issue among Trinibagonian teachers.

In the ideal and current situation of relationships in the Caribbean, a dual economy exists. One economy operates outwardly and is concerned with what is happening 'elsewhere'. The actual conception of 'elsewhere' determines the relationships and values that countries hold. In the case of Barbados and Trinidad and Tobago, elsewhere usually refers to North America and Europe. The other economy operates inwardly and is the national or local economy. However interviews reveal the limited nature of the inward economy as national development initiatives are hindered by forces of tradition. The outward gaze towards the 'centre' is also a force away from reinforcing national initiatives. Thus, the outward gaze 
overrides national support for island programmes. However, the similarity of these initiatives is striking, mostly due to a global agenda. National initiatives therefore are not indigenous and cannot simply be grafted into the system without considered indigenization. Most of the English speaking Commonwealth islands in the Caribbean are usually viewed as being the same and thus a panaceaic approach is used. The differences in context are an interesting issue. While islands see themselves as having distinct historical, cultural and economic contexts, they are usually viewed as similar in policy. Regardless of perspective, to what extent do these differences actually matter? The findings of this study confirm that perspective impacts cross national attraction. The perceived distinctions from the points-ofview of both islands make 'horizontal borrowing' difficult regardless of how it is viewed by others in the international community. Ironically, the perception by teachers on both islands of Maths as universal does not translate into 'horizontal borrowing' opportunities from each other, but translates into looking 'elsewhere' and justifying the gaze towards high performing countries in South East Asia (see 6.5).

\subsubsection{Assessing Phillips and Ochs' (2004) model}

Simply put, there is no evidence of Phillips and Ochs' (2004) notion of 'borrowing' currently in place. Further, the possibilities for formal 'horizontal borrowing' between Barbados and Trinidad and Tobago are extremely low despite enthusiasm from policymakers. There is a dearth of cross-national attraction and the strength of potential difficulties in the implementation phase is strong. As mentioned earlier, the most likely barrier to further development of 'horizontal borrowing' is likely to be the 'phoney' policy rhetoric (see 3.2.1). Buzzwords such as best practices, peer review and South-South cooperation may be used out of necessity by aid agencies who feel they need to subscribe to the global aid agenda. These simple representations of 'borrowing' are in circulation as education is heavily entrenched in the world of politics. Context is of little importance, as discussed by Ponting, a former British civil servant who comments on the thoughts of Ministers:

The questions they ask are: 'how can this issue be exploited politically to maximum advantage?' 'How can the party gain and how can we maximize problems for the opposition?' and finally 'Does this issue increase my political exposure and will it benefit my career?' (Ponting, 1986 cited in Halpin and Troyna, 1995: 308) 
While the motivation behind the use of policy 'borrowing' rhetoric in documents is unclear, uncritical transfer is certainly evident. Quite possibly, there may be a naïveté about 'horizontal borrowing'. Ochs and Phillips (2004: 774) show how the following does not pay attention to the complexities:

Identification of successful practice $\rightarrow$ introduction into the home context $\rightarrow$ assimilation

However, if we are to ignore Phillips and Ochs' first circular model and instead apply other aspects of their work such as their discussion of lenses, there is perhaps some insight regarding slow reception and implementation of foreign ideas rather than their narrower term of 'education borrowing'. It is possible to understand some of the data of this thesis in the light of Phillips and Ochs' lenses. Innovation from foreign ideas is filtered through first lens of interpretation and transmission in which a cultural slant is taken. An example is the inspiration for the NCSE and the ministry's search for curriculum models to examine. The next lens of reception/implementation, where practitioners scrutinize practice, seems to fit into the training or lack thereof provided for members of the ministry and teachers. It is possible to conclude that the foreign idea did not filter beyond this stage due to the inconsistencies of understanding among some respondents of the aims of NCSE. Further lenses thus become inapplicable and the idea is in a limbo stage of implementation.

\subsubsection{Other conceptions of 'borrowing'}

\subsubsection{Examples of foreign ideas in Barbados and Trinidad and Tobago}

While there is no evidence of formal 'borrowing' according to Phillips and Ochs' model, there are instances of foreign ideas used in policy formation, particularly in Trinidad and Tobago. There was some consultation with New Zealand for the new curricula of the NCSE and a Canadian consultant also worked on the report. There is certainly the tendency to look abroad for inspiration, in both policy and academia. Research from the 'west' may have a stronger influence than findings from neighbouring islands. As electronic journals are easily accessible, one academic pointed to the benefits of low cost and physical access of both North American and Australian journals. Steiner-Khamsi (2004) and Chisholm 
(2007) argue that institutionalized networks such as publications and conferences serve as platforms for 'borrowing'. Policy personnel also served as bridges for foreign ideas, according to one Trinibagonian policymaker. Although no further information on this programme was found in fieldwork interviews, Phillips and Ochs (2003) note the expertise provided by Sandra Deane, a Canadian-Trinidadian, to Trinidad and Tobago to implement a Canadian project focusing on the responsibility of communities in the role of child rearing. The influence of foreigners in policy innovation follows Steiner-Khamsi's (2004) notion of the Maris O'Rourke effect in transposing OBE across the globe (see 3.3.3). On a regional level, the most significant area of foreign influence was the creation of the Caribbean Examinations Council, which involved international consultation from the UK, the NTCM, an American association for Maths education, as well as some feedback from Canada as the approval of North American universities was important. Interestingly, Trinidad and Tobago consulted the CXC when setting up the NCSE. While the CXC may be an indigenized version of the British GCSEs, and thus an interesting model to examine, the NCSE could also be viewed as reflection twice removed from the GCSEs, following Steiner-Khamsi's (2004) assertion of twins and triplets of ideas in which very few can claim to be copies of the original.

Thus, the role of Trinidad and Tobago as a 'recipient' appeared to be accepted as both policymaker respondents and policy documents admitted the need for improvement and foreign references were provided. While Trinibagonian respondents mentioned examples of foreign influences, Barbados was positioned as a model. Through the interviews and fieldwork, it was apparent that Barbados was viewed as a stronger influence in the region than Trinidad and Tobago. The role of 'lender' appeared to hold strong. The nation building document of Barbados illustrates its vision towards developed nation status and certainly aims to export 'the Bajan Way' or the Barbados Model to other countries. One respondent mentioned the reliance of Windward Islands on Barbados for teacher training in the eastern Caribbean. Yet along with any type of dependency, the relationship is tenuous. In this way, Barbados may be viewed as an 'exporter' and Trinidad and Tobago as an 'importer'. Despite Barbados' positioning as a 'lender', and Trinidad and Tobago's own conception of itself as a 'recipient', 'horizontal borrowing' between the two islands appears to be illusive. Although the relationship between Barbados and the Windward Islands was not examined in this thesis, this type of 'borrowing' appears to be that of 'imposition' according to 
Phillips and Ochs' (2004) work on the spectrum of 'education borrowing'. The Windward Islands may be dependent on the work of UWI Cave Hill and have little choice but to follow the prescribed methods. However, this needs further investigation to understand the full extent of the Barbadian influence.

\subsubsection{Ways to view foreign ideas}

As Phillips and Ochs' (2004) model of the 'borrowing' cycle is ruled out and their work on lenses only provides a small view of the dynamics of foreign ideas, attention will be paid to other conceptions of the 'borrowing' process. Based on the notion that the process of adaptation of the reform is heavily dependent on individual actors, Dolowitz and Marsh (2000) created a list of nine types of actors involved in the process from importing a borrowed idea to implementation (see 3.2.2). This is consistent with the notion of filters. In the case of Barbados and Trinidad and Tobago, the process of considering Caribbean borrowed ideas may not have passed through the appropriate number of lenses, particularly at the ministry level as they may be viewed as inferior to ideas from the 'West'. The idea of regional 'horizontal borrowing' may have only lasted as far as the international policy phase, followed by a quiet death among national governments.

Ideas from outside the region, however, may be viewed as welcome due to the notion of legitimization (see 3.1.1). Steiner-Khamsi (2004: 204) suggests that referring to foreign models helps to substantiate home education reforms: "...the raison d'etre for externalization is the existence of a legitimacy crisis in an educational system..." The use of foreign ideas such as the New Zealand and Canadian education systems in Trinidad and Tobago as well as the reliance of CXC and CAPE content on UK curriculum may stem from the need to justify choices at the national level. For example, the Trinibagonian NCSE curriculum justifies its six key learning outcomes by stating they are universally accepted and "... underscored by other educational jurisdictions and have been described as essential..." (Government of Trinidad and Tobago, 2002b: 6). Examples from another country become a resource for politicians to show that reforms are 'right' as well as possible (Whitty and Edwards, 1998). Interestingly, this may also hold true for traditional practices in the Caribbean such as the persistence of Victorian teaching methods and the $11+$ exams. Silvona (2004: 76) argues that education policy transfer is used to "legitimize 
the maintenance of 'old' institutional structures..." Regardless of whether or not the foreign policy was transferred, political discourse associated with the ideas may be transferred (Steiner-Khamsi, 2000 cited in Silvona, 2004). This seems to be consistent with the interviews as discourse appears to be strong. Many respondents talked about the similarities of the education systems of other Commonwealth countries rather than pointing out the similarities between islands. Yet, it is possible that all of this discourse is simply rhetoric as the mere mention of foreign ideas legitimates national choices, concomitant with Spreen's $(2004 a, 2004 b)$ assertion that circulating reforms to legitimize world-class standards is a bandwagon governments jump on. By using external reference points, indigenous policies are justified in Trinidad and Tobago. Yet these 'flags of convenience' (Lynch, 1988 cited in Spreen, 2004a) may not be sufficient as home initiatives such as new curricula in Barbados and Trinidad and Tobago may require further justification to necessitate more ownership by teachers.

Yet the notion of legitimization alone is not sufficient to explain fieldwork findings. Although the interviews revealed foreign influence and interest in foreign ideas from the ambiguous 'centre', respondents did not engage in discussions regarding the impact of these ideas nor the extent to which investigation into the 'Other' took place. Perhaps this is indicative of the desire to distance policies from their origins. Ideas that appear to be Barbadian or Trinibagonian may in fact suffer from 'institutional amnesia' and thus may have heritage elsewhere such as 'the West'. This follows the work of Spreen (2004a, $2004 \mathrm{~b}$ ) who points out the obvious irony of this in light of the initial use of foreign examples to legitimize home policies. The power of foreign models in creating a 'consensus' that a reform idea is successful loses its power during the process of transfer (Spreen, 2004a, 2004b). As indigenization occurs, the original foreign appeal withers away and the borrowed framework, reform or idea is adapted to the cultural context in order for it to be accepted by a wider audience and be implemented with some success. Interviews with policymakers and academics indicate an absence of institutional heritage with ideas that provoked policy in the islands as they did not elaborate on the influences from elsewhere. 


\subsection{Explanations of some aspects of data}

\subsubsection{Cultural resistance to 'horizontal borrowing'}

Trinidad and Tobago's resistance to 'horizontal borrowing' from Barbados may stem from beliefs, attitudes or cultural values. A historical reason may be linked to competition between the two islands. In colonial times, Barbados and Trinidad and Tobago were governed separately with the exception of the failed Federation of the West Indies. Geographically, islands are at risk of insularity and existing on the fringes (see 2.1.1 for more on small states). While resistance may be more prevalent in teacher communities rather than educational circles or policy development, there is certainly a resistance to sharing between the two islands. Yet the tendency to look towards the 'West' may be a result of assumptions that countries such as those in South East Asia and UK and USA have managed to achieve a success in particular aspects of education. In particular, one respondent suggested the lack of expertise in the Caribbean: "Perhaps because the Caribbean does not have developed nation status. We are not a force where industry or technology is concerned" (T26, Trinibagonian headteacher). Despite similarities between the two islands, both nations may be self determined to proceed on their own paths - which happen to be similar as well. I3 discusses the self focused view that each island may be taking: "it seem to me they are the least likely to borrow from each other as they are firm on creating their own education..." Clearly, respondents at the policy development level seemed more interested in participating on a global scale rather than a regional level. Initiatives occurring in neighbouring islands may be off the radar and simply deemed irrelevant. Rather, there is a desire to be 'global' rather than 'regional'. This may be evident in the description of the curriculum content as relatively 'universal', particularly Maths. In the same vein, teacher B6 suggested the existence of a 'canon', or "a certain body of Math knowledge out there". While there may be a generally accepted constructed notion of what constitutes an average Eurocentric Maths curriculum, the assertion of Maths curricula as culture free is certainly contested (Bishop, 1994). Further, this acceptance of a 'global' Maths curriculum in Barbados and Trinidad and Tobago may be a result of dependence on international recognition of the curriculum in place of a more culturally relevant content. I6, an international respondent discusses the need to ensure the curriculum is relevant for the majority of learners. Perhaps the curriculum continues to act as a postcolonial gateway 
of entry for the elite. Yet discussions involving colonialism and postcolonialism are complicated. The next section will discuss some colonial and postcolonial explanations of this thesis data.

\subsubsection{Forces of tradition}

The findings of this thesis may be better explained through the powerful role of tradition. Based on observations of classrooms, teaching practices are based on traditional modes of pedagogy where the teacher is the holder of knowledge. Conventional aspects of teaching and learning are preferred over new initiatives as they maintain the status quo. The $11+$ exam and its subsequent stratification process is a traditional aspect of Caribbean society. Along with the $11+$, the esteem attributed to success in CAPE exams is based on traditional conceptions of achievement. The elitism attached to success in secondary school is legitimated by the high social standing attributed to university education from international institutions. For any Barbadian or Trinibagonian, receiving a national scholarship and having the opportunity to study internationally is the highest privilege accorded. By heaping esteem on national scholarships, success in secondary school becomes another form of social stratification. Deviations from the norm thus risk disapproval. Stemming from colonial structures, education is a means of social stratification and rote methods. Although there is always discussion surrounding the abolition of the $11+$ exam, it remains a fixture in both Barbados and Trinidad and Tobago. While it is recognized that governments zealously guard the unique education systems of their nation states as it reflects nationalism in countries, the role of tradition has long been debated as it is both a benefit and detriment to education systems. Traditions benefit education systems as they create a common understanding of the purposes of education in a nation state. Society adheres to stable values of schooling and there is a widespread consistency across actors. In some societies, values are widespread and all actors believe the systems work, resulting in collective support among groups with various priorities such as the government, teachers, parents and pupils. Yet failure on embarking change is in part due to binding tradition. Perhaps the smallness of scale helps to reinforce and enclose a system of indoctrination where subjects are pressured to accept the dominant ideology of stratification and the status quo. In small states, societal values run the risk of dictating national initiatives. 
Cypher and Dietz (2004: 173) also recognize the irony of the ability of education to suffocate and liberate progress:

...(O)rganized educational institutions can be hostile to 'educating' and be a determined element in society's efforts to inculcate and perpetuate the prevailing ceremonial structures. Indeed, this is often the case with educational institutions in poorer nations, even through the university level.

As a result of binding traditions and societal values, islands are held back from actualizing new ideas in the form of indigenous national development. Coupled with the needs of the knowledge economy for international certificates and the risk of peripheral insularity, islands are conscious of the need to look towards the 'centre'. International policies advocating south-south collaboration or sharing best practices with other states in developing regions is an unattractive option. This gaze towards the 'centre' overpowers incentives to implement national policies. At the same time, the gaze towards the 'centre' distracts the islands from inward change. Thus, any impetus for innovation from local policymakers is resisted by both traditional views of education as well as fears of insularity. It is certainly possible that the forces of the knowledge economy are weaker than the anchor of the status quo. Islands may be concerned with what is happening elsewhere but this does not necessarily motivate change. The binding power of traditional is stronger than international policies advocating 'horizontal borrowing' as well as national initiatives to improve quality and equality of education. Sharing between the islands therefore becomes a marginalized concept as it is inferior to the gaze towards the 'centre' and island values. The reason behind the forces of tradition may be attributed strongly to colonialism, which will be discussed in the next section.

\subsubsection{The impact of colonialism: desire and resistance}

It is essential to analyze the impact of colonialism as Phillips and Schweisfurth (2008: 92) note that "... in any attempt to explain such data the historical background should be an essential part of the analysis...". See 3.4.1 for a review of colonial education. The awkward dynamic of despising colonization and adhering to colonial values on the other hand is evident through the forces of tradition. Inherited from colonial economies, CARICOM countries consist of "weak agricultural and manufacturing sectors, heavy dependence on the foreign investor, and reliance on extra-regional sources for a preponderance of food and 
manufactured goods (Griffith, 2002: 80). There is resistance to entrepreneurial and industrial activities, stemming from imperial values of colonists who benefited from exploitation and did not need direct contact with either of these activities. As colonial education reflected dominant values of the Empire including values of subservience, a spirit of entrepreneurialism was obviously missing. Further, in present day Caribbean societies, there is also a strong preference for branded foreign goods and services due to advertising as well as the consumption preferences of tourists from richer countries (Caribbean Commonwealth Regional Secretariat, 1972 cited in Griffith, 2002). The essential desire to create something different may be strongly stifled by society's preference for foreign products. The only solution for successful development, according to Ayres, “...requires a revamping of those institutions, and the behavioural patterns that accompany them, which continue to be detrimental to the creation of an indigenous technological capacity" (1962, cited in Cypher and Dietz, 2004: 173).

While both islands insisted on independence from colonial powers, there were remnants of a colonial gaze towards the 'centre'. On the one hand, there is a desire for the island states to succeed on their own; on the other hand there is the reality of vulnerability to greater powers. Ceding to the 'centre' often means ensuring standards were kept with the 'rest of the world'. Acceptance into the global economy - particularly by former colonial powers in the 'centre' - may be a result of Young's (2003, cited in Rizvi, Lingard and Lavia, 2006) assertion that after independence, former colonial people are internally and psychologically colonized. Postcolonial critic Franz Fanon argues that after independence, 'national consciousness' does not equate to freedom because citizenry are surveyed and coerced with often similar vocabulary of dominance by local elites (cited in Rizvi, Lingard and Lavia, 2006). Education is directly affected by phenomenon. Ruled by the local colonial bourgeois, "(e)lites in the south remain irresolute in their determination that education continues in its traditional way to sort people into eligibility for entry into elite ranks" (Jones, 2007a: 334). This may include a separation of society by class and education achievement. The persistence of the $11+$ exam and national scholarships for international higher education may be viewed as two key gates. By making secondary education certificates commonplace, the education hierarchy begins to be dismantled, resulting in a loss of power for the elites. Thus in order for attempts by multilaterals to ensure education opportunities for postcolonial countries are even minimally effective, they must understand 
the challenge of speaking for the subaltern. In this case, 'subaltern' refers particularly to the majority of children in the Caribbean who are marginalized from the school system rather than those who are part of the intellectual elite. The act of speaking for the postcolonial subject, according to postcolonial critic Gayatri Spivak is not possible as she argues that any attempt to speak for them to improve their condition through a collective voice "invariably involve the problem of a dependence upon intellectuals to 'speak for' their condition, rather than allowing them to speak for themselves" (Rivzi, Lingard and Lavia, 2006: 252). Spivak further argues that there is a risk of essentialism in subaltern collectivity that ignores heterogeneity in colonial citizenry (Rivzi, Lingard and Lavia, 2006). Perhaps this is the main problem with multilateral intervention as it tends to provide a one-size-fitsall approach.

While regional cooperation does exist, it seems out of necessity for survival rather than innovation. Thus mutual dependence is needed to pool together resources and expertise and is seen as an alternative rather than a priority. Policymakers operating on a global agenda tend to see the Caribbean as a region rather than individual nations. Yet another respondent questions the forces behind South-South collaboration: "But it is clear that there are regional bodies that are interventionalist in education policy so this is forcing developing countries to look at each other as neighbours, if you like, in the region" (I6). Thus, the lack of regional 'horizontal borrowing' between Barbados and Trinidad and Tobago may be a form of neo-colonial resistance. Dale (1999: 11) points out the domination by supranational organizations and links it to colonialism:

...(W)hat distinguishes globalization and imperialism and colonialism is that it supranational; it is not initiated by a single country, or carried out by nations on nations, but by supranational organizations, albeit dominated by the same group of nations that were previously involved separately in bilateral mechanisms.

As aid agencies tend to align themselves to larger initiatives such as the Millennium Development Goals (I6) which encompass health, education, poverty and sustainability, aid becomes less localized and more global. See 2.1.3 for a discussion of the role of multilaterals. The universal approach to aid leads to similar approaches to policy rather than a tailored, needs based approach to programme development. 
Although island states may resist control by multilaterals, the intentions of these agencies may be benign. Aid is complicated and is often viewed as neo-colonialist. Attempts to make countries less aid dependent on first world countries and ideas may be seen as an improvement to older forms of aid programmes where resources and expertise are solely provided by western agencies. Even the success of teacher training in Barbados may be a result of both donor agendas and national coordination of efforts. Certainly, the relationship between colonization and multilateralism is complicated, particularly when it involves states that are incredibly vulnerable to the forces of the 'centre'. In the words of one respondent, "l think many developing countries find [South-South collaboration] harder to do because of the global agenda in which countries are more likely to look to Europe than each other" (I6). While this may be due to a colonial gaze, it may simply be a result of the 'globalized' world in which multilaterals operate globally rather than locally. As Rivzi, Lingard and Lavia (2006: 252-255) conclude “...it is more urgent than ever to think about the questions of domination and resistance raised by postcolonial studies. Globalization has given rise to new transnational networks that imply the need to rethink narratives of colonization and anti-colonization.

\subsubsection{Globalization and convergence}

Existing and future similarities between Barbados and Trinidad and Tobago may be due to powerful global forces rather than an instance of 'horizontal borrowing'. In this case, global forces appear in the form of globalization and convergence. This is made possible by the 'global architecture of education', a web of ideas, networks, frameworks, financial arrangements and structured organizations - essentially “...a system of global power relations that exerts a heavy, even determining, influence of how education is constructed around the world" (Jones, 2007a: 325). Globalization and convergence are two forces of this global architecture of education and will be discussed in the next two subsections. Convergence can be posited as on particular effect of globalization, which Schriewer and others have worked to define. Globalization and convergence are often lumped together, as Crossley and Watson (2003: 53) explain:

...(T)he popular view of globalization represents rather ill-defined and questionable notions of the exponential spread of a common world culture with the prospect of societies converging and becoming very much the same in nature and operation. 
The next two sections will examine globalization and convergence separately. These two aspects overlap in some discussions, such as Crossley and Watson's (2003) three perspectives of globalization and much of the discussion on convergence is stemmed from ideas of globalization.

\subsubsection{Globalization}

Rivzi (2004) argues that the discussion of globalization is rather shallow as it has been both passionately debated and used as a buzzword, linked to almost every social change from the knowledge economy to the decline of the nation state to the spread of neoliberalism. While definitions of globalization will differ according to sectors, the definition offered by Giddens (1994, cited in Rivzi, 2004: 160) is widely accepted. In his view, globalization is transforming time and space. In other words, globalization is simply 'action at a distance' due to the developments of communication and transportation, and the interconnected nature of economics, politics and culture (Giddens, 1994 cited in Rivzi, 2004). Dale (2001) argues there are two uses of the discourse of globalization: as an answer and as a solution. Globalization may be posited as an answer in this thesis as it provides a useful explanation of how education systems in both countries have evolved. Globalization is also described as a solution as foreign examples are introduced as a result of the movement of ideas and the rise of technology opens up new possibilities for capacity building.

More specifically, Held et al. (1999, cited in Crossley and Watson, 2003: 53) note three perspectives on globalization: hyperglobal, sceptic and transformational. Crossley and Watson (2003: 53) describe the three groups as follows: “...the hyperglobalists see globalization as defining a new world era dominated by the influence of the global marketplace". Yet on the other hand, "from the sceptics perspective, globalization is linked to the perpetuation of the economic dependence and marginalization of the poorer nations of the South" (Crossley and Watson, 2003: 54). Finally, “...the transformationalists do not envisage any particular future world scenario, but pay more attention to globalization as an historical process, that affects all societies and their many dimensions" (Crossley and Watson, 2003: 54). At the same time, transformationalists do not envisage convergence, but surmise the emergence of new power relationships in the world (Crossley and Watson, 
2003). In other words, transformationalists do not see the demise of countries, but nation states are required to adapt to effectively engage with economic forces and powerful global agencies (Crossley and Watson, 2003). In this thesis, all three of these perspectives are pursued to some extent to explain the findings. From a hyperglobalist point of view, the lack of 'horizontal borrowing' between Barbados and Trinidad can be explained by the preference of this global marketplace where influential policies arise from the 'centre' which is permeable - at times it is the United States and at other times it is New Zealand or South East Asia, depending on education achievement (see 6.5). Globalization from a hyperglobal point of view explains why 'horizontal borrowing' is not relevant in the Caribbean as much of the action in island states happens at a distance by other external factors. Despite the presence of national initiatives, actors gaze towards the centre to ensure involvement in global trends as exemplified through one participant's response when asked about the future of education reform in Barbados: “...we try to keep up with the global changes, wherever it is, and that will be the influence for whatever is going on". From a sceptic's point of view, globalization is the cause of the marginalization faced by small states. Provoked by existing on the periphery, islands look to the 'centre' and reject national initiatives over appeasing the 'international community'. Jules (2008: 204-205) notes that small states are "...faced with the promise and the peril of globalization". Yet Jules (2008) notes the positive side of globalization has resulted in rise of ICT, opening new possibilities for education and learning. However, this has led to the commodification of education which could further marginalize small states (Jules, 2008) as islands are vulnerable to action at a distance. This results in education paradigms which are removed from the context of small states. This is further exacerbated through the lack of institutional capacity necessary for small states to participate in bargaining with institutions related to trade and economics (Bacchus, 2008). Thus Jules (2008: 203) explains the outcome:

The erosion of preferential trading arrangements, changes in the alignment of interstate relations, and increasing power of the multilateral financial-intellectual complex to dictate acceptable solutions have weakened the capacity the SIDS [Small Island Developing States] to maintain even elemental levels of relative autonomy in the global configuration.

The transformationalist's view holds true as well. The islands may be vulnerable, but they have also learned to adapt to the global agenda and submit to the reality of economic forces in order to reduce isolation and ensure a standard of living for their people. Small states are 
"...not in a position to isolate themselves from such influences and must accept the problems that globalization creates as challenges..." (Bacchus, 2008: 141). Attempts to seal themselves off from the world would “...result in their economic stagnation and a much lower standard of living for their population" (Bacchus, 2008: 141). Even if governments were to isolate themselves from policy involvement, the effect of media importation cannot be underestimated. The dominance of foreign media impacts the preferences of citizens and leads to the erosion of local culture in societies. The findings in this study regarding the low levels of enthusiasm for national initiatives (see 6.3.1, 6.4.1) can be explained through preferences for foreign ideas through the impact of globalization on national development.

The process of globalization on national policies is further explained through the work of Dale (1999: 2) who describes globalization and its effect on national policy as "...a classic 'black box' analysis where the input is clearly related to the output, but where the means by which the transformation is brought about are not apparent (or by implication important)". In this description, it appears that national policies are the inputs, which are impacted mysteriously and ambiguously by globalization and the resulting output is an augmented national policy. The process, according to Dale (1999) is not specifically described and thus he attempts to identify globalization effects. Further, these mechanisms are diverse and do not follow the traditional processes associated with the changes that education policies traditionally encounter (Dale, 1999). As these globalization mechanisms impact national policies in distinct ways, Dale (1999) provides a series of terms to distinguish the combinations of mechanisms. Instead of referring to all processes of change to national policies as simply globalization, terms such as imposition, harmonization and 'borrowing' are introduced to refer to the spectrum of impact that globalization has on state policies. Thus, Dale (1999) identifies the mechanisms as follows: nature of relationship (for example: voluntary), explicitness of process, scope (examples: multiple policies, particular policy goals), locus of viability (examples: national, international fora), process (examples: 'learning', condition of membership), partners involved (examples: bilateral, multilateral), source of initiative (examples: supranatural, collective agreement), dimension of power (examples: conscious decision, agenda setting) and nature of effect on education (examples: indirect, regime). Using Dale's mechanisms (see Appendix K), it appears that the dynamics of globalization on Barbados and Trinidad and Tobago through the new curriculum (see 5.2.2 and 5.3.3) are defined by the following mechanisms: 
EXAMPLE: The new curriculum for forms 1-3 in Barbados and Trinidad and Tobago

Nature of relationship: Formally voluntary

Explicitness of process: Explicit

Scope: Multiple policies

Locus of viability: National

Processes: persuasion - Agenda setting (EFA)

Partners involved: International

Source of initiative: 'International community'

Dimension of power: Agenda setting, rules of the game (knowledge economy and smallness of scale) and conscious decision

Nature of the effect on education: Direct - sector

According to these mechanisms and Dale's chart, these mostly fall under the classification of 'dissemination'. There are also some aspects of standardization. In other words, globalization takes the form of dissemination and standardization of polices with regards to education in Barbados and Trinidad and Tobago.

It is important to note that the notion of a 'conscious decision' in globalization is difficult for small states as they are vulnerable to activities of the metropole. The definition of globalization as action at a distance involves participation on the part of the small state to both the values of the metropole and the 'world order' in which it operates regardless of how much it agrees with these tenets, such as neoliberalism and the knowledge economy. While neoliberalism was not apparent on the islands, Caribbean nations seem to strongly subscribe to the notion of the knowledge economy. This is due to the colonial esteem held for places at international universities and the highly coveted national scholarships which traditionally equated to admissions to Oxbridge or London. Yet the knowledge economy brings with it more than the necessity for academic currency - it creates more knowledge workers while employment opportunities remain the same. Jarvis (2000) prefers the term 'learning society' and explains the phenomenon as it relates to globalization as follows: the richest countries have the biggest proportion of knowledge workers and, "(a)s other countries industrialize, they generate more knowledge-based workers but their work-force remains predominately agricultural and manufacturing" (Jarvis, 2000: 345). Postcolonial Caribbean citizens have also internalized negative values towards forms of industrial production due to colonial values towards work (Griffith, 2002). Few Caribbean students would choose to pursue careers in industrial industries, as explained by Griffith (2002: 85): 
"Thus, if given the opportunity to take silk or become an industrial entrepreneur, few CARICOM students will pursue the latter". Yet there does seem to be government concern over the impact of the knowledge economy. The similar commitments by both island governments to increase the number of secondary school leavers and expand higher education in their own country rather than reliance on the University of West Indies or foreign universities shows the force of the knowledge economy. Or this may simply be a result of convergence, as discussed in the next section.

\subsubsection{Convergence}

Chisholm (2007: 295) points out the striking presence of 'institutional isomorphism':

There is also little understanding of whether ideas have spread because of, despite or in tandem with one another, in a process of mutual attraction..., or whether the influence of external agencies in the developing world context is more telling in ensuring their spread...

Meyer and his colleagues support a 'common world educational culture' view that globalization spreads "a supranational set of ideas, norms and values around the world and a convergence in universal values and common culture" (Tarabini-Castellini, 2007: 23). If the expansion of local higher education institutions and new secondary curriculum is an indication (see 5.5.1), convergence seems to be occurring on the islands. Yet this common world culture may simply be a result of the agenda set by international agencies. Closer examination of the two countries may reject the notion of a common educational culture as similarities may result from one of Bennett's (1991, cited in Steiner-Khamsi, 2004) four political processes that may contribute to convergence, namely, emulation such as copying the actions of other places; elite networking stemming from transnational policy communities, harmonization developed by international regimes; and penetration initiated by actors. It appears that some of the above occur in Barbados and Trinidad and Tobago. There is certainly the emulation of actions elsewhere (NCSE) and harmonization developed by international regimes. Although there was no clear evidence of penetration initiated by actors, elite networking may exist among policy communities. Academics in the islands have connections elsewhere and graze on research from the 'centre'. 
There are others, however, who disagree with the notion of convergence.

...(T)he school as an "evolutionary universal" turns out to be not so much universal as socioculturally particular as soon as one systematically analyzes the multiple interrelationships between educational credentials and the privileges they bestow; between educational accomplishment and career success; between education and employment; between selection in schools and stratification in society; between the structures of schooling and public law... (Schriewer, 2000: 326)

While Schriewer and Martinez (2004) did not find a convergence of educational knowledge, Schriewer (2000) argues that this expansion coincides with the acceptance of a standardized model of schooling as a framework for orientating and evaluating policies globally. This model includes features such as a "general administrative framework...controlled by the State", "a school system internally differentiated according to successive levels", "...the professionalization of teachers and teaching methods"; and "the use of certificates...to link school careers with occupational careers, connecting selection in schools with social stratification" (Schriewer, 2000: 314-315). Barbados and Trinidad and Tobago are part of this standard model of schooling. This process of standardization may stem from a colonialist model and the perpetuation of normalization is rooted in its desire to be part of the 'centre'. Yet it is important to note that the smallness of scale may increase vulnerability to convergence. Bacchus (2008: 133) uses the example of personnel constraints to illustrate the way in which policies are inevitably formed by foreign staff that may bring their own ideas:

The restricted number of highly trained personnel in small states also makes it difficult for them to implement new projects, by using their limited local staff.... Even when qualified individuals are obtained through 'aid' and other forms of technical assistance, small states are usually unable to release their own qualified staff, who are often few in number, to serve as counterparts to the expatriate personnel. This often results in national programmes drawn up almost entirely by foreign staff that lack a deep understanding of the social and cultural roots of these small states.

Thus the notion of convergence is not an organic process but an intended action that is pulsed by harmonization of policies, dissemination of initiatives by international agencies and a resistance to existence on the periphery of world order. 


\subsubsection{Divide between policy and practice}

The slow realization of goals such as 'horizontal borrowing' and improving pedagogy may simply be a result of the classic divide between policy and practice. As national initiatives in both Barbados and Trinidad and Tobago have also not been fully realized, policymakers in the region may suffer from difficulties with implementation of international agendas as well as their own on the ground level. This may be due to poor communication of policy intentions with those working on the ground, a lack of involvement with teachers in the creation of curriculum and insufficient training for teachers. The challenges of improving education in Barbados and Trinidad and Tobago are shared by many developing countries. While resistance to national initiatives may be due to societal values that privilege the colonial elitism of education (see 3.4.1 and 7.3.3 for more discussion on colonialism), Mundy (2007) and King (2007) provide insight into the divide between policy and practice between education multilaterals and local practice. Mundy (2007: 347) points out that educational multilateralism is, "...torn between the chartering notion of education as a universal value, and the fact that educational systems are largely contained within territorial nation states". Multilaterals have had to confront matters of constituency, agency mandates, and how individual agencies relate to collaboration at bilateral, regional and global levels as the North-South divide continues to widen (Jones, 2007a: 321). Despite the 'good' intentions of aid agencies and multilaterals, they share the same critical challenge of implementation and indigenization in 'horizontal borrowing' and policy transfer.

In an editorial, Jones (2007b: 321 ) also points to several challenges faced by multilaterals of global developments:

(a) The multifaceted impact of economic globalization and its associated reworkings of conventional governance and govermentalism,

(b) The global spread of threats to world order and the political, cultural and economic consequences of states' multiple responses to them,

(c) The escalating need for new kinds of emergency, peace-keeping, humanitarianism and reconstruction interventions, and

(d) The higher premium placed within multilateral programming on private sector and non-governmental interventions, often as a substitute for the conventional programming undertaken by nation states and multilateral agencies. 
Further, multilaterals have had to confront matters of constituency, agency mandates, and how individual agencies relate to collaboration at bilateral, regional and global levels as the North-South divide continues to widen (Jones, 2007a: 321). Yet King's (2007) analysis of the collaboration among $\mathrm{UN}$ agencies and the developing world in the case of Education for All (EFA) and the Millennium Development Goals (MDGs) initiatives is not a favourable evaluation. Not only are measurable quantifiable goals favoured over equally imperative qualitative goals for both EFA and MDGs (King 2007: 383), but participation of researchers, governments and NGO personnel from developing countries in developing initiative such as the Jomtien EFA Declaration was "minor, if not minimal" (King, 2007: 381). King (2007: 378) concludes the following about the EFA Declaration: “...the allegedly global education agenda was perceived by many analysts in the south to have been principally developed by multilateral agencies in the north". Funding is related to these measurable goals as the MDGs provide a framework to assess country strategies (King, 2007). A further problem is the suitability of these initiatives and goals to the developing context. As commitments towards funding have focused on basic education, overemphasis in this area is "at the expense of other levels of education removes the indigenous capacity for research and innovation which is centrally important if countries are to link education to indigenously determined future development priorities..."(Tikly, 2004: 190). Perhaps this in part explains the complexities surrounding changing time frames for initiatives such as Education for All which has been extended now to 2015 from its original due date of 2000. Agenda extensions may result partially from the recognition by multilaterals to balance between strict adherence to goals and respecting nation state autonomy. Clemens (2004, cited in King, 2007) in his examination of international education goals, found that short time frames of setting and resetting goals was counterproductive. King (2007: 387) explains why:

[Short time horizons] take insufficient account of the factors that have really secured and sustained school enrolment over time: Raising school enrolment, like economic development is general, takes a long time. This is partly because, as a mountain of empirical evidence now shows, economic conditions and slowlychanging parental education levels determine children's school enrolment to a greater degree than education policy interventions ...

As education is certainly not a panacea for development needs, nor is it successful under time constraints, the projection for education in developing countries looks bleak. What 
purpose does it serve, and is there a need for multilaterals or should aid agencies face redundancy? While this explanation of data is perhaps the least culturally specific, more research is needed into the success of multilateral dissemination of policies, the difficulties found in other countries with ensuring success of national initiatives as well as investigation into the effectiveness of implementation of policies at the ground level. The divide between policy and practice explains some of the data; the cultural context holds much weight and cannot be ignored. The data from this thesis examines more than a typical gap between policy documents, teacher training and implementation. The nuances of gazing towards the 'centre', neo-colonial resistance and the awkward and often ironic dynamics of vulnerability/nationalism, desire/resistance and tradition/nationalism complicate the divide between policy and practice. 


\section{Conclusion: Moving forward and considerations for policymakers}

This final chapter provides ways forward and considerations for policymakers by summarizing the main findings and situating them in the context of the Caribbean, small states and developing countries. There is a clear discussion of the limitations of this research, while noting the implications of the analysis in the previous chapter. Sections 8.3 and 8.4 note the contribution of the research and suggests ways to move forward in an under researched field. Certainly more work is welcome in small states, as they exist on the fringes of world order and their needs are often ignored in the global arena. This thesis illuminates the voices of two island states and highlights perspectives from the periphery, which need to be taken into account in global initiatives. The chapter ends with some final considerations to consider. As the findings illustrate, Barbados and Trinidad and Tobago resist the very policies they are asked to follow. The effectiveness of such policies is thus called into question. Policymakers should seriously consider their perspectives and understand the patterns of 'borrowing', which occurs 'vertically' due to overriding concern for the 'centre'.

\subsection{Summary of main findings}

In the introduction, the main aim of the thesis was stated as follows:

The aim of this study is to contribute to the literature on 'education borrowing' by adding a Commonwealth Caribbean perspective through an investigation of the possibilities and limitations for 'borrowing' in the small states of Barbados and Trinidad and Tobago. Attention will be paid to competing objectives of improving quality in secondary education, encouragement of 'sharing' by the international community and the impulses towards the 'centre'

Chapters 2 and 3 provided a context for this aim by reviewing the geopolitical and sociocultural aspects of the Caribbean as well as a summary of current literature on 'borrowing' and education in the region. Through Chapter 5, EFA objectives of improving quality and equality were discussed and the notion of 'horizontal borrowing' from each other was identified through dissemination of a global agenda. The fieldwork in Chapters 4 and 6 probed the perspectives of policymakers, teachers and academics on international and 
national objectives in Barbados and Trinidad. Chapter 7 examined the degree to which 'horizontal borrowing' was possible between countries according to the parameters set forth in literature on 'borrowing' (see 7.2) and examined the presence of 'vertical borrowing' through some explanations of the findings such as cultural resistance to sharing, forces of tradition, colonialism, globalization and convergence and the divide between policy and practice (see 7.3). Chapter 7 also highlights the two main findings of this doctoral research:

1. Despite encouragement by UNESCO and Commonwealth Secretariat policy documents, there was no evidence of 'horizontal borrowing' between Barbados and Trinidad and Tobago and

2. Possibilities for cross-national attraction were limited due to the overriding attention paid to the global 'centre' for 'vertical borrowing' rather than concern for regional growth and cohesion. (see section 6.5 and 7.2 for more discussion).

With regards to both findings, it is important to note that elements of cooperation exist in the form of membership with regional institutions and agencies such as the CXC, University of West Indies, CARICOM and the Caribbean Development Bank. Despite eight years of negotiation before the agreement between islands was signed, inter island differences and even suspicions, the $\mathrm{CXC}$ has survived "all the vicissitudes common to any federal enterprise in the Caribbean" (Brock, 1984: 190). There is a baseline level of cooperation in this regard.

Existing and future similarities may be a result of dissemination of policies from a global agenda on education, with particular emphasis on improving quality and equality as most of the policy direction appears to be set by the international community. Such global initiatives are expected to take on national indigenization. Yet the thesis research found the use of other foreign examples in policy formation, particularly in Trinidad and Tobago (see section 6.5). However, through the fieldwork interviews and observations, aspects of international, regional and national policies such as UNESCO's four pillars of learning, CXC aims for the Maths curriculum and new national secondary curricula were not implemented by teachers (see 6.4.1). This resistance stems from the forces of tradition, evidenced by fieldwork observations of rote teaching and the importance placed on the $11+$ achievement and selection exam. Emphasis on 'academic' education is one of these traditional values, where the knowledge children hold outside of the classroom is not taken 
into consideration (see $6.4 .2,6.4 .3$ ). Thus, a dynamic of traditions and equality emerges as follows. Governments aim to cater to the cohort of pupils leaving without sufficient CXC qualifications while recognizing the importance of certificates that offer a global currency of education. Curricular ideas are developed by policymakers with attention paid to the 'centre' and the global agenda of EFA to improve quality and equality of basic education. While teachers have good relationships with pupils as noted in classroom observations, there is resistance to new pedagogy and curriculum which moves away from conventional values of education, due to teacher enculturation and societal values. Both island states have strong nation-building documents which aim to reach developed nation status in the next decade, using education as one of the mechanisms for improving the workforce and raising the quality of living. Yet Louisy (2004) argues that citizens need to be grounded in cultural development to understand how to take advantage of their traditions and translate this knowledge in the global marketplace to develop the region's identity and economic goals.

Thus the patterns of 'horizontal borrowing' are far more complex than simply importing ideas from another source. There appear to be three tenets of limitations to cross national attraction:

1. Island policymakers look internationally for innovation, thereby rejecting policies advocating 'borrowing' from each other;

2. Sharing is not part of the island histories and cultures; and

3. Forces of tradition bind existing teaching and education values.

With the exception of instances of necessary cooperation such as the common financial currency in the eastern Caribbean states and recognized school leaving certificates, 'sharing' or 'horizontal borrowing' holds the most potential in the dissemination and indigenization processes of global policies due to existing EFA regional forums. Yet this is also limited by 2) and 3) above. Despite encouragement from the international community to share best practices or 'replicate' aspects of a successful system, there is no formal 'horizontal borrowing' between the nations of Barbados and Trinidad and Tobago. In other words, the islands are members of collective regional organizations, but partnerships of 'horizontal borrowing' do not appear to be found. While the intention behind South-South collaboration may be to ensure less dependence on the global 'centre', it appears to be a stubborn residual legacy of colonialism. In the larger context of developing countries, this 
gaze towards the 'centre' may be largely due to a history of colonization. More importantly, the dynamics between power and vulnerability to the 'centre' arise from the seemingly uncontrollable forces of globalization and convergence. As individual education systems do not operate in vacuo, patterns of geopolitical influence impact in explicit and implicit ways on developing country systems, some of which have been identified and discussed in this work.

\subsection{Limitations of findings}

Although a critique of the methodology is outlined in 4.4 , it is important to note the limitations of these findings. While 'horizontal borrowing' was not evident between the two island states, other relationships may be present. Some respondents noted an element of 'competition' between islands and this needs to be probed further. Relationships between Barbados and Trinidad and Tobago in areas such as health and trade may be far more cooperative. One of the limitations of this research lies in its focus on education policy, particularly in the area of Mathematics. While this helped to reduce confounding factors in interviews with policymakers, teachers and academics, if another subject was examined, more evidence of regionalism and 'horizontal borrowing' may be evident. Another limitation stems from the 'outsider' nature of the researcher. Some aspects of sociocultural context may not have filtered down through reading about the region and spending less than four months in the field. Thus, the analytical lens of the thesis may be different from an indigenous researcher working in the region. One of the issues with comparative education and development studies, as expressed by Little (2000), is the number of 'western' contributors to the field. As studies collectively shape the direction of literature and future research, there is certainly a need to ensure the voices of those who live and work in Southern contexts are heard.

As discussed in 4.4.1, there are limitations to the methods used in the fieldwork. The integrity of interviews was difficult to preserve due to limited space for confidential interviews and the busy nature of schools. More interviews with policymakers could have taken place as their perspectives would have helped to solidify the impact of foreign ideas on policy formation. The timing of the academic interviews to establish connections created a case of oversampling of this group in the pilot. As a result, their perspectives were limited 
in the main findings although lessons were learned from the pilot. Thus, the sample was weighted towards teachers due to accessibility. While teachers provided a valuable source of information, their knowledge of the influence on foreign ideas on national policies is limited in some cases. One of the key findings on the implementation of national initiatives as outlined in 8.1 arose mostly from interviews with teachers. Although this finding reflects a vast majority of the opinions from the study, a larger sample of policymakers may have added a different perspective. More investigation into the relationship between Trinidad and Tobago could have been undertaken. Although both islands are under the jurisdiction of the same government, curriculum and education structures, more could have been researched on the degree of dependence of Tobago on Trinidad. Less attention was paid to the context of the isle of Tobago. By spending some time on the lesser populated island, more could have been written about the generalizability of respondents from Trinidad on the degree to which they represent views on both islands.

\subsection{Contribution to existing research}

The work of this thesis adds to the body of knowledge of 'education borrowing' as it strengthens existing assertions. Writers such as Rodwell (1998) point to the need for critical transfer, and Phillips and Ochs (2003) note the importance of critical adaptation to ensure contextual needs of small states are met in the indigenization process of global initiatives such as MDGs (see 3.1.1 and 3.2.2). The work of this thesis concurs strongly with both of these assertions, along with writers who discuss the vulnerability of small states to globalization such as Jules (2008), Bacchus (2008) and Crossley and Holmes (1999). This thesis work also examines perceptions on international policies of 'horizontal borrowing' as well as local reactions to national reforms. While vulnerability to outside forces is discussed in this study, cultural resistance to sharing and the implementation challenges of national curricula are also examined as inside pulses. Research on small states tends to point out the infrastructural and personnel limitations of scale (Bacchus and Brock, 1987; Crossley and Holmes, 1999; Bacchus, 2008). The findings of this thesis identified the strong presence of another factor which is not uncommon in countries - the forces of tradition. While Brock $(1984,1988)$ notes the idiosyncratic histories and cultures of Caribbean islands but the forces of tradition in developing islands have not been examined closely in recent literature. As this thesis concentrates exclusively on Barbados and 
Trinidad and Tobago, this work provides a specific context to literature on issues facing by the Caribbean as discussed regionally by writers such as Brock (1988), Hickling-Hudson (2004) and Louisy (2004). Although Bell-Hutchinson's (1999) work on changing Mathematics teaching practices is situated in Jamaica (see 3.4.2.1), the focus of Maths education in this thesis adds to the body of knowledge. Specific country studies and comparative studies are particularly helpful to ascertain implications from regional discussions to the level of island states.

By examining two small states of the Caribbean, the geographical scope of 'borrowing' literature is widened. Much of the literature on 'education borrowing' is focused on European countries transitioning from communism towards democracy, neoliberal reforms in the UK and the USA, and interest in high achieving countries such as Finland, Japan and South East Asia (see 3.3.1). While the context of developing nations is under-researched in the field of 'education borrowing', the context of small states is even further removed as they exist on the periphery of world order and research interests. Although Phillips and Ochs (2003) point out some considerations for small states, specific research on 'horizontal borrowing' between Caribbean islands is absent. Through the consistencies found between some ideas on 'borrowing' such as Steiner-Khamsi's (2004) notion of legitimization, Phillips and Ochs' (2004) 'phoney' type of decision mentioned in their first phase of 'borrowing', and the findings of this study, current literature is proven to be more robust as it applies to the contexts studied by the writers as well as Barbados and Trinidad and Tobago. Similarities between the two countries studied in this thesis and previously examined cases in developing countries also exist. While the context of Schweisfurth's (2006) work on Rwanda is vastly different from the Caribbean, her work notes the impact of global forces and foreign ideas on the post-genocide country and contributes to the continuum of 'borrowing'. Similarly, the work of this thesis shows the lack of formal 'horizontal borrowing' between Barbados and Trinidad and Tobago but identifies other pulses of influence and resistance. Discussions of 'borrowing' are thus enlarged to include instances in which Phillips and Ochs' model does not fit, but the impact of foreign ideas is interesting and significant to the development of education systems. The presence of 'vertical borrowing' is certainly interesting. As the government of Trinidad and Tobago was interested in the New Zealand curriculum, this finding adds to the work of Steiner-Khamsi (2006), Jansen (2004) and Spreen (2004a, 2004b) on OBE and its influence in developing 
countries. The finding that foreign ideas such as those from New Zealand are used in the two island states, particularly Trinidad and Tobago to legitimate ideas, builds on SteinerKhamsi's (2004) notion of legitimization and Lynch's (1988 cited in Spreen, 2004a) concept of 'flags of convenience'.

This thesis confirms the challenges faced by small states in the era of globalization. The work of Bacchus (2008) and Jules (2008) highlights the geopolitical factors that must be considered to understand the vulnerability of small states, particularly in light of Jones' (2007) global architecture of education, in which powerful multilateral forces influence and build reforms. This thesis adds to the discussion of the role of the international community and national initiatives in education reform in the Caribbean. Although policy documents advocate 'sharing', 'borrowing' and 'replication', this work illustrates the complexities of transfer in the Caribbean among island states and questions the applicability of international policies. While the literature on 'borrowing' has mostly been focused on transitional states such as those in east Europe and East-West attraction between the UK and/or America and Asia, this thesis focuses more on the role of colonialism, globalization and the forces of tradition in the process of 'horizontal' and 'vertical borrowing', and challenges the role of small nation states in their ability to consciously 'borrow'. While Phillips and Ochs (2004) provide an interesting model of conscious borrowing, the role of other pulses - both external and internal to the countries - may override the four phases outlined. This study questions the notion of cross-national attraction as may not exist in the realm of globalization and convergence. At best, political affiliation and world order may impact the larger policy picture.

\subsection{Areas for further research}

Further questions remain regarding the larger context of small states, the impact of the international community and South-South collaboration. To what extent can the international community support national initiatives and reduce the gaze towards the 'centre'? How can regional working groups postulated by international agencies move beyond acting as a platform for ensuring the dissemination of global ideas? How can island states build up their own capacity for national initiatives and at the same time satisfy donors and international agencies? Or are these questions meaningless without challenging 
tradition? Is it possible to devalue traditional aspects such as the $11+$ in countries such as Barbados and Trinidad and Tobago? Does this require the prerequisite of alternative pathways for education, such as stronger capacity for lifelong learning and expanding higher education to widen participation at all levels? Examination into capacity building in Caribbean small states is also necessary. Do the islands receive logistical and expertise support from agencies and bilateral organizations? If so, is capacity building thus coloured with a foreign influence, leading to a destabilized national framework? As there was some mention of the influence of Barbados' policies and the sharing of institutions with the Windward Islands, a further study could examine 'horizontal borrowing' between Barbados and the neighbouring cluster of islands. Yet many of the above listed questions require further studies examining the nature of multilaterals and their relationships with Caribbean islands. A deeper understanding of the ways in which globalization affects the autonomy of developing countries in the face of a global agenda of education is needed. Perhaps this needs to take place in a small states context, or perhaps the notion of small states is meaningless due to the wide variation of geographic location, economic achievement, population size and degree of insularity. The relevancy of categorizing countries by size needs reconsideration as the experience of small states in the Caribbean is different from those in the South Pacific, the Indian Ocean, the African continent and Europe, although the challenge of vulnerability and scale may be similar.

Other areas for further study include the nature of regional institutions. Perspectives on organizations such as the University of West Indies, CARICOM and the Caribbean Development Bank were not sought. While formal 'horizontal borrowing' may not occur, it would have been interesting to investigate the degree to which policymakers and governments view the role of such institutions and agencies. Further, examination into the successful features of these organizations would have revealed pathways for 'replication' to improve the quality of education in the Caribbean. In the same vein, it must be recognized that regionalism may be limited to a few necessary institutions as autonomy is important to nation states. In particular, education is a way of ensuring nationalism. Thus, island states may resist additional organizations to the CXC and the OECS which synchronize school leaving qualifications and currency. The balance between nationalism and regionalism is not new or unique to the Caribbean as the European Union also struggles to find a balance between cooperation and uniformity. Raising the quality and equality of education is also a 
common challenge in many countries. As Barbados and Trinidad and Tobago are at various stages of implementing a national curriculum for Forms 1 to 3, one of the key concerns is equipping children who leave without $\mathrm{CXC}$ qualifications with some form of nationally recognized acknowledgement of their secondary schooling. A similar experience occurred in the United Kingdom with the development of the GCE, the CSE and finally the GCSE. Thus, more research on the challenges and reforms of Barbados and Trinidad and Tobago in light of the experiences of other countries should be undertaken to determine the relative degree of resistance from the ground. This would be especially useful in determining the extent to which the smallness of scale, regional values and the forces of tradition impact reforms of quality and equality the two island states. While small states may be more idiosyncratic, forces of tradition are generally prevalent in all societies. Further research on how the forces of tradition in Barbados and Trinidad and Tobago compare with other areas of the world working on similar reforms would help identify trends. A closer examination of the structure of these forces of tradition may help policymakers understand malleable areas for reform. This would greatly assist with the indigenization process of both types of 'borrowing' and dissemination, or prove that education systems, like national identity, are difficult to change (see 7.3.5).

\subsection{Final comments}

Criticality is the key ingredient for all further studies along with time and financial support. This leads the discussion back to some aspects of the Education for All goals (see 5.1.1). In many ways, the discussion is far more complex than postulated by international agencies although the end goals may be the same. The difference is in the process and the criticality required to unpack the patterns of influence and the dynamics of change in individual nation states as they are often treated the same in policies despite vast differences in context. Indigenization alone is not sufficient for disseminating policies as it continues to reinforce emphasis on central control. The more pertinent issue seems to be recognition of the patterns of influence, cooperation and resistance. While EFA and MDG needs are of pressing urgency, much time and money has already been wasted implementing action plans which do not account for local perspectives. Yet ensuring the right of every child to education carries an overexerted framework as education is viewed as both an object for improvement and as a vehicle for delivering other aspects of aid agendas. Since the 
declaration for Education for All at Jomtien, education has a larger mandate in the fight against poverty, child mortality, sustainable development and diseases such as malaria and HIV/AIDS (King, 2007). Education is seen as a panacea for development and security, as illustrated in the UNESCO constitution: "That since wars begin in the minds of men [sic], it is in the minds of men [sic] that the defences of peace must be constructed" (UNESCO, 1945 cited in Jones, 2007). On the one hand, this is a beneficial purpose of education but on the other hand, the way in which the international community carries out this process has the potential to be malignant.

Changes of focus and the willingness of the international community to unseat itself from the central throne poses a major challenge for countries and international agencies as this relationship of power and vulnerability was not built in a day, and will certainly not be broken down completely for decades to come. While this may sound dire and pessimistic, the main findings of this thesis pertain to approaching encouragement of regionalism and 'horizontal borrowing' with critical caution as South-South collaboration is difficult to achieve under existing power dynamics with the 'West'. Phillips and Schweisfurth (2008: 98, italics theirs) note "Research that results in warnings against certain courses of action can be valuable as that which encourages change". Although uncritical transfer is a present challenge, it is mindful to recall 35 years ago, the struggle in the Caribbean appeared to be uncritical imitation:

Like other Western-trained specialists West Indian educational planners and administrators have often been guilty of uncritical imitation. The colonialist perspective has clouded our horizons so that institutions designed for temperate climates, European cultures and metropolitan capitalist economies have been imposed upon a tropical, multicultural and exploited amalgam of peoples. Our own imprisoned consciousness and the threatening impasse and breakdown of our total society is forcing our politicians and thinkers to assess the weakness of the present situation and to indicate possible choices for the way forward (Mitchell, 1974 cited in Brock, 1984).

Yet 'borrowed' concepts, regardless of their origin from former colonial powers or from other countries in the centre, are not necessarily better or worse than national ideas. Innately, reforms have little value but gain effectiveness through support from local actors, indigenization and implementation processes and are consistent with societal values. However, careful consideration of 'horizontal borrowing' policies implies a stronger 
accountability is needed for the 'centre' as it is clear that foreign ideas are used to inform and innovate policies in periphery countries through globalization and the resulting vulnerability felt by states. This is a difficult challenge, as reforms are usually created by the home country for use in the home country given the local context. ldeas travel also through various networks which cannot be shut down such as conferences, academic journals and policy personnel. Limiting these mechanisms of transmission is not a worthwhile task; unearthing the needs of vulnerable nations to these networks through further studies on under-researched island states may be a quieter subversion to the status quo gaze towards the 'centre'. By drawing attention to the intricacies of nation states and building capacity for inward change, the gaze towards the 'centre' will hopefully be broken down to yield a stronger confidence in national initiatives. Through focusing on the periphery, the power of the 'centre' may be reduced. It is hoped that this thesis study on two island states in the Caribbean has played a useful albeit small role in this difficult process. 


\section{Bibliography}

Bacchus, M.K. and Brock, C. (1987) The Challenge of Scale: educational development in the small states of the Commonwealth. London: Commonwealth Secretariat.

Bacchus, M.K. (2008). 'The education challenges facing small nation states in the increasingly competitive global economy of the twenty-first century'. Comparative Education. 44(20), pp.127-145.

Bell -Hutchinson, C. (2004) Teaching-For-Thinking: The Implementation of ThinkingFocused Pedagogy in Two Grade 8 Mathematics Classrooms in Jamaica. Ph.D Thesis. Jamaica: University of West Indies.

Bishop, A. (1994) 'Cultural conflicts in mathematics education: Developing a research agenda'. For the Learning of Mathematics. 14(2), pp15-18.

Brock, C. (1988) 'Beyond the Fringe? Small States and the Provision of Education'. Comparative Education. 24(2), pp.167-179.

--- (1984). 'Education and a Multicultural Caribbean'. Education in Multicultural Societies. Corner, T (ed). New York: St. Martin's Press.

Brown, J., Newland, A., Anderson, P. and Chevannes, B. (1997) Caribbean Fatherhood: Underresearched, Misunderstood. Caribbean Families: Diversity Among Ethnic Groups. Roopnarine, J. and Brown, J. (eds). Advances in Applied Developmental Psychology Series No. 14. Connecticut: Ablex Publishing

Briguglio, L., Persaud, B., and Stern, R. (2006) Towards an Outward-Oriented Development Strategy for Small States: Issues, Opportunities, and Resilience Building: A review of the Small States Agenda purposed by the Commonwealth/World Bank Task Force Report of April 2000. London: Commonwealth Secretariat.

Burke-Ramsay, A. and Degazon-Johnson, R. (2004) Early Childhood Education: Good Practice in Achieving Universal Primary Education. A handbook for education policymakers and practitioners in Commonwealth countries compiled from a Caribbean Early Childhood Education Conference presented by the Jamaica Teachers Association, Ocho Rios, Jamaica, April 2004. London: Commonwealth Secretariat.

CARICOM (2001). Revised Treaty of Chaguaramas Establishing The Caribbean Community Including the CARICOM Single Market and Economy. Georgetown, Guyana: CARICOM.

Caribbean Examinations Council (2001) Secondary Education Certificate Examinations. Mathematics Syllabus: Effective for examinations from May/June 2003. St. Michael, Barbados: Caribbean Examinations Council.

Chan, J. (2007) 'Between efficiency, capability and recognition: competing epistemes in global governance reforms'. Comparative Education. 43(3), pp.359-376. 
Chisholm, L. (2007) 'Diffusion of the National Qualifications Framework and outcomesbased education in southern and eastern Africa'. Comparative Education. 43(2), pp.295309.

Central Intelligence Agency (2008) The World Factbook. [Online] Available from www.cia.gov/library/publications/the-world-factbook. [Accessed 29.11.08].

Cohen, L., Manion, L. and Morrison, K. (2000) Research Methods in Education. $5^{\text {th }}$ Ed. London: Routledge Falmer

Coultas, J. and Lewin, K. (2002) 'Who becomes a teacher? The characteristics of student teachers in four countries'. International Journal of Educational Development. 22(3), pp.243-260.

Commonwealth Secretariat (2007). Commonwealth Heads of Government Meeting: The Kampala Communiqué. London: Commonwealth Secretariat.

--- (2006) Commonwealth Education: Good Practice Awards 2006: Recognising good and promising practices in Education throughout the Commonwealth. London: Commonwealth Secretariat.

--- (2005) 15CCEM Mid-Term Review Meeting: Caribbean Region and Canada. Summary Report. Nassau, The Bahamas 27-30 July. London: Commonwealth Secretariat.

--- (2004) Protocol for the Recruitment of Commonwealth Teachers. Adopted by Ministers of Education at Stoke Rochford Hall Conference Centre, Lincolnshire, United Kingdom, Sept 1, 2004. London: Commonwealth Secretariat.

--- (2003) Report on the $15^{\text {th }}$ Conference of Commonwealth Education Ministers: Access, Inclusion and Achievement: Closing the Gap. Edinburgh, UK, 27-30 October 2003.

London: Commonwealth Secretariat.

--- (1991) Harare Commonwealth Declaration. London: Commonwealth Secretariat.

--- (1971) Declaration of Commonwealth Principles. London: Commonwealth Secretariat.

Cowen, R. (2006) Comparing and transferring: Visions, politics and universities. Higher Education and National Development: Universities and Societies in Transition. London: Routledge.

Crossley, M. and Holmes, K. (1999) Educational Development in the Small States of the Commonwealth: Retrospect and Prospect. London: Commonwealth Secretariat.

Crossley, M. and Watson, K. (2003) Comparative and International Research in Education: Globalisation, context and difference. Oxford: Routledge Falmer.

Cypher, J. and Dietz, J. (2004) The Process of Economic Development. London: Routledge. 
Dale, R. (2001) 'Constructing a Long Spoon for Comparative Education: charting the career of the "New Zealand model"'. Comparative Education. 37(4), pp.493-500.

--- (1999) 'Specifying globalization effects on national policy: a focus on the mechanisms'. Journal of Education Policy. 14(1), pp.1-17.

Dolowitz, D. and Marsh, D. (2000) 'Learning from Abroad: The Role of Policy Transfer in Contemporary Policy-Making'. Governance: An International Journal of Policy and Administration. 13(1), pp.5-23.

Donnell, A. and Welsh, S. (1996) General Introduction. The Routledge Reader in Caribbean Literature. Donnell, A. and Welsh, S. (eds). London: Routledge.

Evans, H. and Davies, R. (1997). Overview Issues in Childhood Socialization in the Caribbean. Caribbean Families: Diversity Among Ethnic Groups. Roopnarine, J. and Brown, J. (eds). Advances in Applied Developmental Psychology Series. No. 14.

Connecticut: Ablex Publishing.

Fairbrother. G. (2007) Qualitative and Quantitative Approaches. Comparative Education Research. Bray, M., Adamson, D. and Mason, M. (eds). Hong Kong: Comparative Education Research Centre, Hong Kong University.

Gooch, C. (1995) "“Loitering on Colonial Premises after Closing Time”: An Analysis of Television Programming Policy in Barbados'. Globalization, Communications and Caribbean Identity. Dunn, H. (ed). New York: St. Martin's Press.

Green, A. (2000) 'Converging Paths or Ships Passing in the Night? An 'English' critique of Japanese school reform'. Comparative Education. 36(4), 417-436.

Griffith, W. (2002) 'A tale of four CARICOM countries'. Journal of Economic Issues. 36(1), pp.79-97.

Government of Barbados (2007) Global Excellence Barbadian Traditions. The National Strategic Plan of Barbados 2006-2025. Bridgetown: Government of Barbados.

--- (2001) Secondary Mathematics Syllabus Levels 1 and 2. Bridgetown: Ministry of Education, Youth Affairs and Culture, Government of Barbados.

--- (2000a) Education in Barbados Information Handbook. Bridgetown: Ministry of Education, Youth Affairs and Culture, Government of Barbados.

--- (2000b) Curriculum 2000 Barbados. Rationale and Guidelines for Curriculum Reform in Barbados. Bridgetown: Ministry of Education, Youth Affairs and Culture, Government of Barbados.

--- (1995) White Paper on Educational Reform: Preparing for the Twenty-first Century. Each One Matters...Quality Education for all. Bridgetown: Ministry of Education, Youth Affairs and Culture, Government of Barbados. 
Government of Trinidad and Tobago (2007) Vision 2020: Operational Plan 2007-2010.

Section 1: Developing Innovative People. Port of Spain: Government of Trinidad and

Tobago.

--- (2005) National Test Report 2005. Ministry of Education. Port of Spain: Division of Educational Research and Evaluation, Government of Trinidad and Tobago.

--- (2004) National Report on the Development of Education in Trinidad and Tobago 2004.

"Quality Education for All Young People: Challenges, Trends Priorities". Port of Spain:

Ministry of Education, Government of Trinidad and Tobago.

--- (2002a) Strategic Plan 2002-2006, Government of Trinidad and Tobago, Ministry of Education 2002. Port of Spain: Government of Trinidad and Tobago.

--- (2002b) Secondary Education Modernization Programme. Draft Secondary School Curriculum: Mathematics. Port of Spain: Curriculum Development Division, Government of Trinidad and Tobago.

--- (1993a) Education Policy Paper (1993-2003) National Task Force of Education (White Paper). Port of Spain: Government of Trinidad and Tobago

--- (1993b) Education Policy Paper (1993-2003) National Task Force of Education (White Paper) Philosophy and Educational Objectives. Port of Spain: Government of Trinidad and Tobago.

--- (1960) The Concordat of 1960: Assurances for the Preservation and Character of Denominational Schools. Port of Spain: Government of Trinidad and Tobago.

Hayhoe R (2007) 'The use of ideal types in comparative education: a personal reflection'. Comparative Education. 43(2), pp.189-205.

Hickling-Hudson, A. (2004) 'Towards Caribbean "knowledge societies": dismantling neocolonial barriers in the age of globalization'. Compare. 34(3), pp.293-300.

Halpin, D. and Troyna, B. (1995) 'The Politics of Education Policy Borrowing'. Comparative Education. 31(3), pp.303-310.

Howe, G. (2003) Educating for Life: A Stocktaking Review of Citizenship Education Policies and Practices in the Anglophone Caribbean. Extract of Main Findings and Recommendations. Paris: International Bureau of Education.

Hufton, N. and Elliott, J. (2000) 'Motivation to learn: the pedagogical nexus in the Russian school: some implications for transnational research and policy borrowing'. Education Studies. 26(1), pp.115-136

Jansen, J. (1995) 'Effective Schools?' Comparative Education. (31)2:181-200.

--- (1998) 'Curriculum Reform in South Africa: a critical analysis of outcomesbased education’. Cambridge Journal of Education. 28(3), pp.321- 331. 
--- (2004) 'Importing Outcomes-Based Education into South Africa: policy borrowing in a post-communist world'. Educational Policy Borrowing: historical perspectives. Phillips, D. and K, Ochs. (eds). Oxford Studies in Comparative Education. Oxford: Symposium Books.

Jarvis, P. (2000) 'Globalization, the Learning Society and Comparative Education'. Comparative Education. 36(3), pp.343-355.

--- (2000) 'Globalization, the Learning Society and Comparative Education'. Comparative Education. 36(3), pp.343-355.

Jones, P. (2007a) 'Education and World Order'. Comparative Education. 43(3), pp.325-337

--- (2007b) 'Global governance, social policy and multilateral education'. Editorial.

Comparative Education. 43(3), pp.321-323.

Jules, D. (2008) 'Rethinking education for the Caribbean: A radical approach'. Comparative Education. 44(2), pp.203-214.

Jules, V. and Panneflek, A. (2000) EFA in the Caribbean: Assessment 2000. Sub-Regional Report, Vol 1. Lighting the Way Forward: Sub-Regional Summary and Action Plan. Paris: UNESCO.

King, K. (2007) 'Multilateral agencies in the construction of the global agenda on education'. Comparative Education. 43(3), pp.377-391.

Lashley, L. (1995) 'Television and the Americanization of Trinibagonian Youth: A Study of Six Secondary Schools'. Globalization, Communications and Caribbean Identity. Dunn, H. (ed). New York: St. Martin's Press.

Lavia, J. (2007) 'Girls and special education in the Caribbean'. Support for Learning. 22(4), pp.189-196.

Leo-Rhynie, E. (1997) 'Class, Race, and Gender Issues in Child Rearing in the Caribbean'. Caribbean Families: Diversity Among Ethnic Groups. Roopnarine, J. and Brown, J. (eds). Advances in Applied Developmental Psychology Series No. 14. Connecticut: Ablex Publishing.

Little, A. (2000) 'Development Studies and Comparative Education: Context, content, comparison and contributors'. Comparative Education. 36(3), pp.279-296.

London, N. (2002) 'Curriculum and Pedagogy in the Development of Colonial Imagination: a case study'. Pedagogy, Culture and Society. 10(1), pp.95-121.

--- (2001) 'Language for the Global Economy: some curriculum fundamentals and pedagogical practices in the colonial educational enterprise'. Educational Studies. 27(4), pp.393-423. 
Louisy, P. (2004) 'Whose context for what quality? Informing education strategies for the Caribbean'. Compare. 34(3), pp.285-292.

--- (2001) 'Globalisation and Comparative Education: a Caribbean perspective'. Comparative Education. 37(4), pp.425-438.

--- (1999). 'Introduction'. Educational Development in the Small States of the Commonwealth: Retrospect and Prospect. Written by Crossley, M. and Holmes, K.

London: Commonwealth Secretariat.

Luschei, T. (2004) 'Timing Is Everything: The Intersection of Borrowing and Lending in Brazil's Adoption of Escuela Nueva'. Global Politics of Educational Borrowing and Lending. Steiner-Khamsi, G. (ed). New York: Teachers College Press.

McEwan, P. and Benveniste, L. (2001) 'The politics of rural school reform: Escuela Nueva in Colombia'. Journal of Education Policy. 16(6), pp.547-559.

McKeever, M. (2000) 'Snakes and ladders: Ethnical issues in conducting educational research in a postcolonial context'. Situated Ethics in Educational Research. Simons, H. and Usher, R. (eds). London: Routledge Falmer.

Mundy, K. (2007) 'Global governance, educational change'. Comparative Education. 43(3), pp.339-357.

Noah, H. and Eckstein, M. (1969) Toward a Science of Comparative Education. New York: MacMillian.

Ochs, K. and Phillips, D. (2004) 'Processes of Educational Borrowing in Historical Context'. Educational Policy Borrowing: historical perspectives. Phillips, D. and K, Ochs. (eds). Oxford Studies in Comparative Education. Oxford: Symposium Books

Ochs, K. (2006) 'Cross-national policy borrowing and educational innovation: improving achievement in the London Borough of Barking and Dagenham'. Oxford Review of Education. 32(5), pp.599-618.

Ozga, J. (2000) Policy Research in Educational Settings: Contested Terrain. Milton Keynes: Open University Press.

Parry, J. and Sherlock, P. (1956). A Short History of the West Indies. Oxford: MacMillan.

Parry, O. (1996) 'In One Ear and Out the Other: Unmasking Masculinities in the Caribbean Classroom'. Sociological Research Online. 1(2).

Peters, B. and Best, G. (2005) 'Enhancing Access to Tertiary Education in Barbados:

Promises to Keep'. Journal of Eastern Caribbean Studies. 30(2), pp.1-42.

Phillips, D. (2004) 'A Typology of Cross-National Attraction in Education'. Global Politics of Educational Borrowing and Lending. New York: Teachers College Press. 
--- (2002) 'Comparative Historical Studies in Education: Problems of Periodisation

Reconsidered'. British Journal of Educational Studies. (50)3, pp.363-377.

--- (2000a) 'Beyond Travellers' Tales: Some Nineteenth-Century British Commentators on Education in Germany'. Oxford Review of Education. 26(1), pp.49-62.

--- (2000b). 'Learning from elsewhere in education: some perennial problems revisited with reference to British interests in Germany'. Comparative Education. 36(3), 297-307.

--- (1995). (ed). Education in Germany: Tradition and Reform in Historical Context. Oxford: Routledge.

Phillips, D. and Ochs, K. (2004) 'Researching policy borrowing: some methodological challenges in comparative education'. British Education Research Journal. 30(6), pp.773784.

--- (2003) 'Educational Policy Borrowing: Some questions for small states'.

Commonwealth Education Partnerships 2004. Matlin, S. (ed). London: The Stationary Office.

Phillips, D. and Schweisfurth, M. (2008). Comparative and International Education: An introduction to Theory, Method, and Practice. London: Continuum.

Reynolds, F. and Farrell, S. (1996). Worlds Apart? A Review of International Studies of Educational Achievement Involving England. London: HMSO for OFSTED.

Rhys, J. (1966) Wide Sargasso Sea. London: Penguin.

Riddell, A (1997) 'Assessing Designs for School Effectiveness Research and School Improvement in Developing Countries'. Comparative Education Review. 41(2), pp.178204.

Rizvi F, Lingard, B and Lavia, J. (2006) 'Postcolonialism and education: negotiating a contested terrain'. Pedagogy, Culture and Society. 14(3), pp.249-262.

Rivzi, F. (2004) 'Debating globalization and education after September 11'. Comparative Education. 40(2), pp.157-171.

Rodwell, S. (1998) 'Internationalisation or Indigenisation of Educational Management Development? Some issues of cross-cultural transfer'. Comparative Education. 34(1), pp.41-54.

Scott, D. and Usher, R. (1999) Researching Education: Data, Methods and Theory in Educational Enquiry. London: Continuum.

Schriewer, J. (2000) 'World Systems and Interrelationship Networks: The Internationalization of Education and the Role of Comparative Inquiry'. Educational Knowledge: Changing Relationships between the State, Civil Society, and the Educational Community. Popkewitz, T. (ed). New York: State University of New York Press. 
Schriewer, J. and Martinez, C. (2004) Constructions of Internationality in Education. Global Politics of Educational Borrowing and Lending. Steiner-Khamsi, G. (ed). New York: Teachers College Press.

Schweisfurth, M. (2006) 'Global and cross-national influences on education in postgenocide Rwanda'. Oxford Review of Education. 37(5), pp.697-709.

Silova, I. (2004) 'Adopting the New Language of the New Allies'. Global Politics of Educational Borrowing and Lending. Steiner-Khamsi, G. (ed). New York: Teachers College Press.

Spreen, C. (2004a) 'Appropriating Borrowed Policies: Outcomes-Based Education in South Africa'. Global Politics of Educational Borrowing and Lending. Steiner-Khamsi, G. (ed). New York: Teachers College Press.

--- (2004b) 'The Vanishing Origins of Outcomes-Based Education'. Educational Policy Borrowing: historical perspectives. Phillips, D. and Ochs, K. (eds). Oxford Studies in Comparative Education. Oxford: Symposium Books.

Steiner-Khamsi, G. (2004) 'Blazing a Trail for Policy Theory and Practice'. Global Politics of Educational Borrowing and Lending. Steiner-Khamsi, G. (ed). New York: Teachers College Press.

--- (2006) 'The economies of policy borrowing and lending: a study of late adopters'. Oxford Review of Education. 32(5): 665-678.

Stevenson, H. and Stigler, J. (1992). The Learning Gap: Why our schools are failing and what we can learn from Japanese and Chinese education. New York: Simon \& Schuster.

Tarabini-Castellani Clemente, A. (2007) 'The spread of targeted educational policies in Latin America: global thesis and local impacts'. International Studies in Sociology of Education. 17(1/2), pp.21-43.

Tikly, L. (2004) 'Education and the new imperialism. Comparative Education. 40(2), pp.173-198.

UNESCO (2009). EFA Global Monitoring Report 2009: Overcoming inequality: why governance matters. Paris: UNESCO.

--- (2007) EFA Global Monitoring Report 2007: Strong Foundations Early Childhood Care and Education. Paris: UNESCO.

--- (2008) EFA Global Monitoring Report 2008: Will we make it? Paris: UNESCO.

--- (2006a). EFA Global Monitoring Report 2006: Literacy for life. Paris: UNESCO.

--- (2006b) Report by the Director-General on the Global Action Plan to Achieve the Education for All (EFA) Goals. UNESCO Executive Board. Hundred and seventy-fifth 
session 25 Aug 2006. Annex 1: Global Action Plan: Improving Support to Countries in Achieving the EFA Goals Edition of 10 July 2006. Paris: UNESCO.

--- (2002) Medium Term Strategy: Contributing to peace and human development in an era of globalization through education, the sciences, culture and communication. Paris:

UNESCO.

--- (2000) The Dakar Framework for Action: Education for All: Meeting our Collective Commitments. World Education Forum, Dakar, Senegal 26-8 April 2000. Paris: UNESCO.

UNESCO Santiago (2007) The State of Education in Latin America and the Caribbean: Guaranteeing Quality Education for All. A regional report, Reviewing and Assessing the Progress toward Education For All within the framework of the Regional Education Project EFA/PRELAC. Paris: UNESCO.

University of Trinidad and Tobago (2008). University of Trinidad and Tobago website. [Online] Available from www.utt.edu.tt. [Accessed 11.12.08].

Vavrus, F. (2004) 'The Referential Web: Externalization Beyond Education in Tanzania'. Global Politics of Educational Borrowing and Lending. Steiner-Khamsi, G. (ed). New York: Teachers College Press.

Wellington, J. (2000) Educational Research: Contemporary Issues and Practical Approaches. London: Continuum.

Whitty, G. and Edwards, T. (1998) 'School Choice Policies in England and the United States: an exploration of their origins and significance'. Comparative Education. 34(2), pp.211-227.

Williams, P. (2006) Achieving Education for All: Good Practice in Crisis and Post-Conflict Reconstruction: A Handbook for Education Policy Makers and Practitioners in Commonwealth Countries. London: Commonwealth Secretariat.

Yates, L. (2004) What does Good Education Research look like? Conducting Educational Research Series. Torrance, H. (series ed). Milton Keynes: Open University Press. 


\section{Table of Appendices}

Appendix A: History of the Caribbean

Appendix B: Additional information on sociocultural context

Appendix C: Phillips and Ochs' (2004) circular model

Appendix D: OBE and central Asia

Appendix E: Description of the candidate

Appendix F: Interview question bank

Appendix G: Additional information sheet

Appendix H: EFA goals

Appendix I: Debriefing document for participants

Appendix J: Feedback session participants

Appendix K: Dale's (1999) chart

Appendix L: Sample interview transcript

Appendix M: Bibliography of appendices 


\section{Appendix A: History of the Caribbean}

Much of the history of the individual islands is related to the history of the region as islands developed similarly through stages of colonization, sugar wars and independence. Specific historical dates for the two countries are as follows:

\section{Barbados}

The island was discovered in 1625 by the British. lt is believed that the Caribs settled from neighbouring islands in the Barbadian parishes of St. Lucy and St. Phillip (Government of Barbados, 2008). The first significant slave uprising was in 1816 , led by the slave Bussa and Washington Franklin, a freed Mulatto (Government of Barbados, 2008). Barbados boasts the third oldest parliament in the Western world. Although the island was ruled exclusively and uninterrupted by the British, votes were given to the freed coloured population in 1831 (Government of Barbados, 2008). Up until then, the political system was dominated by the planter and merchant classes. 1838 saw the emancipation of slaves (Government of Barbados, 2008). Political awakening of the black population began in the 1920s (Government of Barbados, 2008), leading to the popularity of the Barbados Labour Party. The first election with universal suffrage took place in 1951, followed by the granting of self governing status in 1961 (US Department of State, 2008a). In 1966, Barbados gained independence from Britain. Through the Govenor-General, the British monarchy is recognized as the figurehead chief of state.

\section{Trinidad}

In 1498, Christopher Columbus discovered Trinidad and Tobago, habituated by the Arawaks and Carib peoples (Government of Trinidad and Tobago, 2008). This discovery opened the twin isle to colonization, beginning with the Spaniards occupying Trinidad until the $15^{\text {th }}$ century. The British captured Trinidad in 1797 and it became a crown colony in 1802. The history of Tobago is closely aligned with those of the Lesser Antilles as Tobago changed hands 22 times between the Dutch, French and the British (US Department of State, 2008b) - more than any other West Indian island. Tobago became an official colony in 1814 and was officially joined with Trinidad in 1889 (Government of Trinidad and Tobago, 2008). After African slaves were freed in 1838, indentured workers arrived from India in 1845 to make up for labour storages (US Department of State, 2008b). Independence was achieved in 1962 and the two islands became a republic in 1976. The first political election showed party alliances by racial groups, notably Afro-Trinidadians and Indo-Trinidadians (US Department of State, 2008b). 1990 saw the attempted coup by an extremist Black Muslim group, Jamaat al Muslimeen over unresolved land claims, holding the Prime Minister and MPs hostage for 5 days (US Department of State, 2008b). The Jamaat leaders surrendered to government authorities after being granted amnesty during the hostage (US Department of State, 2008b).

The following is a summary of the historical stages of development of the Caribbean.

\section{A1. Discovery and a 'disjointed' history}

In their significant book $A$ Short History of the West Indies, Parry and Sherlock (1965: 1) trace the beginnings of West Indian history to the arrival of Christopher Columbus in 1492 and the subsequent disappearance of the indigenous peoples such as the Arawaks due to the "impact of an aggressive alien culture". The only exception seems to be the Caribs in St. 
Lucia who ousted settlers between 1638 and 1641 and the Amerindians, who are situated in Guyana and are regaining political and cultural prominence (Donnell and Welsh, 1996). Yet the response to the presence of colonial powers was greeted with "sullen apathy" by the Ameridians (Parry and Sherlock, 1965: 71). However, little is known of the indigenous population as much more has been written about the colonization and battles for the Caribbean region which has been likened to "less of a meeting and crossing place than a corridor" (Parry and Sherlock, 1965: vi). Yet the significance of the lack of a remaining indigenous group lies in the process of identity formation. Donnell and Welsh (1996) attribute the extinction of the Caribs, Arwaks and near annihilation of the Amerindians to the problem of a lack of cultural base in the Caribbean. They argue that "The project to establish an 'independent' cultural identity and literary identity was probably more fraught in the Caribbean than other post-colonial societies" (Donnell and Welsh, 1996: 6). The disjointed nature of the history as the beginning populace was made virtually extinct forms a history that seems neither linear nor fully owned by one particular group. Thus, Parry and Sherlock (1965) offer some perspectives on how history in the West Indies is viewed. They describe it as a battle for the "outlying barbicans of a gate" as "hundreds of ships, thousands of men and great stores of treasure have passed through the Caribbean" (Parry and Sherlock, 1965: vii) and "a story told from someone else's point of view" as it appears "disjoined the unreal to West Indians today" (Parry and Sherlock, 1965: vii). Certainly, outside circumstances dictated major events as colonial powers fought over islands before the arrival of slaves. Although there were settlements of Europeans, the beginning of Caribbean civilization may appear to be disconnected to sociohistorical aspects of present day West Indian citizenry which consists of descendants of both former colonial powers and slaves, as well as generations of immigrants.

A full historical account of the history of the Caribbean is beyond the scope of this dissertation. However, a brief summary of significant events post-Columbus will follow. The empire of the Caribbean began with the sole presence of Spain in the $16^{\text {th }}$ century in which Santo Domingo was the centre of activity, although Hispaniola and Havana were also significant places (Parry and Sherlock, 1965). The challenge to Spain caused the beginning of the English and French empires in the Caribbean and echoed aspects of political challenge in Europe - a theme that would prevail throughout the scramble to secure the island pursuits. The first settlers from Spain were relatively humble and lived pastorally, raising cattle, cassava, maize, tobacco and sugar (Parry and Sherlock, 1965). Although this last crop is the most significant as it dictated the rise and fall of island economies, it was a modest commodity in Spanish Caribbean civilization (Parry and Sherlock, 1965).

\section{A2: Colonialism}

In the early Spanish settlements, it is interesting to note that the enslavement and illtreatment of the remaining Indians was forbidden as they were inhabitants of the islands and therefore entitled to protection by the Spanish Crown (Parry and Sherlock, 1965). Ironically, African slavery was permitted in the early setttlements as the Spanairds were of the opinion that the African slave was better than the Indian "because he was stronger less primitive and more adaptable" (Parry and Sherlock, 1965: 24) and were not subjects of the Spanish King, but rather subjects of independent kings of West Africa (Parry and Sherlock, 1965: 24). 
The Spanish were the sole European power in the Caribbean until the arrival of pirates and smugglers in the 1530s (Parry and Sherlock, 1965). The principal 'object' was African slaves which were smuggled by the Portuguese and Flemish as well as the Spanish. The Truce of Nice in 1583 ended the organized fighting until 1542 when a war was unleashed between the Spanish and their interlopers (Parry and Sherlock). France became involved and eventually captured Havana, the centre of the convoy system. Although the Treaty of Cateau-Cambresis in 1559 was settled in favour of Spain, the challenge to the sole presence of Spain in the Caribbean was no longer possible (Parry and Sherlock, 1965). A few years later, Englishmen under the leadership of John Hawkins arrived in trading voyages. However, the Spanish monopoly was never completely broken in the $16^{\text {th }}$ century despite the alliance made between England and the Netherlands in the Treaty of The Hague in 1596 (Parry and Sherlock, 1965). Parry and Sherlock (1965) assert that over the next 200 years the English, Dutch and French admirals attempted full scale naval operations which resembled those of Francis Drake, an Englishman who devised an attack first on Santo Domingo, followed by smaller port towns, leading to the capture of Havana. By the end of the $16^{\text {th }}$ century, Spain retained its power over settled colonies.

With the Truce of Antwerp in 1609, the Dutch were newly independent and began asserting their own empire in the Caribbean through maritime presence and the subsequent establishment of the Dutch West India Company, which "was to be the foster-parent of the French and British empires" (Parry and Sherlock, 1965: 44). Between 1630 and 1640, they seized Curacao, Saba, St. Martin and St. Eustatius (Parry and Sherlock, 1965). Other islands were discovered by the English such as Barbados and St. Kitts in 1624 (Parry and Sherlock, 1965). With the cooperation of the French and the Dutch, settlements began on other Caribbean islands such as St. Croix (1625), Tobago (1625), Nevis (1628), Antigua (1632), Montserrat (1632), Martinique (1635), Guadeloupe (1635) and St Lucia (1638-41). Some of these islands, such as Martinique and Guadeloupe were French territory, while others such as St. Croix were jointly occupied by the English and Dutch.

The settlements began with the aim of producing crops and led to settlements by indentured men who offered to serve for a period of 3-7 years in return for passages to the Caribbean and the expectation of land at the end of their indenture (Parry and Sherlock, 1965). Although they were not paid any wages, there was an abundance of servants as "the miserable condition of a landless labourer in England, and the lure of free land in the West Indies, combined to supply a powerful incentive" (Parry and Sherlock, 1965: 56). In the mid 1640s, the white population in all the islands reached its peak and has since not recovered (Parry and Sherlock, 1965). Yet the beginnings of these settlements did not quickly transpire into financial gains for the French or the English as this was seen as "a period of greater activity than achievement, especially by comparision with the much larger and more solid development of the mainland colonies" (Parry and Sherlock, 1965: 63). For example, the tobacco from Barbados and Leeward Island could not compete with the crops from Virginia (Parry and Sherlock, 1965). Further, the French and English islands were dependent on Dutch commercial activity as they were regarded as the masters and teachers of Europe due to their fluid capital, updated business methods and cheap and easy handling on their ships (Parry and Sherlock, 1965). Parry and Sherlock (1965: 56) conclude: "Much of the profit to be derived from the colonial settlements of all European nations found its way into Dutch pockets".

\section{A3: Slavery}


The economic landscape drastically changed after 1650 in which sugar became the sole product of importance (Parry and Sherlock, 1965). This revolution changed the entire composition of the islands and was regarded as a "rich man's crop" (Parry and Sherlock, 1965: 66) as factories, once established, had a high earning potential. As a result, the island of Barbados became a land filled with large estates and approximately 12,000 small holders and proprietors who were not able to participate in the sugar revolution were driven out (Parry and Sherlock, 1965). Further, "establishments of this type required a large and welldisciplined labour force, which the old practice of indenture could not adequately supply" (Parry and Sherlock, 1965: 68). Further, the process of the landless labourer in England arriving in the Caribbean to work for several years in return for land was no longer possible as no land remained apart from those acquired by the estates (Parry and Sherlock, 1965). There was an attempt to bring labourers from Europe, in which "every conceivable method of propaganda was employed to recruit labour" from North German individuals homeless by the Thirty Years War, Royalist prisoners, Irish rapparees and transportation sentences for convicted criminals" (Parry and Sherlock, 1965: 68). Yet this was not suffice and the French and English planters drew upon African slaves as their Spanish and Portuguese counterparts had done before (Parry and Sherlock, 1965). There was the perception that West Africa had an "inexhaustible reservoir of humanity" (Parry and Sherlock, 1965: 69). Although the white population remained stationary, by 1701 , the total population of slaves was 44,000 , a figure which increased dramatically by 1710 , in which Martinique alone had 21,000 slaves (Parry and Sherlock, 1965).

The slave markets were situated along the middle stretches of the cost, in areas such as Sierra Leone, Libera, the Ivory, Gold and Slave Coasts, the Oil Rivers of the Niger Delta, Cameroon, Gaboon and Loango (Parry and Sherlock, 1965). The languages of the slaves belonged to either the Sundanic or Bantu families and the principle tribes were the FantiAshanti peoples of the Gold Coast, the Dahomeans, the Yoruba of western Nigeria and the Bini of southern Nigeria (Parry and Sherlock, 1965). Yet Parry and Sherlock (1965: 71) assert that "all these peoples were composites of many smaller groups, welded through a long process of conquest into more or less homogeneous kingdoms ruled by powerful, stable and often ruthless dynasties". Slavery existed before the arrival of West Indian planters as "Prisoners taken in inter-tribal war were commonly enslaved, and wars were undertaken deliberately for the purpose" (Parry and Sherlock, 1965: 71). Rulers of the area possessed large numbers of slaves, recruited by kidnapping or purchased for a price (Parry and Sherlock, 1965). Ironically, the recruitments of slaves did not discriminate between chiefs, shamans and the captives: Africans with higher social status were captured as well (Parry and Sherlock, 1965).

\section{A4: Resistance}

Upon arrival to the West Indies, West African slaves reacted strongly against their captured lives with active resentment with the first recorded servile mutiny in Barbados in 1649 (Parry and Sherlock, 1965). Throughout the history of Caribbean slavery, there were uprisings. Berry (1986) asserts there were revolts on every island and each rebellion was bloodier and crushed more severely than the previous uprising. He writes of the mental condition that lead the slaves to their actions:

The confiscation of freedom made a terrific impact on Afro-Caribbean people. The forced-labour experience they endured - that not belonging to yourself, that endless 
no-pay work, that being ineligible for common rights that uphold human dignity, that way of life called slavery, translated itself into a burdensome loss. Freedom became a haunting thought and prayer and dream of Afro-Caribbean people. It aroused resistance. It has come to arouse a dynamic desire for reclamation (Berry, 1986: 67).

Although overt rebellions could be prevented or punished, individuals expressed their resentment through suicides, infanticides or running away, Parry and Sherlock (1965: 73) assert that "resentment found regular expression in calculated idleness, giving the owner the bare minimum of labour necessary to escape the whip; in willful carelessness and destructiveness in handling the owner's property, whether tools, fences, buildings or stock; and in feigned stupidity". Through time, a characteristically West Indian way of life slowly emerged which was not drawn directly from any specific African group nor a collaboration of African folk traditions (Parry and Sherlock, 1965). Yet a dream for a return to Africa seemed to prevail: "From early on, finding themselves landed in the Caribbean, the Africans held on to the belief that they would get back to their African 'nations' to welcomes and rejoicings. That hope stayed with them year after year and decade after decade" (Berry, 1986: 70).

While the diversity of African traditions and former social statuses were replaced with a "West Indian amalgam" (Parry and Sherlock 1965: 72), the European plantation community was changed by the plantation economy. Planters were placed among the top, appearing as ruthless men of enterprise alongside the elite of doctors, lawyers and merchants who controlled the islands (Parry and Sherlock, 1965). The next level on the socioeconomic scale were the employees of plantations which supported the sugar economy, such as book-keepers, skilled tradesmen, carpenters, masons and smiths (Parry and Sherlock, 1965). The poor white labourers were further down the scale as they worked alongside slaves and lived a similar quality of life. Yet this small population soon disappeared as Acts were passed to improve the condition of white servants to provide other areas of employment, mostly due to the growing disportion of Europeans and Africans and the shortage of a militia (Parry and Sherlock, 1965). Due to legislation such as "Deficiency Acts' which required planters to fix quotas on the number of white servants, created a division of society according to colour rather than economic status: "naturally, the poor whites clung fiercely to the theory of social superiority which the Acts implied" (Parry and Sherlock, 1965: 73). White indented servants soon became were a rare commodity. Parry and Sherlock (1965) note that Spanish slaves were treated better than other European indentures, although French law forbid cruel treatment, prescribed minimal conditions of feeding and housing to assure the conservation of slaves, and affirmed their civil rights to formal trials, marriage and preservation of family units.

\section{A5: Sugar Wars}

With the 1654 restoration of slaving stations of Angola and Congo Delta to Portugal and the 1664 and 1667 seizures of Dutch barraccons by the English and French, the Dutch West India Company went bankrupt in 1674 and the English and French empires continued to find profits (Parry and Sherlock, 1965). Yet wars continued throughout the late $17^{\text {th }}$ century between these three groups, in which Outer Antilles islands were the subject of treaties. St. Eustatius, for example, "changed hands ten times between 1664 and 1674" (Parry and Sherlock, 1965: 81). No such formalities were made in the Greater Antilles which were 
controlled by buccaneers: "Their suppression, delayed by political and strategic needs, was economically essential to merchant and planter alike" (Parry and Sherlock, 1965: 94). Yet the $18^{\text {th }}$ century raids of Greater Antilles islands such as Jamaica, Western Hispaniola, Tortuga and Bay Islands provided to be important for empires, with triumphs of admirals over "gangs of ruffians for private profit" (Parry and Sherlock, 1965: 94), illustrating the significance of conquering the West Indies for both economic profit and status in the challenge for superiority in European power.

Wars between the strongest empires of English and French were common throughout the $18^{\text {th }}$ century which was spurned by rivalries over sugar colonies. Parry and Sherlock (1965: 114) describe the aims of the sugar wars:

Each side hoped not to acquire and exploit the enemy's colonies but to destroy and depopulate them; to burn the canes, to wreck the machinery, and above all, to carry off the slaves, who were the most necessary, most valuable, and most mobile part of the planters' capital. Failing the destruction of the enemy's colonies, the next-best thing was to cut off their trade, starve them of provisions and slaves, and prevent them from selling their sugar.

These tactics proved to be successful, although wars between the French, British and some involvement from the Spanish continued at a high cost:

The only changes in Caribbean territory were the cession of Florida to Spain and Tobago to France. These were trivial results indeed for years of bitter and destructive fighting; but nobody in France, Spain or England yet appeared to question whether the West Indies were worth the enormous cost of war" (Parry and Sherlock, 1965: 139).

In the end, Parry and Sherlock (1965: 141) conclude that the British empire grew stronger "not from efforts to diversity their economy....but from the destruction of the rival French sugar trade, by the disasters of revolution and resulting war".

\section{A6: The road to independence}

At the end of the $18^{\text {th }}$ century, revolutions and rebellions paved the way for freedom for slaves. In 1733, almost all the European residents were murdered during an uprising on the Danish island of Saint John. Jamaica and Saint-Domingue gained their reputations for mutinies (Parry and Sherlock, 1965). Until the late eighteenth century, most people in Europe accepted the necessity of the slave trade as the main source of national profits and power. However, later in the eighteenth century, economists and industrialists questioned the assumptions of the colonial system and the role of the British West Indies in open trade world market among the expanding societies of North and South American and the East (Parry and Sherlock, 1965). Similarly, humanitarians and intellectuals attacked the notion of the trade, with Rousseau and his successors influencing American leaders in the War of Independence and the revolution in France (Parry and Sherlock, 1965). Religious leaders such as Wesley and Whitfield appealed to morality and missionary societies, and in short, "the initiative for the abolition of the slave trade came from within English society, and not from within West Indian society" (Parry and Sherlock, 1965: 177). Political movement steadily increased until the Act for the abolition of the slave trade passed in 1807 and came 
into force on 1st January 1808 (Parry and Sherlock, 1965). Although Denmark abolished the trade in 1804, the abolition of the slave trade by British law was significant as the United Kingdom reigned supreme in the Caribbean as the French were limited to Guadeloupe and the Spain to Cuba and Puerto Rico (Parry and Sherlock, 1965). More importantly, more than half of the slave trade was under British control and 750,000 slaves were working in the British West Indies (Parry and Sherlock, 1965). Both France and Spain followed suit in abolishing the slave trade in 1818 and 1820 respectively but "both of these powers were half hearted about the matter and slave dealing was for long an open business in ports like Nantes" (Parry and Sherlock, 1965: 181).

After the historic 1808 act, there was a stronger push for increasing the conditions of slavery itself, such as legalizing marriage between slaves and limiting the owner's power to punish (Parry and Sherlock, 1965). However failure to adopt this 'policy of amelioration' was greeted with increasing demands in England for the complete abolition of slavery itself (Parry and Sherlock, 1965). There was also the fear of mutiny. Governor Bentinck wrote from British Guyana in 1812 about this possibility:

In a country like this where on an extent of coast of near 150 miles there is a population of only 1,746 white inhabitants and 847 people of colour that could in case of necessity be called on to repel an insurrection of 31,484 male slaves, if such a calamitous event should ever arise, too many precautions cannot be taken to prevent as far as possible the assemblage of negroes in considerable numbers under any pretence whatsoever (cited in Parry and Sherlock, 1965: 184).

This fear of uprising became a reality as outbreaks in Guyana, Barbados and Jamaica in the 1820s (Parry and Sherlock, 1965). The 1831 insurgence in Jamaica saw scores of Methodist and Baptist chapels burnt and in England, rioting ensued in the same year when the House of Lords rejected the Bill to end slavery (Parry and Sherlock, 1965). In the end, "agitation, mutiny, political pressure, and administrative skill, all played their part in preparing the Emancipation Act which finally became law in 1833"(Parry and Sherlock, 1965: 186). In 1848, France abolished slavery throughout the French colonies and authorized payment of compensation to former owners (Parry and Sherlock, 1965). Although slavery remained in the Spanish islands until as late as 1865 in Cuba, the process of independence for French and British Caribbean islands was another journey (Parry and Sherlock, 1965).

\section{A7: Federation of the West Indies and Nationhood}

During the 1950s and 1960s, discussion surrounding the Federation of the British West Indies created political and diplomatic controversy between the colonial power of the United Kingdom and the entities of Barbados, Jamaica and Trinidad and Tobago, although other territories were included such as Antigua and Barbuda, Dominica, Grenada, Jamaica, Montserrat, the former St Kitts-Nevis-Anguilla union, St. Lucia and St Vincent (CARICOM, 2008). The Federation was established in 1958 with the aim of creating a political union among former territories. The Federation was headed by the Governor General, Lord Hailes of Britain. The Prime Minister was the Premier of Barbados, Sir Grantley Adams, with the capital located in Trinidad and Tobago (CARICOM, 2008). The University of West Indies, with three campuses in Jamaica, Barbados and Trinidad was established along with BWIA, a West Indian airline. Yet the Federation faced problems of unity, such as the following: 
(T)he governance and administrative structures imposed by the British; disagreements among the territories over policies, particularly with respect to taxation and central planning; an unwillingness on the part of most Territorial Governments to give up power to the Federal Government; and the location of the Federal Capital (CARICOM, 2008).

After conducting a national referendum in 1961 on its continued participation and support for the Federation, Jamaica withdrew from the union and soon received independence from Britain. Shortly after, the Premier of Trinidad and Tobago stated that 'one from ten leaves nought' and withdrew from the Federation as Jamaica was the largest of islands (CARICOM, 2008). The Federation collapsed in January 1962.

Although this federation was a failed endeavour, it resulted in national independence for the islands. Trinidad and Tobago gained independence in 1962 and Barbados gained independence in 1966. Donnell and Welsh (1996: 6) report a "surge of nationalisms in many Anglophone Caribbean territories in this period, especially those such as Jamaica and Trinidad" which can be seen in the literature of that period. Since independence, each island retains the sentiment of desired autonomy. For example, Gooch (1995: 117) writes "Barbados faces numerous development tasks, including the formidable challenge of fostering cultural identity". Gooch recalls the late Prime Minister Errol Barrow's 1966 speech on the eve of independence in which he proclaimed that his nation would "not be found loitering on colonial premises after closing time' (Barbados Constitutional Conference in London 1966, cited in Gooch, 1995: 117). Yet politically and culturally, this vision has struggled throughout the islands as small states tend to exist on the periphery of world order.

\section{A8: Migration and Development}

Although movement became possible after the abolition of slavery, migration of Caribbean peoples to other parts of the world became a reality in the middle of the $20^{\text {th }}$ century. Opportunities to work on the Panama Canal drew thousands of Caribbean workers to the region, as well as the banana plantations in Costa Rica, fruit farms in the southern United States and sugar plantations in Cuba (Wong, 1986). In the United States, a contract labour system was developed (Wong, 1986). However, with the passing of the Walters-McCarran Act of 1952 which restricted the number of Caribbean workers, Britain inherited the surplus labour (Wong, 1986) and movement was eastward to the United Kingdom. After the Second World War, Caribbean migrants actively sought employment and educational opportunities for their children (Sutcliffe, 1986). They arrived in places such as the United States, Canada and Great Britain, bringing hope for both the future and a welcoming multicultural society. Yet Sutcliffe (1986) argues that this "new dimension was and still is poorly understood by the white majority" (Sutcliffe, 1986: 1). This perhaps is a result of the complexities surrounding multiethnic Britain and the inability to reconcile its imperial past with migration needs of Caribbean peoples. Wong (1986: 111) points to the outcomes of colonialism, such as under-development of the islands and "the creation of a reserve army of labour on which Britain drew to fuel its economic boom".

Although migration appears to be a strong effect of colonialism, it is impossible to ignore the other outcome of under-development. International agencies and multilaterals have worked to raise the quality of life in Caribbean islands, which range from those with high 
amounts of private banking (Cayman Islands) to rural areas vulnerable to insularity and disappearance from world order (the Grenadines), to those with civil conflict (Haiti) and high violence rates (Jamaica). While the place of international aid is a contentious issue, the International Monetary Fund has played a role in the development of the Caribbean. While the role of the IMF will be judged by history, Boyd (1988) offers a critique of structural adjustment programs which were a condition of receiving loans: "These measures have had a severe impact on households, and in Jamaica and Trinidad have widened the earning gap between the rich and the poor" (cited in Evans and Davies, 1997: 12). As a result, less is spent on social services such as education and households are also earning less (Evans and Davies, 1997), reducing public market for services that families cannot fund through their own income. 


\section{Appendix B: Additional information on sociocultural context}

\section{B1: Gender}

Evans and Davies (1997) conclude that the main concern about such gender roles is the resulting messages for males and the possible contribution towards male dysfunctionality in Caribbean societies: "The concern is that boys are brought up to regard themselves as superior to girls, but girls are provided the experiences that make them in the long term more competent and more able to cope with the demands of life" (Leo-Rhynie, 1997: 10). Conventionally, the male are supposed to be responsible for economic aspects of family life whereas women are conceived as the nurturer (Leo-Rhynie, 1997). While this forms the ideal for two parent households, the reality of female economic participation may skew this model. Yet the shift from traditional religious ideals of male headship to the high proportion of households headed by women may cause young males to struggle with the mixed messages regarding the role of men. Leo-Rhynie (1997: 37) outlines this problem:

Despite the fact that women, in many cases, manage the household, make the decisions and often provide most if not all of the financial support for the maintenance of the home, headship of the household is usually ascribed to the man if he is present. This may well be the communication of an expectation that the man will assume financial responsibility of the home, or it could be a reflection of the societal and religious ideal of male headship.

This may have a long term effect on male participation in society as enrolment data from Jamaica shows girls outnumber boys in high school and at the University of the West Indies at a ratio of 2:1 (Leo-Rhynie, 1997). Further, women are 10 percentage points above males for literacy rates (Leo-Rhynie, 1997).

The preferences for sons and daughters may be linked to perceptions of boys and girls. Middle-class parents may prefer a boy to carry on the family name, but lower class mothers often prefer girls, perhaps due to the feeling that boys are more troublesome and the expectation that girls will look after them in their old age (Leo-Rhynie, 1997). Brown et al (1997: 94) comment that this culturally sanctioned bond stems from the feeling that "Caribbean mothers raise daughters to be independent and/or resourceful helpmates to eventual partners, but raise sons to remain sons". This may be a result of the mother's need for financial support in her old age as this may not be guaranteed from a partner (Brown et al., 1997). In addition, Brown et al. (1997) carried out a study on 700 low income men in Jamaica, Guyana and Dominica titled the Contribution of Caribbean Men to the Family (CCMF) 1990-1992 on the attitudes of fathers in relation to their families. They found that men contribute to their families more than they are credited and most men aspire to be 'good fathers'. Despite other research that indicates that men do not participate in household duties, the men sampled in the Brown et al. (1997: 93) study found men active in the domestic sphere: " $40-50 \%$ of the urban samples of men cook, tidy the house and go to the shop at least once a week". This finding of participation may be linked to the strong personal meanings of fatherhood that men in this study felt towards their children, in particular to their own natural offspring (Brown et al., 1997). Fathering was part of a man's definition of himself and seen as a route to maturity (Brown et al., 1997). Further, urban fathers expressed dissatisfaction with their fathering roles due to separation from their children: "a quarter to a third of the respondents were dissatisfied with their fathering role 
and/or how their children were growing, and in many cases fathers cited the mother's lack of cooperation in allowing visits" (Brown et al., 1997: 93). This finding is supported by the work of Brown (1993) who found that in spite of their absence, fathers play a significant role in the rearing of their children: "Parenting appears to have much personal meaning for fathers, although there is wide variation in their understanding of the social and psychological aspects of fathering" (cited in Evans and Davies, 1997: 10). This is echoed in the sample of Brown et al. (1997) in which respondents expressed the contributions of both of their own parents to their development, stating that the influence of church, street culture, school and poverty were "overridden or strongly mediated by the nature of the positive or negative parenting they received" (Brown et al., 1997: 95).

Grant et al.'s (1983) Parent Interview Schedule for parents of children from birth to three found that parents strongly agreed that children are expected to be obedient and behave well. They also found that the majority of all parents except those in Barbados agreed that the 'rod should not be spared' (cited in Leo-Rhynie, 1997: 48). However, there was a division in the sample with regards to the opinion of whether children should be both seen and heard, and whether or not too much love and attention will spoil the child (Leo-Rhynie, 1997). Evans and Davies (1997: 5) also identified another common child rearing notion that children "should be seen and not heard". They found that middle class parents complained about their children asking too many questions or talking too much, "ignoring the value of such interchange for the development of language and the understanding of concepts" (Evans and Davies, 1997: 5). In general, conversing and reasoning with children is limited and in low-income homes, it was found that children have few opportunities for extended conversations with parents or guardians, although there were plenty of opportunities to play with their peers (Evans and Davies, 1997). In fact, it was found that the majority of parents and guardians talk to their basic school age children only once or twice a week (Evans and Davies, 1997).

\section{B2: Language}

While colonialists left the legacy of languages such as Spanish and French in the region, other ethnicities have brought with them the languages of their home countries, creating a multilingual environment. However, the prevalence of creoles and patois have created a particular West Indian niche in the world of languages, and Caribbean English has been referred to as a 'World English' to ensure its unique but recognized linguistic status. Although Caribbean creoles may appear to have less 'status' than older languages such Spanish and French as Caribbean Englishes may deviate from vocabulary, idiom, pronunciation and grammar, Sutcliffe (1986) notes the languages are capable of being flexible and there should be the recognition that language "refracts the light of experience through many different systems of expression and embodies it in many different oral traditions" (Sutcliffe, 1986: 3). Donnell and Welsh (1996: 11) identify the term 'Nation Language' as a culturally specific term which provides a positive status for non-standard Caribbean linguistic forms, whereas the terms 'dialect' and 'patois' are considered 'pejorative' and less linguistically accurate terms for 'creole' or 'nation language'. However, these terms have been "re-appropriated and re-inflected as positive terms of cultural resistance by certain writers" (Donnell and Welsh, 1996: 11). The terms "Nation Language' and 'creole' will be used interchangeably, and where possible, 'Nation Language' will be used in place of 'creole'. 
Caribbean Nation Languages appeared in the late $17^{\text {th }}$ and early $18^{\text {th }}$ century when slaves of different linguistical backgrounds arrived from West and Central Africa to work on Caribbean plantations and new common languages in place of old tribal divisions were created to ensure alliances against whites (Sutcliffe, 1986). Colonial languages of English and French formed the basis of vocabulary, although some scholars link creoles to aspects of African grammars, others have pointed to a universal grammar common to all languages (Sutcliffe, 1986). It is assumed that the early slaves interpreted colonial languages through their own African patterns of speech production and reception. Thus, Sutcliffe describes these new systems as "(largely) European-derived words pronounced in a distinctively African way" and as "the medium for the African's own culture and oral traditions, in large part a continuation of the ancestral traditions" (Sutcliffe, 1986: 4). While much has been written on linguistic aspects of nation language within language research, Berry (1986) provides a description of two aspects of Nation Language. He identifies the use of "alltime-is-now" in which "the language disregards past and future tenses and bring its knowing into the present" Berry (1986: 95) provides the following example:

It is not 'Buddy came and saw me last night' but 'Buddy come see me last night', not 'I will be going to the market on Saturday' but 'I go market Saturday'.

Berry (1986: 95) also points to the heavy reliance on sound as Caribbean Nation Language attempts to translate sounds into written words: "More and more the words appear on the page with sharp, clear Afro-Caribbean sounds. For example, 'me' has become 'mi'; 'for', which used to be 'fe', has become 'fi..."'

While Berry's (1986) identification of these two aspects of Nation Language may not be found in speech patterns of all Caribbean peoples, Hodge (1990) claims that nearly all Caribbean peoples use some form of Nation Language some of the time (Donnell and Welsh, 1996). The term post-creole continuum refers to the range of speech "the most creolized forms at one end and language forms which are closer to (and virtually indistinguishable from) a standard language at the other end" (Decamp, 1971 cited in Donnell and Welsh, 1996: 13). Decamp (1971) also argues that the use of Nation Language is dependant on the situation, which he refers to as: "the breath of the span depending on the breath of [their] social contacts" (Decamp, 1971 cited in Donnell and Welsh, 1996: 13) which is referred to as code-switching. The use of Nation Language may be attributed to its strong roots within society, although Hodge (1990) expresses the complicated sentiments surrounding it: "We speak creole, we need creole, we cannot function without creole, for our deepest through processes are bound up in the structure of creole, but we hold creole in contempt" (cited in Donnell and Welsh 1996: 13). Berry (1986: 96) acknowledges this delicate balance of attachment to Nation Language with pressure to conform to standardized English and reports that parents of British born Caribbean children want their children to use a language that will reap qualifications and achievements as they are "[c]onditioned to believe that their own language is 'bush talk" and 'bad' and 'down-grading".

This may be attributed to the influence of reggae and Rastafarianism on Nation Language. Bones (1986a) argues that reggae breaches the language barrier and widens the horizon of word, thus bridging the gap between singing and talking. He writes: "For reggae, most definitely, the music and langauge are one and the same thing. The message can't be different because its one sound, one word and one mouth, people, culture and all else that 
related to the people of reggae and Afro-Lingua" (Bones, 1986a: 55). More is written regarding the impact of reggae on Caribbean culture in section 4. 3. On the other hand, Berry (1986: 95) acknowledges the influence of Rastafarianism on language, and provides the following example:

They have brought in their 'I-and-I', meaning both 'Jah' and 'I-human'. They have reinterpreted words (Jamaica becomes 'Jah-mek-yah' meaning 'Jah makes here' or 'Jah is/was made here').

Wong (1986) provides a further analysis of Afro-Linguistic (often referred to as patois) words which are rooted in biblical and Rastafarian concepts of redemption. A list of words is provided as an example (Wong, 1986):

$\begin{array}{ll}\text { English } & \text { Afro-Lingua } \\ \text { Unity } & \text { inity } \\ \text { Politics } & \text { politricks } \\ \text { System } & \text { shitstem } \\ \text { Understand } & \text { overstand } \\ \text { Oownpression }\end{array}$

Wong (1986: 120) argues that the use of such words is a conscious move by black youth to relate their speech to the struggle within a dominant society: "For the black rebels Patois is the principal and private bearer of their cultural capital. It is one way of asserting individuality, an assertion that in its aggressive expression often invites responses of annoyance and dislike..."

\section{B3: Religion}

While Wong's (1986) analysis of Rastafarian influence on language provides a strong indication of its presence within Caribbean society, it is important to note that not all Caribbean peoples are not devoted Rastafarians. Religions such as Christianity, Catholicism, Islam, Hinduism, Sikhism and Buddhism exist throughout the islands as well as other variants such as the Church of Scientology. However, Rastafarian remains as one of the religions historically rooted in Africa and is a notable aspect of Caribbean context. Bones (1986b) states that there are many substantial Rastafarian communities in Jamaica, all of the former English-speaking islands of the Caribbean and in former French, Spanish and Dutch colonies.

In 1930, Negus Tafari, a Rastafarian was crowned the Emperor of Ethiopia and this act symbolized the need to spread the word that Christ had returned as he was seen to be the King of Israle or of the Jews (Bones, 1986b). His disciples believed that the African people were the true and original Israelites who God would save as long as they kept serving him by obeying his laws: "This conception is fundamentally spiritual or religious but is intimately related to racial, political and economic realities" (Bones, 1986b: 39-40). The early Rastafarians were not only defining a racial awareness by also a national awareness through their emphasis on Africa, which can be seen in early Rastafarian Marcus Garvey's motto: "Africa for the Africans, those at home and those abroad"" (Bones, 1986b: 40). As a result of such a powerful slogan, Rastafarians rejected assimilation into mainstream 
Caribbean society and appeared as a segregationist movement, establishing a Rastafarian community in Pinnacle in the parish of St. Catherine, Jamaica (Bones, 1986b). Although the government of Jamaica demolished Pinnacle 15 years later, Rastafarians fled to other parishes such as Kingston and made their presence known (Bones, 1986b). By 1956, there was a rapid conversation to the Rastafarianism in Jamaica (Bones, 1986b). Wong (1986: 114) explains the attraction to the faith: "The popular appeal of the Rastafarian Movement is seen by oppressed blacks as a 'primary form of resistance' to the physical and historical realities of the society that dominates them".

However, Wong (1986) notes that this resistance to historical and political issues is often ignored and the Rastafarian youth is regarded as a criminal due to stereotypes. He describes the images associated with Rastafarianism: "The popular, media-packed image of a Rasta is a ganja-smoking cultist, speaking in an untutored but quaint tongue, who believes in the deity of Haile Selassie and is for ever in a drugged stupor, dreaming of the millennial return to Ethiopia or rocking until the wee hours to a monotonous beat" (Wong, 1986: 114). Yet the appeal of Rastafarianism, according to Wong (1986) lies in its ability to offer young people in both the Caribbean and those who have migrated to other countries such as the United Kingdom a way to express their resistance to cultural and political assimilation to mainstream infiltration of a Afro-Saxon identity. He concludes: "It is a timely, "homegrown' ideology of liberation, which contains the social, cultural and political forces that they can use to harness, adapt, legitimize and develop all the social practices and cultural elements of their sub-proletariat status and roots culture - aspects considered shameful and subnormal by British society" (Wong, 1986: 116). In particular, black Afro-Caribbean peoples in Britain are drawn by Rastafarianism because of "its flexible and all embracing (the combination of the material and transcendent) nature: the emphasis on slavery, colonialism and the African homeland, denuded on the transcendent, could become the means of expression of a black nationalist politics" (Miles, 1978 cited in Wong, 1986: $115)$.

\section{B4: The Arts}

The most innovative area of Caribbean culture may rest in its contribution to music, and in particular, the style of reggae. Along with cultural inventions such as Rastafarianism and Afro-Linguistics are indeed representative of the richness of Caribbean culture, reggae has drawn attention to the Caribbean experience. Reggae has strong roots in Jamaica, and the popularity of reggae may be related to the strength of Jamaica in this region as it dominates the rest of English-speaking Caribbean (Bones, 1986a). Johnson (1976) states that reggae is significant as it is "the spiritual expression of a historical experience of the Afro-Jamaican" (cited in Wong 1986: 115) and reflects the life experiences of black youth by providing an ideology of liberation (Wong, 1986: 115). In particular, the music of Bob Marley "highlights the destructive nature of a capitalist society in which viciousness and competitiveness result in each man's being the potential enemy of the other" (Hylton, 1975 cited in Wong, 1986: 115). Music is a particularly important expression as "[s]inging and talking are related social behaviours. They rely on words, sound and power in order to acquire definition, structure and relevance, in order to obtain response and a sense of commonality" (Bones, 1986a: 54).

Literature from the Caribbean region has also drawn attention from the Western world and in some cases, has drawn a sense of commonality among other post colonial literatures as it 
subverts colonialist assumptions. However it is important to note that the term "post colonial' does not subscribe to the centrality of the definitions (Donnell and Welsh, 1996) and the diversity of literature from this region shows the vast experiences of its peoples. This may stem from the lack of a stable, unified culture and increased the demand for "the role of imaginative forms more vital during periods of nationalist struggle" (Donnell and Welsh, 1996: 6). Although some federalist Caribbean journals such as Kyk-over-al have enabled writers to contribute to a unified West Indian literature over separate national literatures in a process coined 'West Indian island to Carribean matrix' by Braithwaite (1997), it has been argued that this sentiment was short lived during the 1950s talks regarding the West Indian Federation (Donnell and Welsh, 1996). Nevertheless, the relationship between 'Caribbeanness' and literature of the region is difficult to define (Donnell and Welsh, 1996).

However, there are some common themes in Caribbean literature such as the following: "naming the landscape; validating the local; the architecture of a literature; accommodation; alienation; personhood and community; the autobiographical mode; childhood and matrilineal links; exile; nostalgia; rewriting histories; and a realist tradition persist as classic areas of enquiry" (Donnell and Welsh, 1996: 8). Further, Berry (1986) provides a brief summary of the different themes of Caribbean literature beginning with 'Restricted Existence' (Guyanian A. J. Seymour's 1957 poem 'First of August'), followed by post slavery upper and middle class score towards the deprivation of Caribbean peoples in what he coins the period of 'Traditional Great-House Indifference'. An example is Geoffrey Drayton's Christopher in which there is "neither a social conscience nor an involvement with the well-being and development of their former unpaid workers" (Berry, 1986: 73). The next theme identified is the tension of 'Poverty and Wealth' or 'Poverty and Poverty' (Berry, 1986). An example of this theme can be seen in Roger Mais Blackout in which a sense of superiority and the subsequent humiliation is illustrated in the meeting of a female white American and black Jamaican male. Barbadian George Lamming's 1953 In the Castle of my Skin illustrates another of Berry's (1986: 76) themes 'Restless for Change', in which "disgusted self-contempt has a way of expressing an unconscious worry". Another theme is illustrated through Nobel laureate V.S. Naipaul's work in 1959 Miguel Street set in Port of Spain which includes characters who are frenzied but lost (Berry, 1986). Finally, Berry (1986) describes several other themes of migration to the United Kingdom such as 'Travellers in Reflection and Hope' (The Emigrants by George Lamming), 'The New Days in Britain' (Trinidadian Samuel Selvon The Lonely Londoners), and 'Renewal, Outcry, Resistance, Memory, Outrage' (Jamaican Oku Onuora's A Slum Dweller Declares).

At the same time, Berry (1986) is also critical of the British black poetry and the AfroCaribbean experience. He claims that black writers need to stimulate imagination through his following comments:

They need to remember that Caribbean countries have not yet evolved new economic and social structures to replace the old colonial ones effectively. Caribbean nations have not yet dreamed up the good life for their people. While they may have invented steelpan music as the most effective twentieth-century musical instrument, they have explored hardly any depths of the Caribbean psyche with it or composed any appropriate top-class, original music to play on it. A 
workable plan for educational, economic, industrial or social change could be better than a great poem (Berry, 1986: 105).

Berry's (1986) comments may refer to other forms of literature which have been strongly influenced by Rastafarianism and the black power movement in both the United Kingdom and the Caribbean such as dub poetry which carries confrontational political messages. Dub poetry was written during the militant atmosphere of 1970s Britain during two tumultuous decades of discrimination against blacks, unemployment against black youths and perception of police intolerance and violence in multiracial neighbourhoods (Donnell and Welsh, 1996). However, dub poetry is often omitted from the canon of Caribbean literature as " $[\mathrm{t}]$ here remains a common belief that dub is at best a limited form, at worst...not really 'literature' at all" (Donnell and Welsh, 1996: 23) 


\section{Appendix C: Phillips and Ochs' (2004) model}

1. Cross-national attraction

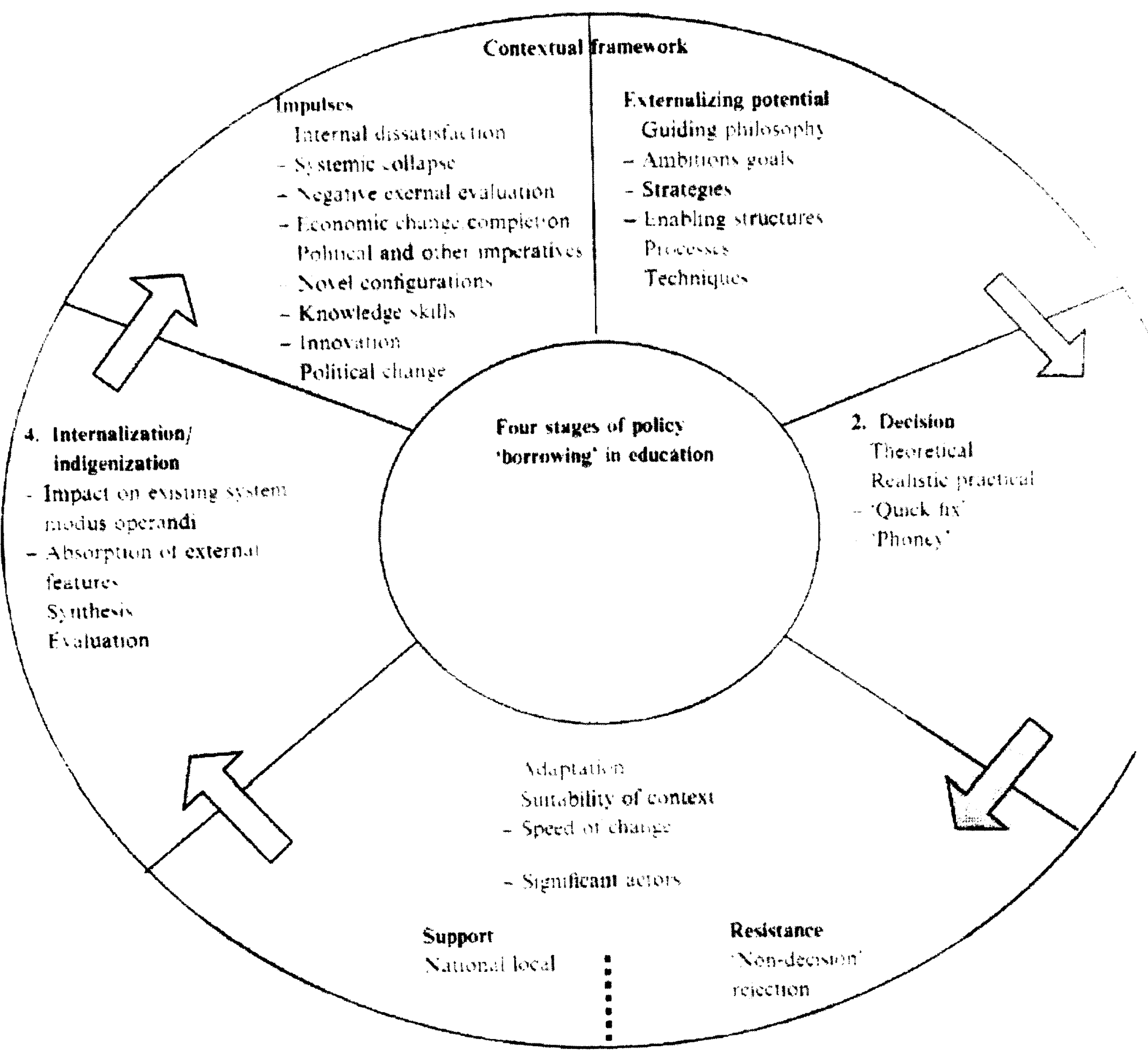

3. Implementation 


\section{Appendix D: OBE and central Asia}

The countries of Mongolia, the Kyrgyzstan and Kazakhstan adopted OBE by the time that the epidemic of OBE reached the burnout stage where "they are at the same time everybody's and nobody's reform", making them global without a geographical heritage (Steiner-Khamsi, 2006: 666). By the time these Central Asian states adopted OBE, Ministries of Education and teacher unions across the globe were disenchanted with the reform and had moved on to new models (Steiner-Khamsi, 2006). Steiner-Khamsi (2006) also finds great interest in the timely movement of the OBE reform across geographical areas, as well as the specific exemplars countries afflicted by the epidemic viewed as reference points as they point to the interrelationships of actors in the world system. As discussed in the case of South Africa, the act of borrowing is thus closely connected to international politics.

Steiner-Khamsi (2006: 671) argues that contrary to what borrowing advocates may assert, "...borrowing does not occur because reforms from elsewhere are better, but because the very act of borrowing has a salutary effect on domestic policy conflict". She thus concludes that there must exist a window of opportunity for innovative reform in the local context (Steiner-Khamsi, 2006). It is this precise window of opportunity which is interesting in the case of the Central Asian countries as the timing of loans granted by development banks best explains the late adoption of OBE by Central Asian countries (Steiner-Khamsi, 2006). Lynn Ilon (1994) notes that OBE reforms were initiated in countries to reverse the effects of structural adjustment policies on education (cited in Steiner-Khamsi, 2006). There is an ambiguity of the degree of coercion during this window of opportunity of funds available as a situation is created where 'voluntary policy transfer' coincides with 'coercive policy transfer' (Dolowitz and Marsh, 2000 cited in Steiner-Khamsi, 2006) in aid dependent countries. International funding is often earmarked by specific strategies and projects in a sector, and in the case of Central Asia, "...international funding was only made available if OBE-type reform was systemically pursued" (Steiner-Khamsi, 2006: 674, italics hers). Clearly, education borrowing in the case of Central Asia raise significant concerns about the practice of borrowing and policy transfer as the impact of international aid has strong implications for the autonomy of the nation state and the neo-colonial relationships between the 'First World' and developing countries. 


\section{Appendix E: Description of the Candidate}

My parents immigrated to Canada from Hong Kong in the late 1960s after my father completed his engineering degree at Queen's University, Canada and his Masters at University of Toronto, Canada. My mother was a Maths teacher in Hong Kong. Both of their families left Guangzhou, China during the Cultural Revolution. All three of their children were born in Toronto, Canada. I attended Queen's University, Canada and completed a four year undergraduate honours degree in English and Maths and a Bachelor of Education at the intermediate-senior level. During my undergraduate degree, I worked as a classroom assistant and completed my Education placements in Toronto, Kingston (Ontario) and Hong Kong. After graduating, I taught Maths at the secondary level before pursuing a Masters degree in Comparative and International Education at Oxford University, England. My thesis focused on Maths teachers' perspectives of indigenous pupils in New Zealand and Saskatchewan, Canada. At Green College, Oxford, I met my husband, Paul, a Barbadian medical student of Afro-Caribbean, Indian, Chinese and Jewish heritage. His father's family came from San Fernando, Trinidad, although both his parents were born in Barbados. Paul taught secondary Maths and studied at the University of West Indies, Cave Hill for a year before pursuing medicine at Oxford. In 2006, I was appointed at Bath Spa University as a lecturer in International Education and have worked there for three years while completing my doctoral studies. Paul and I married in Barbados in March 2008, followed by a traditional Chinese reception in Toronto. In total, I have three years teaching experience at the classroom level. I have traveled to Barbados six times, Port of Spain three times and visited the Bahamas once. My other travels have taken me to small states in Europe and developing countries in Asia. We currently live in Bristol, UK and visit our families in Toronto and Barbados frequently. 


\section{Appendix F: Interview Question Bank}

Interviews were semi-structured. Questions were drawn largely from the interview question bank, although at times the direction of the interviews changed and questions were reworded for clarification purposes, or additional questions were posed to glean as much information as possible from the respondent. Full transcripts are available upon request.

\section{Teachers}

1. How long have you been teaching?

2. Tell me about your qualifications. How many teachers in your department have teaching qualifications?

3. When students leave your classroom at the end of their formal schooling, what would you like them to have achieved?

4. What are some of the strong features of education in Barbados/Trinidad?

5. What are some of the weak features?

6. Is the syllabus appropriate for pupils?

7. Do you have the opportunity to share best practices with other teachers in the department? What about teachers from other schools? Other islands?

8. Would that be something you would be interested in?

9. How do students best learn Maths?

10. How would you describe your teaching methods? What type of teaching styles or methods do you employ?

11. What are the benefits of chalk and talk? What are the disadvantages?

12. To what degree do think problem solving is emphasized in Maths?

13. To what extent is group work emphasized?

14. To what extent are connections to 'real life' emphasized?

15. To what degree is hands-on interactive learning emphasized?

16. To what degree are problem solving inquiry approaches emphasized?

17. Do you think Maths needs to be embedded in the cultural context of Barbados/Trinidad? Do you think this is important?

18. To what degree do teachers bring Barbadian/Trinibagonian culture into the Mathematics classroom?

19. Why do students need to learn Maths?

20. Please describe the achievement levels of your pupils, based on last year's results.

21. What do you think of the new curriculum/NCSE?

22. When your pupils leave your Maths classroom at the end of their formal schooling, what would you like them to have achieved?

23. How do you structure your lessons?

24. How would you describe your relationship with your pupils?

25 . Where do you get your ideas about lesson planning?

26. How would you describe the attitudes and beliefs of pupils towards Mathematics?

27. Why is it important for your pupils to learn Maths?

28. What contributes to Mathematics achievement at your school?

29. It has been said that many students are leaving secondary school without any formal qualifications. How can this situation be improved in Maths?

30. What are the benefits of exams?

31. What does your department do for the School Based Asssessment of CSec exams? 


\section{Policy makers, academics, international respondents}

1. How did you become involved in the creation of the CXC Maths examination?

2. What sources did you draw upon to create the CXC Maths examination? Were any of these sources from other countries?

3. With regards to the CXC Maths examination, has there been any interest from other countries for 'borrowing'?

4. What skills are the CXC Council looking for in these completed Maths exam papers? Why are these skills important?

5. In your opinion, what are the strengths of the Barbadian/Trinibagonian education system?

6. What are the weaknesses of the Barbadian/Trinibagonian education system?

7. To what extent to you think traditional 'chalk and talk' methods exist? Why?

8. Recently the BBC reported that more students were sitting the CXC Maths examination. Why do think this may have happened?

9. How is Barbados/Trinidad \& Tobago Maths education similar to other Caribbean islands?

10. How is Barbados/Trinidad \& Tobago Maths education different from other Caribbean islands?

11. Are these similarities or differences a result of cultural values?

12. Will the curriculum remain the same or change in a few years' time? Why or why not?

13. To what extent have international agencies become involved in policy development in member states?

14. To what extent do countries in the Caribbean look to each other for borrowing?

15. What are some of the development challenges in the Caribbean? What are some of the challenges with education reform in small states?

16. What work are international agencies currently doing in Barbados/Trinidad?

17. What are some of the ways quality of education can be improved in the Caribbean?

18. In what ways is this assistance similar among countries? In what ways is this assistance different?

19. What are the challenges with working with education ministers in policy change?

20 . How are the new curriculum goals related to the national goals?

21. Is borrowing possible? What are some of the challenges with policy borrowing?

22. To what extent is it possible to overcome the contextual factors of policy borrowing between countries?

23. Is borrowing possible between islands of the English speaking Caribbean?

24. Both Barbados and Trinidad are creating their own sec ed leaving certifications alongside the regional unit of Caribbean examinations council. What is more important, the local or the regional?

25. What are some of the best practices in other countries for improving quality of education? In other words is there a good case study or country study that you would like to discuss? 


\section{Appendix G: Additional Information Sheet}

This document was distributed to the Ministries of Education in Barbados and Trinidad and Tobago. It was also shared with head teachers and heads of Maths departments to brief them on the study and gain access to schools. All respondents were briefed orally.

\section{Examining Mathematics Education in the Caribbean: A Brief Description of Ph.D Study}

\section{Central Purpose}

The aim of this study is to explore the features of Mathematics education in the Caribbean. This Ph.D research aims to uncover characteristics of Mathematics education in Trinidad and Barbados, and whether 'education borrowing' is possible between countries in the region. Other islands such as Grenada and St. Lucia may be examined later in the study.

\section{Overall research questions}

What values are found in the Mathematics curricula in Trinidad and Barbados? Are there similarities or differences in policies or pedagogical practices in Maths education in the Caribbean? Is Mathematics education borrowing possible in the Caribbean? What social or cultural factors need to be considered?

\section{$\underline{\text { Rationale }}$}

Although education borrowing is not a new concept, this Ph.D study will focus on the under-researched region of the Caribbean. This research will look at the potential for other countries to learn from Maths education in a small state. Factors that affect small states are often unique, and it is important to understand both their contribution to the world and how they are able to achieve the mandate of education.

I have chosen the island of Trinidad (and in particular, Port of Spain) it has committed the recommended GDP to Education for All (EFA) goals. As Trinidad is a participant in the EFA initiative, I will be looking for ways in which Trinidad may benefit from education borrowing as a 'recipient' and perhaps also as a 'lender'. In particular, I am interested in Maths as this is often used in international comparisons among countries. Although Caribbean islands have not been involved in such studies, recently, the BBC has reported that more students are taking CXC Maths examinations. Although the education systems in Latin America and the Caribbean are in the process of changing and developing, the multicultural city of Port of Spain is interesting place of study. As Barbados is the only country in the Caribbean that has reached its EFA goals, I will look to see if there are particular features that may make education borrowing possible between Barbados and Trinidad. This Ph.D will attempt to identify implications for further collaboration among islands.

\section{$\underline{\text { Potential Documents }}$}

Curriculum documents will be examined for the topics chosen and the examples provided in the documents on how they should be taught. Assessment documents such as frameworks for evaluation as well as exams will be analyzed. Past CXC Maths exams would also be very helpful. 


\section{Data Collection}

Classroom visits would be ideal for uncovering and classifying Mathematics education paradigms. Teachers, teacher educators, policy makers and pupils may be interviewed to uncover other values that may be implicit in the curriculum. Although individual pupils' experiences will be helpful for understanding classrooms, the focus of this $\mathrm{Ph} . \mathrm{D}$ study will centre on educationalists rather than students.

\section{Dates and Time Scale}

I will be visiting Port of Spain from May 20 - May 25, 2007. During this time, I would like to visit a few secondary schools and meet some Maths headteachers.

I may make subsequent visits to carry out further observations. These visits may occur during the following times:

October 2007: Interviews and non-participant observations (2-3 weeks)

April 2008: Interviews and participant observations (2-3 weeks)

Jan 2009: Debriefing and discussion with fellow educationalists to review findings (2-3 weeks)

I selected these times based on my work and Ph.D academic schedule. However, these times are flexible and 1 welcome further discussion to ensure optimal compatibility. I will also be making visits to Barbados. I plan to submit my Ph.D in December 2009.

\section{Ethics and Considerations}

Institutions, individuals and postholders may withdraw from this study at any time. There will be an opportunity for educationalists to participate in debriefing sessions and findings will be shared. The identities of institutions, individuals and postholders will remain anonymous in this study and any related drafts or published papers. The completed research document may be distributed to interested educationalists in both countries as well as the academic community.

\section{About the student}

I am a Ph.D student at Bath Spa University (UK) with a background as a secondary Mathematics teacher. I have taught in Toronto, Hong Kong and several cities in England. Currently, I am lecturing in the UK in the area of International Education. The focus of my Ph.D study is Maths education in the Caribbean.Contact: E.Lam@bathspa.ac.uk 


\section{Appendix H: EFA Goals}

The following is taken verbatim from Global Monitoring Report 2005 (UNESCO, 2005).

The six EFA Goals

1. Expanding and improving comprehensive early childhood care and education, especially for the most vulnerable and disadvantaged children

2. Ensuring that by 2015 all children, particularly girls, children in difficult circumstances and those belonging to ethnic minorities, have access to, and complete, free and compulsory primary education of good quality.

3. Ensuring that the learning needs of all young people and adults are met through equitable access to appropriate learning and life-skills programmes

4. Achieving a 50 per cent improvement in levels of adult literacy by 2015 , especially for women, and equitable access to basic and continuing education for all adults.

5. Eliminating gender disparities in primary and secondary education by 2005 , and achieving gender equality in education by 2015 , with a focus on ensuring girls' full and equal access to and achievement in basic education of good quality.

6. Improving all aspects of the quality of education and ensuring excellence of all so that recognized and measurable learning outcomes are achieved by all, especially in literacy, numeracy and essential life skills (UNESCO, 2005). 


\section{Appendix I: Debriefing documents for respondents}

This document was distributed to all respondents following the distribution of their interview transcripts for verification. The document was sent to respondents in Spring 2008.

\section{$\underline{\text { Summary of Findings }}$}

\section{The respondents}

50 interviews were completed between January 2007 and November 2007 in both Barbados (BB) and Trinidad (TT). 24 teachers ( 8 BB, 16 TT), 8 Heads of Mathematics (5 BB, 3TT), 2 members of senior school management (1 BB, 1 TT), 3 policymakers (1 BB, 2 TT) and 7 academics $(3 \mathrm{BB}, 4 \mathrm{TT})$ were included in the study. An additional 6 members affiliated with international organizations were interviewed. The researcher also undertook 87 hours of observations to ensure the findings were consistent with classroom activity.

\section{Similarities and differences}

Some respondents in the pilot felt that the contextual differences between Barbados and Trinidad may be difficult to overcome for the purposes of borrowing due to history and sociocultural makeup. Conversely, others disagreed. One respondent summed up the similarities and differences between the two countries and those in the Caribbean in this way: "From my experience, we're all essentially the same. Maths education maintains the same flavour. In some countries, there is a difference in access such as Barbados and Trinidad, but that doesn't mean difference in quality". Secondary school teachers in Barbados usually hold a first degree and a teacher training certificate and are thus more qualified than their Trinidadian counterparts. Several Trinidadian teachers commented on the problem of teacher commitment.

\subsection{Barbados: Identified areas of strengths and weaknesses}

Many of the respondents were able to provide answers, such as moving at the same pace as children, students who enjoy Maths, the CXC exams, involvement of teachers in setting questions and marking exams, ability to choose books and the computerization of the system. One respondent mentioned accessibility from early years to tertiary education, trained teachers and provision for textbooks and school meals. Some respondents were supportive of the system, while others felt that the system produced both strong students and left others behind. There seemed to be agreement that high achievers were successful. Thus, the system may work well due to its ability to help students obtain qualifications. One respondent said: "I wouldn't say there are strengths but [the system] prepare[s] the students to pass the examination. For the students that are capable they are well prepared and pass the exam".

\subsection{Trinidad: Identified areas of strengths and weaknesses}

Trinidadian respondents found it difficult to answer the question "What are the strong features of education in Trinidad?" Some used this question as an opportunity to talk about the weaknesses of the system instead. However, at least 3 respondents pointed out the provision of schools over a short period of time to ensure Education for All. One respondent noted to the ability of the system to produce high achieving students: "The 
strong features is that it is convergent, because students can become experts in a certain area. This is different from places like Canada where it is quite divergent". Through the interviews, it was revealed that there is little provision for low achieving pupils, although various terms were used to describe the 'problem'. A few teachers identified free secondary education while others pointed to the lack of special needs provision as a source of the 'problem' and poor primary education.

\section{Aspects of teaching and learning}

\subsection{Rote methods}

In general, teachers from both countries had mixed responses regarding less traditional modes of teaching such as problem solving, group work, cultural contexts of Mathematics and real life examples. Some teachers stressed the necessity and frequency of use of these techniques while others stated they did not use them. While teachers were critical of "chalk and talk' methods, they often admitted they taught in this style. Some teachers, however, felt that teacher centered methods were not only effective, but also ideal. When asked how students best learn Maths, one teacher replied, "by watching very carefully what the teacher is doing, and once they have the basics, you can apply that in different settings. It's fairly teacher based". This finding is consistent with the observations. Others insisted they used group work and stressed problem solving techniques. Teachers cited both lack of time and the exam oriented system as restraining factors for dependence on chalk and talk. Although not witnessed in the observations, some teachers described their styles as interactive. This may be a result of the differences in definition of the word. It is possible that respondents felt that interactive learning involved participation on the part of students, whether during dictation exercises or repetition of mathematical concepts. Some teachers claimed to use group work; however this was only seen once in the 6 weeks of fieldwork.

\section{2 'Real life' Mathematics}

As a whole, teachers in both countries expressed some interest in 'real life' Mathematics. Some of the respondents stated they used such examples and attempt to emphasize the relevance of Maths to real life; however this was not noted in the classroom observations. However, teachers were able to identify topics and types of questions such as consumer arithmetics and interest. Beyond stereotypical constructions of Mathematics as 'useful' in counting and business, the wider context of Mathematics was not explicitly discussed. In particular, the Mathematics associated with the students' own culture - that of their home environment or out of classroom culture - was not identified within lessons. When asked if outside school knowledge was built upon in the classroom, a few respondents noted that the communities in which some of these children live carry out practices that are not approved by the teachers. However, relevance to 'real life' and connections to out-of-classroom experiences are seen as necessary by teachers in both countries.

\subsection{Mathematics and Caribbean culture}

When asked about the importance of regional or local Caribbean culture, respondents seemed ambivalent to the idea. A few respondents asked for examples while others agreed but did not express enthusiasm. There were other respondents who stressed the importance of a global awareness rather than a regional awareness. A few teachers questioned the effectiveness of these techniques. One respondent offered various ways in which Maths is present in the local Trinibagonian context through examples of patterns on steel pans and trapezium motifs, flutes in Hosay festivals, wing spans of carnival costumes and several 
others in an unpublished paper. On the other hand, one Barbadian educationalist argued that a cultural conflict in Mathematics only exists up to a point.

\subsection{Accommodations for Lower Achieving Pupils}

Although there was not a systematic approach to supporting lower achieving pupils, teachers appeared to have techniques to accommodate students. Some methods for facilitating lower achieving pupils include splitting children up into 'fast', 'normal' and 'slow groups, placing them beside a brighter student, standing next to them, and helping them after class. While these methods may work, alternative styles of teaching were not mentioned and these techniques were seen as specific accommodations to traditional modes of teaching. Similarly, in classroom observations, teachers treated lower achieving pupils as needing more enforcement with basic concepts. These approaches may be considered 'addon' techniques in place of a more holistic approach on inclusion.

\section{Education borrowing}

Schools in both countries appeared to work mostly in isolation, although teachers from different schools discussed education topics informally at workshops hosted by the Ministry. The recognition of similar problems across schools may be a preliminary step for collaboration. Some respondents were enthusiastic. Others noted the existence of opportunities for sharing, such as informal discussions during marking sessions for CXC exams and meetings held by the Caribbean Association of Headteachers. Yet with the exception of some examples of collaboration, it appears that the individual islands tend to look to each other minimally for inspiration, best practices or policy borrowing. This is perhaps contrary to the beliefs of others in the international community who encourage sharing in the Caribbean. Yet the tendency to look towards the 'West' may be a result of assumptions that countries such as those in South East Asia and UK and USA have managed to achieve a success in particular aspects of education. Indeed, this was seen to be consistent with the interview findings in which educationalists revealed interest in areas such as South East Asia due to their performance in TIMSS. Academics referred to research in online journals from Australia, the USA and UK. On a policy level, there was some consultation with New Zealand for the new curricula of the NCSE. One respondent states: "we look to a large extent outside the region, the New Zealand model, what's happening in the UK and USA and pulling together 'best practices' together and seeing how the ideas work together'. However, the use of international consultants was noted for a wide range of ideas such as the TechVoc programme in Jamaica and the CXC headquarters in Barbados for the Trinidadian NCSE marking systems. This process of 'sharing' is supported by international organizations such as the Commonwealth Secretariat and UNESCO. In addition, one respondent felt that the pull of the 'west' or 'global' trends is not necessarily positive.

However, the element of competition between the two islands may be an impediment to sharing and collaboration. One respondent noted: "I don't think that everyone having qualifications is a good thing. We have good rates of passes at this school $-93 \%$. We wouldn't have such high rates, - and Barbados does have good passes - it's just that places like Jamaica and Guyana do not". Another educationalist stated, "Sharing is not part of the culture here. This is why I'm interested in your study and will be interested in what you find". One respondent believed that the insularity of the islands may contribute to the lack of interest in sharing: “...every single political leader wants to keep his kingdom, so every 
one of them wants to keep its own. It will feel it will lead to federation. They won't want to unite - it's so good to be king despite things like Caricom, etc".

Through the interviews, respondents identified possible areas of interest for improvement. These may be seen as possible areas of collaboration as well - or these may be perceived as universal Mathematics education problems in which solutions may be found through looking regionally or 'globally' to the west. The problems identified among Maths educationalists appear to be prevalent in other countries, such as the problem of not liking Maths. However, respondents at the policy development level seemed more interested in participating on a global scale rather than a regional level. This is evident in the description of the curriculum content as relatively 'universal', as one respondent noted that "the concepts are essentially the same - it is just a question of how to get students to apply it in their own environment. Trig in Australia is the same in Barbados". Others in the region agreed that Maths is universal. This acceptance of the constructed 'global' Maths curriculum may be a result of dependence on international recognition of the curriculum in place of a more culturally relevant curriculum. One respondent noted the influence of aid on education. Countries may feel pressured to follow 'best practices' as advocated by international agencies and thus education reforms look remarkably similar.

Thus, is borrowing possible? Within the small states of the Caribbean, one respondent believes it is: "Yes. Because I've seen it happen, effectively because of the size of the Caribbean and the proximity of the countries to each other and already from the standpoint of officials and ministers, there is a lot of cross fertilization and learning that goes on". Another respondent felt that the cultural differences between islands in the Caribbean are not profound and concludes that a student would probably be able to move from Trinidad to Dominica with ease. However, one Trinidadian educationalist asserts a significant difference: "we are the capitalists in the Caribbean because oil has driven us through the years. That is why it is difficult to make comparisons between Trinidad and any other country". There was also the suggestion that borrowing may be better suited for the smaller Windward Islands.

In Barbados and Trinidad, borrowing as a concept may have 'arisen' of the process from colonization to globalization, rather than actual interest in sharing education policies. Following a dominant global agenda is a more likely activity for policymakers in place of regional education borrowing. The individual identities of the islands and the similar directions may provide impulses for borrowing - but the key ingredient as identified by Phillips and Ochs (2004) of cross-national attraction does not appear to exist. Instead, an attraction to participation in the knowledge economy may be of greater importance. Research from the 'west' may have a stronger influence than findings from neighbouring islands, due to research from the UK, USA and New Zealand. The success of Barbados in achieving its Education for All goals may be an impetus for sharing. Trinidad may be able to learn lessons on how the government implemented its teacher training initiatives from Barbados. However, if Trinidad is to adopt similar policies, this would most likely be a result of both donor agendas and a worldwide push to increase the training capacity of educators rather than Trinidadian interest in Barbados. The intention of keeping up with the world is expressed in the perspective of one of the respondents: "What happens here happens in the wider world, a global thing. So we try to keep up with the global changes, wherever it is, and that will be the influence for whatever is going on". Hopefully the global 
community will be more attentive to the movements in both of these small states to ensure that global directives take into account the needs of Caribbean islands.

Work Cited

Phillips, D. and Ochs, K. (2004) 'Researching policy borrowing: some methodological challenges in comparative education'. British Educational Research Journal. 30(6), pp773-784

Thank you for your participation in this study. Please feel free to comment on my findings in the space below and if you wish, you may continue on a separate sheet of paper. Please send any correspondence to E.Lam, School of Education, Bath Spa University, Newton Park Campus, Bath BA2 9BN United Kingdom. Alternatively, you may wish to email me at E.Lam@bathspa.ac.uk. A full draft of findings (25 pages) is available upon request. You are welcome to withdraw from this study at any time. 


\section{Appendix J: List of feedback session participants}

Barbados

Teachers: B1, B2, B6, B11, B15, B10 (5 schools invited, 4 responded)

Policy: B17 (2 invited, 1 responded)

Academics: B4

Trinidad and Tobago

Teachers: T2, T25, T22, T23, T18,T16 and 3 others (see note)

Policy: T3

Academics: T6

International Respondents

I1

\section{Note:}

Three teachers who were involved in the research but were not formally interviewed also participated in the debriefing process: one teacher who was observed but not interviewed due to staff absence, one Head of Department who was not interviewed or observed but granted the researcher access to staff, and one Headteacher who represented staff as the school was closed due to vandalism. 
Appendix K: Dale's (1999) Chart

\begin{tabular}{|c|c|c|c|c|c|c|c|c|c|c|}
\hline 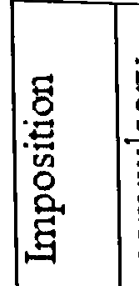 & 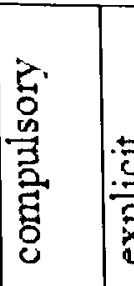 & 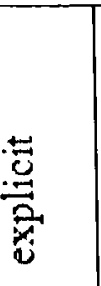 & 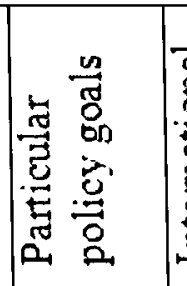 & 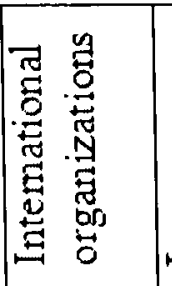 & 总 & 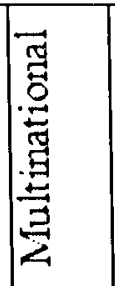 & 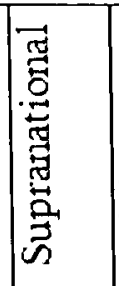 & 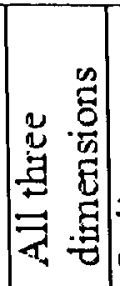 & 悹莣 & 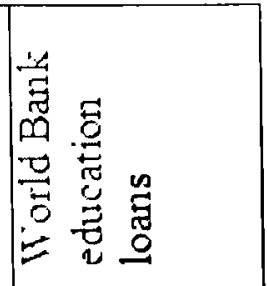 \\
\hline 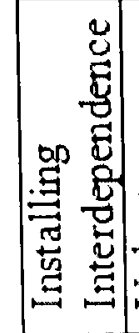 & 蔮 & 离 & \begin{tabular}{l}
$n$ \\
0 \\
0 \\
$0 n$ \\
0 \\
0 \\
\hdashline 0 \\
0 \\
0
\end{tabular} & 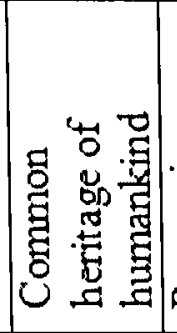 & 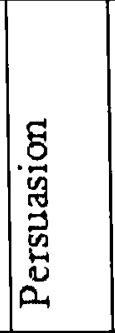 & 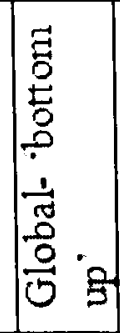 & 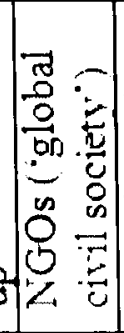 & 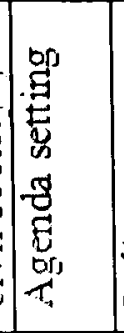 & 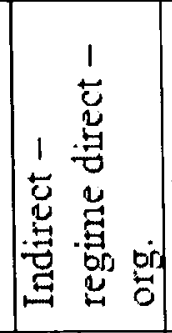 & 焉蛋 \\
\hline 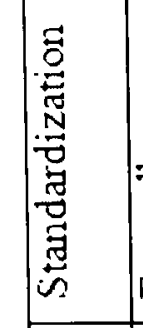 & 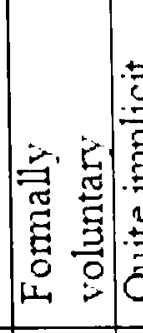 & 总 & 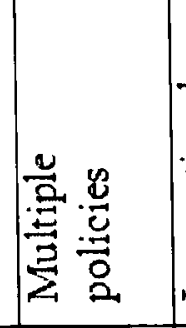 & 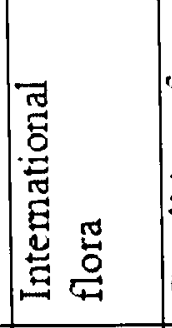 & 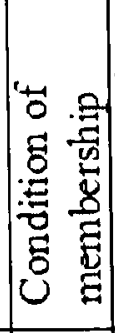 & 昰 & 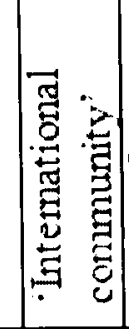 & 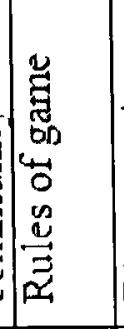 & 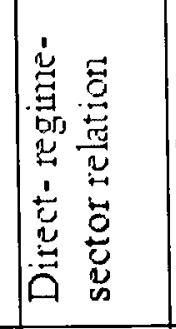 & 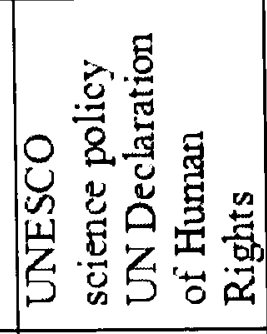 \\
\hline : & 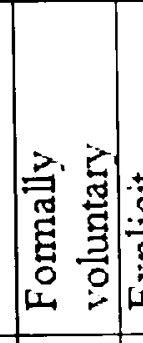 & 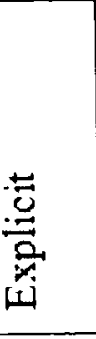 & 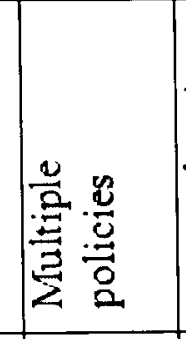 & 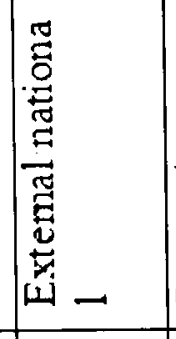 & 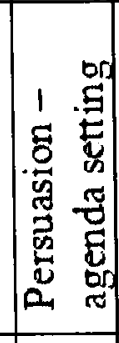 & 至 & 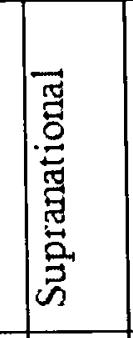 & 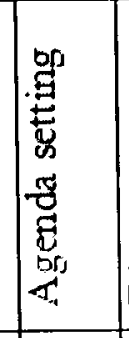 & 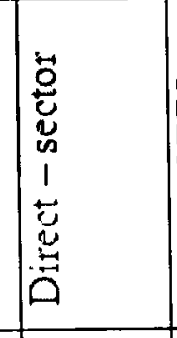 & 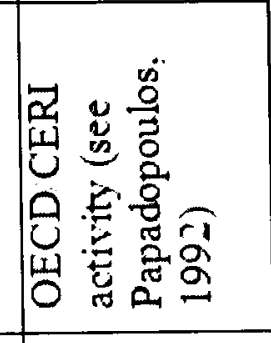 \\
\hline 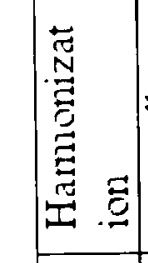 & 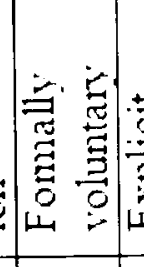 & 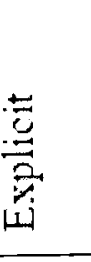 & 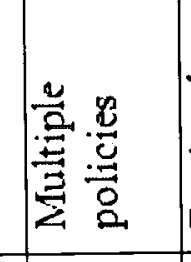 & 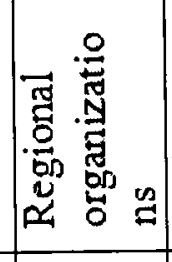 & 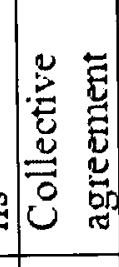 & : & 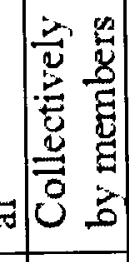 & 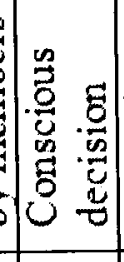 & 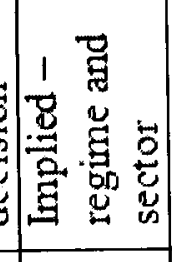 & 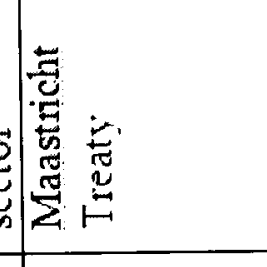 \\
\hline 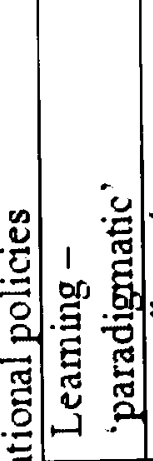 & 资 & 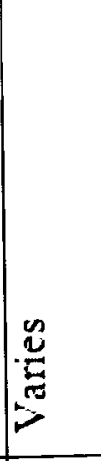 & 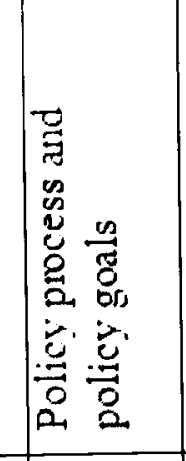 & 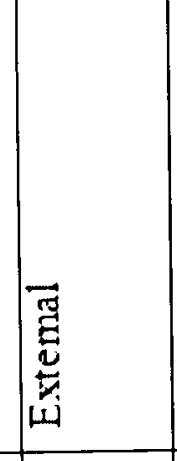 & 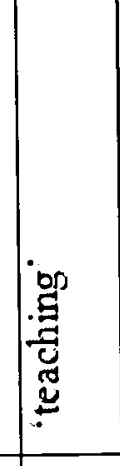 & 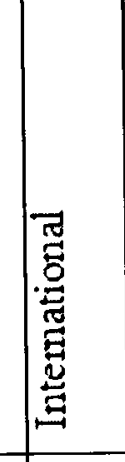 & 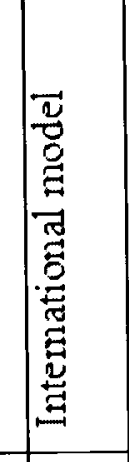 & 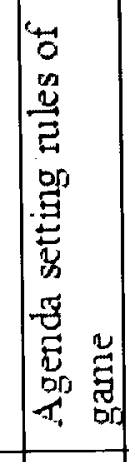 & $\sum_{0}$ & 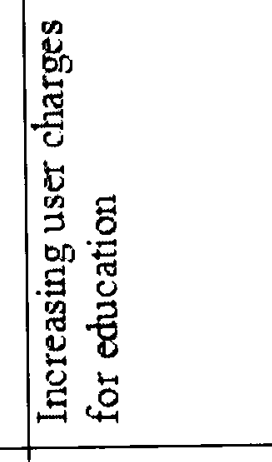 \\
\hline 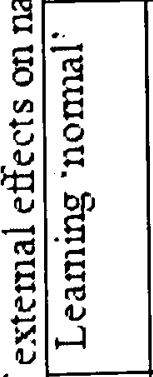 & 嘉 & 惫 & 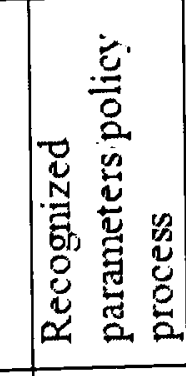 & 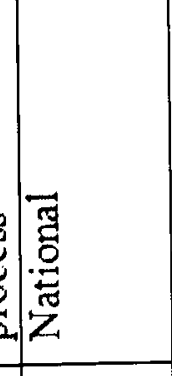 & 量 & 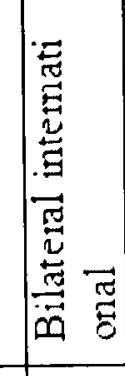 & 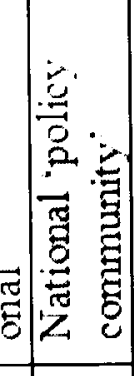 & $\hat{0}$ & : & 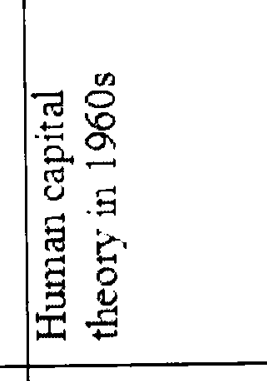 \\
\hline 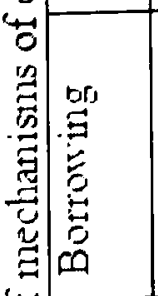 & 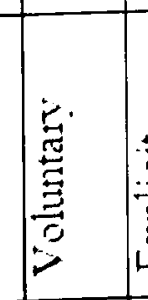 & 韬 & 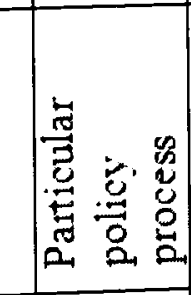 & 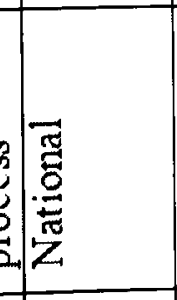 & 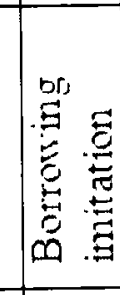 & 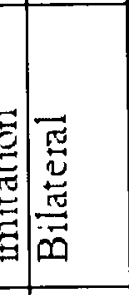 & 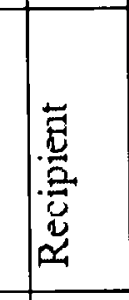 & 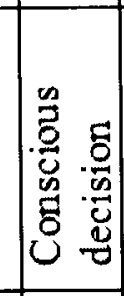 & 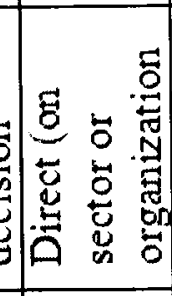 & 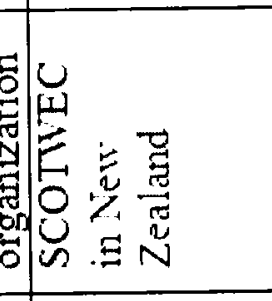 \\
\hline- & 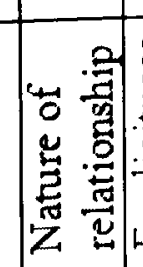 & 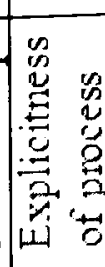 & 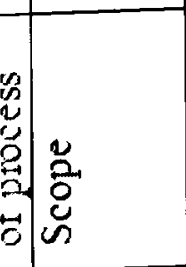 & 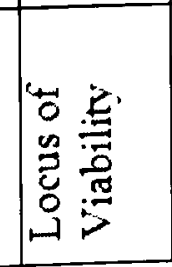 & 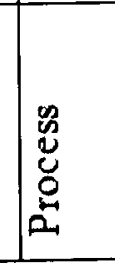 & 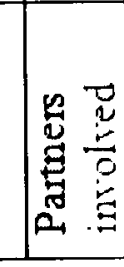 & 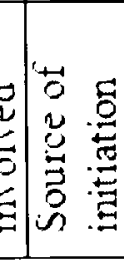 & 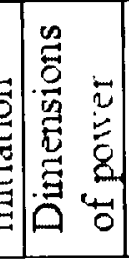 & 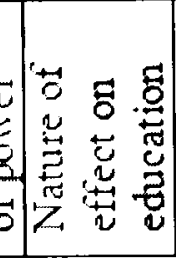 & 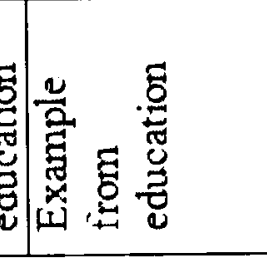 \\
\hline
\end{tabular}




\section{Appendix L: Sample interview transcript}

Fieldwork interview with respondent

Autumn 2007

EL: Elaine Lam

R: Respondent

EL: How many years have you been teaching?

$R: 30$ in the classroom, since [the 1970s].

EL: When your pupils leave your Maths classroom at the end of their formal schooling, what would you like them to have achieved?

R: To be able to think quickly in terms of the Mathematics and analyze a question and not just regurgitate mere facts. I emphasize a lot on the language of Maths, it should provoke some form of response instead of trying to pigeonhole Maths into different groupings. I also like to see them relate Mathematics to everyday situations, since I have a [other subject] background, most of the examples I use come from [other subject] areas, so they can see the links, and see the links between Maths and other areas.

EL: How do pupils best learn Mathematical concepts?

R: By practice. Practice mainly.

EL: How do you structure your lessons?

R: Well for us, we usually, well the first thing I hardly use books, they will get a handout on the topic, and several questions to look at concepts, that I want them to get through the lesson, I will go through them and listen to what they say and then go through others, identify areas they have problems and then go over to try to reinforce the concept.

EL: What type of teaching styles or methods do you employ?

R: Unfortunately for Mathematics, it's mainly chalk and talk, unfortunately - but when we get technology we can include that into the teaching and learning situation.

EL: What are the benefits of chalk and talk?

$\mathrm{R}$ : The benefits would be that the teacher is there to always guide the student, the student can see where things are going wrong. The teacher can pick up any errors that students are making. Because the chalk and talk method, because even though we are on the board, we are still going around to see what they are doing, to see what is taking place. For me one of the benefits is that you get immediate responses from students to see the concepts practiced in the lesson. 


\section{EL: And what about the drawbacks?}

$\mathrm{R}$ : One of the drawbacks is that it usually pigeonholes the students into adopting specific approaches to particular problems. So you don't have a lot of opportunity for student input, unless you pause. We are directing the course of the lesson instead of students having their input to the lesson.

EL: How would you describe your relationship with your pupils?

$\mathrm{R}$ : One of mutual respect, I hardly get trouble from any of the students in the classes, because I get the students to be relaxed, at least I don't sense any tense students when I'm in the classroom

EL: Where do you get your ideas about lesson planning?

$\mathrm{R}$ : I also did a diploma in education, so you would have done lesson planning as part of the course.

EL: Are you directed by the syllabus, students needs?

$\mathrm{R}$ : The head of department is charged with the responsibility with what parts of the syllabus to teach at different levels, the department head tells you which topics but which order you do them in is up to you. In addition, the MOE has attainment targets, so we follow. We have tailored our syllabus to the attainment levels, but we go beyond that. The targets are limited because it's average for all the schools, but some students can far exceed what they have set at a particular level. We start at level 2 , whereas some schools would have to start at level 1 .

EL: Are most teachers in the department trained?

R: Yes. Most of the teachers are trained.

EL: How do you cater for lower achieving pupils? How do lower achieving pupils learn best?

R: For the most part, we try to give those persons a bit more individualized attention so we would go around to the classrooms and stand or sit beside the individuals, and encourage them and give them hints and so on. And from time to time, when time permits, I would get individuals in the class to assist those pupils, so when they get handouts they assist each other. I often say I don't mind if they work together but the wholesale copying bothers me, I don't like it. As a matter of fact, I don't give marks for homework assignments.

EL: How would you describe the attitudes and beliefs of pupils towards Mathematics? How do they feel about it?

$\mathrm{R}$ : Most of the pupils bring their attitudes from primary school, in other words, those who liked it in primary school like it for the most part. Those who hate it, the idea that Maths is a difficult subject, they bring it with them. I have gotten a few students who 
considered themselves weak in Maths, I have gotten them to like Maths and achieve a level of success. (Pause). One of the first things I do when I got into a class at third form level, is that I tell them I expect them to pass the exam at the end of the year, and then outline some strategies to help them get to that goal. Some of them will come into third form having failed Maths at second form.

EL: Just to clarify, they write CSEC exams and school exams?

R: Yes. And ours are across the school, all our second forms and third forms do the same exam.

EL: What are the benefits of having exams every year?

R: If there's no exam, the student would relax, the exam helps them to focus on the task at hand. We however have a program where we do continuous assessment, so they are allowed to carry forward to the final exam mark marks from the first and second terms. $10 \%$ of their first and second term marks, and the exam out of 80 , so they don't just have final mark for the exam, thus incorporating continuous assessment as part of our marking process. Other departments are going this route. This policy was not laid down by administration, but something we as a department thought would be a useful thing, rather than the one shot exam. This would give them the opportunity to work consistently throughout the school year, and that is the way the exam system is going, and school based assessment would be part of continuous assessment.

\section{EL: Do you see any drawbacks to this exam system?}

R: There are some drawbacks. I have seen students who I would consider to be brighter than others not achieve the grade that is what I consider to their mathematical abilities. I saw students who got grade $3 \mathrm{~s}$ who are far better than those who ended up getting grade $2 \mathrm{~s}$. On the exam, the topics that a particular student is familiar with may come, whereas the student with a wider knowledge may not have questions that they are very good at come on that day.

\section{EL: Why is it important for your pupils to learn Maths?}

$\mathrm{R}$ : Any (pause). The world is coming increasing technological and any movement in those areas will require a mathematical base, so you need to have some knowledge of mathematics to progress in science and technology in order to go in that direction. Illiteracy is a bad thing, innumeracy is even worse; meaning that if you can't count, then anyone can make a fool of you on the job. We have persons in [the country] who may not be able to read or comprehend stuff, but when it comes to money, they are on top. One aspect of Maths is the ability to count, but in general Maths is important in the way the world is going, technology and science.

EL: To what degree do your teachers bring [name of country] culture into the Mathematics classroom? Is this important? Alan Bishop argues that there is always a cultural conflict in the classroom because of cultural context. What do you think? 
$\mathrm{R}: 1$ don't think the cultural aspect should become too important in a Maths programme. I believe that there is a certain body of Math knowledge out there, that the average person should attempt to acquire.

EL: What's in that body?

$\mathrm{R}$ : Ability to make reasonable estimates in terms of measurement, somebody should be able to estimate the size of the room, how many people can occupy the room, in terms of how much air and space they require, the ability to deal with buying and selling, the ability to deal with wages, bills, consumer mathematics. Everybody should be familiar with that type of mathematics.

EL: To what degree is 'real life Mathematics' emphasized in [your Caribbean country]?

R: Emphasized heavily, at every level of the syllabus. This is the schools adaptation of the general syllabus, we try to have some aspect of consumer mathematics at every level.

\section{EL: To what degree is hands-on interactive learning emphasized?}

R: That's not emphasized to a great extent, that would only come about after we have introduced the concepts; we would give a few questions just to see if they can handle the concepts, but one of those things preventing us would be time constraints.

\section{EL: To what degree are problem solving inquiry approaches emphasized?}

R: In my classes, 1 use a problem solving approach, and sometimes I will say, "don't give me the answer, tell me how you would approach the question", I am interested in how they would approach it rather than the answer. I emphasize that in my classes where appropriate. Sometimes I will hear, I know the answer but I can't tell you how I got the answer, I find that is a problem where they can't articulate how they got it.

EL: It has been said that many students are leaving secondary school without any formal qualifications. How can this situation be improved in Maths?

R: It's a relatively big problem, but it doesn't happen at this school, but at schools where students would have gone in with poor marks at common entrance, very few come out without any qualification. (Pause). I think the MOE is spending lots of money but in not the right areas, they need to strengthen the programmes at the primary and pre primary level and get more trained teachers at those levels. We find at the primary level, they are more untrained, inexperienced persons at the classroom and sometimes you have persons teaching mathematics at the primary level who don't understand mathematical concepts, so you have someone who doesn't understand some mathematical concepts teaching someone else, so false concepts are being reinforced at primary level. A lot of money spent at tertiary and secondary level and then you come down to primary and not much money spent.

EL: How do you engage your students with Mathematics? How do you make them excited about it? 
R: I get excited (laughs). And I try to bring the excitement, enthusiasm to arouse the excitement in them.

EL: Please describe the overall achievement level of your pupils, based on last year's classes.

R: Our school does exceptionally well based on our intake. Ranked fifth in terms of intake from common entrance, but we would have students who surpassed those at the number one ranked. Our end product far exceeds our intake. We may have students who come in at $60 \%$ in Maths, but at the end they come out with grade ones, and there are students at the first school who may go in with 90-95 but at the end may not come out with grade ones. This year we had in excess of [over 140] out of [around 200] students obtain five or more passes. We had a virtual [higher than 75\%] pass rate. The Caribbean average is about $60 \%$; we have always been above the [name of country] average, you can probably check it from CXC website.

EL: With regards to the School Based Assessment, what do students do for CSec/CAPE maths?

$\mathrm{R}$ : They have been trying to implement it in Maths from the early 80 s but Mathematics teachers have resisted.

EL: Where do you think the resistance comes from?

$\mathrm{R}$ : Teachers will not resist the SBAs if you indicate to them the body of questions to be set, but it is getting appropriate questions to test the various aspects of the syllabus, sometimes some people will say that the questions are too trivial. Where the examining body does not stipulate the question to be asked, the standard is going to be very varied, depending on the school and the territory. 


\section{Appendix M: Bibliography of Appendices}

Berry, J. (1986). 'The Literature of the Black Experience'. The Language of the black experience: Cultural expression through word and sound in the Caribbean and black Britain. Sutcliffe, D. and Wong, A. (eds). London: Basil Blackwell.

Bones, J. (1986a) 'Reggae Deejaying and Jamaican Afro-Lingua'. The Language of the black experience: Cultural expression through word and sound in the Caribbean and black Britain. Sutcliffe, D. and Wong, A. (eds). London: Basil Blackwell.

--- (1986b) 'Language and Rastafari'. The Language of the black experience: Cultural expression through word and sound in the Caribbean and black Britain. Sutcliffe, D and Wong A (eds). Basil Blackwell.

Brown, J., Newland, A., Anderson, P. and Chevannes, B. (1997) Caribbean Fatherhood: Underresearched, Misunderstood. Caribbean Families: Diversity Among Ethnic Groups. Roopnarine, J. and Brown, J. (eds). Advances in Applied Developmental Psychology Series No. 14. Connecticut: Ablex Publishing.

CARICOM (2008). 'History: The West Indies Federation'. CARICOM website. [Online]. Available from

http://www.caricom.org/jsp/community/west indies_federation.jsp?menu=community.

[Accessed 04.01.2009]

Donnell, A. and Welsh, S. (1996) General Introduction. The Routledge Reader in Caribbean Literature. Donnell A and Welsh S (eds). London: Routledge.

Evans, H. and Davies, R. (1997). Overview Issues in Childhood Socializiation in the Caribbean. Caribbean Families: Diversity Among Ethnic Groups. Roopnarine, J. and Brown, J. (eds). Advances in Applied Developmental Psychology Series. No. 14. Connecticut: Ablex Publishing:.

Gooch, C. (1995) "'Loitering on Colonial Premises after Closing Time”: An Analysis of Television Programming Policy in Barbados'. Globalization, Communications and Caribbean Identity. Dunn, H. (ed). New York: St. Martin's Press.

Government of Barbados (2008). 'Society'. Government Information Service website. [Online]. Available from http://www.barbados.gov.bb/society.htm. [Accessed 04.01.2009].

Government of Trinidad and Tobago (2008). 'History'. Government of Trinidad and Tobago website. [Online]. Available from

http://www.gov.tt/citizen/service.aspx?id=\{54E303EC-624E-46A1-BC2ECCAFC3A7D36B . [Accessed 04.01.2009].

Leo-Rhynie, E. (1997) 'Class, Race, and Gender Issues in Child Rearing in the Caribbean'. Caribbean Families: Diversity Among Ethnic Groups. Roopnarine, J. and Brown, J. (eds). Advances in Applied Developmental Psychology Series No. 14. Connecticut: Ablex Publishing. 
Parry, J. and Sherlock, P. (1956). A Short History of the West Indies. Oxford: MacMillan.

Sutcliffe, D. (1986) 'Introduction'. The Language of the black experience: Cultural expression through word and sound in the Caribbean and black Britain. Sutcliffe, D. and Wong, A. (eds). London: Basil Blackwell.

UNESCO (2005) 'Education for All Goals'. Global Monitoring Report, 2005. [Online]. Available from http://portal.unesco.org/education/en/ev.phpURL $1 \mathrm{D}=43811 \&$ URL DO=DO TOPIC\&URL SECTION=201.html. [Accessed 03.01.2009]

US Department of State (2008a). 'Background Note: Barbados'. US Department of State website. [Online]. Available from http://www.state.gov/r/pa/ei/bgn/26507.htm [Accessed 04.01.2009].

--- (2008b). 'Background Note: Trinidad and Tobago'. US Department of State website. [Online]. Available from http://www.state.gov/r/pa/ei/bgn/35638.htm. [Accessed 04.01.2009].

Wong, A. (1986). 'Creole as a Language of Power and Solidarity'. The Language of the black experience: Cultural expression through word and sound in the Caribbean and black Britain. Sutcliffe, D. and Wong, A. (Eds). London: Basil Blackwell. 